\title{
Lifestyle factors and risk of pancreatic cancer
}

Citation for published version (APA):

Heinen, M. M. (2011). Lifestyle factors and risk of pancreatic cancer. [Doctoral Thesis, Maastricht University]. Datawyse / Universitaire Pers Maastricht. https://doi.org/10.26481/dis.20110224mh

Document status and date:

Published: 01/01/2011

DOI:

10.26481/dis.20110224mh

Document Version:

Publisher's PDF, also known as Version of record

\section{Please check the document version of this publication:}

- A submitted manuscript is the version of the article upon submission and before peer-review. There can be important differences between the submitted version and the official published version of record.

People interested in the research are advised to contact the author for the final version of the publication, or visit the DOI to the publisher's website.

- The final author version and the galley proof are versions of the publication after peer review.

- The final published version features the final layout of the paper including the volume, issue and page numbers.

Link to publication

\footnotetext{
General rights rights.

- You may freely distribute the URL identifying the publication in the public portal. please follow below link for the End User Agreement:

www.umlib.nl/taverne-license

Take down policy

If you believe that this document breaches copyright please contact us at:

repository@maastrichtuniversity.nl

providing details and we will investigate your claim.
}

Copyright and moral rights for the publications made accessible in the public portal are retained by the authors and/or other copyright owners and it is a condition of accessing publications that users recognise and abide by the legal requirements associated with these

- Users may download and print one copy of any publication from the public portal for the purpose of private study or research.

- You may not further distribute the material or use it for any profit-making activity or commercial gain

If the publication is distributed under the terms of Article $25 \mathrm{fa}$ of the Dutch Copyright Act, indicated by the "Taverne" license above, 
Lifestyle factors and risk of pancreatic cancer 
Lifestyle factors and risk of pancreatic cancer Mirjam Heinen

ISBN:

9789461590343

Cover design: Bas Verhage

Lay-out: Mirjam Heinen

Printed by: Datawyse - Universitaire Pers Maastricht

(C) Copyright Mirjam Heinen, Maastricht 2011

All rights reserved. No part of this thesis may be reproduced or transmitted in any form or by any means, electronic or mechanical, including photocopying, recording or any information storage or retrieval system, without permission in writing from the author, or, when appropriate, from the publishers of the publications. 


\title{
Lifestyle factors and risk of pancreatic cancer
}

\author{
PROEFSCHRIFT \\ ter verkrijging van de graad van doctor aan de Universiteit Maastricht, \\ op gezag van de Rector Magnificus, \\ Prof. mr. G.P.M.F. Mols, \\ volgens het besluit van het College van Decanen, \\ in het openbaar te verdedigen \\ op donderdag 24 februari 2011 om 14:00 uur \\ door
}

Mirjam Maria Heinen

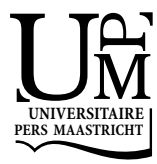




\section{Promotor}

Prof. dr. ir. P.A. van den Brandt

\section{Copromotor}

Dr. B.A.J. Verhage

\section{Beoordelingscommissie}

Prof. dr. M.F. von Meyenfeldt (voorzitter)

Dr. H.B. Bueno-de-Mesquita (Rijksinstituut voor Volksgezondheid en Milieu, Bilthoven)

Dr. A.L.C. Driessen

Prof. dr. A.A.M. Masclee

Prof. dr. R.A. Woutersen (TNO Kwaliteit van Leven, Zeist)

\section{itution}

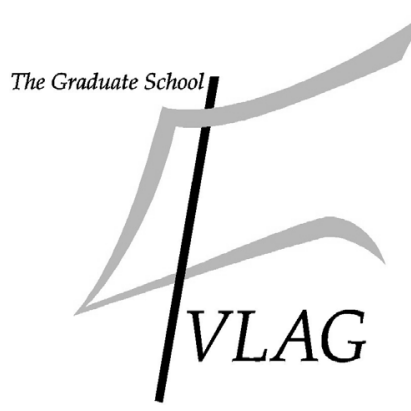

The studies presented in this thesis were conducted at the department of Epidemiology (Maastricht University), Nutrition and Toxicology Research Institute Maastricht (NUTRIM), which participates in the Graduate School VLAG (Food Technology, Agrobiotechnology, Nutrition and Health Sciences), accredited by the Royal Netherlands Academy of Arts and Sciences.

Financial support for the printing of this thesis was kindly provided by the Stichting Nationaal Fonds tegen Kanker - voor onderzoek naar reguliere en aanvullende therapieën in Amsterdam and the Department of Epidemiology (Maastricht University). 


\section{CONTENTS}

$\begin{array}{lll}\text { Chapter } 1 & \text { Introduction } & 7\end{array}$

Chapter 2 Physical activity, energy restriction, and the risk of pancreatic cancer: a prospective study in the Netherlands

Chapter 3 Alcohol consumption and risk of pancreatic cancer in the

Netherlands Cohort Study

Chapter 4 Glycemic load, glycemic index, and pancreatic cancer risk in the Netherlands Cohort Study

Chapter $5 \quad$ Meat and fat intake and pancreatic cancer risk in the Netherlands Cohort Study

Chapter 6 Intake of vegetables, fruits, carotenoids, and vitamins $\mathrm{C}$ and $\mathrm{E}$ and pancreatic cancer risk in the Netherlands Cohort Study

Chapter 7 Active and passive smoking and the risk of pancreatic cancer in the Netherlands Cohort Study

Chapter 8 Discussion

Summary

Samenvatting

Dankwoord

Curriculum vitae 



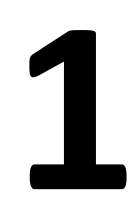

Introduction 


\section{THE PANCREAS AND ITS EXOCRINE AND ENDOCRINE FUNCTION}

The pancreas is a gland which is located behind the stomach. The head of the pancreas is lying immediately adjacent to the duodenum; the body, which forms the main bulk of the organ, ends in a tail that lies in contact with the spleen (Figure 1.1). ${ }^{1}$ The organ consists of an exocrine and endocrine part.

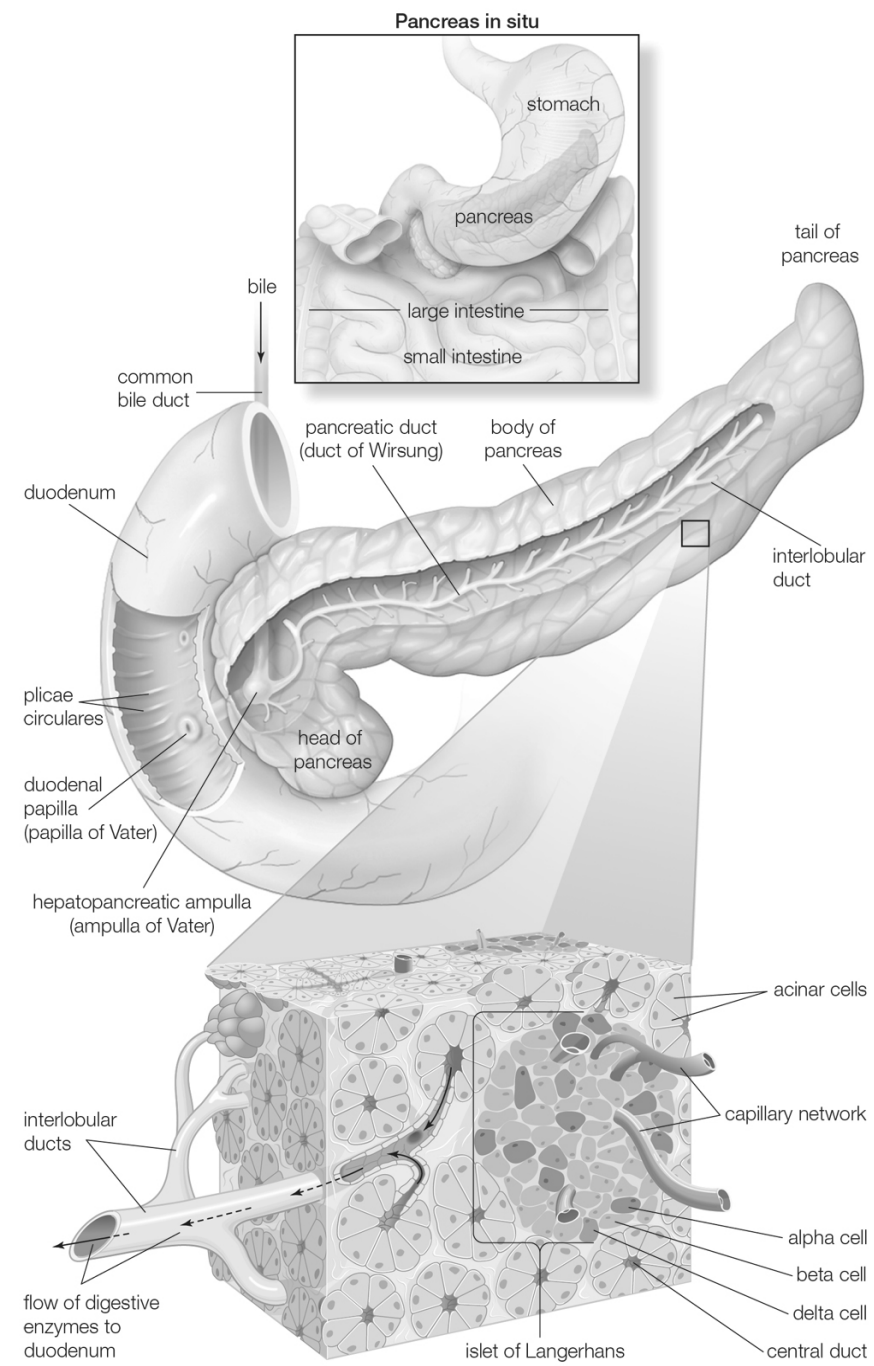

FIGURE 1.1 The anatomy of the pancreas

Source: http://www.britannica.com/EBchecked/topic/440971/pancreas (accessed on June 2010)

The exocrine part of the pancreas consists of acinar cells, which are grouped into lobules. ${ }^{1-3}$ Their main function is to secrete pancreatic juice containing digestive en- 
zymes. These enzymes, including trypsinogen, chymotrypsinogen, pancreatic lipase and pancreatic amylase, help in the further breakdown of the carbohydrates, protein, and fat in the chyme. These enzymes are released by the pancreas in response to the small intestine hormones secretin and cholecystokinin. ${ }^{1,2}$ Another component of the exocrine pancreas are ductal cells that form the epithelium lining of the highly branched ducts, which transport the digestive enzymes produced by the acinar cells into the duodenum. ${ }^{3,4}$

The endocrine part is made up of cell clusters called islets of Langerhans, which secrete hormones. These cell clusters account for only 1-2\% of pancreatic tissue. There are five main types of islets cell. The beta-cells are the most common and are responsible for insulin production. The other types include alpha, delta and F (or PP) cells, which secrete glucagon, somatostatin, and pancreatic polypeptide, respectively. ${ }^{2,3}$

\section{PANCREATIC CANCER}

\section{Carcinogenesis}

Approximately $90 \%$ of the pancreatic neoplasms are adenocarcinomas. ${ }^{5}$ There is general agreement that the pancreatic ductal epithelial cell gives rise to this type of pancreatic malignancy. However, animal studies indicated that transdifferentiation of other pancreatic cell types, such as acinar cells, might serve as an alternative route to pancreatic adenocarcinoma.,

Several molecular genetic alterations have been identified in adenocarcinomas of the pancreas. Over $90 \%$ of human pancreatic adenocarcinomas have a point mutation in the KRAS gene, whereas the p16/INK4A gene is inactivated in virtually all pancreatic adenocarcinomas. In addition, two other genes were frequently inactivated in pancreatic adenocarcinomas, that is, SMAD4/DPC4 (60\%) and TP53 (50-80\%). ${ }^{6-8}$

The improved understanding of the genetic alterations that characterize invasive pancreatic adenocarcinoma can be used to classify noninvasive precursor lesions in the pancreas. Researchers have characterized three premalignant lesions, including pancreatic intraepithelial neoplasia (PanIN), intraductal papillary mucinous neoplasia (IPMN) and mucinous cystic neoplasia, from which pancreatic cancer appears to arise. ${ }^{6,7,9,10}$

PanINs show a spectrum of divergent morphological alternations relative to normal ducts and seem to represent progressive stages of neoplastic growth that may be precursors to pancreatic adenocarcinomas. ${ }^{6}$ The consecutive stages have been classified as normal duct, PanIN-1A or PanIN-1B, PanIN-2, PanIN-3, and adenocarcinoma. The PanINs usually involve the smaller pancreatic ducts ( $<5 \mathrm{~mm}$ in diameter). ${ }^{10}$

A growing number of studies have identified mutations in KRAS, TP53, SMAD4/ DC4, and p16/INK4A genes in PanIN lesions, which were shown to accumulate during progression through the various stages of PanIN lesions. This provides more evidence that PanINs might be precursors of pancreatic adenocarcinoma. ${ }^{6,8}$ 
IPMNs are larger than PanINs (usually $>1 \mathrm{~cm}$ ) and seem to arise in the larger pancreatic ducts. ${ }^{7,10}$ IPMNs may be a precursor to invasive adenocarcinoma of the pancreas and are growing in importance because more of these lesions are detected as the resolutions of imaging improves. ${ }^{7}$ These lesions often harbor the same mutations as are found in invasive pancreatic adenocarcinomas, including KRAS, PT53 and p16/ INK4A, although at a lower frequency. ${ }^{7}$

\section{Classification}

Of the pancreatic adenocarcinomas, approximately two-thirds of pancreas tumors occur in the head of the organ with the remainder in the body or tail. ${ }^{11,12}$ At the moment, screening is not an option because it is unknown at what age screening should begin, in which high-risk groups, and whether any of our current methods are able to detect early pancreatic cancers. ${ }^{5}$ At diagnosis, most cases present with unresectable tumors (TNM-stage III [tumor extends beyond pancreas and have invaded major blood vessels] and stage IV [distant metastasis]). In the US, less than $10 \%$ of patients present with local disease at diagnosis, whereas $52 \%$ have distant metastases, mainly in the liver and peritoneal cavity. ${ }^{13}$ In the Netherlands, similar estimates have been found with only $7 \%$ of the patients presenting localized disease (stage IA [tumor $\leq 2 \mathrm{~cm}$ in greatest dimension] and stage IB [tumor $>2 \mathrm{~cm}$ ]; Figure 1.2) and $56 \%$ of the patients having distant metastasis (stage IV).

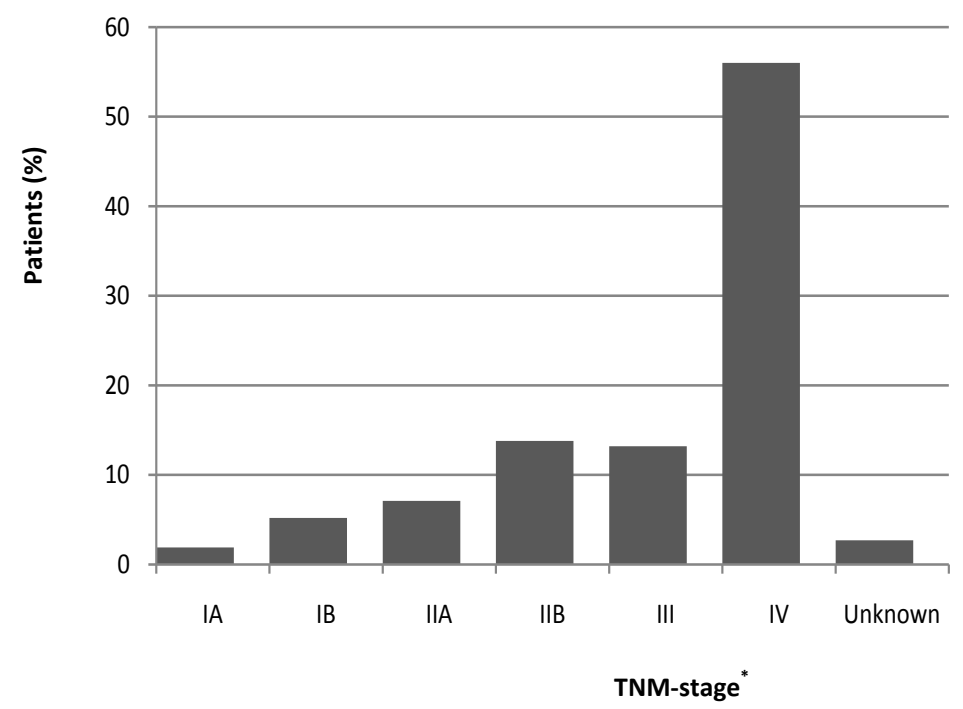

FIGURE 1.2 Distribution of patients by stage ${ }^{*}$ at diagnosis with pancreatic cancer, the Netherlands, 2003-2007

Source: http://www.ikcnet.nl/page.php?id=114 ${ }^{14}$

* Staging system developed by the TNM committee of the UICC (International Union Against Cancer; $6{ }^{\text {th }}$ edition). 
Besides exocrine pancreatic cancer there are also endocrine subtypes, such as Islet-cell tumors, sarcomas, and lymphomas; these are very uncommon tumors ${ }^{11}$ which are not further discussed here because these types probably have a different etiology. Many analyses of epidemiologic data do not distinguish between exocrine and endocrine neoplasms, most probably because of lack of data to obtain microscopic confirmation. But since pancreatic endocrine neoplasms are quite rare, their exclusion would probably not have altered the conclusions from studies in which they were included.

\section{Diagnosis and treatment}

\section{Symptoms of pancreatic cancer}

Many patients present with very minor symptoms including abdominal pain, change in digestive problems and weight loss. ${ }^{1}$ Also jaundice is observed in more than $50 \%$ of the patients. ${ }^{12}$ Some patients $(\leqslant 10 \%)$ present with new -onset diabetes. ${ }^{12}$ Especially in the elderly, pancreatitis may be a first signal of pancreatic neoplasia when there is no obvious cause such as gallstones or alcohol abuse. ${ }^{12}$ Symptoms differ with location of the tumor: in patients with cancer of the head of the pancreas is jaundice (due to obstruction of the bile duct) a more common symptom, whereas in patients with tail and body tumors abdominal pain is a more common symptom. ${ }^{1,12}$ This abdominal pain is often dull in character and radiates through to the back. Other symptoms are more nonspecific such as anorexia and weight loss. Bile duct obstruction and jaundice may infrequently be a late phenomena. ${ }^{1}$

\section{Diagnosing techniques}

The most common imaging modalities for diagnosis and staging of pancreatic cancer include transcutaneous ultrasound (TCUS), computed tomography (CT) scan, magnetic resonance imaging (MRI), and most recently endoscopic ultrasound (EUS). ${ }^{15}$ Helical CT scan is the imaging procedure of choice for the initial evaluation. ${ }^{16}$ In patients where no visible mass is identifiable on $\mathrm{CT}$, but in whom pancreatic cancer is suspected based on the symptoms, EUS could be of help detecting pancreatic tumors ${ }^{12,15}$ because this modality is superior to CT for detecting small tumors. ${ }^{12}$

Biopsies in patients with resectable pancreatic tumors can be taken during surgery. For patients who are not suitable candidates for radical surgery, the most common approaches to obtain a tissue diagnosis are by CT-guided biopsy, by endoscopic retrograde cholangiopancreatography (ERCP) or by EUS with fine-needle aspiration (FNA). ${ }^{16}$ It has been shown that EUS-guided FNA is the most accurate diagnostic modality. ${ }^{15}$ Complications are rare but include tumor seeding, so obtaining tissue diagnosis using these types of diagnostic modalities should be reserved only for patients who will not undergo surgery. ${ }^{12}$

\section{Histological confirmation}

To date, pancreatic cancer continues to have among the lowest proportion of histologically verified cases of any major cancer. ${ }^{11}$ This is because the organ is inconveniently 
located and because of the morbidity associated with biopsy. In Table 1.1, the average proportion of incident male cases are presented that has been verified histopathologically for various registries in various countries. ${ }^{17}$

TABLE 1.1 Percentages of incident cancer of pancreas confirmed histopathologically, in men

\begin{tabular}{|c|c|c|c|}
\hline \multirow[t]{2}{*}{ Area } & \multirow[b]{2}{*}{ Number of registries } & \multicolumn{2}{|c|}{$\begin{array}{l}\text { Proportion of incident male cases } \\
\text { confirmed histopatholgically (\%) }\end{array}$} \\
\hline & & Mean & Range \\
\hline Africa & 5 & 35 & $16.7-59.1$ \\
\hline Japan & 7 & 37 & $25.9-48.8$ \\
\hline United Kingdom & 11 & 39 & $31.1-48.2$ \\
\hline Latin America & 11 & 50 & $17.9-91.1$ \\
\hline Poland & 3 & 51 & $39.5-59.6$ \\
\hline Canada & 10 & 61 & $52.5-80.0$ \\
\hline Netherlands & 2 & 63 & $50.4-74.6$ \\
\hline Scandinavia & 5 & 73 & $60.9-87.5$ \\
\hline United States $^{\dagger}$ & 42 & 77 & $68.3-85.4$ \\
\hline
\end{tabular}

Source: Curado et al. (2007)

"Scandinavia: Denmark, Iceland, Finland, Norway, and Sweden. ${ }^{+}$Where percentages were provided by race, the data for "white" or "non-Hispanic white" was used.

These figures vary throughout the world. This suggests that the accuracy of pancreatic cancer incidence estimates across countries/regions depends on enumeration of cases with and without histological examination. ${ }^{11}$ The enumeration of cases with diagnoses that are histologically unconfirmed are highly dependent on various factors, including proportion of cases ascertained through autopsy, accuracy of clinical records, motivation and training of the persons who code or screen the records for evidence of cancer diagnosis, and quality of diagnosis itself. This means that the enumeration of accurate diagnoses may be incomplete and variable throughout the world. ${ }^{18}$ This should be kept in mind, when interpreting differences in incidence and mortality rates described in the section below. Additionally, American data from SEER registries indicates that the proportion of cases with microscopic confirmation decreases with age at diagnosis. ${ }^{19}$

The group of cases not histologically verified is most probably comprised of a mixture of true pancreatic cancers and of other tumors arising in neighboring sites and infiltrating or metastasizing to the pancreas ${ }^{20}$ or can even include patients with chronic pancreatitis.

\section{Treatment}

Broadly, the treatment strategy can be divided into two different ways. The first is radical surgery for patients with early stage of disease, mainly stage I and partially stage $1{ }^{12}{ }^{12}$ Just few patients (15-20\%) present with a locally resectable tumor. ${ }^{5,12}$ In these patients, the standard treatment option is radical pancreatic resection according to Whipple procedure (pancreatoduodenectomy, the most commonly performed resection procedure), distal pancreatectomy, or total pancreatectomy. ${ }^{12,16}$ The role of postoperative therapy with chemotherapy alone (e.g., 5-fluorouracil or gemcitabine) 
or in combination with radiotherapy in patients with resected pancreatic cancer is controversial, showing some improved but still very poor survival (median survival is 17-20 months in the groups not receiving adjuvant therapy after surgery and 20-22 months in the treatment groups). ${ }^{12,16}$

When there are distant metastases or when the tumor has invaded any major vascular structures surrounding the tumor, the tumor is not resectable. ${ }^{5}$ In that case, the aim of treatment is the palliation of distressing symptoms related to this cancer, such as jaundice, pain, gastrointestinal symptoms etc. ${ }^{12}$ These patients may benefit from palliative bypass of biliary obstruction (head of pancreas) and/or palliative bypass of intestinal obstruction. In addition, treatment with chemotherapy alone or in combination with radiotherapy might palliate symptoms. ${ }^{12,16,21}$

Because there is no effective way to screen for this malignancy and survival is low due to late diagnosis and low number of resectable tumors, prevention could have a major impact on pancreatic cancer mortality.

\section{Burden of pancreatic cancer}

Pancreatic cancer is the $13^{\text {th }}$ common cause of cancer in Europe and $10^{\text {th }}$ in the United States and it is the $5^{\text {th }}$ leading cause of death in Europe and $4^{\text {th }}$ in the United States in the year $2006 .^{13,22}$ Incidence and mortality rates are almost similar due to the rapid fatality rates of pancreatic cancer.

Figure 1.3 shows a map of the worldwide distribution of pancreatic cancer incidence rates for $2008 .^{23}$

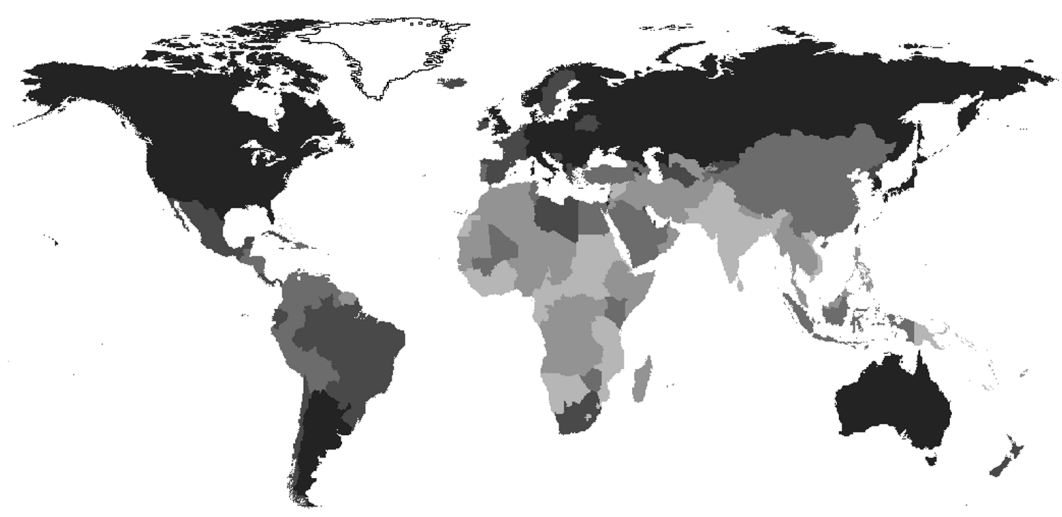

Age-standardized (world) incidence rates for pancreatic cancer (per 100,000)

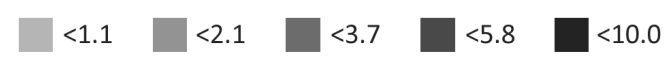

FIGURE 1.3 Worldwide distribution of the age standardized (world) incidence rates per 100,000 for pancreatic cancer -2008

Source: $h t t p: / / g l o b o c a n . i a r c . f r .^{23}$ 
Men have an approximately 1.5 greater age-adjusted incidence rate than women. ${ }^{11,12}$ Higher rates are observed in more developed countries (including the Netherlands, United States, and Japan) versus less developed countries (including all the regions of Africa, Asia [excluding Japan], and Latin America). Age-standardized incidence rates (world; ASR[W]) per 100,000 for 2008 in the United States, Japan, Europe, and the Netherlands are 7.0, 7.9, 6.4, and 5.4, respectively. ${ }^{23}$ For Africa, China, and India, incidence rates for 2008 are 1.7, 2.8, and 1.0, respectively. ${ }^{23}$ In the United States, black Americans have higher incidence rates than white Americans (SEER, 9 registries; 19982002) (ASR[W] per 100,000 are 10.9 versus 7.0 for males and 8.6 versus 5.7 for females, respectively). ${ }^{17}$ As described in the previous section, some of these differences in incidence rates reflect diagnostic capacity rather than differences in risk factors. ${ }^{18}$ Therefore, the differences in incidence rates described above should be interpreted very cautiously.

In the United States, mortality rates for men increased steeply from the mid1930s to the mid-1950s, reached a peak in 1970 and then gradually declined (Figure 1.4). ${ }^{24}$

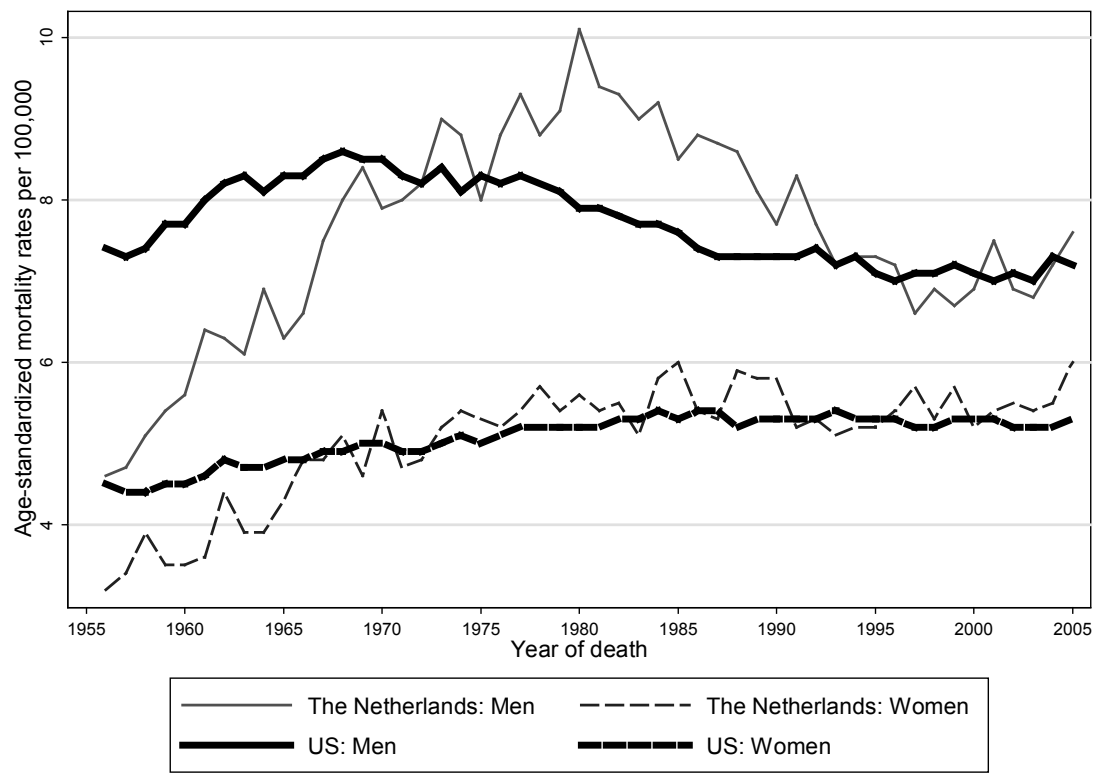

FIGURE 1.4 Trends in overall age-standardized (world) mortality rates (per 100,000) for pancreatic cancer in men and women in the United States and the Netherlands, 1955-2005

Source: http://www.who.int/whosis/whosis/25

For women, the rise of female mortality was slower but continuous from 1935 onwards, ${ }^{24}$ which leveled off in the 1990s (Figure 1.4). In the Netherlands, mortality rates 
have increased between the late 1950s and the 1980s in men, followed by a decline until the late 1990s (Figure 1.4). Among women, mortality rates have increased until the 1990s followed by a leveling off until 2000 (Figure 1.4). In Europe as a whole, similar patterns have been observed as in the Netherlands, ${ }^{26}$ although mortality rates seem to have been more stable over time from the late $1990 \mathrm{~s}^{27}$ The decline or leveling off of pancreatic cancer mortality rates observed in the United States and Europe might partly be due to the decline in smoking, at least in men, ${ }^{28}$ which is an established risk factor for pancreatic cancer. ${ }^{29}$ For incidence rates, similar patterns have been observed. $^{23,27}$

Survival rates for pancreatic cancer are amongst the worst of all cancers with a median survival of about 3 months. ${ }^{11}$ Survival rates have almost not improved over time, with 5 -year relative survival rates ranging from $3 \%$ in 1980 s to $5 \%$ late 1990 searly 2000 in the United States, Europe and the Netherlands. ${ }^{14,30-32}$ Survival rates were similar in both men and women. Survival rates of pancreatic cancer differ between stages at diagnosis in the Netherlands (Table 1.2), ranging from a $30 \%$ survival rate in stage IA (tumor limited to pancreas, $\leq 2 \mathrm{~cm}$ in greatest dimension) to $1 \%$ in stage IV (distant metastasis).

TABLE 1.2 Five-year relative survival rates among patients diagnosed with pancreatic cancer by stage at diagnosis, the Netherlands, 2003-2007

\begin{tabular}{lc}
\hline TNM-stage $^{*}$ & 5-year relative survival rate (\%) \\
\hline IA & 30 \\
IB & 11 \\
IIA & 10 \\
IIB & 7 \\
III & 2 \\
IV & 1 \\
Unknown & 8 \\
Source: $h t t p: / / w w w . i k c n e t . n l / p a g e . p h p ? i d=114^{14}$ & \\
"Staging system developed by the TNM committee of the UICC (International Union Against Cancer; $6^{\text {th }}$ \\
edition).
\end{tabular}

\section{RISK FACTORS}

\section{Demographic factors}

Age is one of the most important risk factors for pancreatic cancer. In the first three decades of life, this cancer is extremely uncommon. After the age of 30 , rates increases steeply with age. The majority of cases occur between ages 65 and 79 years in the United States ${ }^{11}$ and between the ages 60 and 79 years in the Netherlands. ${ }^{14}$

As reported in the previous section, the incidence rates are approximately 1.5 times higher among blacks than among whites in the United States, whereas incidence rates among blacks living in Africa appear to be low in comparison to those among African-Americans. ${ }^{11,33}$ Silverman et al. ${ }^{33}$ results suggested that the excess risk among 
black Americans could potentially be explained by established risk factors, such as cigarette smoking and diabetes in men. The excess risk among black women could be explained by these two established risk factor plus less established risk factors, i.e., heavy alcohol drinking and elevated body mass index (BMI). A large cohort study was, however, unable to replicate these results and did not identify any individual or combinations of factors that explained the excess risk of pancreatic cancer in black Americans. $^{34}$ This might indicate that the excess pancreatic cancer risk in black Americans might be explained by other risk factors for pancreatic cancer, not yet determined, or by differences in genetic susceptibility.

\section{Lifestyle and environmental factors}

As already indicated above, cigarette smoking is one of the established risk factors for pancreatic cancer, ${ }^{29,35}$ with most studies indicating that current cigarette smokers have about a 2-fold increased pancreatic cancer risk compared with never smokers. ${ }^{35-39}$ Regarding other types of smoking, pooled estimates for pipe smoking showed a nonsignificantly increased pancreatic cancer risk of 39\%, whereas for cigar smoking a significantly increased risk of $53 \%$ was observed. ${ }^{35}$ Four case-control studies ${ }^{40-43}$ and four cohort studies ${ }^{44-47}$ have examined the relation between passive smoking and the risk of pancreatic cancer. Three of these studies observed a positive association with passive smoking in never smokers. ${ }^{41,44,47}$

One other established risk factor for pancreatic cancer is overweight/obesity. ${ }^{48,49}$ One meta-analysis of prospective cohort studies investigating the association between $\mathrm{BMI}$ and pancreatic cancer risk, observed an increased pancreatic cancer risk of 1.12 (95\% Cl: $1.06-1.17)$ per $5 \mathrm{~kg} / \mathrm{m}^{2}$ increase in $\mathrm{BMI}^{49}$ In addition to $\mathrm{BMI}-$ which is a measure of total body fat - the distribution of fat has been investigated in relation to pancreatic cancer risk by means of waist circumference or waist-to-hip circumference ratio (WHR), showing inconsistent results so far. Epidemiological studies observed either an increased pancreatic cancer risk with a higher waist circumference ${ }^{50-52}$ or $\mathrm{WHR}^{50,53}$ or no association with waist circumference ${ }^{53}$ or WHR. ${ }^{52,54}$

Results regarding physical activity and pancreatic cancer risk have been inconsistent so far, observing both decreased risks ${ }^{55,56}$ and no association. ${ }^{50,57}$ Two metaanalyses observed only for occupational physical activity a decreased pancreatic cancer risk - which were based on only a few prospective cohort studies (three and four studies, respectively) - and no association with leisure-time physical activity. ${ }^{58,59}$

Occupation and workplace exposures have extensively been examined in relation to pancreatic cancer. ${ }^{11}$ However, studies performed so far have found no consistently strong association with pancreatic cancer and data is insufficient to identify any specific exposure as likely to substantially increase the risk of pancreatic cancer. ${ }^{11}$

\section{Hormonal and reproductive factors}

Because pancreatic cancer is more common among men than women, and estrogen receptors are present in normal pancreatic tissue and in neoplastic pancreatic tissues, 
it is plausible that hormonal and reproductive factors could play a role in pancreatic carcinogenesis. ${ }^{11,60}$ Data from epidemiologic studies, however, do not support an effect of hormonal and reproductive factors on pancreatic cancer risk. ${ }^{11,60,61}$

\section{Dietary factors}

So far, numerous epidemiological studies have investigated the relation between meat, eggs, different types of fat, fruit and vegetables and pancreatic cancer (summarized in Ref. 48). These data have shown inconsistent results so far. In the second World Cancer Research Fund (WCRF)/American Institute for Cancer Research (AICR) expert report, it was concluded that there is limited evidence suggesting that red meat is a cause of pancreatic cancer in humans, whereas fruit might protect against pancreatic cancer. ${ }^{48}$ Data on processed meat, chicken, fish, eggs, dietary fat, specific fatty acids, vegetables and vitamin $C$ were either of too low quality, too inconsistent, or the number of studies too few to allow conclusions to be reached.

Another factor that is investigated in relation to pancreatic cancer is the glycemic index (GI). This is a measure that can be used to quantify the postprandial glycemic effects of individual foods items. ${ }^{62}$ To estimate the total glycemic effect of the diet, the glycemic load (GL) is calculated by using both the overall Gl of a diet as well as the actual amount of carbohydrates consumed in the diet. ${ }^{63}$ Studies investigating the influence of dietary GI and GL on pancreatic cancer have been limited so far. A metaanalysis on cohort studies observed no associations between pancreatic cancer risk and high GI or GL. ${ }^{64}$

For alcohol intake, inconsistent findings were observed in cohort studies and the numerous case-control studies that have been conducted (findings are summarized in Ref. 48). Recently, the second WCRF/AICR expert report concluded that low-tomoderate levels of alcohol consumption were unlikely to have an effect on pancreatic cancer risk, but it could not be excluded that heavy drinking might have an effect. ${ }^{48}$

Furthermore, animal studies showed that moderate energy restriction decreased pancreatic cancer risk. ${ }^{65,66}$ So far, no observational studies have investigated the relation between energy restriction and pancreatic cancer risk.

Early studies indicated that coffee consumption was positively associated with pancreatic cancer risk; however, the majority of studies conducted have failed to confirm such a risk. ${ }^{67,68}$ Both a Working Group of The International Agency for Research on Cancer (IARC) and the second WCRF/AICR expert report have concluded that there was little evidence to support a causal relation between coffee consumption and pancreatic cancer risk. ${ }^{48,68}$

\section{Medical history}

The role of several medical conditions in the etiology of pancreatic cancer has been investigated. Diabetes mellitus has been examined most extensively and there is evidence for a causal association between longstanding diabetes mellitus and pancreatic cancer risk; ${ }^{69,70}$ even when for reasons of reverse causality cases are excluded who are 
diagnosed with diabetes mellitus less than 5 years prior to diagnosis of pancreatic cancer. In addition, patients with chronic pancreatitis have an increased risk of developing pancreatic cancer. ${ }^{11,71,72}$ Several studies have investigated the relation between pancreatic cancer risk and other medical conditions, such as gallstones, ${ }^{73,74}$ cholecystectomy, ${ }^{11,73-75}$ peptic ulcer and peptic ulcer surgery, ${ }^{11,76}$ hypertension, ${ }^{11,77}$ and hepatitis, ${ }^{11,78}$ but results have been inconsistent.

Although animal and laboratory studies have shown that aspirin and other NSAIDs may inhibit pancreatic carcinogenesis, findings from observational epidemiologic studies of aspirin and NSAID use in relation to pancreatic cancer risk have been inconsistent. $^{11,79}$ Two meta-analyses recently conducted, have concluded that current epidemiologic data does not indicate that use of aspirin or NSAIDs is associated with pancreatic cancer risk. $^{79,80}$

\section{Family history and genetic predisposition to pancreatic cancer}

Up to $10 \%$ of pancreatic cancer patients report a family history of the disease. This familial clustering may be due to genetics, shared environment, or both. ${ }^{81-86}$ Furthermore, the first-degree relatives of pancreatic cancer cases are at an estimated 2- to 4fold higher risk, ${ }^{82,85}$ with the risk increasing up to as high as 57-fold if 3 or more relatives are affected. ${ }^{86}$ A large twin study, including 44,788 pairs of twins listed in the Swedish, Danish, and Finnish twin registries, showed that heritable factors account for $36 \%$ (95\% confidence interval [CI]: 0-53\%), whereas (non-shared) environmental factors account for $64 \%(95 \% \mathrm{Cl}: 47-86 \%)$ of the variation in occurrence of pancreatic cancer among twins. $^{87}$

The observed familial clustering of pancreatic cancer may be explained by the presence of germline mutations in a major pancreatic cancer susceptibility gene, analogues to the breast cancer susceptibility genes BRCA1 and BRCA2. Indeed, a complex segregation analysis, including 287 families of pancreatic cancer cases, produced evidence supporting the role of a rare major gene (or multiple genes acting in a similar fashion) influencing risk of pancreatic cancer within families. ${ }^{84}$ To date, this major pancreatic cancer gene has not yet been identified. The results from a linkage study, based on a single multiplex familial pancreatic cancer kindred, pointed out the 4q32-34 region as a susceptibility locus for pancreatic cancer. ${ }^{88}$ This result could not be replicated in subsequent linkage studies, nor did these studies produce evidence for further pancreatic cancer susceptibility loci. ${ }^{89-91}$

Pancreatic cancer is associated with several genetic syndromes, where germline mutations in specific genes are involved. ${ }^{92}$ These include hereditary breast cancer (BRCA2), familial atypical multiple mole melanoma syndrome (CDKN2A), Peutz-Jeghers syndrome (STK11/LKB1), hereditary pancreatitis (PRSS1, SPINK1), and hereditary nonpolyposis colorectal cancer (mismatch repair genes, including $h M S H 2$ and $h M L H 1$ ). These syndromes, however, explain little of the observed familial aggregation of pancreatic cancer. 
It is likely that relatively common genetic variants, with modest effects on pancreatic cancer risk, play an important role in both the familial and sporadic forms of the disease (i.e., without a clear-cut inheritance pattern), either individually or in interaction with environmental factors. Such variants typically display a relatively high frequency in the population, as opposed to the rare high-penetrance variants, and could therefore, potentially explain a substantial portion of pancreatic cancer risk. To date, association studies employing a candidate gene approach have tested variants in genes involved in carcinogen metabolism, DNA repair, inflammation, one-carbon metabolism, and mitochondria (reviewed by Milne et al. ${ }^{93}$ ). None of these variants have been conclusively established as risk factors, partly due to the lack of replications in independent data sets and the inherent problems of the candidate gene approach.

The emergence of new high-throughput genotyping technologies, and consequent decrease in their cost, means that genome-wide association studies (GWAS) are becoming more feasible. Results for other complex diseases, including cancers from various sites, suggest that GWAS may be more effective in identifying main effects of common low-penetrance genetic variants. ${ }^{94}$ So far, four GWAS have been performed. ${ }^{95-98}$ The first GWAS consisted of a consortium ("Panscan1") of 12 prospective cohort studies and a hospital-based case-control study, providing 1,896 cases and 1,939 controls. Eight additional case-control studies (2,457 cases and 2,654 controls) were used for replication. This GWAS identified a single nucleotide polymorphism (SNP) in the first intron of the $A B O$ blood group gene, conferring an odds ratio (OR) of 1.20 (95\% Cl: $1.12-1.28) .{ }^{95}$ This finding is in line with earlier epidemiological evidence that individuals with blood group $\mathrm{O}$ may have a lower risk of pancreatic cancer compared with groups A and B. ${ }^{99}$ The second GWAS, using a smaller population of 160 cases and 172 controls, reported an association with a variant in the GGT1 gene ( $\gamma$ glutamyltransferase $1 ; \mathrm{OR}=1.66,95 \% \mathrm{Cl}: 1.18-2.32) .{ }^{96}$ The third GWAS reported was a second scan of the Panscan-consortium, which identified multiple susceptibility loci, including 13q22.1 (KLF5 and KLF12, OR = 1.26, 95\% Cl: 1.18-1.35), 1q32.1 (NR5A2, OR = 1.30, 95\% Cl: 1.19-1.41), and 5p15.33 (CLPTM1L-TERT, OR = 1.19, 95\% Cl: $1.11-1.27){ }^{98}$ The most recent GWAS, using 991 cases and 5,209 controls from Japan, identified three pancreatic cancer susceptibility loci, including $6 \mathrm{p} 25.3$ (OR $=1.29,95 \% \mathrm{Cl}$ : $1.17-$ 1.43), $12 \mathrm{p} 11.21$ (OR $=1.32,95 \% \mathrm{Cl}: 1.19-1.47)$, and 7q36.2 (OR = 3.73, 95\% Cl: $2.24-$ 6.21). ${ }^{97}$ The results from these initial GWAS await additional replication and functional studies to elucidate the (genetic) etiology of pancreatic cancer.

\section{RATIONALE AND AIMS OF THIS THESIS}

\section{Rationale}

Because the pancreas is intimately related to digestion and absorption, it is reasonable to place diet high among the possible causal factors for pancreatic cancer. However, 
the specific dietary components and mechanisms involved in the etiology of pancreatic cancer remain unclear, primarily because of limited and inconsistent study findings.

One of the reasons that study findings have been inconsistent between casecontrol studies and cohort studies might be because case-control studies are prone to more biases, including recall bias, compared with cohort studies. Recall bias could lead to risk estimates that are either exaggerated or underestimated because dietary intake is assessed in cases after diagnosis. Furthermore, patients in case-control studies tend to report current rather than past diet which can introduce bias because current diet might be influenced by prediagnostic symptoms of disease. ${ }^{100}$ Differential misclassification of the exposure could also have occurred due to the need to use next-of-kin interviews in case-control studies because pancreatic cancer is rapidly fatal. Indeed, a study has shown that this resulted in misclassification of exposure and that this misclassification varies according to the type of exposure and the relation of the proxy respondent to the subject. ${ }^{101}$ In addition, case-control studies of pancreatic cancer are highly susceptible to selection bias. Due to the high fatality rates, many cases are either not approached for studies because they die before they could be included in the study, or they are unable or unwilling to participate because of the severity of their disease. Excluding these patients might introduce selection bias because the included cases might differ from excluded cases regarding the aggressiveness of the disease or in other ways. Also, pancreatic cancer shows relatively low incidence rates, which has resulted in relatively low case numbers in most prospective studies. A large-scale cohort study with a substantial number of cases would be informative to overcome these biases and to make a substantial contribution to the epidemiological knowledge regarding the association between risk factors and pancreatic cancer risk. The prospective design avoids differential misclassification and the need to use next-of-kin respondents.

\section{Design Netherlands Cohort Study}

The prospective Netherlands Cohort Study (NLCS) was initiated in September 1986 and included initially 58,279 men and 62,573 women aged 55-69 years from 204 Dutch municipalities with computerized population registries. ${ }^{102} \mathrm{~A}$ self-administered 11-page food frequency and lifestyle questionnaire, including detailed information on potential risk factors for pancreatic cancer, was completed at baseline in 1986. For increased efficiency in the processing of the questionnaire and follow-up, the case-cohort approach was used. ${ }^{103}$ Incident cases were derived from the entire cohort, whereas the person-years at risk were estimated from a random sample of 5,000 subjects $(2,411$ men and 2,589 women). This subcohort was chosen immediately after baseline and followed up for vital status information. The entire cohort is being monitored for cancer occurrence by annual record linkage to the Netherlands Cancer Registry and the Netherlands Pathology Registry. ${ }^{104,105}$ Follow-up is still ongoing for the NLCS, which is why two different follow-up periods were used in this thesis. A schematic presentation of the design is given in Figure 1.5. For the first part of the thesis, a total of 13.3 years 
of follow-up (baseline to December 1999) was used for the analysis, for which 408 incident exocrine pancreatic cancer cases (ICD-O-3 code C25; excluding Islet-cell carcinoma [ICD-O-3 code C25.4]) were available. Sixty-six percent of these cases were microscopically confirmed pancreatic cancer $(n=269)$, whereas microscopic confirmation was lacking for $34 \%(n=139)$. Diagnosis of the latter group was made by the treating clinician and was based on clinical symptoms, physical examination, and imaging results. ${ }^{106}$ Data were abstracted and recorded by a trained tumor registrar. When data became available in 2008 for a period of 16.3 years (baseline to December 2002), the follow-up period was extended. This extended follow-up period was used for the analyses described in the last chapters of this thesis, for which 520 incident exocrine pancreatic cancer cases (62\% microscopically confirmed) were available.

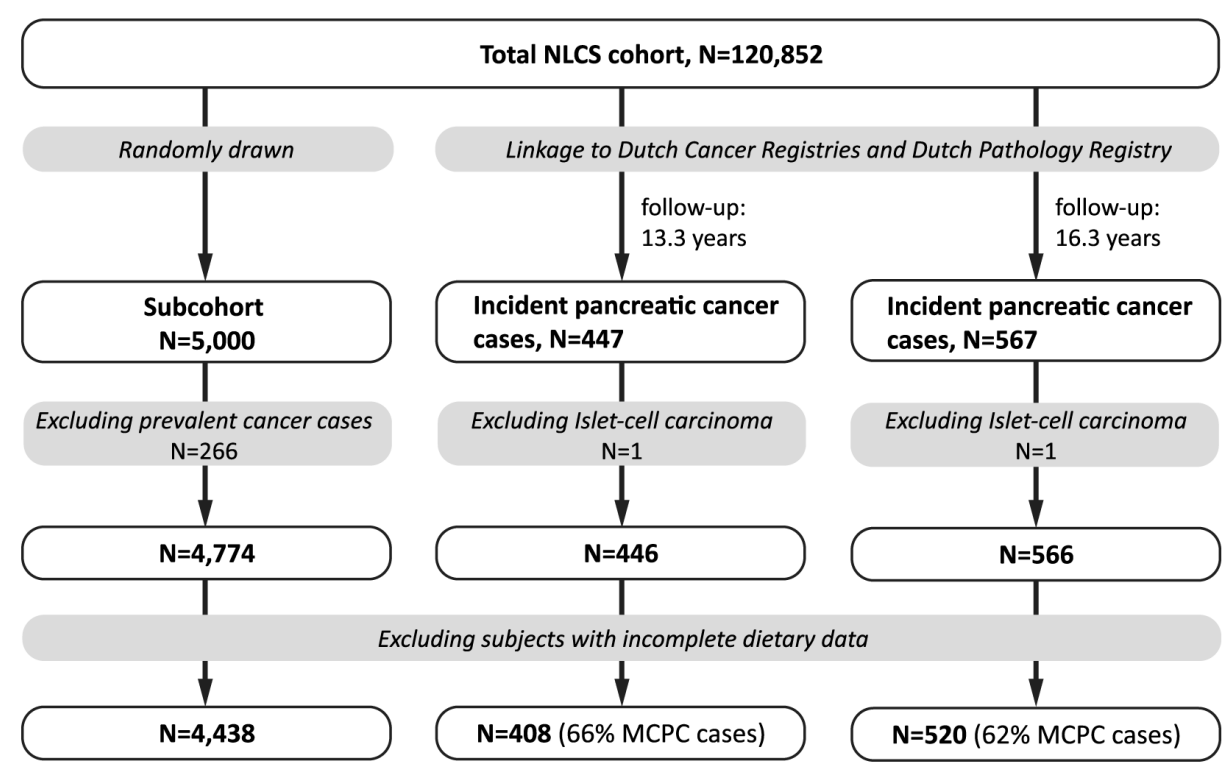

FIGURE 1.5 Schematic presentation of Netherlands Cohort Study design Abbreviations: MCPC, microscopically verified pancreatic cancer; NLCS, Netherlands Cohort Study.

In a previous analysis of anthropometric measures and pancreatic cancer risk within the NLCS, a significantly positive association between BMI and pancreatic cancer risk was observed only among microscopically verified cases, whereas this association was obscured when non-microscopically verified cases were included. ${ }^{107}$ Also, two other studies showed that diagnostic misclassification for pancreatic cancer biased risk estimates towards the null when they investigated the relation between pancreatic cancer risk and exposure to cigarette smoking or exposure to DDT. ${ }^{19,108}$ Therefore, next to the overall analyses including all pancreatic cancer cases, we restricted additional 
analyses in this thesis to microscopically verified cases to create a group with a higher degree of diagnostic certainty of pancreatic cancer.

\section{Aims}

The overall aim of this thesis was to investigate associations between dietary and lifestyle factors and pancreatic cancer risk. These factors were investigated within the context of the NLCS on diet and cancer. In Chapter 2, the following hypotheses were investigated: (i) Physical activity is inversely associated with pancreatic cancer risk and will be more protective in those who are overweight or obese; and (ii) energy restriction in adolescence is associated with a reduced risk of pancreatic cancer. Additionally, several other dietary factors were investigated in relation to pancreatic cancer risk. The following factors were hypothesized risk factors: a high alcohol intake (described in Chapter 3) a diet high in GI and GL (Chapter 4), and a high meat and fat intake (Chapter 5). In Chapter 6, we investigated the hypothesis that a high intake of vegetables, fruits, carotenoids, and vitamin $C$ and $E$ is inversely associated with pancreatic cancer risk. Furthermore, we have investigated whether cigarette smoking and passive smoking exposure were positively associated and quitting cigarette smoking was inversely associated with pancreatic cancer risk (Chapter 7). Finally, the findings described in this thesis are discussed, as well as implications for future research regarding risk factors for pancreatic cancer (Chapter 8). The association between anthropometry and pancreatic cancer risk has already been investigated within the NLCS, observing an association between BMI and gain in BMI from age 20 years and pancreatic cancer risk. ${ }^{107}$ These factors were therefore, not included in the current thesis. 


\section{REFERENCES}

1. Burroughs AK, Westaby D. Liver, biliary tract and pancreatic disease. In: Kumar P, Clark M, eds. Clinical medicine, $5^{\text {th }}$ ed. UK: Bath Press Limited, 2002.

2. Encyclopædia Britannica. "Pancreas". Encyclopædia Britannica Online.

URL: http://www.britannica.com/EBchecked/topic/440971/pancreas (accessed on June 2010).

3. Edlund H. Pancreatic organogenesis - developmental mechanisms and implications for therapy. Nat Rev Genet 2002;3:524-32.

4. Grapin-Botton A. Ductal cells of the pancreas. Int J Biochem Cell Biol 2005;37:504-10.

5. DiMagno EP, Reber HA, Tempero MA. AGA technical review on the epidemiology, diagnosis, and treatment of pancreatic ductal adenocarcinoma. American Gastroenterological Association. Gastroenterology 1999;117:1464-84.

6. Bardeesy N, DePinho RA. Pancreatic cancer biology and genetics. Nat Rev Cancer 2002;2:897-909.

7. Hruban RH, Adsay NV. Molecular classification of neoplasms of the pancreas. Hum Pathol 2009;40: 612-23.

8. Ottenhof NA, Milne AN, Morsink FH, et al. Pancreatic intraepithelial neoplasia and pancreatic tumorigenesis: of mice and men. Arch Pathol Lab Med 2009;133:375-81.

9. Hruban RH, Adsay NV, Albores-Saavedra J, et al. Pancreatic intraepithelial neoplasia: a new nomenclature and classification system for pancreatic duct lesions. Am J Surg Pathol 2001;25:579-86.

10. Hruban RH, Takaori K, Klimstra DS, et al. An illustrated consensus on the classification of pancreatic intraepithelial neoplasia and intraductal papillary mucinous neoplasms. Am J Surg Pathol 2004;28:

977-87.

11. Anderson KE, Mack TM, Silverman DT. Cancer of the pancreas. In: Schottenfeld D, Fraumeni JF Jr, eds. Cancer epidemiology and prevention, $3^{\text {rd }}$ ed. New York: Oxford University Press, 2006. P. 721-62.

12. de Braud F, Cascinu S, Gatta G. Cancer of pancreas. Crit Rev Oncol Hematol 2004;50:147-55.

13. Jemal A, Siegel R, Ward E, et al. Cancer statistics, 2006. CA Cancer J Clin 2006;56:106-30.

14. IKCnet. Dutch incidence and mortality databases [in Dutch]. URL: http://www.ikcnet.nl/page.php?id=114 (accessed on June 2010).

15. Klapman J, Malafa MP. Early detection of pancreatic cancer: why, who, and how to screen. Cancer Control 2008;15:280-7.

16. Hidalgo M. Pancreatic cancer. N Engl J Med 2010;362:1605-17.

17. Curado MP, Edwards B, Shin HR, et al. Cancer incidence in five continents, Vol IX. IARC Scientific Publications No. 160. Lyon, France: International Agency for Research on Cancer, 2007.

18. Anderson KE, Potter JD, Mack TM. Pancreatic cancer. In: Schottenfeld D, Fraumeni JF Jr., eds. Cancer Epidemiology and Prevention, $2^{\text {nd }}$ ed. New York: Oxford University Press, 1996. P. 725-71.

19. Silverman DT, Schiffman M, Devesa S. Diagnostic certainty in pancreatic cancer. J Clin Epidemiol 1996; 49:601-3.

20. Porta M, Malats N, Pinol JL, Rifa J, Andreu M, Real FX. Diagnostic certainty and potential for misclassification in exocrine pancreatic cancer. PANKRAS I Project Investigations. J Clin Epidemiol 1994;47: 1069-79.

21. Huguet F, Girard N, Guerche CS, Hennequin C, Mornex F, Azria D. Chemoradiotherapy in the management of locally advanced pancreatic carcinoma: a qualitative systematic review. J Clin Oncol 2009; 27:2269-77.

22. Ferlay J, Autier $\mathrm{P}$, Boniol $\mathrm{M}$, Heanue $\mathrm{M}$, Colombet $\mathrm{M}$, Boyle $\mathrm{P}$. Estimates of the cancer incidence and mortality in Europe in 2006. Ann Oncol 2007;18:581-92.

23. Ferlay J, Shin HR, Bray F, Forman D, Mathers C, Parkin DM. GLOBOCAN 2008, Cancer Incidence and Mortality Worldwide IARC CancerBase No. 10 [Internet]. Lyon, France: International Agency for Research on Cancer, 2010. URL: http://globocan.iarc.fr (accessed on June 2010).

24. Weiss W, Benarde MA. The temporal relation between cigarette smoking and pancreatic cancer. Am J Public Health 1983;73:1403-4.

25. World Health Organization. Mortality database. URL: http://www-dep.iarc.fr/WHOdb/WHOdb. htm (accessed on June 2010). 
26. Levi F, Lucchini F, Negri E, La Vecchia C. Pancreatic cancer mortality in Europe: the leveling of an epidemic. Pancreas 2003;27:139-42.

27. Karim-Kos HE, de Vries E, Soerjomataram I, Lemmens V, Siesling S, Coebergh JW. Recent trends of cancer in Europe: a combined approach of incidence, survival and mortality for 17 cancer sites since the 1990s. Eur J Cancer 2008;44:1345-89.

28. Pierce JP. International comparisons of trends in cigarette smoking prevalence. Am J Public Health 1989;79:152-7.

29. La Torre G, de Waure C, Specchia ML, et al. Does quality of observational studies affect the results of a meta-analysis?: the case of cigarette smoking and pancreatic cancer. Pancreas 2009;38:241-7.

30. EUROCARE-3. "Survival of cancer patients in Europe: The EUROCARE-3 study". URL: http://www.eurocare.it/Portals/0/CDEu3/Index.htm (accessed on June 2010).

31. EUROCARE-4. "Survival of cancer patients in Europe: The EUROCARE-4 study". URL: http://www.eurocare.it/Portals/O/CDEU4/Index.htm (accessed on June 2010).

32. Jemal A, Siegel R, Ward E, Hao Y, Xu J, Thun MJ. Cancer statistics, 2009. CA Cancer J Clin 2009;59: 225-49.

33. Silverman DT, Hoover RN, Brown LM, et al. Why do Black Americans have a higher risk of pancreatic cancer than White Americans? Epidemiology 2003;14:45-54.

34. Arnold LD, Patel AV, Yan Y, et al. Are Racial Disparities in Pancreatic Cancer Explained by Smoking and Overweight/Obesity? Cancer Epidemiol Biomarkers Prev 2009;18:2397-405.

35. Iodice S, Gandini S, Maisonneuve P, Lowenfels AB. Tobacco and the risk of pancreatic cancer: a review and meta-analysis. Langenbecks Arch Surg 2008;393:535-45.

36. Batty GD, Kivimaki M, Gray L, Smith GD, Marmot MG, Shipley MJ. Cigarette smoking and site-specific cancer mortality: testing uncertain associations using extended follow-up of the original Whitehall study. Ann Oncol 2008;19:996-1002.

37. Luo J, Iwasaki M, Inoue M, et al. Body mass index, physical activity and the risk of pancreatic cancer in relation to smoking status and history of diabetes: a large-scale population-based cohort study in Japan - the JPHC study. Cancer Causes Control 2007;18:603-12.

38. Lynch SM, Vrieling A, Lubin JH, et al. Cigarette smoking and pancreatic cancer: a pooled analysis from the pancreatic cancer cohort consortium. Am J Epidemiol 2009;170:403-13.

39. Stevens RJ, Roddam AW, Spencer EA, et al. Factors associated with incident and fatal pancreatic cancer in a cohort of middle-aged women. Int J Cancer 2009;124:2400-5.

40. Hassan MM, Abbruzzese JL, Bondy ML, et al. Passive smoking and the use of noncigarette tobacco products in association with risk for pancreatic cancer: a case-control study. Cancer 2007;109:2547-56.

41. Lo AC, Soliman AS, El-Ghawalby N, et al. Lifestyle, occupational, and reproductive factors in relation to pancreatic cancer risk. Pancreas 2007;35:120-9.

42. Mizuno S, Watanabe S, Nakamura K, et al. A multi-institute case-control study on the risk factors of developing pancreatic cancer. Jpn J Clin Oncol 1992;22:286-91.

43. Villeneuve PJ, Johnson KC, Mao Y, Hanley AJ. Environmental tobacco smoke and the risk of pancreatic cancer: findings from a Canadian population-based case-control study. Can J Public Health 2004;95:

32-7.

44. Bao Y, Giovannucci E, Fuchs CS, Michaud DS. Passive smoking and pancreatic cancer in women: a prospective cohort study. Cancer Epidemiol Biomarkers Prev 2009;18:2292-6.

45. Gallicchio L, Kouzis A, Genkinger JM, et al. Active cigarette smoking, household passive smoke exposure, and the risk of developing pancreatic cancer. Prev Med 2006;42:200-5.

46. Nishino $Y$, Tsubono $Y$, Tsuji I, et al. Passive smoking at home and cancer risk: a population-based prospective study in Japanese nonsmoking women. Cancer Causes Control 2001;12:797-802.

47. Vrieling A, Bueno-de-Mesquita HB, Boshuizen HC, et al. Cigarette smoking, environmental tobacco smoke exposure and pancreatic cancer risk in the European Prospective Investigation into Cancer and Nutrition. Int J Cancer 2010;126:2394-403.

48. World Cancer Research Fund/American Institute for Cancer research. Food, nutrition, physical activity, and the prevention of cancer: a global perspective. Washington DC: AICR, 2007. 
49. Larsson SC, Orsini N, Wolk A. Body mass index and pancreatic cancer risk: A meta-analysis of prospective studies. Int J Cancer 2007;120:1993-8.

50. Berrington de Gonzalez A, Spencer EA, Bueno-de-Mesquita HB, et al. Anthropometry, physical activity, and the risk of pancreatic cancer in the European prospective investigation into cancer and nutrition. Cancer Epidemiol Biomarkers Prev 2006;15:879-85.

51. Larsson SC, Permert J, Hakansson N, Naslund I, Bergkvist L, Wolk A. Overall obesity, abdominal adiposity, diabetes and cigarette smoking in relation to the risk of pancreatic cancer in two Swedish population-based cohorts. Br J Cancer 2005;93:1310-5.

52. Stolzenberg-Solomon RZ, Adams K, Leitzmann M, et al. Adiposity, physical activity, and pancreatic cancer in the National Institutes of Health-AARP Diet and Health Cohort. Am J Epidemiol 2008;167: 586-97.

53. Arslan AA, Helzlsouer KJ, Kooperberg C, et al. Anthropometric measures, body mass index, and pancreatic cancer: a pooled analysis from the Pancreatic Cancer Cohort Consortium (PanScan). Arch Intern Med 2010;170:791-802.

54. Sinner PJ, Schmitz KH, Anderson KE, Folsom AR. Lack of association of physical activity and obesity with incident pancreatic cancer in elderly women. Cancer Epidemiol Biomarkers Prev 2005;14:1571-3.

55. Michaud DS, Giovannucci E, Willett WC, Colditz GA, Stampfer MJ, Fuchs CS. Physical activity, obesity, height, and the risk of pancreatic cancer. Jama 2001;286:921-9.

56. Zhang J, Dhakal IB, Gross MD, et al. Physical activity, diet, and pancreatic cancer: a population-based, case-control study in Minnesota. Nutr Cancer 2009;61:457-65.

57. Nothlings U, Wilkens LR, Murphy SP, Hankin JH, Henderson BE, Kolonel LN. Body mass index and physical activity as risk factors for pancreatic cancer: the Multiethnic Cohort Study. Cancer Causes Control 2007;18:165-75.

58. Bao Y, Michaud DS. Physical activity and pancreatic cancer risk: a systematic review. Cancer Epidemiol Biomarkers Prev 2008;17:2671-82.

59. O'Rorke MA, Cantwell MM, Cardwell CR, Mulholland HG, Murray LJ. Can physical activity modulate pancreatic cancer risk? a systematic review and meta-analysis. Int J Cancer 2010;126:2957-68.

60. Navarro Silvera SA, Miller AB, Rohan TE. Hormonal and reproductive factors and pancreatic cancer risk: a prospective cohort study. Pancreas 2005;30:369-74.

61. Stevens RJ, Roddam AW, Green J, et al. Reproductive history and pancreatic cancer incidence and mortality in a cohort of postmenopausal women. Cancer Epidemiol Biomarkers Prev 2009;18:1457-60.

62. Jenkins DJ, Kendall CW, Augustin LS, et al. Glycemic index: overview of implications in health and disease. Am J Clin Nutr 2002;76:266S-73S.

63. Foster-Powell K, Holt SH, Brand-Miller JC. International table of glycemic index and glycemic load values: 2002. Am J Clin Nutr 2002;76:5-56.

64. Mulholland HG, Murray $\amalg$, Cardwell CR, Cantwell MM. Glycemic index, glycemic load, and risk of digestive tract neoplasms: a systematic review and meta-analysis. Am J Clin Nutr 2009;89:568-76.

65. Roebuck BD, Baumgartner KJ, MacMillan DL. Caloric restriction and intervention in pancreatic carcinogenesis in the rat. Cancer Res 1993;53:46-52.

66. Roebuck BD, Yager JD, Jr., Longnecker DS. Dietary modulation of azaserine-induced pancreatic carcinogenesis in the rat. Cancer Res 1981;41:888-93.

67. Howe GR, Burch JD. Nutrition and pancreatic cancer. Cancer Causes Control 1996;7:69-82.

68. International Agency for Research on Cancer Coffee, tea, mate, methylxanthines and methylglyoxaled., vol. 51. Lyon, France: International Agency for Research on Cancer, 1991. P. 41-206.

69. Everhart J, Wright D. Diabetes mellitus as a risk factor for pancreatic cancer. A meta-analysis. Jama 1995;273:1605-9.

70. Huxley R, Ansary-Moghaddam A, Berrington de Gonzalez A, Barzi F, Woodward M. Type-Il diabetes and pancreatic cancer: a meta-analysis of 36 studies. Br J Cancer 2005;92:2076-83.

71. Kalapothaki V, Tzonou A, Hsieh CC, Toupadaki N, Karakatsani A, Trichopoulos D. Tobacco, ethanol, coffee, pancreatitis, diabetes mellitus, and cholelithiasis as risk factors for pancreatic carcinoma. Cancer Causes Control 1993;4:375-82. 
72. McKay CJ, Glen P, McMillan DC. Chronic inflammation and pancreatic cancer. Best Pract Res Clin Gastroenterol 2008;22:65-73.

73. Chow WH, Johansen C, Gridley G, Mellemkjaer L, Olsen JH, Fraumeni JF, Jr. Gallstones, cholecystectomy and risk of cancers of the liver, biliary tract and pancreas. Br J Cancer 1999;79:640-4.

74. Schernhammer ES, Michaud DS, Leitzmann MF, Giovannucci E, Colditz GA, Fuchs CS. Gallstones, cholecystectomy, and the risk for developing pancreatic cancer. Br J Cancer 2002;86:1081-4.

75. Silverman DT, Schiffman M, Everhart J, et al. Diabetes mellitus, other medical conditions and familial history of cancer as risk factors for pancreatic cancer. Br J Cancer 1999;80:1830-7.

76. Bao Y, Spiegelman D, Li R, Giovannucci E, Fuchs CS, Michaud DS. History of peptic ulcer disease and pancreatic cancer risk in men. Gastroenterology 2010;138:541-9.

77. Ansary-Moghaddam A, Huxley R, Barzi F, et al. The effect of modifiable risk factors on pancreatic cancer mortality in populations of the Asia-Pacific region. Cancer Epidemiol Biomarkers Prev 2006;15: 2435-40.

78. El-Serag HB, Engels EA, Landgren O, et al. Risk of hepatobiliary and pancreatic cancers after hepatitis C virus infection: A population-based study of U.S. veterans. Hepatology 2009;49:116-23.

79. Larsson SC, Giovannucci E, Bergkvist L, Wolk A. Aspirin and nonsteroidal anti-inflammatory drug use and risk of pancreatic cancer: a meta-analysis. Cancer Epidemiol Biomarkers Prev 2006;15:2561-4.

80. Capurso G, Schunemann HJ, Terrenato I, et al. Meta-analysis: the use of non-steroidal antiinflammatory drugs and pancreatic cancer risk for different exposure categories. Aliment Pharmacol Ther 2007;26:1089-99.

81. Del Chiaro $M$, Zerbi A, Falconi $M$, et al. Cancer risk among the relatives of patients with pancreatic ductal adenocarcinoma. Pancreatology 2007;7:459-69.

82. Fernandez E, La Vecchia C, D'Avanzo B, Negri E, Franceschi S. Family history and the risk of liver, gallbladder, and pancreatic cancer. Cancer Epidemiol Biomarkers Prev 1994;3:209-12.

83. Ghadirian $\mathrm{P}$, Boyle $\mathrm{P}$, Simard A, Baillargeon J, Maisonneuve P, Perret C. Reported family aggregation of pancreatic cancer within a population-based case-control study in the Francophone community in Montreal, Canada. Int J Pancreatol 1991;10:183-96.

84. Klein AP, Beaty TH, Bailey-Wilson JE, Brune KA, Hruban RH, Petersen GM. Evidence for a major gene influencing risk of pancreatic cancer. Genet Epidemiol 2002;23:133-49.

85. McWilliams RR, Rabe KG, Olswold C, De Andrade M, Petersen GM. Risk of malignancy in first-degree relatives of patients with pancreatic carcinoma. Cancer 2005;104:388-94.

86. Tersmette AC, Petersen GM, Offerhaus GJ, et al. Increased risk of incident pancreatic cancer among first-degree relatives of patients with familial pancreatic cancer. Clin Cancer Res 2001;7:738-44.

87. Lichtenstein P, Holm NV, Verkasalo PK, et al. Environmental and heritable factors in the causation of cancer - analyses of cohorts of twins from Sweden, Denmark, and Finland. N Engl J Med 2000;343: 78-85.

88. Eberle MA, Pfutzer R, Pogue-Geile KL, et al. A new susceptibility locus for autosomal dominant pancreatic cancer maps to chromosome 4q32-34. Am J Hum Genet 2002;70:1044-8.

89. Earl J, Yan L, Vitone LJ, et al. Evaluation of the 4q32-34 locus in European familial pancreatic cancer. Cancer Epidemiol Biomarkers Prev 2006;15:1948-55.

90. Klein AP, de Andrade M, Hruban RH, et al. Linkage analysis of chromosome 4 in families with familial pancreatic cancer. Cancer Biol Ther 2007;6:320-3.

91. Pierce BL, Friedrichsen-Karyadi DM, Mclntosh L, et al. Genomic scan of 12 hereditary prostate cancer families having an occurrence of pancreas cancer. Prostate 2007;67:410-5.

92. Shi C, Hruban RH, Klein AP. Familial pancreatic cancer. Arch Pathol Lab Med 2009;133:365-74.

93. Milne RL, Greenhalf W, Murta-Nascimento C, Real FX, Malats N. The inherited genetic component of sporadic pancreatic adenocarcinoma. Pancreatology 2009;9:206-14.

94. McCarthy MI, Abecasis GR, Cardon LR, et al. Genome-wide association studies for complex traits: consensus, uncertainty and challenges. Nat Rev Genet 2008;9:356-69.

95. Amundadottir L, Kraft P, Stolzenberg-Solomon RZ, et al. Genome-wide association study identifies variants in the ABO locus associated with susceptibility to pancreatic cancer. Nat Genet 2009;41: 986-90. 
96. Diergaarde B, Brand R, Lamb J, et al. Pooling-based genome-wide association study implicates gammaglutamyltransferase 1 (GGT1) gene in pancreatic carcinogenesis. Pancreatology 2010;10:194-200.

97. Low SK, Kuchiba A, Zembutsu H, et al. Genome-wide association study of pancreatic cancer in Japanese population. PLoS One 2010;5:e11824.

98. Petersen GM, Amundadottir L, Fuchs CS, et al. A genome-wide association study identifies pancreatic cancer susceptibility loci on chromosomes 13q22.1, 1q32.1 and 5p15.33. Nat Genet 2010;42:224-8.

99. Marcus DM. The $\mathrm{ABO}$ and Lewis blood-group system. Immunochemistry, genetics and relation to human disease. N Engl J Med 1969;280:994-1006.

100. Hart AR. Pancreatic cancer: any prospects for prevention? Postgrad Med J 1999;75:521-6.

101. Lyon JL, Egger MJ, Robison LM, French TK, Gao R. Misclassification of exposure in a case-control study: the effects of different types of exposure and different proxy respondents in a study of pancreatic cancer. Epidemiology 1992;3:223-31.

102. van den Brandt PA, Goldbohm RA, van 't Veer P, Volovics A, Hermus RJ, Sturmans F. A large-scale prospective cohort study on diet and cancer in The Netherlands. J Clin Epidemiol 1990;43:285-95.

103. Prentice RL. A case-cohort design for epidemiologic cohort studies and disease prevention trials. Biometrika 1986;73:1-11.

104. van den Brandt PA, Schouten LJ, Goldbohm RA, Dorant E, Hunen PM. Development of a record linkage protocol for use in the Dutch Cancer Registry for Epidemiological Research. Int J Epidemiol 1990;19: 553-8.

105. Casparie M, Tiebosch AT, Burger G, et al. Pathology databanking and biobanking in The Netherlands, a central role for PALGA, the nationwide histopathology and cytopathology data network and archive. Cell Oncol 2007;29:19-24.

106. van der Sanden GA, Coebergh JW, Schouten L, Visser O, van Leeuwen FE. Cancer incidence in The Netherlands in 1989 and 1990: first results of the nationwide Netherlands cancer registry. Coordinating Committee for Regional Cancer Registries. Eur J Cancer 1995;31A:1822-9.

107. Verhage BA, Schouten LJ, Goldbohm RA, van den Brandt PA. Anthropometry and pancreatic cancer risk: an illustration of the importance of microscopic verification. Cancer Epidemiol Biomarkers Prev 2007;16:1449-54.

108. Malats N, Real FX, Porta M. DDT and pancreatic cancer. J Natl Cancer Inst 1993;85:328-9.2 



\title{
2
}

\section{Physical activity, energy restriction, and the risk of pancreatic cancer: a prospective study in the Netherlands}

\author{
Mirjam M. Heinen \\ Bas A.J. Verhage \\ R. Alexandra Goldbohm \\ L.H. Lumey \\ Piet A. van den Brandt
}

Submitted for publication 


\section{ABSTRACT}

\section{Background}

Previous studies suggested that higher physical activity levels and energy restriction might decrease pancreatic cancer risk. The insulin-like growth factor axis might play a mechanistic role in these associations.

\section{Objective}

We examined prospectively the associations between physical activity, energy restriction, and pancreatic cancer risk.

\section{Methods}

The Netherlands Cohort Study consisted of 120,852 men and women who completed a baseline questionnaire in 1986 . After 13.3 years of follow-up, 408 incident pancreatic cancer cases were available for analysis. Self-reported information on physical activity was collected. Three indicators were used as proxies for energy restriction: place of residence during the Hunger winter (1944-1945) and World War II years (1940-1944), and father's employment status during the Economic Depression (1932-1940).

\section{Results}

For sports activity in the past, we observed a statistically significantly decreased pancreatic cancer risk (hazard rate ratio $[\mathrm{HR}]=0.78,95 \%$ confidence interval $[\mathrm{Cl}]$ : 0.62 0.98). Compared with individuals who resided in non-western area during the Hunger winter, residing in western rural area increased cancer risk with $37 \%(95 \% \mathrm{Cl}: 1.00-$ 1.86), whereas no association was observed for residing in a western city. Individuals who resided in a city in 1942 had a decreased risk ( $\mathrm{HR}=0.76,95 \% \mathrm{Cl}$ : 0.59-0.98). Occupational physical activity and exposure to energy restriction during the Economic Depression were not associated with pancreatic cancer risk.

\section{Conclusions}

Overall, our results suggest a modestly decreased pancreatic cancer risk for sports activity in the past, whereas findings with respect to proxies for energy restriction did not support our hypothesis that energy restriction may reduce pancreatic cancer risk. 


\section{INTRODUCTION}

Pancreatic cancer is the $5^{\text {th }}$ leading cause of death in Europe and $4^{\text {th }}$ in the United States, ${ }^{1,2}$ with a 5 -year survival rate of $6 \%$ or less. ${ }^{2,3}$ So far, just few risk factors have been identified, including cigarette smoking, body mass index, and diabetes mellitus. ${ }^{4-7}$

Observational studies on pancreatic cancer suggest that high insulin concentrations, glucose intolerance and insulin resistance may play a role in carcinogenesis, even without a diagnosis of diabetes mellitus. ${ }^{8,9}$ Furthermore, experimental studies show that insulin might act as a growth promoter and mitogen in the pancreas. ${ }^{10,11}$ Additionally, excess insulin can downregulate insulin-like growth factor (IGF)-1 binding proteins resulting in more bioavailable IGF-1, which has been positively associated with cell proliferation in pancreatic cancer. ${ }^{9,12}$ Human intervention studies showed that prolonged exercise (e.g., marathon running) lowers IGF-1 levels. ${ }^{13}$ In addition, intervention studies showed that chronic exercise training reduces insulin resistance, even in the absence of weight loss. ${ }^{5,9,14}$ Experimental studies have shown that energy restriction reduces levels of circulating IGF-1 and insulin. ${ }^{5,9}$ Furthermore, energy restriction suppresses tumor development in experimental animals. ${ }^{5}$ In rat models, it was also shown that moderate energy restriction decreased pancreatic cancer risk. ${ }^{15,16}$ Therefore, we hypothesized that both physical activity and energy restriction may reduce pancreatic cancer risk.

So far, findings from epidemiological studies investigating physical activity in relation to pancreatic cancer risk have been inconsistent. Some cohort and case-control studies suggest that higher physical activity levels (both occupational and nonoccupational) might decrease risk, especially in overweight or obese persons. ${ }^{17-20}$ Other cohort studies, however, did not observe an association between physical activity and pancreatic cancer risk. ${ }^{21-24}$ To our knowledge, no observational study has investigated the relation between energy restriction and pancreatic cancer risk.

In the current study, we investigated both non-occupational and occupational physical activity in relation to pancreatic cancer risk. We also investigated whether the association between physical activity and pancreatic cancer risk was modified by body mass index (BMI), and change in BMI. Finally, the Netherlands Cohort Study (NLCS) is comprised of individuals who grew up during the Hunger winter (winter of 1944-1945). This period offers the rare opportunity to study the effect of severe short-term energy restriction during adolescence on the risk of pancreatic cancer in later life. We also had information on two preceding periods of more moderate energy restriction: World War II (WW II; 1940-1944) and the Economic Depression (1932-1940). Although individual food intake data is not available for these three time periods, proxy measures have been collected from cohort members that reflect their exposure to energy restriction; that is, place of residence during the Hunger winter and WW II, and employment status of the father during the Economic Depression. 


\section{SUBJECTS AND METHODS}

\section{Study population and cancer follow-up}

The study design of the NLCS has been reported in detail elsewhere. ${ }^{25}$ Briefly, the NLCS was begun in September 1986 and included initially 58,279 men and 62,573 women aged 55-69 years from 204 Dutch municipalities with computerized population registries. A self-administered questionnaire on dietary habits and other risk factors for cancer was completed at baseline, including non-occupational physical activity at baseline, history of sports participation and occupational history. Also included were questions about the residences of the cohort members during their entire life, including the residence in the war years and the winter of 1944-1945, and the fathers' employment status during the Economic Depression. For increased efficiency in the processing of the questionnaire and follow-up, the case-cohort approach was used. ${ }^{26}$ Incident cases were derived from the entire cohort, whereas the person-years at risk were estimated from a random sample of 5,000 participants (2,411 men and 2,589 women). This subcohort was chosen immediately after baseline and followed up for vital status information. The entire cohort is being monitored for cancer occurrence by annual record linkage to the Netherlands Cancer Registry and the Netherlands Pathology Registry. ${ }^{27,28}$ A total of 13.3 years of follow-up (baseline to December 1999) was used for the current analysis. Only two subcohort member were lost to follow-up and completeness of cancer follow-up was estimated to be $>96 \%{ }^{29}$

All prevalent cancer cases at baseline other than skin cancer were excluded, resulting in a subcohort of 4,774 men and women. After 13.3 years of follow-up, 447 incident pancreatic cancer cases (ICD-O-3 code C25) were identified. Of these cases, endocrine subtypes (ICD-O-3 code C25.4; $n=1$ ) were excluded. Sixty-five percent of the 446 pancreatic cancer cases were microscopically confirmed pancreatic cancer (MCPC; $n=290)$, whereas confirmation was lacking for $35 \%(n=156)$. Diagnosis of the latter group was made by the treating clinician and was based on clinical symptoms, physical examination and imaging results. Data were abstracted and recorded by a trained tumor registrar. ${ }^{30}$ The NLCS has been approved by the institutional review boards of the TNO Nutrition and Food Research Institute (Zeist, the Netherlands) and Maastricht University (Maastricht, the Netherlands).

\section{Exposure assessment}

Questionnaire data were key-entered and processed for all incident cases in the cohort and subcohort members in a standardized manner, blinded with respect to case or subcohort status. This was done to minimize observer bias in the coding and interpretation of the data. Subcohort members and cases with incomplete or inconsistent dietary data were excluded from analyses. Additional details are given elsewhere. ${ }^{31}$ This resulted in a final subcohort of 4,438 participants (2,191 men, 2,247 women) and 408 exocrine pancreatic cancer cases ( 217 men, 191 women) available for analysis. 


\section{Physical activity}

Information on both non-occupational and occupational physical activity was assessed in the questionnaire. In this paper, we use the term "non-occupational physical activity" to cover both leisure-time physical activity and other physical activities outside of the job. Our calculations did not include household chores.

Non-occupational physical activity at baseline was calculated by adding the number of minutes spent per day on cycling or walking to work, shopping, and walking the dog, and the number of hours spent per week on gardening or odd jobs, recreational cycling or walking, and sports or exercise as reported previously. ${ }^{32}$ The minutes spent per day on these activities were categorized: $<30,30-<60,60-<90$, and $\geq 90 \mathrm{~min} /$ day.

Data on history of sports participation was also available; respondents were asked what type of sport they had conducted, the number of hours per week and the duration of this sport in years. In total, respondents could describe three sports. Participating in sports activity was first dichotomized to "never" or "ever" participating in sports. ${ }^{32}$ The total duration of sports activities in years was calculated by adding up the duration of all episodes of participation in each sport (accounting for the overlap between sports). Duration of sports participation was categorized as $<15,15-<30$, and $\geq 30$ years of sports participation. The total numbers of hours per week that respondents had participated in each sport were also added up. This variable was categorized as $<2,2-<4$, and $\geq 4$ hours/week of sports participation. The respondents who reported "never to have participated in sports" where assigned the value zero.

Respondents were asked for their lifetime occupational history, with regard to job title and duration. We used information about the longest job ever held as well as information about the last occupation as indicators for the lifetime physical activity at work. Two different measures of occupational physical activity have been used: (i) sitting time (hours/day) and (ii) energy expenditure (kJ/min). ${ }^{33}$ For sitting time respondents were classified into three groups: $>6,2-6$, and $<2$ working hours/day spent sitting. Total energy expenditure was based on a rating system developed by Hettinger et al. ${ }^{34}$ Respondents were classified into three energy expenditure groups: $<8,8-12$, and $>12 \mathrm{~kJ} / \mathrm{min}^{33}{ }^{33}$ Occupational physical activity was not calculated for women because most Dutch women of this generation had not held a job or had worked for only a short period of time, mostly in the distant past.

\section{Energy restriction}

Individual food intake data of the cohort members was not available for the three mentioned periods of energy restriction in the Netherlands; we therefore used proxy variables to describe exposure to energy restriction. ${ }^{35}$ With respect to the Economic Depression years (1932-1940), the occupation of the father was the best available proxy variable for moderate energy restriction. Several surveys showed that having an unemployed father indicated that the amount of calories available was less and the variation in the individual's food pattern was limited compared with families with an employed father. ${ }^{35,36}$ The exposure variable for the Economic Depression years was 
dichotomous: respondents whose father had a job and respondents whose father had no job during that period.

For the War period (1940-1944) and the Hunger winter (1944-1945), the city of residence during these periods was taken to approximate the exposure to energy restriction. During WW II, food rationing was introduced and caloric intake was reduced to about 1,700 calories a day during 1941-1943. ${ }^{37}$ Between 1943-1944, the nutritional status of the Dutch population deteriorated, especially for those living in the cities. ${ }^{35}$ Place of residence 1942 (midpoint of war years) was used as a proxy for moderate energy restriction during the war. This exposure variable was dichotomous (living in a rural area in 1942 versus living in a city in 1942).

With respect to the Hunger winter, cohort members were specifically asked where they lived during the winter of 1944-1945. Living in a western city in 1944-1945 was considered an indicator for severe energy restriction. Whereas the diet remained nutritionally balanced, individuals living in western urban areas experienced rationing of less than $700 \mathrm{kcal}$ per day. ${ }^{38}$

\section{Statistical analysis}

Age-adjusted and multivariable-adjusted hazard rate ratios (HRs) and corresponding 95\% confidence intervals (95\% Cls) were estimated using Cox proportional hazards models. The total person-years at risk estimated from the subcohort were used in the analyses. ${ }^{39}$ Standard errors were estimated by using a robust covariance matrix estimator to account for increased variance due to sampling from the cohort. ${ }^{40}$ We tested the proportional hazards assumption by using the scaled Schoenfeld residuals. ${ }^{41}$ All analyses were conducted for both sexes combined and separately for men and women.

The following variables were considered as potential confounders: age, sex, smoking, BMI at baseline, height, energy intake, alcohol intake, intake of vegetables and fruit, level of education, family history of pancreatic cancer, history of diabetes mellitus and hypertension. These potential confounding variables were added to the multivariable-adjusted model if they (i) were associated with the disease and with the exposure of interest and (ii) changed the age- and sex-adjusted regression coefficients by at least $10 \%$ (using a backwards stepwise procedure). The following confounders were included in all multivariable-adjusted models: age at baseline (years), sex (included in all models except for occupational physical activity), smoking (current smoking: yes/no; number of cigarettes smoked per day; number of years of smoking), BMI at baseline $\left(\mathrm{kg} / \mathrm{m}^{2}\right)$, level of education (primary school or lower vocational school/intermediate vocational school or high school/higher vocational school or college), energy intake (kcal/day), and intake of vegetables (g/day). The model for energy restriction additionally included non-occupational physical activity (total non-occupational physical activity at baseline, min/day; history of sports participation: never/ever) in the multivariable-adjusted model. To enable comparison, age- and sex-adjusted analyses were restricted to participants included in multivariable-adjusted analyses. Trends 
were evaluated with the Wald test by assigning participants the median value for each level of the categorical exposure variable among the subcohort members and this variable was entered as a continuous term in the Cox regression model.

In the present study the overall analyses included all pancreatic cancer cases. We restricted additional analyses to MCPC cases to create a group with a higher degree of diagnostic certainty of pancreatic cancer, which was shown to be important in previous studies. ${ }^{42,43}$ In additional analyses, respondents who reported a history of diabetes at baseline $(n=184)$ were excluded. To evaluate whether early symptoms of pancreatic cancer before diagnosis could have influenced the results, early cases (diagnosed within 2 years after baseline) were excluded in additional analyses of physical activity. Michaud et al. showed that physical activity was inversely associated with pancreatic cancer risk among individuals with a BMI of $\geq 25 \mathrm{~kg} / \mathrm{m}^{2}$, whereas no association was observed for normal weight individuals. ${ }^{18}$ Therefore, interactions between physical activity (non-occupational physical activity at baseline and history of sports participation), and BMI at baseline (cutoff: $25 \mathrm{~kg} / \mathrm{m}^{2}$ ) were investigated. Also, interactions between physical activity and BMI at age 20 years (cutoff: $21 \mathrm{~kg} / \mathrm{m}^{2}$ ) were investigated. Increases in body weight during adulthood - due to excess energy intake, physical inactivity, or both - depend mostly on accumulation of fat rather than lean tissue. ${ }^{5,44}$ Hence, change in weight may better reflect fatness than adult attained weight itself, which is more dependent of lean mass. Therefore, interactions of physical activity with change in BMI since age 20 years $\left(\geq 6,2-<6\right.$, and $\left.<2 \mathrm{~kg} / \mathrm{m}^{2}\right)$ were investigated as well. All analyses were performed using the STATA statistical software package (intercooled STATA, version 9). All $p$ values were based on two-sided tests and considered statistically significant if $<0.05$.

\section{RESULTS}

In Table 2.1, baseline characteristics (stratified by sex) are presented. Most characteristics did not differ between pancreatic cancer cases and subcohort members; however, there were more current smokers and more individuals with a history of diabetes mellitus among cases than among subcohort members, especially in men. 
TABLE 2.1 Baseline characteristics of pancreatic cancer cases and subcohort members; Netherlands Cohort Study on diet and cancer, 1986-1999

\begin{tabular}{|c|c|c|c|c|}
\hline \multirow[t]{2}{*}{ Characteristic } & \multicolumn{2}{|c|}{ Men } & \multicolumn{2}{|c|}{ Women } \\
\hline & $\begin{array}{l}\text { All pancreatic } \\
\text { cancer cases }\end{array}$ & Subcohort & $\begin{array}{l}\text { All pancreatic } \\
\text { cancer cases }\end{array}$ & Subcohort \\
\hline $\mathrm{n}$ & 217 & 2,191 & 191 & 2,247 \\
\hline Age, years, mean $\pm S D$ & $62.2 \pm 4.0$ & $61.3 \pm 4.2$ & $62.5 \pm 4.2$ & $61.4 \pm 4.3$ \\
\hline Current smokers (\%) & 47.5 & 35.7 & 28.3 & 21.0 \\
\hline Years of smoking ${ }^{*}$, years, mean \pm SD & $35.9 \pm 12.1$ & $33.7 \pm 11.8$ & $29.5 \pm 12.1$ & $27.8 \pm 12.5$ \\
\hline $\mathrm{BMI}$ at baseline, $\mathrm{kg} / \mathrm{m}^{2}$, mean $\pm \mathrm{SD}$ & $25.3 \pm 3.0$ & $25.0 \pm 2.6$ & $25.6 \pm 3.5$ & $25.1 \pm 3.6$ \\
\hline BMl at age 20 years, $\mathrm{kg} / \mathrm{m}^{2}$, mean $\pm \mathrm{SD}$ & $21.8 \pm 2.2$ & $21.7 \pm 2.4$ & $21.4 \pm 3.6$ & $21.4 \pm 2.8$ \\
\hline \multicolumn{5}{|l|}{ Change in BMI since age 20 years, $\mathrm{kg} / \mathrm{m}^{2}$, } \\
\hline mean $\pm S D$ & $3.6 \pm 3.3$ & $3.3 \pm 3.0$ & $4.2 \pm 4.0$ & $3.7 \pm 3.7$ \\
\hline History of diabetes mellitus (\%) & 8.8 & 3.4 & 5.2 & 3.6 \\
\hline History of hypertension (\%) & 23.5 & 23.4 & 31.4 & 29.5 \\
\hline \multicolumn{5}{|l|}{ Level of education (\%) } \\
\hline Low & 46.1 & 45.7 & 57.4 & 56.7 \\
\hline Medium & 33.2 & 35.6 & 35.2 & 34.5 \\
\hline High & 20.7 & 18.7 & 7.4 & 8.8 \\
\hline \multicolumn{5}{|l|}{ Daily intake } \\
\hline Energy intake, kcal, mean \pm SD & $2159 \pm 474$ & $2166 \pm 511$ & $1693 \pm 403$ & $1686 \pm 398$ \\
\hline Total fat ${ }^{\dagger}, \mathrm{g}$, mean $\pm \mathrm{SD}$ & $93.1 \pm 13.8$ & $93.9 \pm 14.3$ & $74.0 \pm 11.4$ & $74.0 \pm 10.3$ \\
\hline Total carbohydrates ${ }^{\dagger}, \mathrm{g}$, mean \pm SD & $223.4 \pm 37.6$ & $226.7 \pm 37.5$ & $176.6 \pm 27.1$ & $178.8 \pm 26.7$ \\
\hline Alcohol, g, median (IQR) & $11.0(0-69.5)$ & $9.7(0-96.7)$ & $2.6(0-41.8)$ & $1.6(0-66.4)$ \\
\hline Vegetable intake, $g$, mean \pm SD & $193.5 \pm 90.6$ & $191.6 \pm 84.9$ & $211.6 \pm 82.7$ & $195.5 \pm 81.3$ \\
\hline Fruit intake, g, mean \pm SD & $150.7 \pm 120.2$ & $154.0 \pm 114.1$ & $192.4 \pm 107.2$ & $196.4 \pm 121.1$ \\
\hline \multicolumn{5}{|l|}{ Non-occupational physical activity } \\
\hline \multicolumn{5}{|c|}{ Non-occupational physical activity at baseline } \\
\hline \multicolumn{5}{|c|}{ Total non-occupational physical activity at } \\
\hline \multicolumn{5}{|l|}{ History of sports participation (\%) } \\
\hline Never & 54.4 & 45.9 & 57.1 & 54.8 \\
\hline Ever & 45.6 & 54.1 & 42.9 & 45.2 \\
\hline \multicolumn{5}{|l|}{ No. of hours of sport per week ${ }^{\ddagger}}$, \\
\hline median (IQR) & $5(1-22)$ & $5(1-36)$ & $3(1-14)$ & $3(0.5-42)$ \\
\hline $\begin{array}{l}\text { Duration of sports participation }{ }^{\ddagger}, \\
\text { years, median (IQR) }\end{array}$ & $15.5(2-51)$ & $12(1-61)$ & $12(2-52)$ & $10(1-61)$ \\
\hline \multicolumn{5}{|l|}{ Occupational physical activity ${ }^{\S}$} \\
\hline \multicolumn{5}{|l|}{ Longest held job } \\
\hline \multicolumn{5}{|l|}{ Sitting time per day, hours/day (\%) } \\
\hline$>6$ & 24.3 & 25.6 & - & - \\
\hline $2-6$ & 40.8 & 44.5 & - & - \\
\hline$<2$ & 34.9 & 29.9 & - & - \\
\hline \multicolumn{5}{|l|}{ Energy expenditure, $\mathrm{kJ} / \mathrm{min}(\%)$} \\
\hline$<8$ & 58.2 & 57.9 & - & - \\
\hline $8-12$ & 27.5 & 25.6 & - & - \\
\hline$\geq 12$ & 14.3 & 15.5 & - & - \\
\hline
\end{tabular}




\begin{tabular}{|c|c|c|c|c|}
\hline & \multicolumn{2}{|c|}{ Men } & \multicolumn{2}{|c|}{ Women } \\
\hline & $\begin{array}{l}\text { All pancreatic } \\
\text { cancer cases }\end{array}$ & Subcohort & $\begin{array}{l}\text { All pancreatic } \\
\text { cancer cases }\end{array}$ & Subcohort \\
\hline \multicolumn{5}{|l|}{ Energy restriction } \\
\hline \multicolumn{5}{|c|}{ Hunger winter $1944-1945$ (\%) } \\
\hline Non-west & 60.4 & 59.8 & 50.3 & 56.6 \\
\hline Western rural area & 19.5 & 15.4 & 18.2 & 15.0 \\
\hline Western city & 20.1 & 24.8 & 31.5 & 28.4 \\
\hline \multicolumn{5}{|c|}{ War years 1940-1944 (\%) } \\
\hline Rural area in 1942 & 53.5 & 49.5 & 52.3 & 46.8 \\
\hline City in 1942 & 46.5 & 50.5 & 47.7 & 53.2 \\
\hline \multicolumn{5}{|c|}{ Economic Depression 1932-1940 (\%) } \\
\hline Father had a job & 89.2 & 89.3 & 88.8 & 88.5 \\
\hline Father had no job & 10.8 & 10.7 & 11.2 & 11.5 \\
\hline
\end{tabular}

Abbreviations: BMI, body mass index; IQR, interquartile range; SD, standard deviation.

*Never smokers excluded. 'Energy-adjusted intake. ${ }^{\ddagger}$ Participants who reported to have never engaged in sports activities excluded. ${ }^{5}$ Women excluded since most women of this generation had not held a job or had worked for only a short period of time, mostly in the distant past.

In Table 2.2, HRs are presented for physical activity. After adjustment for age and sex, we observed no association for total non-occupational physical activity at baseline. For respondents who reported ever to have participated in a sport, we observed a reduction in pancreatic cancer risk, which was of borderline significance. We observed a decreased pancreatic cancer risk for participants who reported to have participated in sports for 2-4 hours per week and for $\geq 4$ hours per week compared with participants who have never participated in sports (Table 2.2), although the highest category was not statistically significant and also no clear dose-response relation was observed ( $p$ for trend $=0.09$ ). For total duration of sports, we observed a statistically significantly reduced pancreatic cancer risk for participants who reported to have participated in sports $<15$ years, but no association was observed when participants participated in sports for 15 years or more (Table 2.2). No associations were observed between occupational physical activity in men and pancreatic cancer risk (Table 2.2).

Most results were similar after including the confounders in the model (Table 2.2). However, the decreased pancreatic cancer risk observed for respondents who reported ever to have participated in sports became statistically significant after including the confounders ( $\mathrm{HR}=0.78,95 \% \mathrm{Cl}$ : 0.62-0.98; Table 2.2). For participants who reported to have participated $\geq 4$ hours in sports, the risk estimate became significant showing a significantly dose-response relation $(\mathrm{HR}=0.74,95 \% \mathrm{Cl}: 0.56-0.98, \mathrm{p}$ for trend =0.04; Table 2.2). After excluding the first 2 years of follow-up, the results were not substantially different (data not shown). 
TABLE 2.2 Age-adjusted and multivariable-adjusted hazard rate ratios (HRs) and $95 \% \mathrm{Cls}$ for pancreatic cancer according to physical activity (both non-occupational and occupational); Netherlands Cohort Study on diet and cancer, 1986-1999

\begin{tabular}{|c|c|c|c|c|}
\hline \multirow[t]{2}{*}{ Exposure variable } & \multirow{2}{*}{$\begin{array}{l}\text { Person- } \\
\text { years }^{*}\end{array}$} & \multicolumn{3}{|c|}{ All pancreatic cancer cases } \\
\hline & & Cases $^{*}$ & $\mathrm{HR}(95 \% \mathrm{Cl})^{\dagger}$ & $\mathrm{HR}(95 \% \mathrm{Cl})^{7}$ \\
\hline \multicolumn{5}{|c|}{ Non-occupational physical activity } \\
\hline \multicolumn{5}{|c|}{ Total non-occupational physical activity at baseline ${ }^{\S}$ (min/day) } \\
\hline$<30^{\|}$ & 9,358 & 67 & 1.00 & 1.00 \\
\hline $30-<60$ & 15,489 & 118 & $1.06(0.78-1.45)$ & $1.08(0.79-1.49)$ \\
\hline $61-<90$ & 10,593 & 89 & $1.20(0.86-1.67)$ & $1.22(0.87-1.71)$ \\
\hline$\geq 90$ & 13,427 & 87 & $0.87(0.63-1.22)$ & $0.87(0.62-1.22)$ \\
\hline $\mathrm{p}$ for trend & & & 0.31 & 0.25 \\
\hline \multicolumn{5}{|c|}{ History of sports participation ${ }^{\S}$} \\
\hline Never" & 24,506 & 198 & 1.00 & 1.00 \\
\hline Ever & 24,869 & 164 & $0.81(0.65-1.00)$ & $0.78(0.62-0.98)$ \\
\hline \multicolumn{5}{|c|}{ No. of hours of sport per week (hours/week) } \\
\hline$<2$ & 3,592 & 30 & $1.11(0.73-1.67)$ & $1.17(0.77-1.78)$ \\
\hline $2-<4$ & 7,637 & 41 & $0.67(0.47-0.95)$ & $0.65(0.45-0.92)$ \\
\hline$\geq 4$ & 12,521 & 84 & $0.79(0.60-1.04)$ & $0.74(0.56-0.98)$ \\
\hline $\mathrm{p}$ for trend & & & 0.09 & 0.04 \\
\hline \multicolumn{5}{|c|}{ Duration of sports participation (years) } \\
\hline$<15$ & 14,214 & 80 & $0.70(0.53-0.92)$ & $0.68(0.51-0.90)$ \\
\hline $15-<30$ & 5,265 & 37 & $0.85(0.58-1.22)$ & $0.84(0.57-1.23)$ \\
\hline$\geq 30$ & 3,712 & 35 & $1.11(0.76-1.62)$ & $1.06(0.71-1.59)$ \\
\hline $\mathrm{p}$ for trend & & & 0.84 & 0.93 \\
\hline \multicolumn{5}{|c|}{ Occupational physical activity" } \\
\hline \multicolumn{5}{|c|}{ Longest held job } \\
\hline \multicolumn{5}{|c|}{ Sitting time per day (hours/day) } \\
\hline$>6 \|$ & 5,383 & 39 & 1.00 & 1.00 \\
\hline $2-6$ & 9,603 & 66 & $0.92(0.61-1.40)$ & $0.93(0.61-1.43)$ \\
\hline$<2$ & 5,678 & 57 & $1.36(0.88-2.09)$ & $1.43(0.87-2.34)$ \\
\hline$p$ for trend & & & 0.15 & 0.17 \\
\hline \multicolumn{5}{|c|}{ Energy expenditure ( $\mathrm{kJ} / \mathrm{min})$} \\
\hline$<8^{\|}$ & 12,439 & 96 & 1.00 & 1.00 \\
\hline $8-12$ & 5,270 & 44 & $1.07(0.73-1.55)$ & $1.01(0.65-1.56)$ \\
\hline$>12$ & 2,954 & 22 & $0.94(0.58-1.53)$ & $0.90(0.53-1.53)$ \\
\hline$p$ for trend & & & 0.94 & 0.76 \\
\hline \multicolumn{5}{|l|}{ Last job } \\
\hline \multicolumn{5}{|c|}{ Sitting time per day (hours/day) } \\
\hline$>6 \|$ & 5,698 & 46 & 1.00 & 1.00 \\
\hline $2-6$ & 10,132 & 70 & $0.85(0.57-1.25)$ & $0.85(0.57-1.27)$ \\
\hline$<2$ & 5,608 & 53 & $1.16(0.76-1.75)$ & $1.18(0.72-1.91)$ \\
\hline$p$ for trend & & & 0.49 & 0.57 \\
\hline
\end{tabular}


TABLE 2.2 continued

\begin{tabular}{lcccc}
\hline & $\begin{array}{c}\text { Person- } \\
\text { years }^{*}\end{array}$ & \multicolumn{3}{c}{ All pancreatic cancer cases } \\
\cline { 3 - 5 } & & Cases $^{*}$ & HR (95\% Cl) & HR (95\% Cl) \\
\hline $\begin{array}{l}\text { Energy expenditure }(\mathrm{kJ} / \mathrm{min}) \\
\quad 8^{\|}\end{array}$ & 13,343 & 103 & 1.00 & 1.00 \\
$8-12$ & 5,067 & 41 & $1.04(0.71-1.53)$ & $1.01(0.64-1.58)$ \\
$>12$ & 3,027 & 25 & $1.06(0.67-1.68)$ & $1.05(0.63-1.77)$ \\
p for trend & & & 0.77 & 0.86 \\
\hline
\end{tabular}

Number of cases and person-years do not add up to the total number because of missing values for covariables. ${ }^{\dagger}$ Adjusted for age (years). ${ }^{\ddagger}$ Adjusted for age (years), smoking (current smoking: yes/no; number of cigarettes smoked per day; number of years of smoking), body mass index $\left(\mathrm{kg} / \mathrm{m}^{2}\right)$, level of education (primary school or lower vocational school/intermediate, vocational school or high school/higher vocational school or college), energy intake (kcal/day), and intake of vegetables (g/day). ${ }^{\S}$ Additionally adjusted for sex. "Reference category. "Women excluded from analyses since most women of this generation had not held a job or had worked for only a short period of time, mostly in the distant past.

For energy restriction (Table $\mathbf{2 . 3}$ ), we observed a borderline statistically significantly increase in risk for individuals who resided in western rural area during the Hunger winter in 1944-1945 compared with individuals who resided in non-west area, whereas no association was observed for individuals who resided in a western city during the Hunger winter. For the energy restriction during WW II and during the Economic Depression, we observed no statistically significant associations, although living in a city in 1942 during WW II suggested a decreased risk. Adding confounders to the model did not materially change the results. However, the decreased pancreatic cancer risk observed for individuals living in a city in 1942, was of similar strength compared with the age- and sex-adjusted effect estimate, but became statistically significant after including the confounders ( $\mathrm{HR}=0.76,95 \% \mathrm{Cl}$ : 0.59-0.98; Table 2.3).

Results did not differ between men and women (results not shown). The exclusion of participants without histological confirmed pancreatic cancer did not change most findings (results not shown), although the statistically significantly decreased pancreatic cancer risk observed for respondents who reported ever to have engaged in sports became non-significant ( $\mathrm{HR}=0.77,95 \% \mathrm{Cl}$ : 0.58-1.02). For participants who reported to have participated $\geq 4$ hours in sports, the risk estimate attenuated and became nonsignificant ( $\mathrm{HR}=0.81,95 \% \mathrm{Cl}: 0.58-1.13)$, as did the dose-response relation ( $\mathrm{p}$ for trend $=0.22$ ). For energy restriction, the increased risk observed among individuals who resided in western rural area during the Hunger winter attenuated and became statistically non-significant $(\mathrm{HR}=1.19,95 \% \mathrm{Cl}: 0.81-1.75)$. The risk estimate observed for individuals who lived in a city in 1942 during the war became non-significant (HR = $0.77,95 \% \mathrm{Cl}$ : 0.56-1.05), when we excluded participants without histological confirmed pancreatic cancer, possibly due to smaller numbers. 
TABLE 2.3 Age-adjusted and multivariable-adjusted hazard rate ratios (HRs) and 95\% Cls for pancreatic cancer according to energy restriction; Netherlands Cohort Study on diet and cancer, 1986-1999

\begin{tabular}{|c|c|c|c|c|}
\hline \multirow[t]{2}{*}{ Exposure variable } & \multirow{2}{*}{$\begin{array}{l}\text { Person- } \\
\text { years }^{*}\end{array}$} & \multicolumn{3}{|c|}{ All pancreatic cancer cases } \\
\hline & & Cases ${ }^{*}$ & $\mathrm{HR}(95 \% \mathrm{Cl})^{\dagger}$ & $\mathrm{HR}(95 \% \mathrm{Cl})^{\ddagger}$ \\
\hline \multicolumn{5}{|c|}{ Hunger winter 1944-1945 } \\
\hline Non-west ${ }^{\S}$ & 24,944 & 175 & 1.00 & 1.00 \\
\hline Western rural area & 6,594 & 61 & $1.36(1.00-1.85)$ & $1.37(1.00-1.86)$ \\
\hline Western city & 11,781 & 75 & $0.91(0.69-1.21)$ & $0.89(0.67-1.18)$ \\
\hline \multicolumn{5}{|l|}{ War years 1940-1944 } \\
\hline Rural area in $1942^{\S}$ & 17,334 & 150 & 1.00 & 1.00 \\
\hline City in 1942 & 19,015 & 133 & $0.80(0.62-1.02)$ & $0.76(0.59-0.98)$ \\
\hline \multicolumn{5}{|c|}{ Economic Depression 1932-1940 } \\
\hline Father had a job ${ }^{\S}$ & 41,692 & 302 & 1.00 & 1.00 \\
\hline Father had no job & 5,175 & 37 & $0.97(0.68-1.38)$ & $0.91(0.63-1.31)$ \\
\hline
\end{tabular}

Number of cases and person-years do not add up to the total number because of missing values for covariables. ${ }^{\dagger}$ Adjusted for age years) and sex. ${ }^{\ddagger}$ Adjusted for age (years), sex, smoking (current smoking: yes/no; number of cigarettes smoked per day; number of years of smoking), body mass index $\left(\mathrm{kg} / \mathrm{m}^{2}\right)$, level of education (primary school or lower vocational school/intermediate, vocational school or high school/higher vocational school or college), total baseline leisure-time physical activity (min/day), history of sports participation (never/ever), energy intake (kcal/day), and intake of vegetables (g/day). ${ }^{\delta}$ Reference category.

$\mathrm{BMI}$ at baseline, and change in BMI between age 20 years and baseline did not modify the association between pancreatic cancer risk and baseline non-occupational physical activity (results not shown). For history of sports participation, we observed a HR of 0.59 (95\% Cl: $0.42-0.82)$ for lean individuals at baseline $\left(<25 \mathrm{~kg} / \mathrm{m}^{2}\right)$ who reported ever to have participated in sports compared with overweight individuals who reported never to have participated in sports (Table 2.4). No association was observed among the overweight individuals at baseline $\left(\geq 25 \mathrm{~kg} / \mathrm{m}^{2}\right)$ reporting ever to have participated in sports. The interaction term on a multiplicative scale was, however, not statistically significant ( $p$ for interaction $=0.39$ ). For change in BMI between age 20 years and baseline, we observed a decreased pancreatic cancer risk for individuals who reported to have ever participated in sports and changed less than $6 \mathrm{~kg} / \mathrm{m}^{2}$ in BMI. The interaction term was not statistically significant ( $\mathrm{p}$ for interaction $=0.71$ ). BMI at age 20 years did not modify the association between pancreatic cancer risk and history of sports participation. Our findings remained the same when excluding respondents who reported a history of diabetes at baseline from the analyses (data not shown). 
TABLE 2.4 Multivariable-adjusted hazard rate ratios (HRs) and 95\% Cls for pancreatic cancer according to history of sports participation, stratified by body mass index (BMI) and change in BMI; Netherlands Cohort Study on diet and cancer, 1986-1999

\begin{tabular}{|c|c|c|c|c|c|}
\hline \multirow{3}{*}{$\begin{array}{l}\text { Interaction } \\
\text { variable }\end{array}$} & \multicolumn{5}{|c|}{ History of sports participation } \\
\hline & \multicolumn{2}{|r|}{ Never } & \multicolumn{2}{|c|}{ Ever } & \multirow{2}{*}{$\begin{array}{c}\mathbf{p} \text { for } \\
\text { interaction }\end{array}$} \\
\hline & Cases $^{*}$ & $\mathrm{HR}(95 \% \mathrm{Cl})^{+}$ & Cases $^{*}$ & $\mathrm{HR}(95 \% \mathrm{Cl})^{\dagger}$ & \\
\hline \multicolumn{6}{|c|}{ BMI at baseline $\left(\mathrm{kg} / \mathrm{m}^{2}\right)$} \\
\hline$\geq 25$ & 100 & $1.00^{\ddagger}$ & 87 & $0.85(0.62-1.16)$ & 0.39 \\
\hline$<25$ & 98 & $0.84(0.62-1.13)$ & 77 & $0.59(0.42-0.82)$ & \\
\hline \multicolumn{6}{|c|}{ BMI at age 20 y $\left(\mathrm{kg} / \mathrm{m}^{2}\right)$} \\
\hline$\geq 21$ & 90 & $1.00^{\ddagger}$ & 84 & $0.84(0.60-1.16)$ & 0.30 \\
\hline$<21$ & 79 & $1.20(0.87-1.65)$ & 57 & $0.78(0.54-1.13)$ & \\
\hline \multicolumn{6}{|c|}{ Change in BMI since age 20 years ${ }^{\S}\left(\mathrm{kg} / \mathrm{m}^{2}\right)$} \\
\hline$\geq 6$ & 42 & $1.00^{\ddagger}$ & 33 & $0.85(0.52-1.40)$ & 0.71 \\
\hline $2-<6$ & 72 & $0.82(0.54-1.23)$ & 64 & $0.64(0.42-0.98)$ & \\
\hline$<2$ & 22 & $0.86(0.54-1.36)$ & 44 & $0.57(0.35-0.92)$ & \\
\hline \multicolumn{6}{|c|}{$\begin{array}{l}\text { Number of cases does not add up to the total number because of missing values for covariables. }{ }^{\dagger} \text { The model } \\
\text { included age (years), sex, smoking (current smoking status: yes/no; number of cigarettes smoked per day; } \\
\text { number of years of smoking), intake of vegetables (g/day), energy intake (kcal/day), and level of education } \\
\text { (primary school or lower vocational school/intermediate, vocational school or high school/higher vocational } \\
\text { school or college). }{ }^{\ddagger} \text { Reference category. }{ }^{\S} \text { Model additionally included body mass index at age } 20 \text { years } \\
\left(\mathrm{kg} / \mathrm{m}^{2}\right) \text {. }\end{array}$} \\
\hline
\end{tabular}

\section{DISCUSSION}

Our results showed that participating in sports in the past modestly decreased pancreatic cancer risk compared with never participating, whereas no association was observed for non-occupational physical activity at baseline and occupational physical activity. Results in the literature regarding physical activity and pancreatic cancer risk have been inconsistent so far. Decreased risks have been observed for total physical activity (occupational and non-occupational combined) ${ }^{19,20}$ and non-occuaptional physical activity ${ }^{17,18}$ in two cohort studies and two case-control studies, whereas no association was observed for total physical activity ${ }^{22}$ and non-occuaptional physical activi$\mathrm{ty}^{21,23,24}$ in other cohort studies. A meta-analysis observed for occupational physical activity a $25 \%$ statistically significantly decreased pancreatic cancer risk and no association with leisure-time physical activity. ${ }^{45}$ However, the estimate regarding occupational physical activity was based only on three cohort studies. Because most subjects in the NLCS started to participate in sports before the age of 20 years (interquartile range: 11-21 years), our findings seem to suggest that participating in sports during childhood or adolescence reduces pancreatic cancer risk, whereas being physically active (both at work and outside of work) when middle-aged is not associated with pancreatic cancer risk. So far, previous epidemiological studies have investigated the effect of physical activity on pancreatic cancer risk during adult life only and not during childhood or adolescence. Therefore, our results must be regarded with some caution and further studies are needed to replicate our findings. 
We were unable to reproduce the finding of Michaud et al., who observed an inverse association between total non-occupational physical activity and pancreatic cancer risk among overweight individuals. ${ }^{18}$ It might be, however, that BMI at age 20 years was not the best measure to investigate this for sports history because most subjects started to participate in sports before the age of 20 years as already indicated above. Furthermore, only $7.6 \%$ of our population was overweight $\left(\geq 25 \mathrm{~kg} / \mathrm{m}^{2}\right)$ at the age of 20. It could also be that being physically active in the past resulted in less weight gain and hence a less high BMI at older age compared with individuals that were not physically active in the past, which might explain why we observed a statistically significantly decreased pancreatic cancer risk only in lean individuals who reported to have ever participated in sports.

To our knowledge, we are the first epidemiological study that investigated the relation between energy restriction during adolescence and pancreatic cancer risk. We observed a modestly decreased pancreatic cancer risk for individuals who resided in a city during the war years compared with those who did not, which was meant to indicate a period of more moderate energy restriction. Regarding the exposure to a short period of severe energy restriction during the Hunger winter, individuals living in western rural area had an increased pancreatic cancer risk compared with individuals living in non-western area, whereas living in a western city was not associated. No association was observed for exposure to energy restriction during the Economic Depression. Previous work on the NLCS cohort has found an inverse association between severe energy restriction during adolescence and colorectal cancer risk in men, ${ }^{46}$ but no association has been observed for colorectal cancer in women and for breast cancer. ${ }^{35,46}$ Ecological studies have indirectly associated breast and colorectal cancer risk with the 1940-1945 wartime conditions in Norway, when caloric intake was substantially reduced. ${ }^{47,48}$ A drop in colorectal cancer incidence was observed among cohorts born during or shortly after the war years and a drop in breast cancer incidence was observed among women who experienced puberty during the war. ${ }^{47,48}$ These findings have led to the conclusion that dietary factors early in life, including energy restriction, may have an impact on later breast or colorectal cancer risk.

A factor that could have influenced the results of our study is misclassification of exposure to energy restriction, because of the use of place of residence and father's employment status as proxies for exposure to energy restriction. In a follow-up study in the NLCS, female subcohort members were asked whether they really had experienced hunger during the winter of 1944-1945. These results showed that $75 \%$ of the women living in a western city reported that they experienced hunger during the winter of 1944-1945, of whom 35\% experienced severe hunger. Of the women who reported severe hunger during the Hunger winter, $80 \%$ lived in a Western city during this winter. ${ }^{35}$ The hypothesis that energy restriction might protect against pancreatic cancer risk is based entirely on experimental studies because no epidemiological studies have been conducted so far. However, the animals in these studies were fed from early age onwards an energy restricted diet only, after which they were sacrificed. ${ }^{15,16}$ 
In our population, on the other hand, exposure to energy restriction took place mostly during adolescence and the period of exposure was relatively short, whereas after the war food was abundant again. A study in postmenopausal women observed that adolescence exposure to the Dutch Hunger winter in 1944-1945 was associated with increased plasma levels of IGF-1 and IGF binding protein- $3 ;^{49}$ factors which are associated with an increased cancer risk. ${ }^{9}$ It was hypothesized that this could indicate a permanent overshoot in IGF-1 after the Hunger winter upon improvement of nutritional status after the war. ${ }^{49}$ This could possibly explain our finding for living in western rural area during the Hunger winter. It does, however, not explain why we did not observe a similar increase in risk for living in a western city during the Hunger winter. When we restricted the analyses to microscopically verified cases, the increased pancreatic cancer risk observed for residing in rural area during the Hunger winter attenuated and became non-significant. Furthermore, the period of the Hunger winter was relatively short (7 months of severe deprivation at less than $40 \%$ of normal energy intake) ${ }^{38}$ and was maybe too short to find a decreased effect on pancreatic cancer risk. We did observe a decreased risk for living in a city during the war years compared with those who did not, which was meant to indicate a period of more moderate energy restriction. However, a study by Trienekens suggested that only the composition of the daily food intake had changed during the war years and not the caloric intake. ${ }^{50}$

The IGF axis is responsive to both nutritional status and physical activity levels and may be involved as one of the underlying mechanisms through which energy restriction and physical activity could affect cancer risk. ${ }^{9}$ Human intervention studies showed that a short bout of exercise increases IGF-1 levels, whereas regular exercise ("training"), leading to a negative energy balance, lowers IGF-1 levels. ${ }^{9}$ A few nested casecontrol studies have investigated whether IGF-1 and IGFBP-3 levels were associated with pancreatic cancer risk in humans. These studies showed inconsistent results, observing no ${ }^{51,52}$ and positive ${ }^{53}$ associations with pancreatic cancer risk. Moreover, two of these studies were rather small, with case numbers $<150 .^{51,53}$ Further studies are needed to elucidate the role of the IGF axis on pancreatic carcinogenesis.

The possibility to further restrict the analyses to microscopically verified cases only, where misclassification by disease status would be less likely than among NMCPC cases, ${ }^{42}$ is one of the strengths of this study. Other strengths include the large sample size, and detailed information on potential risk factors of pancreatic cancer. Differential follow-up is unlikely to have made a material contribution to our findings, as completeness of follow-up was high. ${ }^{29}$ The prospective design avoided recall bias and the need to use next-of-kin respondents.

Overall, our results suggest a modestly decreased pancreatic cancer risk for sports activity in the past. Occupational physical activity and non-occupational physical activity at baseline were not associated with pancreatic cancer risk. The findings with respect to proxies for energy restriction did not support our hypothesis. For exposure to energy restriction during the Hunger winter, an increased pancreatic cancer risk was observed for individuals living in western rural area, whereas living in a western city 
was not associated. For exposure to energy restriction during the war years, a modestly decreased pancreatic cancer risk was observed. 


\section{REFERENCES}

1. Ferlay J, Autier P, Boniol M, Heanue M, Colombet M, Boyle P. Estimates of the cancer incidence and mortality in Europe in 2006. Ann Oncol 2007;18:581-92.

2. Jemal A, Siegel R, Ward E, et al. Cancer statistics, 2008. CA Cancer J Clin 2008;58:71-96.

3. Karim-Kos HE, de Vries E, Soerjomataram I, Lemmens V, Siesling S, Coebergh JW. Recent trends of cancer in Europe: a combined approach of incidence, survival and mortality for 17 cancer sites since the 1990s. Eur J Cancer 2008;44:1345-89.

4. Iodice S, Gandini S, Maisonneuve P, Lowenfels AB. Tobacco and the risk of pancreatic cancer: a review and meta-analysis. Langenbecks Arch Surg 2008;393:535-45.

5. World Cancer Research Fund/American Institute for Cancer research. Food, nutrition, physical activity, and the prevention of cancer: a global perspective. Washington DC: AICR, 2007.

6. Larsson SC, Orsini N, Wolk A. Body mass index and pancreatic cancer risk: A meta-analysis of prospective studies. Int J Cancer 2007;120:1993-8.

7. Huxley R, Ansary-Moghaddam A, Berrington de Gonzalez A, Barzi F, Woodward M. Type-II diabetes and pancreatic cancer: a meta-analysis of 36 studies. Br J Cancer 2005;92:2076-83.

8. Stolzenberg-Solomon RZ, Graubard BI, Chari S, et al. Insulin, glucose, insulin resistance, and pancreatic cancer in male smokers. Jama 2005;294:2872-8.

9. Kaaks R, Lukanova A. Energy balance and cancer: the role of insulin and insulin-like growth factor-I. Proc Nutr Soc 2001;60:91-106.

10. Ding XZ, Fehsenfeld DM, Murphy LO, Permert J, Adrian TE. Physiological concentrations of insulin augment pancreatic cancer cell proliferation and glucose utilization by activating MAP kinase, PI3 kinase and enhancing GLUT-1 expression. Pancreas 2000;21:310-20.

11. Fisher WE, Boros LG, Schirmer WJ. Insulin promotes pancreatic cancer: evidence for endocrine influence on exocrine pancreatic tumors. J Surg Res 1996;63:310-3.

12. Bergmann U, Funatomi H, Yokoyama M, Beger HG, Korc M. Insulin-like growth factor I overexpression in human pancreatic cancer: evidence for autocrine and paracrine roles. Cancer Res 1995;55:2007-11.

13. Dossus L, Kaaks R. Nutrition, metabolic factors and cancer risk. Best Pract Res Clin Endocrinol Metab 2008;22:551-71.

14. McTiernan A. Mechanisms linking physical activity with cancer. Nat Rev Cancer 2008;8:205-11.

15. Roebuck BD, Baumgartner KJ, MacMillan DL. Caloric restriction and intervention in pancreatic carcinogenesis in the rat. Cancer Res 1993;53:46-52.

16. Roebuck BD, Yager JD, Jr., Longnecker DS. Dietary modulation of azaserine-induced pancreatic carcinogenesis in the rat. Cancer Res 1981;41:888-93.

17. Hanley AJ, Johnson KC, Villeneuve PJ, Mao Y. Physical activity, anthropometric factors and risk of pancreatic cancer: results from the Canadian enhanced cancer surveillance system. Int J Cancer 2001; 94:140-7.

18. Michaud DS, Giovannucci E, Willett WC, Colditz GA, Stampfer MJ, Fuchs CS. Physical activity, obesity, height, and the risk of pancreatic cancer. Jama 2001;286:921-9.

19. Stolzenberg-Solomon RZ, Pietinen P, Taylor PR, Virtamo J, Albanes D. A prospective study of medical conditions, anthropometry, physical activity, and pancreatic cancer in male smokers (Finland). Cancer Causes Control 2002;13:417-26.

20. Zhang J, Dhakal IB, Gross MD, et al. Physical activity, diet, and pancreatic cancer: a population-based, case-control study in Minnesota. Nutr Cancer 2009;61:457-65.

21. Berrington de Gonzalez A, Spencer EA, Bueno-de-Mesquita HB, et al. Anthropometry, physical activity, and the risk of pancreatic cancer in the European prospective investigation into cancer and nutrition. Cancer Epidemiol Biomarkers Prev 2006;15:879-85.

22. Nothlings U, Wilkens LR, Murphy SP, Hankin JH, Henderson BE, Kolonel LN. Body mass index and physical activity as risk factors for pancreatic cancer: the Multiethnic Cohort Study. Cancer Causes Control 2007;18:165-75.

23. Sinner PJ, Schmitz KH, Anderson KE, Folsom AR. Lack of association of physical activity and obesity with incident pancreatic cancer in elderly women. Cancer Epidemiol Biomarkers Prev 2005;14:1571-3. 
24. Stolzenberg-Solomon RZ, Adams K, Leitzmann M, et al. Adiposity, physical activity, and pancreatic cancer in the National Institutes of Health-AARP Diet and Health Cohort. Am J Epidemiol 2008;167: 586-97.

25. van den Brandt PA, Goldbohm RA, van 't Veer P, Volovics A, Hermus RJ, Sturmans F. A large-scale prospective cohort study on diet and cancer in The Netherlands. J Clin Epidemiol 1990;43:285-95.

26. Prentice RL. A case-cohort design for epidemiologic cohort studies and disease prevention trials. Biometrika 1986;73:1-11.

27. van den Brandt PA, Schouten LJ, Goldbohm RA, Dorant E, Hunen PM. Development of a record linkage protocol for use in the Dutch Cancer Registry for Epidemiological Research. Int J Epidemiol 1990;19: 553-8.

28. Casparie M, Tiebosch AT, Burger G, et al. Pathology databanking and biobanking in The Netherlands, a central role for PALGA, the nationwide histopathology and cytopathology data network and archive. Cell Oncol 2007;29:19-24.

29. Goldbohm RA, van den Brandt PA, Dorant E. Estimation of the coverage of Dutch municipalities by cancer registries and PALGA based on hospital discharge data. Tijdschr Soc Gezondheidsz 1994;72: 80-4.

30. van der Sanden GA, Coebergh JW, Schouten LJ, Visser O, van Leeuwen FE. Cancer incidence in The Netherlands in 1989 and 1990: first results of the nationwide Netherlands cancer registry. Coordinating Committee for Regional Cancer Registries. Eur J Cancer 1995;31A:1822-9.

31. Goldbohm RA, van den Brandt PA, Brants HA, et al. Validation of a dietary questionnaire used in a large-scale prospective cohort study on diet and cancer. Eur J Clin Nutr 1994;48:253-65.

32. Dirx MJ, Voorrips LE, Goldbohm RA, van den Brandt PA. Baseline recreational physical activity, history of sports participation, and postmenopausal breast carcinoma risk in the Netherlands Cohort Study. Cancer 2001;92:1638-49.

33. Zeegers MP, Dirx MJ, van den Brandt PA. Physical activity and the risk of prostate cancer in the Netherlands cohort study, results after 9.3 years of follow-up. Cancer Epidemiol Biomarkers Prev 2005;14: 1490-5.

34. Hettinger TH, Mueller BH, Gebhard H. Ermittlung des Arbeitsenenergieumsatzes bei Dynamisch Muskulaerer Arbeit (Ascertainment of energy expenditure in physically heavy work [in German]). Dortmund: Schriftenreihe der Bundesarbeit fur Arbeitsschutz, 1989.

35. Dirx MJ, van den Brandt PA, Goldbohm RA, Lumey LH. Diet in adolescence and the risk of breast cancer: results of the Netherlands Cohort Study. Cancer Causes Control 1999;10:189-99.

36. den Hartog AP. Werklozen en hun voeding in de jaren 1930-1939 (Unemployed people and their nutrition during the years 1930-1939 [in Dutch]). Voeding 1983;44:92-8.

37. Breunis J. The food supply. Ann Am Acad Pol Soc Sci 1946;245:87-92.

38. Burger GCE, Sandstead HR, Drummond JC. Malnutrition and starvation in Western Netherlands, September 1944 to July 1945. Part I and II. The Hague: General State Printing Office, 1948.

39. Volovics A, van den Brandt PA. Methods for the analysis of case-cohort studies. Biom J 1997;39: 195-214.

40. Barlow WE, Ichikawa L, Rosner D, Izumi S. Analysis of case-cohort designs. J Clin Epidemiol 1999;52: 1165-72.

41. Schoenfeld D. Partial residuals for the proportional hazards regression model. Biometrika 1982;69: 239-41.

42. Silverman DT, Schiffman M, Devesa S. Diagnostic certainty in pancreatic cancer. J Clin Epidemiol 1996; 49:601-3.

43. Verhage BA, Schouten L, Goldbohm RA, van den Brandt PA. Anthropometry and pancreatic cancer risk: an illustration of the importance of microscopic verification. Cancer Epidemiol Biomarkers Prev 2007;16:1449-54.

44. Willett W. Nutritional epidemiology, $2^{\text {nd }}$ ed., vol. 30. New York: Oxford University Press, 1998.

45. Bao Y, Michaud DS. Physical activity and pancreatic cancer risk: a systematic review. Cancer Epidemiol Biomarkers Prev 2008;17:2671-82. 
46. Hughes LA, van den Brandt PA, Goldbohm RA, et al. Childhood and adolescent energy restriction and subsequent colorectal cancer risk: results from the Netherlands Cohort Study. Int J Epidemiol 2010;39: 1333-44.

47. Tretli S, Gaard M. Lifestyle changes during adolescence and risk of breast cancer: an ecologic study of the effect of World War II in Norway. Cancer Causes Control 1996;7:507-12.

48. Svensson E, Grotmol T, Hoff G, Langmark F, Norstein J, Tretli S. Trends in colorectal cancer incidence in Norway by gender and anatomic site: an age-period-cohort analysis. Eur J Cancer Prev 2002;11:489-95.

49. Elias SG, Keinan-Boker L, Peeters PH, et al. Long term consequences of the 1944-1945 Dutch famine on the insulin-like growth factor axis. Int J Cancer 2004;108:628-30.

50. Trienekens G. The food supply in The Netherlands during the Second World War. In: Smith DF, Phillips J. Food, science, policy and regulation in the twentieth century. International and comparative perspectives. London: Routledge, 2000. P. 117-33.

51. Stolzenberg-Solomon RZ, Limburg P, Pollak M, Taylor PR, Virtamo J, Albanes D. Insulin-like growth factor (IGF)-1, IGF-binding protein-3, and pancreatic cancer in male smokers. Cancer Epidemiol Biomarkers Prev 2004;13:438-44.

52. Wolpin BM, Michaud DS, Giovannucci EL, et al. Circulating insulin-like growth factor axis and the risk of pancreatic cancer in four prospective cohorts. Br J Cancer 2007;97:98-104.

53. Lin Y, Tamakoshi A, Kikuchi S, et al. Serum insulin-like growth factor-I, insulin-like growth factor binding protein-3, and the risk of pancreatic cancer death. Int J Cancer 2004;110:584-8. 



\title{
Alcohol consumption and risk of pancreatic cancer in the Netherlands Cohort Study
}

\author{
Mirjam M. Heinen \\ Bas A.J. Verhage \\ Ton A.W. Ambergen \\ R. Alexandra Goldbohm \\ Piet A. van den Brandt
}

Am J Epidemiol 2009;169(10):1233-42 


\section{ABSTRACT}

To examine prospectively the relation between alcohol consumption and pancreatic cancer risk, the authors analyzed data from the Netherlands Cohort Study. Participants were 120,852 persons who completed a baseline questionnaire in 1986. After 13.3 years of follow-up, 350 cases of pancreatic cancer (67\% microscopically confirmed) were available for analysis. Compared with abstention, the highest category of alcohol consumption ( $\geq 30 \mathrm{~g} /$ day of ethanol) was positively associated with pancreatic cancer risk (for all cases: rate ratio $=1.57,95 \%$ confidence interval: $1.03-2.39, \mathrm{p}$ for trend $=$ 0.12 ; for microscopically confirmed cases: rate ratio $=1.54,95 \%$ confidence interval: 0.94-2.54, $\mathrm{p}$ for trend $=0.22$ ). In a subgroup of stable alcohol users (no change during the 5 years before baseline), a similarly increased risk of pancreatic cancer was found. This increased risk was limited to the first 7 years of follow-up. No associations were observed between consumption of specific alcoholic beverages and risk of pancreatic cancer. The associations were not modified by folate intake or smoking. Overall, these findings suggest an increased pancreatic cancer risk for persons with a high ethanol intake ( $\geq 30 \mathrm{~g} /$ day). However, this increased risk was observed only during the first 7 years of follow-up. 


\section{INTRODUCTION}

Pancreatic cancer is among the most fatal cancers worldwide, with a 5-year survival rate of $6 \%$ or less. ${ }^{1,2}$ Since there is no effective way to screen for this malignancy, prevention could have a major impact on pancreatic cancer mortality. So far, cigarette smoking, diabetes mellitus, and body fatness have been identified as risk factors. ${ }^{3-5}$

There is evidence that chronic alcohol consumption may alter pancreatic function, ${ }^{6}$ which may predispose people to pancreatic cancer. Several mechanisms have been suggested. First, heavy alcohol consumption is a known risk factor for chronic pancreatitis, ${ }^{3,7}$ which has been linked to pancreatic cancer. ${ }^{8,9}$ In addition, evidence suggests that the metabolites generated during metabolism of alcohol (e.g., acetaldehyde) may be carcinogenic. ${ }^{3,10,11}$ Furthermore, the effects of alcohol may be mediated through the generation of free-radical oxygen species which can lead to DNA damage. $^{11}$

Eight cohort studies have found no association between alcohol consumption and pancreatic cancer risk. ${ }^{12-18}$ Seven cohort studies have found an increased risk, ${ }^{19-25}$ but results were statistically significant in only $2 .{ }^{22,25}$ Inconsistent findings have also been obtained in the numerous case-control studies that have been conducted. ${ }^{3}$ Recently, the second World Cancer Research Fund/American Institute for Cancer Research expert report concluded that low-to-moderate levels of alcohol consumption were unlikely to have an effect on pancreatic cancer risk, but the possibility could not be excluded that heavy drinking might have an effect. ${ }^{3}$

Our aim in this study was to investigate the association between alcohol consumption and the risk of pancreatic cancer in a large prospective cohort study in the Netherlands. Furthermore, we investigated whether the association between pancreatic cancer risk and alcohol consumption was modified by smoking status or folate intake.

\section{MATERIALS AND METHODS}

\section{Study population and cancer follow-up}

The design of the Netherlands Cohort Study has been reported in detail elsewhere. ${ }^{26}$ Briefly, the study was begun in September 1986 and included initially 58,279 men and 62,573 women aged 55-69 years from 204 Dutch municipalities with computerized population registries. A self-administered questionnaire on potential risk factors for cancer was completed at baseline. For increased efficiency in the processing of the questionnaire (which was very detailed and of which only the first page could be optically scanned) and follow-up, the case-cohort approach was used. ${ }^{27}$ Case subjects were derived from the entire cohort, whereas person-years at risk were estimated from a random sample of 5,000 subjects. This subcohort was chosen immediately after baseline and was followed up for vital status information. The entire cohort is being moni- 
tored for cancer occurrence through annual record linkage with the Netherlands Cancer Registry and the Netherlands Pathology Registry. ${ }^{28}$ For the current analyses, followup was restricted to the period from baseline to December 1999, a total of 13.3 years. Only two subcohort members were lost to follow-up, and completeness of follow-up was estimated to be greater than $96 \%{ }^{29}$

For cases and subcohort members, all persons with prevalent cancer (other than non-melanoma skin cancer) at baseline were excluded $(n=226)$. Of the 447 incident cases of pancreatic cancer, persons with endocrine subtypes (Islet-cell carcinoma; $n=$ 1 ) were excluded. Additionally, subjects with incomplete or inconsistent dietary data (336 subcohort members, 38 cases) and subjects with incomplete alcohol data (130 subcohort members, 13 cases) were excluded from analyses. Details are given elsewhere. ${ }^{30}$ Alcohol data were considered incomplete when all questions on the consumption frequency of alcoholic beverages were left blank and two questions on alcohol consumption pattern did not indicate that the subject was an abstainer. These two questions concerned alcohol intake during the past week and 5 years previously.

The Netherlands Cohort Study protocol has been approved by the institutional review boards of the TNO Nutrition and Food Research Institute (Zeist, the Netherlands) and Maastricht University (Maastricht, the Netherlands).

\section{Questionnaire}

The dietary section of the baseline questionnaire was a 150-item semiquantitative food frequency questionnaire, which concentrated on habitual consumption during the year preceding the start of the study. Alcohol consumption was measured by assessing six items: beer; red wine; white wine; sherry and other fortified wines; liqueurs containing, on average, $16 \%$ ethanol; and (Dutch) gin, brandy, and whiskey. Total mean daily ethanol intake was calculated using the Dutch food composition table. ${ }^{31}$ Data on the folate content of foods were derived from a validated liquid chromatography trienzyme method ${ }^{32}$ used to analyze the 125 most important Dutch foods contributing to folate intake. ${ }^{33}$

We defined low alcohol consumption as drinking $>0-\leq 10 \mathrm{~g} /$ day of ethanol; moderate consumption as drinking $>10-<30 \mathrm{~g} /$ day; and high consumption as drinking $\geq 30$ $\mathrm{g} /$ day. The definition of a standard glass of an alcoholic beverage used in the Netherlands is a beverage that contains approximately $10 \mathrm{~g}$ of ethanol. ${ }^{34}$

One question on the questionnaire requested information on the subject's drinking habits 5 years before baseline. For beer and for "other alcoholic beverages", the subject could indicate whether, 5 years before baseline, he or she had consumed $(a)$ more than at baseline, $(b)$ equal amounts as at baseline, or $(c)$ less than at baseline, or (d) never used those beverages.

The food frequency questionnaire had been validated and tested for reproducibil-

ity. ${ }^{30,35}$ For mean daily alcoholic beverage intake, the Spearman correlation coefficients for correlations between the 9-day diet record and the questionnaire were 0.89 for all subjects and 0.85 for users of alcoholic beverages. ${ }^{30}$ The absolute amount of ethanol 
reported in the questionnaire by users of alcoholic beverages was, on average, $86 \%$ of that reported in the 9-day diet record. ${ }^{30}$

\section{Statistical analysis}

Age-adjusted and multivariable-adjusted incidence rate ratios and corresponding $95 \%$ confidence intervals were estimated using Cox proportional hazards models. The total person-years at risk estimated from the subcohort were used in the analyses. ${ }^{36}$ We estimated standard errors using the robust Huber-White sandwich estimator to account for the additional variance introduced by sampling from the cohort. ${ }^{37}$ We tested the proportional hazards assumption using the scaled Schoenfeld residuals. ${ }^{38}$ In case the proportional hazards assumption was violated with respect to alcohol consumption, we performed a test for interaction between alcohol consumption and time, and we stratified the follow-up period into two periods ( $<7$ years and $\geq 7$ years, according to the midpoint) to investigate further how risk estimates changed during followup. Analyses were conducted for both sexes combined and separately for men and women.

Rate ratios were estimated for categories of ethanol intake, with the abstainers regarded as the reference group. Respondents who consumed alcohol beverages less than once per month were considered abstainers. In addition to considering the total amount of ethanol intake, we examined three types of alcoholic beverages - beer, wine (red wine, white wine, sherry, and other fortified wines), and liquor (liqueurs, gin, brandy, and whiskey) - relative to non-drinkers of beer, wine, and liquor, respectively. Total ethanol intake was divided into five categories: abstention ( $0 \mathrm{~g} / \mathrm{day})$ and consumption of $0.1-<5,5-<15,15-<30$, and $\geq 30 \mathrm{~g} /$ day. For beer, wine, and liquor, categ ories included nonuser and $0.1-<1,1-<5$, and $\geq 5$ glasses/week. Rate ratios were also estimated for continuous exposures, which we report in representative serving sizes; that is, for total ethanol intake, an increment of $10 \mathrm{~g} /$ day was used, and for the specific alcoholic beverages, an increment of 1 glass/day was used. On the basis of pilot study data, standard glass sizes were defined as $200 \mathrm{ml}$ for beer, $105 \mathrm{ml}$ for wine, and $45 \mathrm{ml}$ for liquor, corresponding to $8 \mathrm{~g}, 10 \mathrm{~g}$, and $13 \mathrm{~g}$ of ethanol, respectively. ${ }^{39}$

Besides age and sex, we included smoking in the multivariable-adjusted model, since this is a strong risk factor for pancreatic cancer. ${ }^{8}$ Other variables examined as potential confounders included body mass index (weight $[\mathrm{kg}] /$ height $[\mathrm{m}]^{2}$ ), energy intake, intakes of vegetables and fruit, level of education, non-occupational moderate physical activity, multivitamin use, family history of pancreatic cancer, history of diabetes mellitus, hypertension, cholecystectomy, gallstones, and gastric ulcer. These confounding variables were added to the multivariable-adjusted model if they $(a)$ were associated with the disease and with ethanol intake and $(b)$ changed the risk estimate by at least $10 \%$. This resulted in a multivariable-adjusted model that included age at baseline (years), sex, cigarette smoking (smoking status [current smoking: yes/no]; number of cigarettes smoked per day by current and ex-smokers; number of years of smoking for current and ex-smokers), body mass index, total energy intake (kcal/day), 
and vegetable and fruit intakes (g/day). We additionally adjusted analyses for beer, wine, and liquor for total ethanol intake (g/day) to evaluate the effect of each beverage on pancreatic cancer risk independently of the beverage's alcohol content.

To permit comparison, we restricted age-adjusted analyses to subjects included in multivariable-adjusted analyses, which left 3,980 subcohort members (1,954 men and 2,026 women) and 350 exocrine pancreatic cancer cases (185 men and 165 women) for analyses. Sixty-seven percent of these pancreatic cancer cases were microscopically confirmed pancreatic cancer (MCPC; $n=234$ ), whereas confirmation was lacking for $33 \%(n=116)$. Diagnosis of the latter group was made by the treating clinician and was based on clinical symptoms, physical examination, and imaging results, and data were abstracted and recorded by a trained tumor registrar. ${ }^{40}$

For each analysis, we evaluated trends with the Wald test by assigning participants the median value for each level of the categorical exposure variable among the subcohort members, and this variable was entered as a continuous term in the Cox regression model. To evaluate whether the association between alcohol consumption and pancreatic cancer risk was linear, we examined nonparametric regression curves using restricted cubic splines, using different numbers and positions of knots. ${ }^{41,42}$ Testing the need for nonlinear terms in the models was done using the Wald $\chi^{2}$ statistic. In the present study, the overall analyses were conducted on all pancreatic cancer cases. We restricted additional analyses to MCPC cases in order to create a group with a higher degree of diagnostic certainty of pancreatic cancer, which was shown to be important in a previous study. ${ }^{43}$

Since early symptoms of disease may cause subjects to stop drinking alcohol or to continue their drinking at a lower level, baseline measurement of alcohol intake alone will categorize these drinkers as abstainers or low-level drinkers. This will result in underestimated disease risk. In additional analyses, we evaluated the relation between alcohol consumption and pancreatic cancer risk by restricting the analyses to alcohol drinkers who reported having consumed the same amount of alcohol 5 years before baseline as they did at baseline, using as a reference category the abstainers at baseline who reported having also abstained from alcohol use 5 years before baseline. Hereafter, we refer to this subgroup as stable alcohol users. In addition, we restricted the analyses to alcohol drinkers who reported having consumed more alcohol or less alcohol 5 years before baseline as compared with baseline, using the same reference category as for the analysis in stable alcohol users. Heavy consumers of alcohol may have a reduced folate status, making the pancreas susceptible to carcinogenesis. ${ }^{3,6}$ In addition, it has been suggested that alcohol and tobacco enhance each other's effects. ${ }^{44}$ Therefore, interactions between ethanol intake and cigarette smoking (never smoking, ex-smoking, current smoking) were investigated, as well as interactions between alcohol consumption and dietary folate intake (low and high intakes based on sex-specific median folate intake [212 $\mu \mathrm{g} /$ day for men and $187 \mu \mathrm{g} /$ day for women]). 
All analyses were performed using the STATA statistical software package. ${ }^{45}$ All $p$ values were based on 2-sided tests and were considered statistically significant if they were less than 0.05 .

\section{RESULTS}

At baseline, 79\% of the pancreatic cancer cases consumed alcohol. As Table $\mathbf{3 . 1}$ shows, most baseline characteristics did not differ noticeably between pancreatic cancer cases and subcohort members, but there were more diabetics and smokers among pancreatic cancer cases than among subcohort members. Table $\mathbf{3 . 2}$ shows the percentages of abstainers and heavy alcohol users ( $\geq 30 \mathrm{~g} /$ day of ethanol) according to drinking habits, which did not differ noticeably between pancreatic cancer cases and subcohort members.

In a comparison of the highest category of ethanol intake ( $\geq 30 \mathrm{~g} / \mathrm{day}$ ) with $\mathrm{ab}$ stention, the age-adjusted rate ratio for pancreatic cancer was 1.83 (95\% confidence interval [Cl]: 1.24-2.71; Table 3.3). The $p$ value from the trend test was significant ( $p$ for trend $=0.01$ ), but there was no clear dose-response relation. When we repeated the analyses with adjustment for confounding variables, the risk estimate was attenuated but still significant (rate ratio $[R R]=1.57,95 \% \mathrm{Cl}: 1.03-2.39$ ), again with no clear dose-response relation ( $p$ for trend $=0.12$ ). When we restricted the analyses to MCPC cases, the point estimate remained similar but became non-significant (Table 3.3). No significantly increased risk of pancreatic cancer was found per $10 \mathrm{~g} /$ day increment of ethanol intake in the continuous analyses. After stratification by sex (data not shown), we observed a significantly increased risk for men (heavy alcohol consumers versus abstainers: $\mathrm{RR}=1.82,95 \% \mathrm{Cl}: 1.03-3.23)$, but for women no association was observed (heavy alcohol consumers versus abstainers: $\mathrm{RR}=1.07,95 \% \mathrm{Cl}$ : $0.45-2.53$ ). However, among women there were very few cases in the heavy alcohol consumption group $(n=7)$. 
TABLE 3.1 Baseline characteristics of pancreatic cancer cases and subcohort ${ }^{*}$ members; Netherlands Cohort Study on diet and cancer, 1986-1999

\begin{tabular}{|c|c|c|c|c|c|c|}
\hline \multirow[t]{3}{*}{ Characteristic } & \multicolumn{6}{|c|}{ Microscopically } \\
\hline & \multicolumn{2}{|c|}{$\begin{array}{l}\text { All pancreatic } \\
\text { cancer cases } \\
(n=350)\end{array}$} & \multicolumn{2}{|c|}{$\begin{array}{l}\text { verified pancreatic } \\
\text { cancer cases } \\
(n=234)\end{array}$} & \multicolumn{2}{|c|}{$\begin{array}{l}\text { Subcohort } \\
(n=3,980)\end{array}$} \\
\hline & Mean (SD) & $\%$ & Mean (SD) & $\%$ & Mean (SD) & $\%$ \\
\hline Male sex & & 52.9 & & 55.1 & & 49.1 \\
\hline Age, years & $62.1(4.1)$ & & $61.4(4.0)$ & & $61.3(4.2)$ & \\
\hline \multicolumn{7}{|l|}{ Alcohol consumption } \\
\hline Abstainers & & 20.9 & & 20.5 & & 23.8 \\
\hline Ethanol, g/day & $12.6(15.6)$ & & $12.4(15.5)$ & & $10.3(14.4)$ & \\
\hline Beer, glasses/week & $2.0(5.9)$ & & $1.9(5.7)$ & & $1.6(5.0)$ & \\
\hline Wine, glasses/week & $3.1(5.8)$ & & $3.1(5.7)$ & & $2.6(5.1)$ & \\
\hline Liquor, glasses/week & $3.0(5.6)$ & & $3.0(5.6)$ & & $2.5(5.2)$ & \\
\hline Stable drinkers ${ }^{\dagger}$ & & 59.4 & & 60.3 & & 63.3 \\
\hline \multicolumn{7}{|l|}{ Daily dietary intake } \\
\hline Energy, kcal & 1946 (487) & & $1972(486)$ & & $1926(515)$ & \\
\hline Total fat ${ }^{\ddagger}, \mathrm{g}$ & $83.9(16.2)$ & & 84.7 (15.9) & & $83.8(15.9)$ & \\
\hline Total carbohydrates $^{\ddagger}, \mathrm{g}$ & $201.4(40.2)$ & & 202.7 (38.9) & & $201.9(40.4)$ & \\
\hline Vegetables, g & $203.6(89.8)$ & & $206.5(91.8)$ & & $194.6(82.6)$ & \\
\hline Fruit, g & $171.3(117.4)$ & & $164.4(107.1)$ & & $177.1(119.8)$ & \\
\hline \multicolumn{7}{|l|}{ Other characteristics } \\
\hline Current smoker & & 34.9 & & 35.5 & & 27.3 \\
\hline Years of smoking ${ }^{\S}$ & $33.5(12.3)$ & & $33.3(12.7)$ & & $31.6(12.2)$ & \\
\hline Body mass index" & $25.4(3.3)$ & & $25.8(3.2)$ & & $25.0(3.1)$ & \\
\hline \multicolumn{7}{|l|}{ Non-occupational physical activity, min/day } \\
\hline$<30$ & & 19.1 & & 20.5 & & 20.3 \\
\hline $30-60$ & & 32.9 & & 31.2 & & 31.1 \\
\hline $61-90$ & & 24.6 & & 22.7 & & 21.4 \\
\hline$>90$ & & 23.4 & & 25.6 & & 27.2 \\
\hline History of diabetes mellitus & & 7.1 & & 6.8 & & 3.4 \\
\hline \multicolumn{7}{|l|}{ Level of education } \\
\hline Primary school or lower vocational school & & 49.6 & & 51.1 & & 49.8 \\
\hline Intermediate vocational school or high school & & 36.1 & & 35.6 & & 35.8 \\
\hline Higher vocational school or college & & 14.3 & & 13.3 & & 14.4 \\
\hline
\end{tabular}

Abbreviation: SD, standard deviation.

*A random sample of 5,000 subjects from the cohort chosen immediately after baseline and followed up for vital status information for estimation of the person-years in the entire cohort. 'Stable drinkers were defined as subjects who reported consuming equal total amounts of alcohol 5 years before baseline and at baseline. ${ }^{\ddagger}$ Energy-adjusted intake. ${ }^{\S}$ Number of years of smoking among ever smokers. "Weight $(\mathrm{kg}) /$ height $(\mathrm{m})^{2}$.

In order to investigate whether participants changed their drinking patterns because of preclinical manifestations of disease, we performed some additional analyses. Among stable alcohol users, we found a significantly increased risk among high alcohol consumers compared with abstainers in the total pancreatic cancer group (Table 3.3). Among stable alcohol users in the MCPC group, the increased risk estimate was higher but of only borderline significance ( $R R=1.92,95 \% \mathrm{Cl}$ : $0.99-3.73$ ), possibly because of small numbers of cases. When we restricted the analyses to subjects who reported having consumed more alcohol 5 years before baseline than at baseline (data not 
shown), we found a similar pattern, with an increased pancreatic cancer risk only in the highest category of ethanol intake ( $R R=2.36,95 \% \mathrm{Cl}: 1.11-5.03)$. This risk estimate was attenuated $(R R=1.90)$ and became non-significant when we restricted the analyses to MCPC cases. For subjects who reported having consumed less alcohol 5 years before baseline than at baseline, no association was found (data not shown).

TABLE 3.2 Alcohol drinking habits (\%) of pancreatic cancer cases and subcohort members; Netherlands Cohort Study on diet and cancer, 1986-1999

\begin{tabular}{|c|c|c|c|c|}
\hline & $\begin{array}{c}\text { Drinking more alcohol } \\
5 \text { years before } \\
\text { baseline than at } \\
\text { baseline }\end{array}$ & $\begin{array}{c}\text { Drinking equal amounts } \\
\text { of alcohol } 5 \text { years } \\
\text { before baseline and } \\
\text { at baseline }\end{array}$ & $\begin{array}{c}\text { Drinking less alcohol } \\
5 \text { years before } \\
\text { baseline than at } \\
\text { baseline }\end{array}$ & $\begin{array}{l}\text { Missing or } \\
\text { inconsistent } \\
\text { data }\end{array}$ \\
\hline \multicolumn{5}{|l|}{ All pancreatic cancer cases } \\
\hline Total population $(n=350)$ & 14.9 & 59.4 & 11.7 & 14.0 \\
\hline Abstainers $(n=73)$ & 4.1 & 79.5 & 0 & 16.4 \\
\hline Heavy users ${ }^{\dagger}(n=52)$ & 25.0 & 51.9 & 19.2 & 3.9 \\
\hline \multicolumn{5}{|c|}{ Microscopically verified pancreatic cancer cases } \\
\hline Total population $(n=234)$ & 15.4 & 60.2 & 10.7 & 13.7 \\
\hline Abstainers $(n=48)$ & 4.2 & 79.2 & 0 & 16.6 \\
\hline Heavy users $^{\dagger}(n=36)$ & 22.2 & 52.8 & 19.4 & 5.6 \\
\hline \multicolumn{5}{|l|}{ Subcohort } \\
\hline Total population $(n=3980)$ & 12.9 & 63.3 & 9.1 & 14.7 \\
\hline Abstainers $(n=947)$ & 7.4 & 80.0 & 0 & 12.6 \\
\hline Heavy users $^{\dagger}(n=358)$ & 16.5 & 54.8 & 19.8 & 8.9 \\
\hline
\end{tabular}

A random sample of 5,000 subjects from the cohort chosen immediately after baseline and followed up for vital status information for estimation of the person-years in the entire cohort. ${ }^{\dagger}$ Heavy users were defined as subjects who consumed $\geq 30 \mathrm{~g}$ of ethanol per day.

In addition, since the proportional hazards assumption was violated for ethanol intake, we calculated the interaction between ethanol intake and time and stratified the follow-up period into two periods. In the first part of the follow-up period, cases who consumed $\geq 30 \mathrm{~g} /$ day of ethanol had an approximately 2-fold increased cancer risk, both in the total case group and in the MCPC cases. This association was not observed during the second part of follow-up (Table 3.4), although interaction with time was of borderline significance for MCPC cases ( $p$ for interaction $=0.05$ ) and nonsignificant for all pancreatic cancer cases ( $p$ for interaction $=0.07$ ). For stable drinkers, the difference between early and later follow-up was more pronounced (the interaction with time was statistically significant [ $p$ for interaction $=0.01$ ]; Table 3.4). When we stratified the follow-up period into three time periods to investigate this further, we found a significantly increased risk for cases who consumed $\geq 30 \mathrm{~g}$ of ethanol daily during the first 5 years of follow-up; this risk gradually disappeared during the second and third parts of the follow-up period (data not shown), although the case numbers were quite small in different strata, especially in the third part of follow-up. 


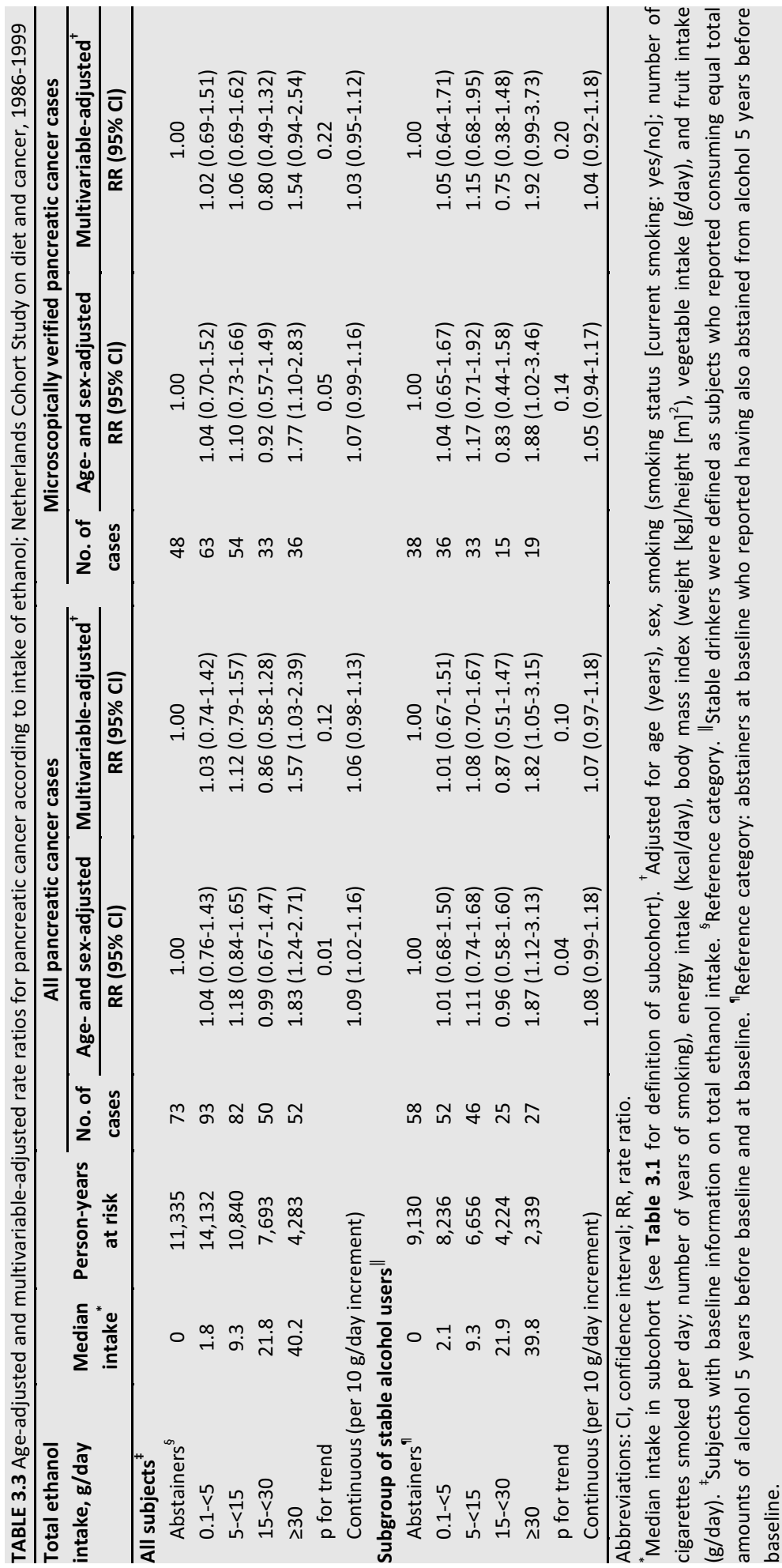




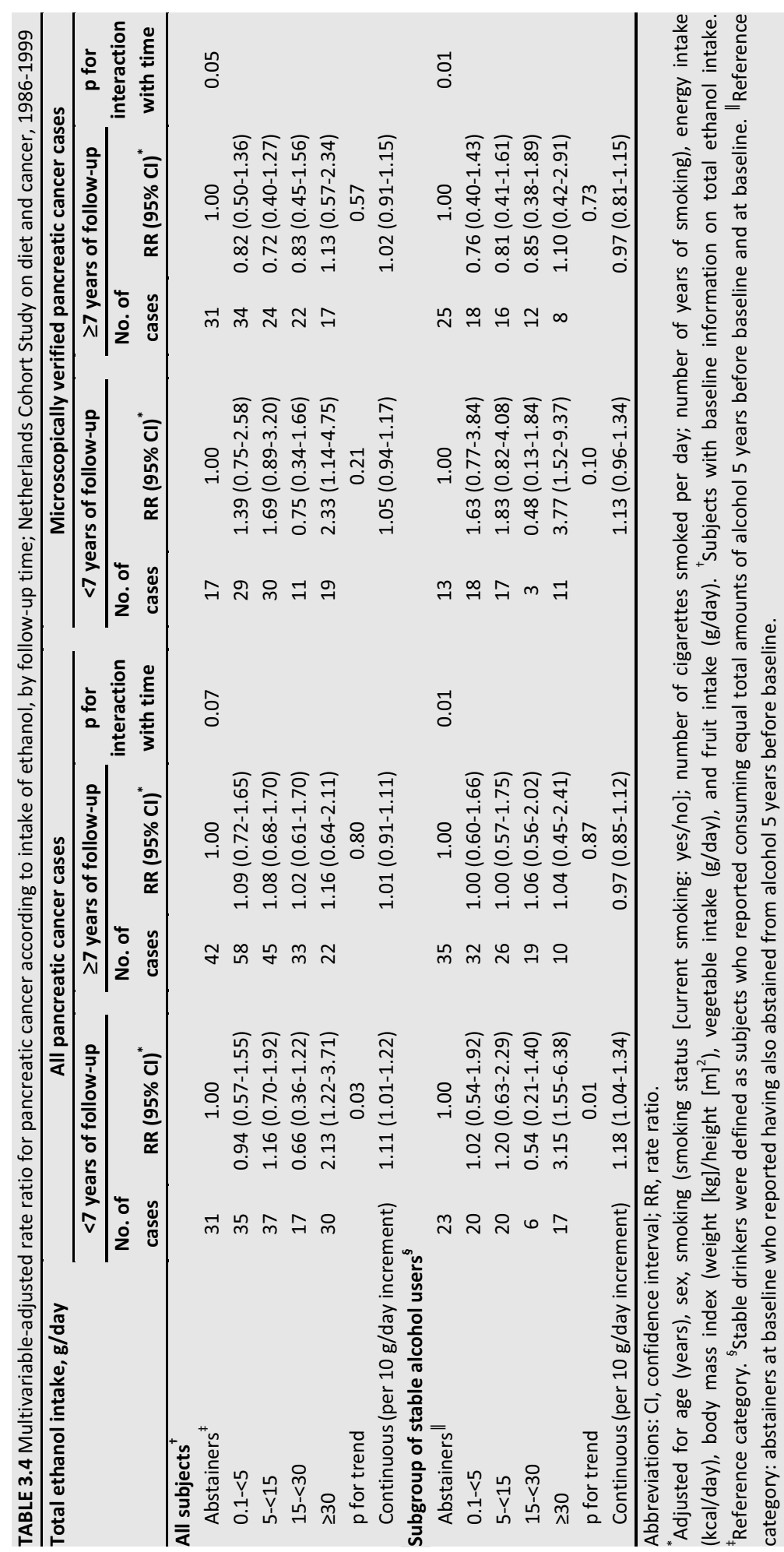


In addition to these analyses of total ethanol intake, we examined the intake of specific types of beverage, with total ethanol included in the multivariable-adjusted model. No clear associations were found between these beverages and pancreatic cancer risk (Table 3.5), indicating no specific effect of any particular beverage type on top of the general effect of ethanol.

No evidence for a nonlinear association was found for any of the exposure variables in the analyses carried out using restricted cubic splines (no significant deviation from linearity using the Wald test [ $p>0.05$ ]; data not shown). Furthermore, no evidence for interaction of alcohol consumption with smoking or folate was found (Table 3.6).

\section{DISCUSSION}

We found no association between low-to-moderate alcohol intake and risk of pancreatic cancer. We did, however, find a significantly increased risk for consumers of a high level of ethanol ( $\geq 30 \mathrm{~g} /$ day).

So far, most cohort and case-control studies have provided little or no support for a causal relation between low-to-moderate alcohol use and pancreatic cancer

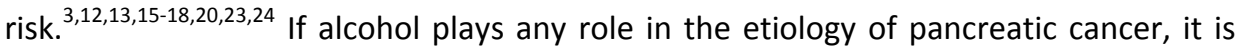
likely to be among heavy drinkers, ${ }^{8}$ which is in agreement with our findings. Two cohort studies suggested an increased risk with higher alcohol intake, ${ }^{19,21}$ and two other prospective studies found significantly increased risks. ${ }^{22,25}$ A cohort study carried out in Japan found a significantly increased risk among former drinkers, while a significant inverse association was found among current drinkers as compared with never drinkers. ${ }^{46}$ Results of case-control studies have also been inconsistent, ${ }^{3}$ with most studies finding no association, while two studies found an increased risk of pancreatic cancer among heavy alcohol drinkers. ${ }^{47,48}$ Bagnardi et al. ${ }^{44}$ conducted a meta-analysis of epidemiologic data and found no association between ethanol intake and pancreatic cancer (for intake of $100 \mathrm{~g} /$ day versus abstention: $\mathrm{RR}=1.18,95 \% \mathrm{Cl}: 0.94-1.49$ ). However, this meta-analysis was based on 13 case-control studies and only four cohort studies. 


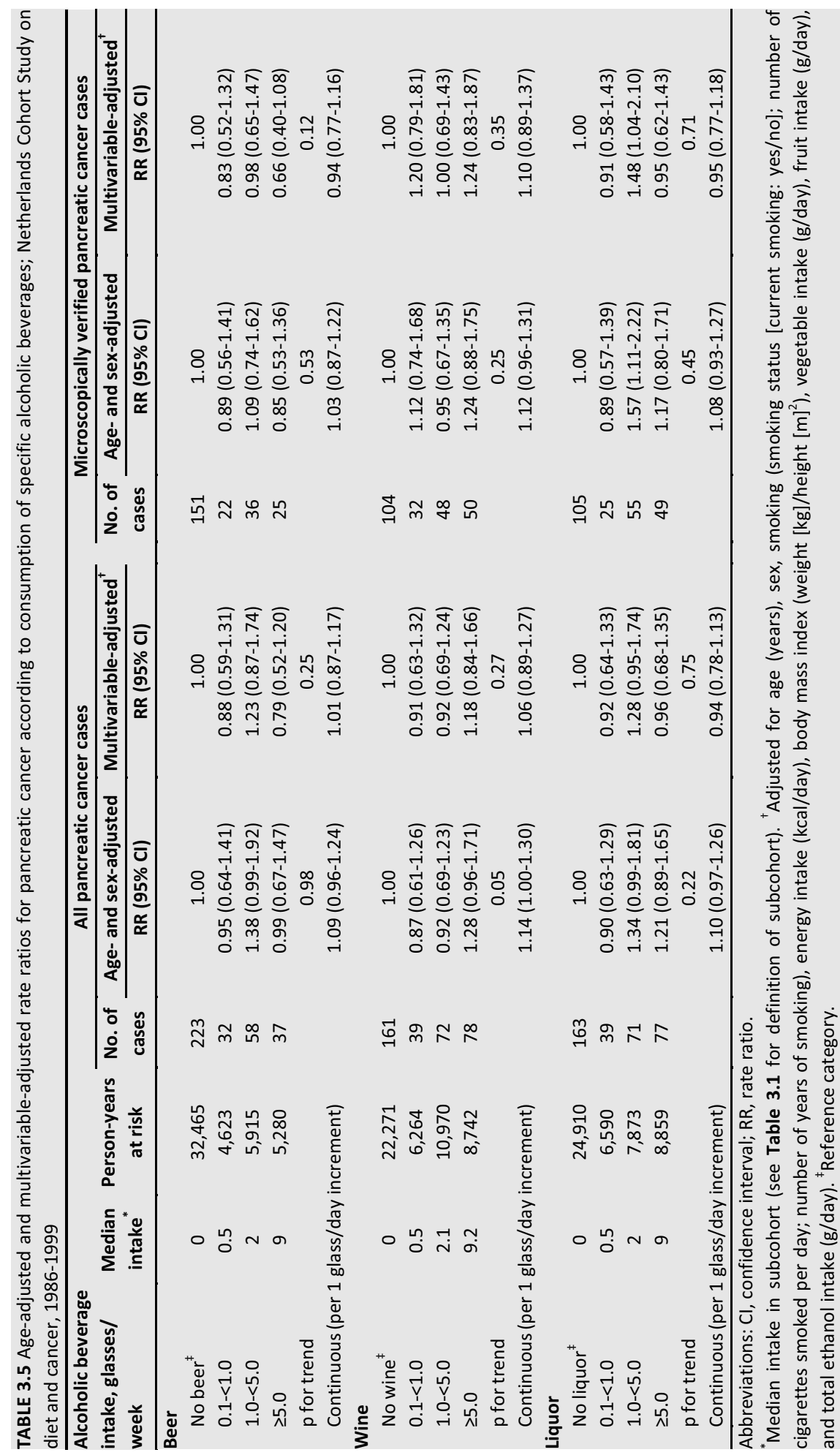




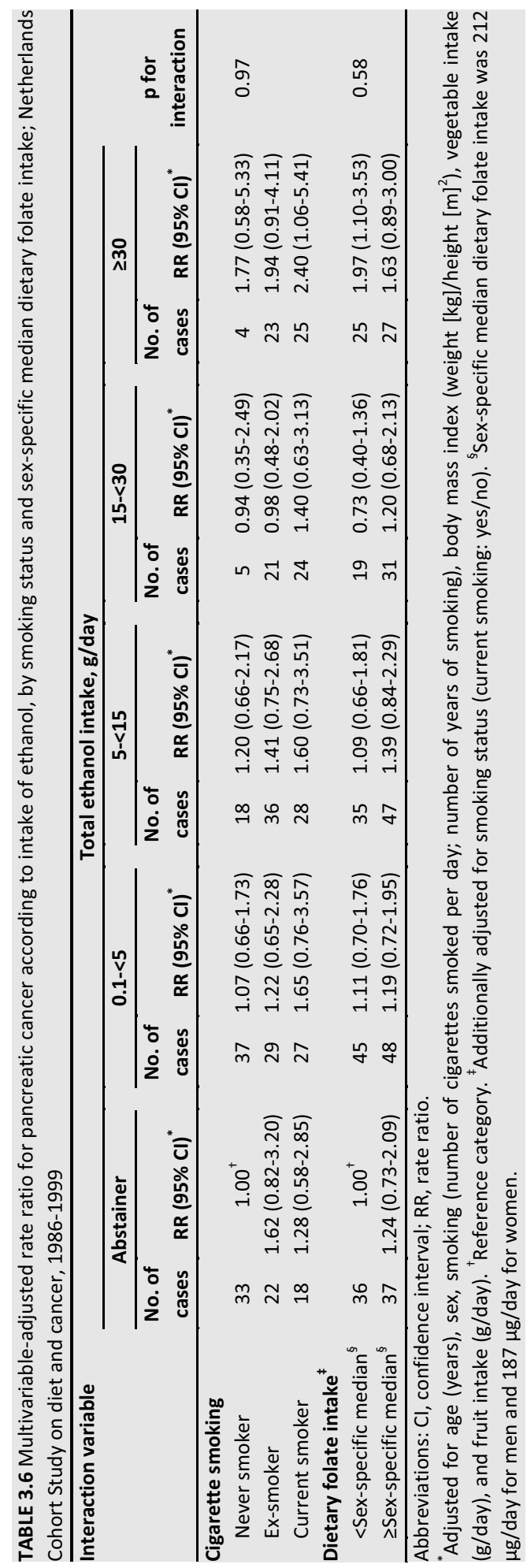


In our main analyses, the increased risk we found for high alcohol consumption was only present during the first part of follow-up; it was not observed during the second part. When we excluded from the analyses subjects who had changed their drinking habits before baseline, possibly because of preclinical manifestations of disease, the difference in effect estimates for early and later follow-up was more pronounced, showing a statistically significant interaction with time. This finding should be interpreted with some caution, since these analyses are based on low case numbers, especially in the highest category of ethanol intake during late follow-up among stable alcohol users in the MCPC group ( $n=8)$. In addition, it could be that recent alcohol intake is of greatest etiologic importance. Moreover, people decrease their alcohol intake or even stop drinking when they become older. ${ }^{49}$ This could, in part, explain our findings. The food frequency questionnaire was tested for reproducibility by Goldbohm et al. ${ }^{35}$ with repeated measurements at 5 annual intervals in independent samples of the cohort. For alcohol, the estimated decrease of the correlation coefficient between baseline and repeated measurement amounted to 0.02 per year, indicating a rather stable measurement during the first 5 years of follow-up. Nevertheless, it is possible that our food frequency questionnaire may not have been representative of the drinking habits of the participants during later follow-up. As far as we know, Michaud et al. ${ }^{23}$ were the first to prospectively investigate an early or late effect of alcohol intake on pancreatic cancer risk. They performed analyses in two US populations, comparing past heavy users of alcohol with never users and then adding an 8-year lag period between measurement of diet and the follow-up period; in neither of these analyses did they find an increased risk of pancreatic cancer. ${ }^{23}$ This should also be investigated in other observational studies with longer durations of follow-up. However, so far, studies that have observed an association between alcohol intake and pancreatic cancer risk and studies that have not observed an association have had similar follow-up times, ranging from 5 years to 20 years.

We did not observe any relation between intake of specific alcoholic beverages and pancreatic cancer risk. This is in agreement with most epidemiologic data, which suggest that it is ethanol itself and not the type of alcoholic beverage which plays a role in carcinogenesis. ${ }^{11}$

Many factors may contribute to the inconsistent results observed in the literature. Pancreatic cancer is particularly difficult to study in case-control studies, because poor survival leads to fewer direct interviews with cases, which could mean that investigators may have to rely on interviews with proxy respondents. In addition, half of the observational studies investigating the role of alcohol in the etiology of pancreatic cancer had low case numbers. Moreover, heavy alcohol drinkers may have lower participation rates than non-drinkers in both population-based case-control studies and cohort studies. $^{44}$

In some animal studies, ethanol consumption slightly enhanced pancreatic carcinogenesis, but in other studies it did not demonstrate any effect on pancreatic carcinogenicity. ${ }^{8,50-52}$ It is still not clear, though, whether ethanol plays a role at initiation or 
at the promotion stage, since this has received limited attention among researchers in the field. ${ }^{10}$

The strengths of our study included the possibility of further restricting the anaIyses to MCPC cases and to stable alcohol drinkers. Selection bias due to differential follow-up is unlikely to have made a substantial contribution to our findings, since there was very little loss to follow-up. ${ }^{29}$ The prospective design helped us avoid the need to use next-of-kin respondents.

A potential limitation is that abstainers and ex-drinkers were not separated in our study but were included in our reference category of abstainers. Since ex-drinkers may differ from abstainers in terms of pancreatic cancer risk, our estimated risks might have been biased in either direction. The proportion of ex-drinkers was probably small, since only $7.2 \%$ of the cohort members and $4.6 \%$ of the cases who consumed less than one alcoholic drink per month reported having consumed alcohol 5 years before baseline. Another limitation is that in some sensitivity analyses, the number of cases was too low to investigate relations in more depth - although, in comparison with other epidemiologic studies, our number of cases was substantial.

In conclusion, our findings suggest an increased risk of pancreatic cancer for persons with a high ethanol intake ( $\geq 30 \mathrm{~g} /$ day). However, this increased pancreatic cancer risk was observed only during the first 7 years of follow-up. 


\section{REFERENCES}

1. Jemal A, Siegel R, Ward E, et al. Cancer statistics, 2008. CA Cancer J Clin 2008;58:71-96.

2. Karim-Kos HE, de Vries E, Soerjomataram I, Lemmens V, Siesling S, Coebergh JW. Recent trends of cancer in Europe: a combined approach of incidence, survival and mortality for 17 cancer sites since the 1990s. Eur J Cancer 2008;44:1345-89.

3. World Cancer Research Fund/American Institute for Cancer research. Food, nutrition, physical activity, and the prevention of cancer: a global perspective. Washington DC: AICR, 2007.

4. Fuchs CS, Colditz GA, Stampfer MJ, et al. A prospective study of cigarette smoking and the risk of pancreatic cancer. Arch Intern Med 1996;156:2255-60.

5. Huxley R, Ansary-Moghaddam A, Berrington de Gonzalez A, Barzi F, Woodward M. Type-II diabetes and pancreatic cancer: a meta-analysis of 36 studies. Br J Cancer 2005;92:2076-83.

6. Marshall JR, Freudenheim J. Alcohol. In: Schottenfeld D, Fraumeni JF Jr., eds. Cancer Epidemiology and Prevention, $3^{\text {rd }}$ ed. New York: Oxford University Press, 2006. P. 243-58.

7. Talamini G, Bassi C, Falconi M, et al. Alcohol and smoking as risk factors in chronic pancreatitis and pancreatic cancer. Dig Dis Sci 1999;44:1303-11.

8. Anderson KE, Mack TM, Silverman DT. Cancer of the pancreas. In: Schottenfeld D, Fraumeni JF Jr., eds. Cancer epidemiology and prevention, $3^{\text {rd }}$ ed. New York: Oxford University Press, 2006. P. 721-62.

9. Lowenfels AB, Maisonneuve P, Cavallini G, et al. Pancreatitis and the risk of pancreatic cancer. International Pancreatitis Study Group. N Engl J Med 1993;328:1433-7.

10. Go VL, Gukovskaya A, Pandol SJ. Alcohol and pancreatic cancer. Alcohol 2005;35:205-11.

11. Seitz HK, Stickel F. Molecular mechanisms of alcohol-mediated carcinogenesis. Nat Rev Cancer 2007;7: 599-612.

12. Coughlin SS, Calle EE, Patel AV, Thun MJ. Predictors of pancreatic cancer mortality among a large cohort of United States adults. Cancer Causes Control 2000;11:915-23.

13. Hiatt RA, Klatsky AL, Armstrong MA. Pancreatic cancer, blood glucose and beverage consumption. Int J Cancer 1988;41:794-7.

14. Hirayama T. Epidemiology of pancreatic cancer in Japan. Jpn J Clin Oncol 1989;19:208-15.

15. Isaksson B, Jonsson F, Pedersen NL, Larsson J, Feychting M, Permert J. Lifestyle factors and pancreatic cancer risk: a cohort study from the Swedish Twin Registry. Int J Cancer 2002;98:480-2.

16. Lin Y, Tamakoshi A, Kawamura T, et al. Risk of pancreatic cancer in relation to alcohol drinking, coffee consumption and medical history: findings from the Japan collaborative cohort study for evaluation of cancer risk. Int J Cancer 2002;99:742-6.

17. Luo J, Iwasaki M, Inoue $M$, et al. Body mass index, physical activity and the risk of pancreatic cancer in relation to smoking status and history of diabetes: a large-scale population-based cohort study in Japan - the JPHC study. Cancer Causes Control 2007;18:603-12.

18. Shibata A, Mack TM, Paganini-Hill A, Ross RK, Henderson BE. A prospective study of pancreatic cancer in the elderly. Int J Cancer 1994;58:46-9.

19. Friedman GD, van den Eeden SK. Risk factors for pancreatic cancer: an exploratory study. Int J Epidemiol 1993;22:30-7.

20. Gaziano JM, Gaziano TA, Glynn RJ, et al. Light-to-moderate alcohol consumption and mortality in the Physicians' Health Study enrollment cohort. J Am Coll Cardiol 2000;35:96-105.

21. Harnack $\amalg$, Anderson KE, Zheng W, Folsom AR, Sellers TA, Kushi LH. Smoking, alcohol, coffee, and tea intake and incidence of cancer of the exocrine pancreas: the lowa Women's Health Study. Cancer Epidemiol Biomarkers Prev 1997;6:1081-6.

22. Heuch I, Kvale G, Jacobsen BK, Bjelke E. Use of alcohol, tobacco and coffee, and risk of pancreatic cancer. Br J Cancer 1983;48:637-43.

23. Michaud DS, Giovannucci E, Willett WC, Colditz GA, Fuchs CS. Coffee and alcohol consumption and the risk of pancreatic cancer in two prospective United States cohorts. Cancer Epidemiol Biomarkers Prev 2001;10:429-37. 
24. Stolzenberg-Solomon RZ, Pietinen P, Barrett MJ, Taylor PR, Virtamo J, Albanes D. Dietary and other methyl-group availability factors and pancreatic cancer risk in a cohort of male smokers. Am J Epidemiol 2001;153:680-7.

25. Zheng W, McLaughlin JK, Gridley G, et al. A cohort study of smoking, alcohol consumption, and dietary factors for pancreatic cancer (United States). Cancer Causes Control 1993;4:477-82.

26. van den Brandt PA, Goldbohm RA, van 't Veer P, Volovics A, Hermus RJ, Sturmans F. A large-scale prospective cohort study on diet and cancer in the Netherlands. J Clin Epidemiol 1990;43:285-95.

27. Prentice RL. A case-cohort design for epidemiologic cohort studies and disease prevention trials. Biometrika 1986;73:1-11.

28. van den Brandt PA, Schouten LJ, Goldbohm RA, Dorant E, Hunen PM. Development of a record linkage protocol for use in the Dutch Cancer Registry for epidemiological research. Int J Epidemiol 1990;19: 553-8.

29. Goldbohm RA, van den Brandt PA, Dorant E. Estimation of the coverage of Dutch municipalities by cancer registries and PALGA based on hospital discharge data. Tijdschr Soc Gezondheidsz 1994;72: 80-4.

30. Goldbohm RA, van den Brandt PA, Brants HA, et al. Validation of a dietary questionnaire used in a large-scale prospective cohort study on diet and cancer. Eur J Clin Nutr 1994;48:253-65.

31. Anonymous. NEVO-tabel: Nederlands voedingsstoffenbestand 1986-1987 (Nevo table: Dutch Food Composition Table 1986-1987 [in Dutch]). The Hague, the Netherlands: Voorlichtingsbureau voor de voeding, 1986.

32. Konings EJ. A validated liquid chromatographic method for determining folates in vegetables, milk powder, liver, and flour. J AOAC Int 1999;82:119-27.

33. Konings EJ, Roomans HH, Dorant E, Goldbohm RA, Saris WH, van den Brandt PA. Folate intake of the Dutch population according to newly established liquid chromatography data for foods. Am J Clin Nutr 2001;73:765-76.

34. Health Council of the Netherlands. Risico's van alcoholgebruik bij conceptie, zwangerschap en borstvoeding (Risks of alcohol consumption related to conception, pregnancy and breastfeeding [in Dutch]). The Hague, the Netherlands: Health Council of the Netherlands, 2005.

35. Goldbohm RA, van 't Veer P, van den Brandt PA, et al. Reproducibility of a food frequency questionnaire and stability of dietary habits determined from five annually repeated measurements. Eur J Clin Nutr 1995;49:420-9.

36. Volovics A, van den Brandt PA. Methods for the analysis of case-cohort studies. Biom J 1997;39: 195-214.

37. Lin DY, Wei L. The robust inference for the Cox proportional hazards model. J Am Stat Assoc 1989;84: 1074-8.

38. Schoenfeld D. Partial residuals for the proportional hazards regression model. Biometrika 1982;69: 239-41.

39. Brants HAM, den Breeijen H, Beschrijving en verantwoording van de codering van NEVO-codes, standaardporties e.d. (Description of and justification for coding of the NEVO-codes, standardized serving sizes, etc. [in Dutch]). Zeist, the Netherlands: Institution CIVO - Toxicology and Nutrition TNO, 1990.

40. van der Sanden GA, Coebergh JW, Schouten $L$, Visser O, van Leeuwen FE. Cancer incidence in The Netherlands in 1989 and 1990: first results of the nationwide Netherlands cancer registry. Coordinating Committee for Regional Cancer Registries. Eur J Cancer 1995;31A:1822-9.

41. Durrleman S, Simon R. Flexible regression models with cubic splines. Stat Med 1989;8:551-61.

42. Greenland S. Dose-response and trend analysis in epidemiology: alternatives to categorical analysis. Epidemiology 1995;6:356-65.

43. Verhage BA, Schouten $\amalg$, Goldbohm RA, van den Brandt PA. Anthropometry and pancreatic cancer risk: an illustration of the importance of microscopic verification. Cancer Epidemiol Biomarkers Prev 2007;16:1449-54.

44. Bagnardi V, Blangiardo M, La Vecchia C, Corrao G. Alcohol consumption and the risk of cancer: a metaanalysis. Alcohol Res Health 2001;25:263-70.

45. Stata Corporation. Intercooled STATA, version 9. College Station, TX: Stata Corporation, 2005. 
46. Inoue M, Tajima K, Takezaki T, et al. Epidemiology of pancreatic cancer in Japan: a nested case-control study from the Hospital-based Epidemiologic Research Program at Aichi Cancer Center (HERPACC). Int J Epidemiol 2003;32:257-62.

47. Hassan MM, Bondy ML, Wolff RA, et al. Risk factors for pancreatic cancer: case-control study. Am J Gastroenterol 2007;102:2696-707.

48. Silverman DT, Brown LM, Hoover RN, et al. Alcohol and pancreatic cancer in blacks and whites in the United States. Cancer Res 1995;55:4899-905.

49. Statistics Netherlands. Statistisch jaarboek 2001 (Statistical Abstract 2001 [in Dutch]). The Hague, the Netherlands: Statistics Netherlands, 2001.

50. Nishikawa A, Furukawa F, Imazawa T, Yoshimura H, Mitsumori K, Takahashi M. Effects of caffeine, nicotine, ethanol and sodium selenite on pancreatic carcinogenesis in hamsters after initiation with $\mathrm{N}$ nitrosobis(2-oxopropyl)amine. Carcinogenesis 1992;13:1379-82.

51. Pour PM, Reber HA, Stepan K. Modification of pancreatic carcinogenesis in the hamster model. XII. Dose-related effect of ethanol. J Natl Cancer Inst 1983;71:1085-7.

52. Woutersen RA, van Garderen-Hoetmer A, Bax J, Scherer E. Modulation of dietary fat-promoted pancreatic carcinogenesis in rats and hamsters by chronic ethanol ingestion. Carcinogenesis 1989;10: 453-9. 



\section{4}

\section{Glycemic load, glycemic index, and pancreatic cancer risk in the Netherlands Cohort Study}

Mirjam M Heinen

Bas AJ Verhage

LH Lumey

Henny AM Brants

R Alexandra Goldbohm

Piet $A$ van den Brandt 


\section{ABSTRACT}

\section{Background}

Recent studies of pancreatic cancer suggest a role for hyperinsulinemia in carcinogenesis. Because insulin is secreted in response to elevated blood glucose concentrations, dietary factors that increase these concentrations may be important in pancreatic carcinogenesis.

\section{Objective}

The objective was to examine prospectively the relation between pancreatic cancer risk and dietary glycemic load (GL), overall glycemic index (GI), and intake of total carbohydrates and mono- and disaccharides.

\section{Design}

The Netherlands Cohort Study consisted of 120,852 men and women who completed a baseline questionnaire in 1986. After 13.3 years of follow-up, 408 pancreatic cancer cases were detected, $66 \%$ of which were microscopically confirmed. A validated $150-$ item food frequency questionnaire, completed at baseline, was used to calculate carbohydrate and mono- and disaccharide intakes and the GL and GI of the diet.

\section{Results}

Dietary GL, Gl, or intake of carbohydrates and mono- and disaccharides were not associated with pancreatic cancer risk in this cohort. Also, the associations were not modified by sex. Our results did not change after the analysis was restricted to microscopically confirmed pancreatic cancer cases or after individuals who reported a history of diabetes at baseline were excluded from the analyses.

\section{Conclusion}

Overall, our findings do not support the hypothesis that GL, GI, or intake of carbohydrates and mono- and disaccharides are positively associated with pancreatic cancer risk. This is in agreement with previous prospective studies that investigated the relation between $\mathrm{GL}$ and $\mathrm{Gl}$ and pancreatic cancer risk. 


\section{INTRODUCTION}

Pancreatic cancer is among the most rapidly fatal cancers worldwide, with a 5-year survival rate of $\leq 5 \%{ }^{1,2}$ Few consistent risk factors for pancreatic cancer have been identified, with cigarette smoking and diabetes mellitus being the most consistent. ${ }^{3-5}$

Evidence indicates that insulin acts as a growth promoter and mitogen in the pancreas. $^{6,7}$ Furthermore, recent observational studies of pancreatic cancer suggest that high insulin concentrations, glucose intolerance, and insulin resistance may play a role in carcinogenesis, even without a diagnosis of diabetes mellitus. ${ }^{8-10}$ Type 2 diabetes seems to develop generally after prolonged periods of high insulin secretion rates, with a gradual increase in insulin resistance of the liver and peripheral tissues. ${ }^{10}$ Because insulin is secreted into the blood in response to elevated blood glucose concentrations, dietary factors increasing these concentrations may be associated with pancreatic cancer risk.

The glycemic index (GI) is a measure that can be used to quantify the postprandial glycemic effects (compared with the glucose response of a reference food, usually white bread or glucose) of individual foods items. ${ }^{11}$ Consumption of high-Gl diets, i.e., diets in which the carbohydrates in the foods are characterized by a high $\mathrm{Gl}$, have been shown to be associated with hyperglycemia and hyperinsulinemia, ${ }^{11}$ whereas low-GI meals have been shown to be associated with a lower postprandial rise in glucose and insulin, probably because of a reduced rate of glucose absorption and, therefore, a reduced postprandial rise in insulin. ${ }^{11}$ Studies that have established GI values for foods used portions that contain a fixed amount of carbohydrate (generally $50 \mathrm{~g}$ ) rather than portions that are typically consumed. ${ }^{12}$ Hence, to estimate the total glycemic effect of the diet, the glycemic load (GL) is calculated by using both the overall GI of a diet as well as the actual amount of carbohydrates consumed in the diet. ${ }^{13}$

Studies of the influence of dietary GI and GL on pancreatic cancer have been limited. To date, the relation between $\mathrm{GL}$ and $\mathrm{Gl}$ and pancreatic cancer risk has been examined in four prospective studies. ${ }^{14-17}$ No associations have been found between GI and GL and pancreatic cancer risk, although Michaud et al. ${ }^{15}$ found a significantly positive association between a high GL and pancreatic cancer incidence in women who were both sedentary and overweight, factors that are associated with insulin resistance. $^{10}$

We examined the association between pancreatic cancer risk and dietary GL and GI, and total carbohydrate and mono- and disaccharide intakes, in men and women within The Netherlands Cohort Study (NLCS) on diet and cancer. 


\section{SUBJECTS AND METHODS}

\section{Study population and follow-up of cancer}

The study design of the NLCS was reported in detail elsewhere. ${ }^{18}$ Briefly, the NLCS was initiated in September 1986 and included 58,279 men and 62,573 women aged 55-69 years at the beginning of the study, which originated in 204 municipalities with computerized population registries. A self-administered questionnaire on dietary habits, lifestyle characteristics, medical history, and other potential risk factors for cancer was completed at baseline. For reasons of efficiency in questionnaire processing (which was very detailed and included open-ended questions) and follow-up, the case-cohort approach was used. ${ }^{19}$ Case subjects were enumerated from the entire cohort, whereas the person-years at risk were estimated from a random sample of 5,000 subjects (2,411 men and 2,589 women). This subcohort was selected immediately after baseline and was followed-up for vital status information. The entire cohort is being monitored for cancer occurrence by annual record linkage to the Netherlands Cancer Registry and the Netherlands Pathology Registry. ${ }^{20}$ The follow-up was restricted to the period from baseline to December 1999 , a total of 13.3 years. No subcohort members were lost to follow-up, and completeness of the follow-up was estimated to be $>96 \%{ }^{21}$

For cases and subcohort members, all prevalent cancer cases at baseline other than non-melanoma skin cancer were excluded. Additionally, subjects with incomplete and inconsistent dietary data were also excluded from the analyses. These subjects either (i) left $>60$ (of 150 items) questionnaire items blank and ate $<35$ items at least once per month or (ii) left one or more item blocks (grouping of items, e.g., beverages) blank. Additional details are given elsewhere. ${ }^{22}$ Of the incident pancreatic cancer cases, all endocrine subtypes based on histology were excluded (Islet-cell carcinomas; $n=1)$. This resulted in a final subcohort of 4,438 subjects $(2,191$ men and 2,247 women) and 408 exocrine pancreatic cancer cases (217 men and 191 women). Of all pancreatic cancer cases, $66 \%$ were microscopically confirmed pancreatic cancer (MCPC; $\mathrm{n}=269)$, whereas $34 \%$ were non-microscopically confirmed pancreatic cancer (NMCPC; $n=139$ ). The diagnosis of the latter group was made by the treating clinician and was based on clinical symptoms, physical examinations, and imaging results and abstracted and recorded by a trained tumor registrar. ${ }^{23}$ The NLCS was approved by the institutional review boards of the TNO Nutrition and Food Research Institute (Zeist, Netherlands) and Maastricht University (Maastricht, Netherlands).

\section{Questionnaire}

The dietary section of the questionnaire was a 150-item semiquantitative food frequency questionnaire (FFQ), which concentrated on the habitual consumption of food and beverages during the year preceding the start of the study. Questionnaire data were key-entered and processed for all incident cases in the cohort and subcohort members in a standardized manner blinded with respect to case and subcohort status. This was done to minimize observer bias in coding and interpretation of the data. Daily 
mean nutrient intakes were calculated by summing the multiplied frequencies and portion sizes of all food items with their tabulated nutrient contents from the Dutch food composition table of $1986 .^{24}$

GI values of foods were obtained from published estimates. ${ }^{13}$ The mean of reported GI values for a food was used if these reported values varied across studies. ${ }^{13}$ Food items for which a GI had not been determined were assigned the Gl of the nearest comparable food (e.g., rusks, liquorice) or were calculated by using recipes (e.g., Dutch spiced cake). A GI for beer could not be found and was estimated by using the type of carbohydrates (65\% maltose, $35 \%$ glucose). For some food items, no GI value could be determined because of the lack of published estimates (e.g., alcohol-free beer, croquettes). For $>90 \%$ of the carbohydrate intake of each subject, a $\mathrm{Gl}$ value was available. Lack of information about the GI of vegetables and legumes was resolved by calculating a mean GI for usually consumed vegetables and legumes in the NLCS. In case of multiple foods per FFQ item, a GI value was assigned to each composing food, and the $\mathrm{Gl}$ of the item was estimated by using the weighted average of Gl values based on carbohydrate content and prevalence of estimated population consumption of these foods. ${ }^{25}$ The overall dietary GI was estimated for each participant by calculating the weighted average GI of all food items eaten by using the carbohydrate intake from that item (g/day) as a weighting factor. The resulting value represents the overall quality of carbohydrate intake for each participant. In addition, the average dietary GL was calculated by multiplying the overall dietary GI by the total amount of carbohydrate, which was then divided by 100 . Each unit of GL represents the equivalent of $1 \mathrm{~g}$ carbohydrate from glucose.

The FFQ was validated and tested for reproducibility. ${ }^{22,26}$ Crude (and energy- and sex-adjusted) Pearson correlation coefficients between the 9-day diet record and the questionnaire for total carbohydrate and mono- and disaccharides were 0.77 (0.71) and $0.78(0.79)$, respectively. For the most relevant food groups, Spearman correlation coefficients were 0.80 for bread, 0.74 for potatoes, and 0.84 for added sugar. ${ }^{22}$

\section{Statistical analysis}

Dietary GL and GI and intake of total carbohydrates, mono- and disaccharides, and fiber were all adjusted for energy intake by the residual method ${ }^{27}$ to enable comparison with previous studies. ${ }^{14-17}$ Pearson correlation coefficients $(r)$ between energyadjusted GL, Gl, carbohydrates, and mono- and disaccharides and food items contributing most to energy-adjusted GL were calculated.

In the present study the overall analyses were executed on all pancreatic cancer cases. In additional analyses we restricted the analyses to MCPC cases to create a group with a higher degree of diagnostic certainty of pancreatic cancer. In a previous analysis of anthropometric measures and pancreatic cancer, a significant positive association was observed between body mass index (BMI) and pancreatic cancer risk among verified cases, which was obscured when NMCPC cases were included. ${ }^{28}$ 
All analyses were conducted for both sexes combined and separately for men and women. Age-adjusted and multivariable-adjusted incidence rate ratios, or relative risks (RRs), and corresponding 95\% Cls were estimated by using Cox proportional hazards models. The total person-years at risk, estimated from the subcohort, were used in the analyses. ${ }^{29}$ SEs were estimated by using the robust Hubert-White sandwich estimator to account for additional variance introduced by sampling from the cohort. This method is equivalent to the variance-covariance estimator presented by Barlow et al. ${ }^{30}$ The proportional hazards assumption was tested by using the scaled Schoenfeld residuals. ${ }^{31}$ RRs for energy-adjusted dietary GL and GI and intake of energy-adjusted total carbohydrates and mono- and disaccharides were estimated for quintiles (with the lowest quintile of intake regarded as the reference group) based on the sex-specific distribution in the subcohort and as continuous variables. Total energy intake (kcal/day) was included in both the age- and multivariable-adjusted models in conformity with the method described by Willett. ${ }^{27}$ The RRs for energy-adjusted total carbohydrates and mono- and disaccharides can be interpreted as the effect of an increase in these variables relative to a decrease of an equivalent amount of energy from other energy-delivering nutrients (i.e., substituting these exposure nutrients for other energy-delivering nutrients). Age at baseline (years), cigarette smoking (current smoking: yes or no; number of cigarettes smoked per day; number of years of smoking), BMI $\left(\mathrm{kg} / \mathrm{m}^{2}\right)$, alcohol intake (g/day), fiber intake (energy-adjusted; g/day), history of diabetes mellitus (yes/no), history of hypertension (yes/no), intake of vegetables (g/day), and intake of fruit (g/day) were included in the confounder-adjusted models because they were associated with GL and affected the RR estimates. We also considered other potential confounders, including level of education, non-occupational moderate physical activity, multivitamin use, family history of pancreatic cancer, history of cholecystectomy, history of gall-stones, and history of gastric ulcer, which were not included in the final model because these variables did not change the RR estimates. To enable comparison, age-adjusted analyses were restricted to subjects included in multivariable-adjusted analyses (e.g., with no missing values on confounders included in the multivariable-adjusted model). For each analysis, trends were evaluated with the Wald test by fitting ordinal exposure variables (quintiles of intake) as continuous terms.

As suggested by a previous study, ${ }^{15}$ we constructed combined categories of BMI (cutoff: $25 \mathrm{~kg} / \mathrm{m}^{2}$ ) and physical activity (<30 versus $\geq 30 \mathrm{~min} /$ day) resulting in three subgroups: a lean and physically active group, an overweight and physically inactive group, and an intermediate group of either lean but physically inactive individuals or overweight but physically active individuals. We stratified our analyses by these combined categories of BMI and physical activity and, in addition, performed a formal test for interaction by constructing multiplicative interaction terms for each of the exposure variables and these combined categories. Although we used quintiles of the dietary intakes in our main analysis, for the stratified analyses we used tertiles to avoid small case numbers. In additional analyses, individuals who reported a history of 
diabetes at baseline $(n=159)$ were excluded. To evaluate whether early symptoms of disease before diagnosis could have influenced the results, early cases (diagnosed within 2 years after baseline) were excluded in the additional analyses. All analyses were performed by using the STATA statistical software package (intercooled STATA, version 9; Stata Corp, College Station. TX). All $p$ values were based on 2-sided tests and were considered statistically significant if $<0.05$.

\section{RESULTS}

Carbohydrate intake was positively correlated with GL $(r=0.96)$ and $\mathrm{GI}(r=0.26)$. Mono- and disaccharide intake was positively correlated with GL $(r=0.67)$, but not with $\mathrm{GI}(r=-0.02)$. For the five food groups contributing most to the $\mathrm{GL}$, correlation coefficients with GI were 0.27 for potatoes, 0.38 for added sugar, 0.31 for bread, 0.03 for Chinese and Indonesian foods, and -0.14 for cookies, cake, and pastry. For GL, correlation coefficients were 0.27 for potatoes, 0.59 for added sugar, 0.43 for bread, 0.14 for Chinese and Indonesian foods, and 0.05 for cookies, cake, and pastry.

In Table 4.1, baseline characteristics (stratified by sex) are presented. A number of characteristics did not differ between pancreatic cancer cases and subcohort members, including age, GL and GI of the diet, and physical activity level. However, in men, there were more diabetics and smokers among pancreatic cancer cases than among subcohort members. Within the pancreatic cancer case group, most characteristics did not differ between total pancreatic cancer cases and MCPC cases, although in women a history of hypertension was higher among total pancreatic cancer cases than among MCPC cases (32.1\% compared with $24.8 \%$ ). 


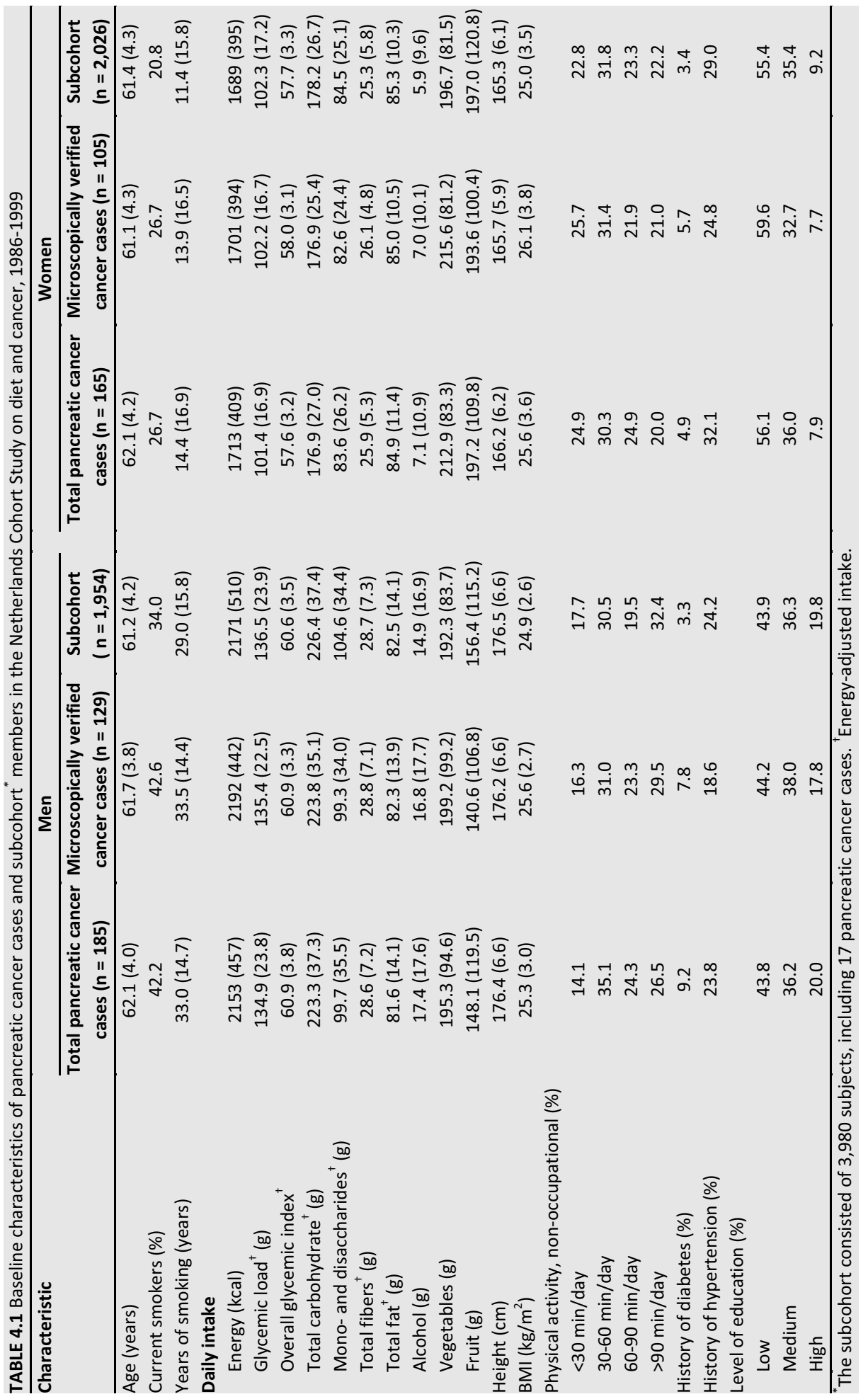


No association was found when examining the association between GL, GI, carbohydrate, mono- and disaccharide intake, and the risk of pancreatic cancer in the total population (Table 4.2). After the NMCPC cases were excluded, these findings remained. When looking at men and women separately, no significant associations were observed for GL, GI, and carbohydrate intake (data not shown). Among men, an inverse association was observed for mono- and disaccharide intake, showing a statistically significantly decreased risk of pancreatic cancer for the highest versus the lowest quintile of mono- and disaccharide intake in the multivariable-adjusted analyses $(\mathrm{RR}=0.56,95 \% \mathrm{Cl}: 0.33-0.97, \mathrm{p}$ for trend $=0.13)$. After the analyses were restricted to microscopically verified cases, this point estimate became non-significant ( $R R=0.64$. 95\% Cl: 0.34-1.01). Among women, no association was observed for mono- and disaccharide intake. Our findings remained the same after individuals who reported a history of diabetes at baseline were excluded from the analyses (325 cases left for analyses; data not shown), although the significant decreased risk with increased mono- and disaccharide intake observed in men became non-significant (multivariableadjusted $\mathrm{RR}=0.59,95 \% \mathrm{Cl}: 0.34-1.02$ ).

In additional analyses, we stratified by both BMI and physical activity level to test whether the risk estimates were more pronounced for overweight and inactive individuals. We observed no associations in the total pancreatic cancer case group (data not shown). When restricting the analyses to MCPC cancer cases (Table 4.3), we observed no associations for GI, but observed non-significantly inverse associations for GL, carbohydrate, and mono- and disaccharide intake among physically inactive and overweight people; among physically active and lean individuals, we observed nonsignificantly positive associations for these dietary measures. In addition, individuals who reported a history of diabetes at baseline were excluded from these analyses (218 cases left for analyses; data not shown). We observed a statistically significant 2-fold increased risk of pancreatic cancer for the highest versus the lowest tertile of GL ( $p$ for trend $=0.03$ ) among lean and physically active individuals. Among overweight and inactive individuals, we observed a statistically significant decreased pancreatic cancer risk for the highest versus the lowest tertile of mono- and disaccharide intake with an RR of 0.31 (95\% Cl: 0.10-0.93, p for trend $=0.03$ ). However, the multiplicative interaction terms for these stratified analyses were not statistically significant, although the interaction between mono- and disaccharide intake and the combined categories of BMI and physical activity, after exclusion of diabetics, was nearly significant $(p=0.06)$.

No associations were observed when we investigated whether an increased consumption of high-Gl food items, such as added sugar, soft drinks, sweet sandwich spreads (e.g., jam), and sweets, were associated with a higher risk of pancreatic cancer (data not shown). After the first 2 years of follow-up were excluded, the results were not substantially different (data not shown). 


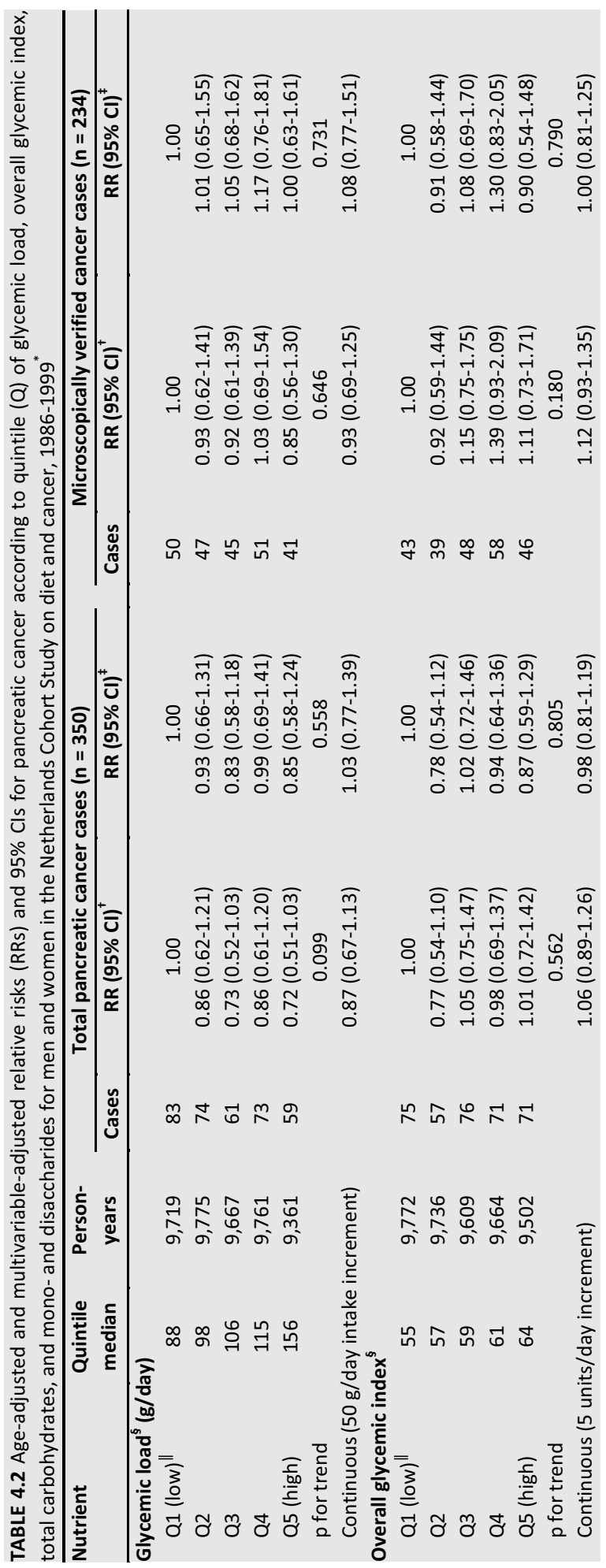




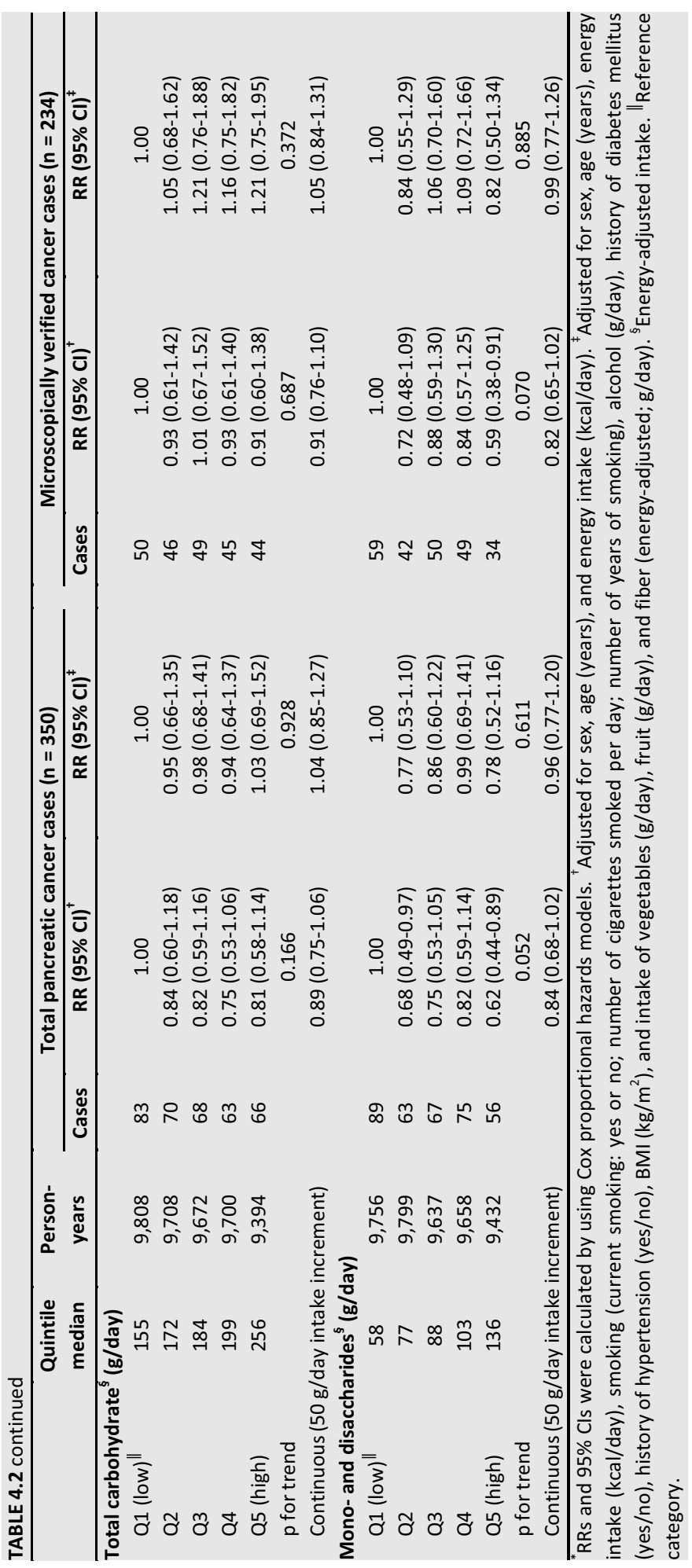




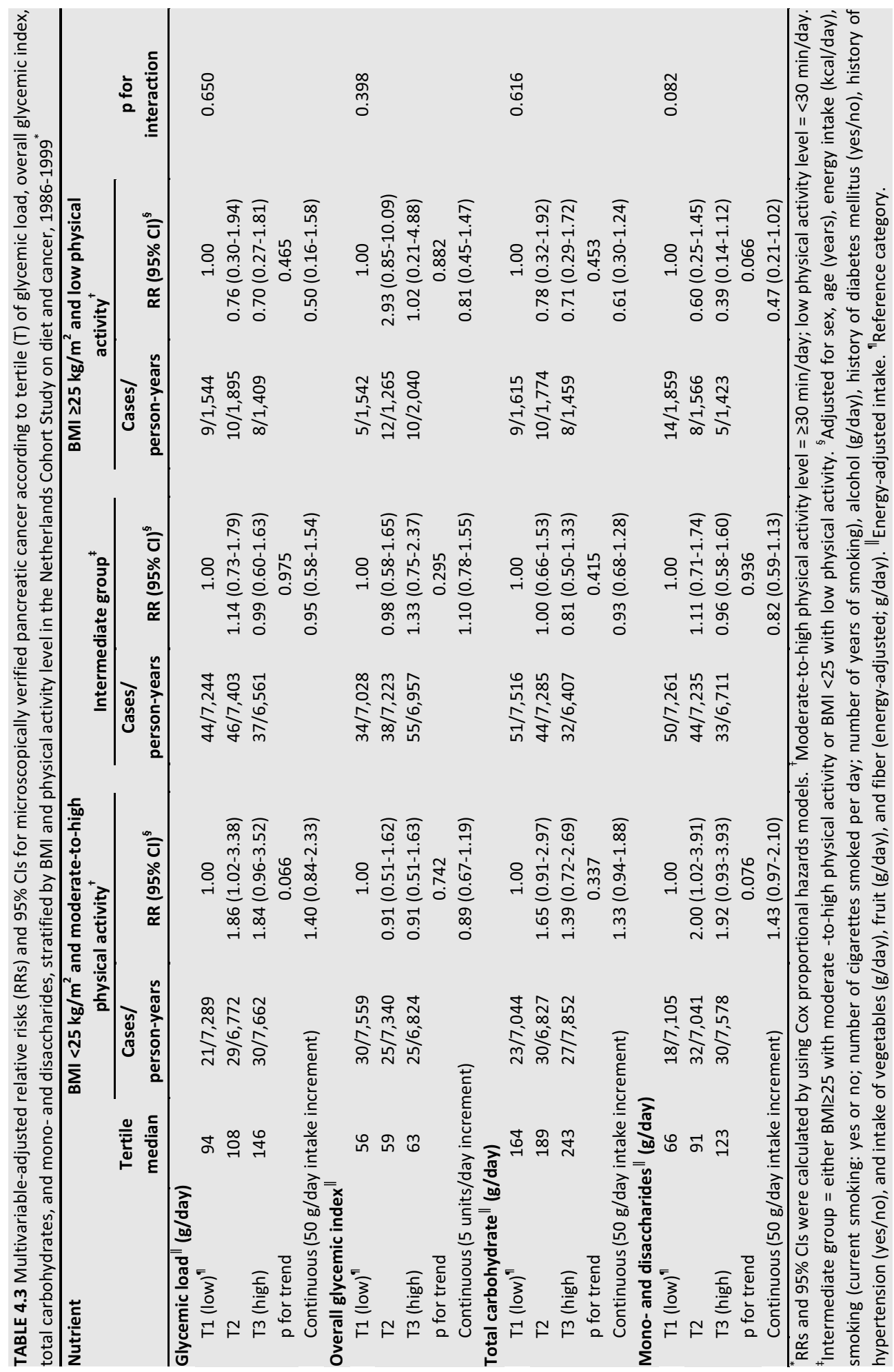




\section{DISCUSSION}

Our results suggest that high $\mathrm{GL}$ and $\mathrm{Gl}$ and a high intake of total carbohydrates are not associated with pancreatic cancer risk. These null findings are consistent with four prospective studies $^{14-17}$ and with five $e^{32-36}$ of seven ${ }^{32-38}$ previous case-control studies that examined GL or Gl and/or carbohydrate intake in relation to pancreatic cancer risk. As regards mono- and disaccharide intake, we found inverse associations for pancreatic cancer risk in men, although these became less pronounced when the analyses were restricted to MCPC cases only.

The 1980s dietary recommendations for diabetics no longer included low simple sugar intake, ${ }^{39,40}$ but probably not all diabetics and their practitioners were aware of these new guidelines at the time of our dietary data collection. ${ }^{40}$ Therefore, we excluded diabetics from our analyses. The observed inverse associations between increased mono- and disaccharide intake and pancreatic cancer risk in men became less pronounced, whereas all other findings remained the same. Eight studies have examined the intakes of simple (monosaccharide and disaccharide) sugars, ${ }^{34,41,42}$ refined sugars, ${ }^{35}$ or sucrose. ${ }^{14-16,32,42}$ Of these studies, just a few found an increased risk of pancreatic cancer. ${ }^{35,41}$

We also examined whether the association between high $\mathrm{GL}, \mathrm{Gl}$, and carbohydrate and mono- and disaccharide intake and the risk of pancreatic cancer is more pronounced for subjects who are overweight as well as inactive; we found no significant association between $\mathrm{Gl}$ and carbohydrate intake and pancreatic cancer risk. When the analyses were restricted to MCPC cases without diabetes, we observed a statistically significant decreased pancreatic cancer risk for mono- and disaccharide intake among overweight and inactive individuals. Only one previous study observed a nonsignificant inverse association between increased mono- and disaccharide intake and pancreatic cancer risk among male smokers, ${ }^{42}$ whereas two other studies ${ }^{34,41}$ did not observe such an association. This finding was unexpected and needs to be confirmed, preferably by other cohort studies. Michaud et al. ${ }^{15}$ reported a significantly positive association between pancreatic cancer risk and GL among obese and sedentary women. We were unable to reproduce this result and even found the opposite when the analyses were restricted to MCPC cases without diabetes. We observed a statistically significant increased risk of pancreatic cancer among lean and physically active individuals but no association among overweight and inactive individuals. This might have been due to a lack of power because of the small number of cases in the overweight and inactive group. This result should be interpreted with caution because this finding might have been due to chance because of the multiple comparisons that were made in the present study.

We observed no associations between increased intake of some high-Gl foods (e.g., added sugar, soft drinks, sweet sandwich spreads, and sweets) and pancreatic cancer risk. Very few studies have examined these relations, and they reported no 
associations for jam and marmalade ${ }^{43}$ and sweets, ${ }^{43}$ but positive associations for soft drinks $^{43,44}$ and added sugar. ${ }^{38,43}$

So far, findings from prospective studies investigating the relation between $\mathrm{GL}$ and $\mathrm{Gl}$ and several chronic conditions, such as type 2 diabetes, coronary heart disease, and breast and colorectal cancer, have been inconsistent, showing positive ${ }^{45-49}$ or $\mathrm{no}^{50-53}$ associations. Another study executed in this cohort, which examined the relation between $\mathrm{Gl}$ and GL and colorectal cancer risk, did not find an association. ${ }^{54}$

Considerable evidence from in vitro, animal, and human observational studies supports a role for insulin in pancreatic cancer etiology; therefore, the investigation of dietary factors that influence plasma insulin concentrations seems rational. The major rationale for using Gl values is based on the assumption that postprandial blood glucose responses and insulin responses are highly correlated, but some studies have shown an inconsistency in glucose and insulin responses. ${ }^{12,55}$ Also, whereas GI values are determined on single food items, people eat meals or snacks consisting not only of carbohydrates, but also of other macronutrients. Protein stimulates insulin release, despite an unchanged or even lower blood glucose concentration, compared with carbohydrates alone. ${ }^{12}$ Dietary fat inhibits gastric emptying, which in turn slows down the absorption of carbohydrates, ${ }^{12}$ which also gives rise to a lower postprandial blood glucose response. In addition, the amount of rapidly available glucose and resistant starch, the degree of osmolality, the viscosity of the gut's contents, are other important factors influencing the degree of postprandial insulin secretion. ${ }^{12}$

The possibility to further restrict the analyses to microscopically verified cases only, where misclassification by disease status would be less likely than among NMCPC cases, $^{56}$ was one of the strengths of this study. ${ }^{28}$ Other strengths included the large sample size and detailed information on potential risk factors for pancreatic cancer. Differential follow-up is unlikely to have made a material contribution to our findings, because the completeness of follow-up was high. ${ }^{21}$ The prospective design avoided recall bias and the need to use next-of-kin respondents, but non-differential misclassification of GL values could not be ruled out. However, because some main dietary nutrients and food items contributing to $\mathrm{Gl}$ and $\mathrm{GL}$ were in general moderately to highly correlated with both the $\mathrm{FFQ}^{22}$ and $\mathrm{GI}$ and $\mathrm{GL}$, the questionnaire most likely adequately ranked subjects according to $\mathrm{GL}$ and $\mathrm{GI}$ values.

A limitation of our study was the use of a single measure of dietary intake that may not have been representative of the dietary habits of the study participants over the course of follow-up. However, the FFQ was tested for reproducibility by Goldbohm et al., ${ }^{26}$ who concluded that a single measurement of dietary intake in the NLCS could characterize dietary habits for a period of at least 5 years. Our estimated GI values were lower and narrower in range and variation than values reported in other large cohorts, ${ }^{14-16,47}$ which may have yielded too little contrast between the highest and lowest quintiles to detect differences in pancreatic cancer risk. Another issue concerning the GI values should be mentioned. The GI values used for this FFQ were obtained from the table published by Foster-Powell et al., ${ }^{13}$ as has been used by others. Howev- 
er, this GI table contains mostly items from Australian or American foods and not from European foods. Recently, Henley et al. ${ }^{57}$ established GI values for a variety of foods available in the United Kingdom, which concluded that most GI values compared well with previously published values; ${ }^{13}$ however, a few values were notably different from those of Foster Powell et al. ${ }^{13}$ It remains to be established whether values determined for American and Australian food items can be applied to European foods.

In summary, our findings do not support the hypothesis that a high GL, overall GI, and carbohydrate and mono- and disaccharide intake are associated with an increased risk of pancreatic cancer. This finding agrees with previous prospective studies that investigated the relation between $\mathrm{GL}$ and $\mathrm{Gl}$ and pancreatic cancer risk. 


\section{REFERENCES}

1. Berrino F, Capocaccia R, Esteve J, et al., eds. Survival of cancer patients in Europe: the EUROCARE 2 study. IARC Scientific Publications No. 151. Lyon, France: International Agency for Research on Cancer, 1999.

2. Jemal A, Siegel R, Ward E, Murray T, Xu J, Thun MJ. Cancer statistics, 2007. CA Cancer J Clin 2007;57: 43-66.

3. Fuchs CS, Colditz GA, Stampfer MJ, et al. A prospective study of cigarette smoking and the risk of pancreatic cancer. Arch Intern Med 1996;156:2255-60.

4. Silverman DT, Dunn JA, Hoover RN, et al. Cigarette smoking and pancreas cancer: a case-control study based on direct interviews. J Natl Cancer Inst 1994;86:1510-6.

5. Huxley R, Ansary-Moghaddam A, Berrington de Gonzalez A, Barzi F, Woodward M. Type-II diabetes and pancreatic cancer: a meta-analysis of 36 studies. Br J Cancer 2005;92:2076-83.

6. Fisher WE, Boros LG, Schirmer WJ. Insulin promotes pancreatic cancer: evidence for endocrine influence on exocrine pancreatic tumors. J Surg Res 1996;63:310-3.

7. Kazakoff K, Cardesa T, Liu J, et al. Effects of voluntary physical exercise on high-fat diet-promoted pancreatic carcinogenesis in the hamster model. Nutr Cancer 1996;26:265-79.

8. Batty GD, Shipley MJ, Marmot M, Smith GD. Diabetes status and post-load plasma glucose concentration in relation to site-specific cancer mortality: findings from the original Whitehall study. Cancer Causes Control 2004;15:873-81.

9. Stolzenberg-Solomon RZ, Graubard BI, Chari S, et al. Insulin, glucose, insulin resistance, and pancreatic cancer in male smokers. Jama 2005;294:2872-8.

10. Kaaks R, Lukanova A. Energy balance and cancer: the role of insulin and insulin-like growth factor-I. Proc Nutr Soc 2001;60:91-106.

11. Jenkins DJ, Kendall CW, Augustin LS, et al. Glycemic index: overview of implications in health and disease. Am J Clin Nutr 2002;76:266S-73S.

12. Pi-Sunyer FX. Glycemic index and disease. Am J Clin Nutr 2002;76:290S-8S.

13. Foster-Powell K, Holt SH, Brand-Miller JC. International table of glycemic index and glycemic load values: 2002. Am J Clin Nutr 2002;76:5-56.

14. Patel AV, McCullough ML, Pavluck AL, Jacobs EJ, Thun MJ, Calle EE. Glycemic load, glycemic index, and carbohydrate intake in relation to pancreatic cancer risk in a large US cohort. Cancer Causes Control 2007;18:287-94.

15. Michaud DS, Liu S, Giovannucci E, Willett WC, Colditz GA, Fuchs CS. Dietary sugar, glycemic load, and pancreatic cancer risk in a prospective study. J Natl Cancer Inst 2002;94:1293-300.

16. Silvera SA, Rohan TE, Jain M, Terry PD, Howe GR, Miller AB. Glycemic index, glycemic load, and pancreatic cancer risk (Canada). Cancer Causes Control 2005;16:431-6.

17. Johnson KJ, Anderson KE, Harnack L, Hong CP, Folsom AR. No association between dietary glycemic index or load and pancreatic cancer incidence in postmenopausal women. Cancer Epidemiol Biomarkers Prev 2005;14:1574-5.

18. van den Brandt PA, Goldbohm RA, van 't Veer P, Volovics A, Hermus RJ, Sturmans F. A large-scale prospective cohort study on diet and cancer in The Netherlands. J Clin Epidemiol 1990;43:285-95.

19. Prentice RL. A case-cohort design for epidemiologic cohort studies and disease prevention trials. Biometrika 1986;73:1-11.

20. van den Brandt PA, Schouten LJ, Goldbohm RA, Dorant E, Hunen PM. Development of a record linkage protocol for use in the Dutch Cancer Registry for Epidemiological Research. Int J Epidemiol 1990;19: 553-8.

21. Goldbohm RA, van den Brandt PA, Dorant E. Estimation of the coverage of Dutch municipalities by cancer registries and PALGA based on hospital discharge data. Tijdschr Soc Gezondheidsz 1994;72: 80-4.

22. Goldbohm RA, van den Brandt PA, Brants HA, et al. Validation of a dietary questionnaire used in a large-scale prospective cohort study on diet and cancer. Eur J Clin Nutr 1994;48:253-65. 
23. van der Sanden GA, Coebergh JW, Schouten $\amalg$, Visser O, van Leeuwen FE. Cancer incidence in The Netherlands in 1989 and 1990: first results of the nationwide Netherlands cancer registry. Coordinating Committee for Regional Cancer Registries. Eur J Cancer 1995;31A:1822-9.

24. Anonymous. NEVO-tabel: Nederlands voedingsstoffenbestand 1986-1987 (Nevo table: Dutch Food Composition Table 1986-1987 [in Dutch]). The Hague, the Netherlands: Voorlichtingsbureau voor de voeding, 1986.

25. Bausch-Goldbohm RA, van den Brandt PA, van 't Veer P, Sturmans F, Hermus RJ. Results of the methodological study for the design of a simplified, self-administered questionnaire. In: Riboli E, Saracci R, eds. Diet, hormones and cancer: methodological issues for prospective studies. IARC Technical Report 4. Lyon, France: International Agency for Research on Cancer, 1988. P. 79-89.

26. Goldbohm RA, van 't Veer P, van den Brandt PA, et al. Reproducibility of a food frequency questionnaire and stability of dietary habits determined from five annually repeated measurements. Eur J Clin Nutr 1995;49:420-9.

27. Willett W. Implications of total energy intake for epidemiologic analyses. In: Willett W., ed. Nutritional Epidemiology. New York: Oxford University Press, 1998. P. 273-301.

28. Verhage BA, Schouten LJ, Goldbohm RA, van den Brandt PA. Anthropometry and pancreatic cancer risk: an illustration of the importance of microscopic verification. Cancer Epidemiol Biomarkers Prev 2007;16:1449-54.

29. Volovics A, van den Brandt PA. Methods for the analysis of case-cohort studies. Biom J 1997;39: 195-214.

30. Barlow WE, Ichikawa L, Rosner D, Izumi S. Analysis of case-cohort designs. J Clin Epidemiol 1999;52: 1165-72.

31. Schoenfeld D. Partial residuals for the proportional hazards regression model. Biometrika 1982;69: 239-41.

32. Kalapothaki V, Tzonou A, Hsieh CC, et al. Nutrient intake and cancer of the pancreas: a case-control study in Athens, Greece. Cancer Causes Control 1993;4:383-9.

33. Olsen GW, Mandel JS, Gibson RW, Wattenberg LW, Schuman LM. Nutrients and pancreatic cancer: a population-based case-control study. Cancer Causes Control 1991;2:291-7.

34. Silverman DT, Swanson CA, Gridley G, et al. Dietary and nutritional factors and pancreatic cancer: a case-control study based on direct interviews. J Natl Cancer Inst 1998;90:1710-9.

35. Baghurst PA, McMichael AJ, Slavotinek AH, Baghurst KI, Boyle P, Walker AM. A case-control study of diet and cancer of the pancreas. Am J Epidemiol 1991;134:167-79.

36. Ghadirian P, Simard A, Baillargeon J, Maisonneuve P, Boyle P. Nutritional factors and pancreatic cancer in the francophone community in Montreal, Canada. Int J Cancer 1991;47:1-6.

37. Howe GR, Jain M, Miller AB. Dietary factors and risk of pancreatic cancer: results of a Canadian population-based case-control study. Int J Cancer 1990;45:604-8.

38. Lyon JL, Slattery ML, Mahoney AW, Robison LM. Dietary intake as a risk factor for cancer of the exocrine pancreas. Cancer Epidemiol Biomarkers Prev 1993;2:513-8.

39. Anonymous. Advies richtlijnen goede voeding (Dietary reference intakes [in Dutch]). The Hague, the Netherlands: Nutrition Council of the Netherlands, 1986.

40. Schouten JA, Heine RJ. De voeding bij diabetes onder normale omstandigheden (Nutrition in diabetics under normal circumstances). In: van den Bogaard PJMA, Dankmeijer HF, Edema JMP, et al., eds. Voeding en diabetes (Nutrition and diabetes mellitus [in Dutch]). Alphen aan den Rijn, the Netherlands: Samsom, 1984.

41. Bueno de Mesquita HB, Moerman CJ, Runia S, Maisonneuve P. Are energy and energy-providing nutrients related to exocrine carcinoma of the pancreas? Int J Cancer 1990;46:435-44.

42. Stolzenberg-Solomon RZ, Pietinen P, Taylor PR, Virtamo J, Albanes D. Stolzenberg-Solomon et al. Respond to "What Do We Know about Pancreas Cancer?" by Potter. Am J Epidemiol 2002;155:796-7.

43. Larsson SC, Bergkvist L, Wolk A. Consumption of sugar and sugar-sweetened foods and the risk of pancreatic cancer in a prospective study. Am J Clin Nutr 2006;84:1171-6.

44. Schernhammer ES, Hu FB, Giovannucci E, et al. Sugar-sweetened soft drink consumption and risk of pancreatic cancer in two prospective cohorts. Cancer Epidemiol Biomarkers Prev 2005;14:2098-105. 
45. Schulze MB, Liu S, Rimm EB, Manson JE, Willett WC, Hu FB. Glycemic index, glycemic load, and dietary fiber intake and incidence of type 2 diabetes in younger and middle-aged women. Am J Clin Nutr 2004; 80:348-56.

46. Salmeron J, Manson JE, Stampfer MJ, Colditz GA, Wing AL, Willett WC. Dietary fiber, glycemic load, and risk of non-insulin-dependent diabetes mellitus in women. Jama 1997;277:472-7.

47. Liu S, Willett WC, Stampfer MJ, et al. A prospective study of dietary glycemic load, carbohydrate intake, and risk of coronary heart disease in US women. Am J Clin Nutr 2000;71:1455-61.

48. Michaud DS, Fuchs CS, Liu S, Willett WC, Colditz GA, Giovannucci E. Dietary glycemic load, carbohydrate, sugar, and colorectal cancer risk in men and women. Cancer Epidemiol Biomarkers Prev 2005; 14: 138-47.

49. Silvera SA, Jain M, Howe GR, Miller AB, Rohan TE. Dietary carbohydrates and breast cancer risk: a prospective study of the roles of overall glycemic index and glycemic load. Int J Cancer 2005;114: 653-8.

50. van Dam RM, Visscher AW, Feskens EJ, Verhoef P, Kromhout D. Dietary glycemic index in relation to metabolic risk factors and incidence of coronary heart disease: the Zutphen Elderly Study. Eur J Clin Nutr 2000;54:726-31.

51. Meyer KA, Kushi LH, Jacobs DR, Jr., Slavin J, Sellers TA, Folsom AR. Carbohydrates, dietary fiber, and incident type 2 diabetes in older women. Am J Clin Nutr 2000;71:921-30.

52. Nielsen TG, Olsen A, Christensen J, Overvad K, Tjonneland A. Dietary carbohydrate intake is not associated with the breast cancer incidence rate ratio in postmenopausal Danish women. J Nutr 2005;135: 124-8.

53. Holmes MD, Liu S, Hankinson SE, Colditz GA, Hunter DJ, Willett WC. Dietary carbohydrates, fiber, and breast cancer risk. Am J Epidemiol 2004;159:732-9.

54. Weijenberg MP, Mullie PFF, Brants HAM, Heinen MM, Goldbohm RA, van den Brandt PA. Dietary glycemic load, glycemic index and colorectal cancer risk: results from the Netherlands Cohort Study. Int J Cancer 2008;122:620-9.

55. Flint A, Moller BK, Raben A, et al. The use of glycaemic index tables to predict glycaemic index of composite breakfast meals. Br J Nutr 2004;91:979-89.

56. Silverman DT, Schiffman M, Devesa S. Diagnostic certainty in pancreatic cancer. J Clin Epidemiol 1996; 49:601-3.

57. Henry CJ, Lightowler HJ, Strik CM, Renton H, Hails S. Glycaemic index and glycaemic load values of commercially available products in the UK. Br J Nutr 2005;94:922-30. 


\section{Meat and fat intake and pancreatic cancer risk in the Netherlands Cohort Study}

Mirjam M. Heinen

Bas A.J. Verhage

R. Alexandra Goldbohm

Piet A. van den Brandt 


\section{ABSTRACT}

Meat contains numerous carcinogens, such as heterocyclic amines, polycyclic aromatic hydrocarbons, and $\mathrm{N}$-nitroso compounds, which can be derived either from natural food or during the process of food preparation. These carcinogens may increase pancreatic cancer risk. Furthermore, studies in animals showed that polyunsaturated fatty acids, especially linoleic acid, increase pancreatic cancer risk. We examined prospectively the relation between pancreatic cancer risk and intake of fresh meat, processed meat, fish, eggs, total fat, and different types of fat. The Netherlands Cohort Study consisted of 120,852 men and women who completed a baseline questionnaire in 1986. After 13.3 years of follow-up, 350 pancreatic cancer cases (66\% microscopically confirmed) were available for analysis. A validated 150 -item food frequency questionnaire was used to calculate intake of fresh meat, processed meat, fish, eggs, fat and different types of fat. No association was found when examining the association between intake of fresh meat, other types of meat, fish, eggs, dietary intake of total fat and different types of fat and risk of pancreatic cancer. It is important for future studies to investigate the relation between different meat-cooking methods and pancreatic cancer. 


\section{INTRODUCTION}

Pancreatic cancer is among the most rapidly fatal cancers worldwide, with a 5-year survival rate of $6 \%$ or less. ${ }^{1,2}$ Since there is no effective way to screen for this malignancy, prevention could have a major impact on pancreatic cancer mortality. So far, cigarette smoking, diabetes mellitus, and body fatness are identified as risk factors. ${ }^{3-5}$

Based on ecological studies, international variation in incidence rates of pancreatic cancer suggested that per capita intakes of animal protein, fat, and eggs were positively related to this type of cancer. ${ }^{6,7}$ Since then, numerous epidemiological studies have investigated the relation between meat, eggs, and different types of fat and pancreatic cancer, including 15 prospective cohort studies ${ }^{3,6,8-12}$ and 31 case-control studies. $^{3,6,13-19}$ In a recent Expert Panel Report, it was concluded that there is limited evidence suggesting that red meat is a cause of pancreatic cancer in humans. ${ }^{3}$ Data on processed meat, chicken, fish, eggs, dietary fat, and specific fatty acids were either of too low quality, too inconsistent, or the number of studies too few to allow conclusions to be reached.

Meat contains numerous carcinogens, such as heterocyclic amines (HCAs), polycyclic aromatic hydrocarbons (PAHs), and $\mathrm{N}$-nitroso compounds, which can be derived either from natural food or during the process of food preparation. These carcinogens may increase pancreatic cancer risk. ${ }^{3,20,21}$ Regarding dietary fat, studies in animals showed that diets high in fat increased the risk of pancreatic cancer compared to lowfat diets, ${ }^{22}$ and suggested that polyunsaturated fatty acids (PUFA), especially linoleic acid (LA), increases pancreatic cancer risk. ${ }^{22,23}$

Therefore, we investigated the association between intakes of fresh meat, processed meat, fish, and eggs, and dietary intake of fat and specific fatty acids, and the risk of pancreatic cancer in a large prospective cohort study in the Netherlands.

\section{MATERIAL AND METHODS}

\section{Study population and cancer follow-up}

The study design of the Netherlands Cohort Study (NLCS) has been reported in detail elsewhere. ${ }^{24}$ Briefly, the NLCS was initiated in September 1986 and includes 58,279 men and 62,573 women aged 55-69 years at the beginning of the study, originating from 204 municipalities with computerized population registries. A self-administered questionnaire on dietary habits, lifestyle characteristics, medical history, and other potential risk factors for cancer was completed at baseline. For reasons of efficiency in questionnaire processing (which was very detailed and included open-ended questions) and follow-up, the case-cohort approach was used (weighting of study subjects based on Prentice's method). ${ }^{25}$ Case subjects were derived from the entire cohort, whereas the person-years at risk were estimated from a random sample of 5,000 subjects (2,411 men and 2,589 women). This subcohort was chosen immediately after 
baseline and followed up for vital status information. The entire cohort is being monitored for cancer occurrence by annual record linkage to the Netherlands Cancer Registry and the Netherlands Pathology Registry. ${ }^{26,27}$ The completeness of cancer follow-up through linkage with the Netherlands Cancer Registry was estimated to be $>96 \% .{ }^{28}$ The follow-up was restricted to the period from baseline to December 1999, a total of 13.3 years. Only two subcohort members were lost to follow-up at the end of the follow-up period.

For cases and subcohort members, all prevalent cancer cases at baseline other than non-melanoma skin cancer were excluded. Additionally, subjects with incomplete or inconsistent dietary data were excluded from the analyses as well. These subjects had either (i) left $>60$ (of the 150 items) questionnaire items blank and ate $<35$ items at least once a month or (ii) left one or more item blocks (grouping of items, e.g., beverages) blank. Additional details are given elsewhere. ${ }^{29}$ of the incident pancreatic cancer cases, all endocrine subtypes based on histology were excluded (Islet-cell carcinomas, $n=1$ ). This resulted in a subcohort of 4,438 subjects (including 19 pancreatic cancer cases) and 408 exocrine pancreatic cancer cases. The NLCS has been approved by the institutional review boards of the TNO Nutrition and Food Research Institute (Zeist, the Netherlands) and Maastricht University (Maastricht, the Netherlands).

\section{Questionnaire}

The dietary section of the questionnaire was a 150-item semiquantitative food frequency questionnaire (FFQ), which concentrated on the habitual consumption of food and beverages during the year preceding the start of the study. Questionnaire data were key-entered and processed for all incident cases in the cohort and subcohort members in a standardized manner, blinded with respect to case/subcohort status. This was done to minimize observer bias in the coding and interpretation of the data. Daily mean nutrient intakes were calculated by summing the multiplied frequencies and serving sizes of all food items with their tabulated nutrient contents from the Dutch food composition table. ${ }^{30}$

Intake of specific fatty acids was based on a separate database with specific fatty acids derived from the TRANSFAIR study. ${ }^{31,32}$ In the database used for the NLCS, the concentrations of fatty acids were based on the concentrations before 1995, when changes in the trans content of manufactured products, such as margarines, led to a substantial decrease in the intake of trans unsaturated fatty acids.

Average daily intakes of meat, fish and eggs were calculated by multiplying the intake frequency of individual items by their weights, using either standard serving sizes or reported portion sizes, and summing over the items within these food groups. Fresh meat consisted of the following items: beef, pork, minced meat (including beef and pork), chicken (including chicken and turkey), liver, and other meat (e.g., horsemeat, lamb). Fresh red meat consisted of the fresh meat items minus the chicken item. Coding of fresh meat items was based on raw weight to take into account the amount of fat originally present in the meat but eventually ending up into the gravy, which is 
usually consumed as well. Processed meat was defined as meat items that had undergone some form of preservation (mostly treatment with nitrite salt, sometimes smoked or fermented).

The FFQ had been validated and tested for reproducibility. ${ }^{29,33}$ Crude (energy- and gender-adjusted between brackets) Pearson correlation coefficients $(r)$ between the 9day diet record and the questionnaire were 0.74 for energy, $0.72(0.52)$ for total fat, $0.73(0.58)$ for saturated fatty acids (SFA), $0.73(0.75)$ for PUFA, $0.66(0.62)$ for cholesterol, and $0.61(0.59)$ for protein. The Spearman correlation coefficients for fresh meat, processed meat, and fish were $0.46,0.54$, and 0.53 , respectively. ${ }^{29}$

\section{Statistical analysis}

Exposure variables in our analyses included the intake (in g/day) of fresh meat, fresh red meat, beef, pork, minced meat, chicken, liver, processed meat, fish, eggs, total fat, vegetable fat, fat from meat, SFA, monounsaturated fatty acids (MUFA), PUFA, cholesterol (in $\mathrm{mg} /$ day), trans unsaturated fatty acids, and specific fatty acids, including LA, linolenic acid, eicosapentaenoic acid (EPA) and docosahexaenoic acid (DHA). Because red meat is the main source of iron and heme, and because serum iron levels were directly related to pancreatic cancer in an exploratory case-control study, ${ }^{34}$ we examined total iron and heme intake. ${ }^{35}$ Other exposure variables were protein (total, vegetable and animal) and nitrite. Intake of fat, specific fatty acids, and protein were all adjusted for energy intake by the residual method. ${ }^{36}$

All analyses were conducted for both sexes combined and separately for men and women. Age-adjusted and multivariable-adjusted incidence relative risks (RRs) and corresponding $95 \%$ confidence intervals (95\% Cls) were estimated using Cox proportional hazards models. The total person-years at risk, estimated from the subcohort, were used in the analyses. ${ }^{37}$ Standard errors were estimated using the robust HuberWhite sandwich estimator to account for additional variance introduced by sampling from the cohort. ${ }^{38}$ The proportional hazards assumption was tested using the scaled Schoenfeld residuals. ${ }^{39}$ In case, the proportional hazards assumption was violated with respect to the determinant of primary interest, the follow-up period was stratified into three categories $(<5 ; 5-10 ; \geq 10$ years of follow-up) and a test for interaction between the determinant and time was calculated to investigate further whether the risk estimates changed during follow-up. Subjects were classified into quintiles of consumption (with the lowest quintile of intake regarded as the reference group) based on the gender-specific distribution in the subcohort and as continuous variables. The latter were reported in representative serving sizes, e.g., one serving size was defined as: 100 $\mathrm{g} /$ week for meat, $15 \mathrm{~g} /$ day for processed meat, $120 \mathrm{~g} /$ week for fish, and $50 \mathrm{~g} /$ week for eggs. For some variables, categories were used instead of quintiles. For liver intake categories, there were a non-user and a user group ( $>0 \mathrm{~g} /$ day). For chicken and fish, intake categories were a non-user and three user categories (0-13.2, 13.2-22.8, and $\geq 22.8 \mathrm{~g} /$ day for chicken; $0-10,10-20$, and $\geq 20 \mathrm{~g} /$ day for fish). For eggs, intake categories were three user groups ( $\leq 1,2-3$, and $\geq 4$ eggs/week). 
Based on literature, the following variables were considered as potential confounders: age, gender, smoking, body mass index (BMI), alcohol intake, intake of vegetables and fruit, level of education, moderate non-occupational physical activity, family history of pancreatic cancer, history of diabetes mellitus, hypertension, gall-stones, cholecystectomy, and gastric ulcer. These potential confounding variables were added to the multivariable-adjusted model if they $(i)$ were associated with the disease and with total fresh meat and energy-adjusted fat intake and (ii) changed the risk estimate by at least $10 \%$ (using a backwards stepwise procedure) resulting in a multivariable-adjusted model including age at baseline (years), gender, cigarette smoking (current smoking: yes/no; number of cigarettes smoked per day; number of years of smoking), BMI $\left(\mathrm{kg} / \mathrm{m}^{2}\right)$, alcohol intake $(0,0.1-4,5-14,15-29$, and $\geq 30 \mathrm{~g} /$ day), history of diabetes mellitus (yes/no), history of hypertension (yes/no), intake of vegetables (g/day) and fruit (g/day). Total energy intake ( $\mathrm{kcal} / \mathrm{day}$ ) was included in both the age- as well as in the multivariable-adjusted model. ${ }^{36}$ The RRs for energy-adjusted total fat and fatty acids can be interpreted as the effect of an increase in these variables relative to a decrease of an equivalent amount of energy from other energy delivering nutrients (i.e., substituting these exposure nutrients for other energy delivering nutrients). In addition, to assess the independent contribution of SFA, MUFA, PUFA, and each specific fatty acid, total fat intake was also included in the multivariable-adjusted model.

To enable comparison, age- and gender-adjusted analyses were restricted to subjects included in multivariable-adjusted analyses (e.g., with no missing values on confounding variables), leaving 3,980 subcohort members (1,954 men and 2,026 women) and 350 exocrine pancreatic cancer cases (185 men and 165 women) for analyses. Sixty seven percent of all pancreatic cancer cases were microscopically confirmed pancreatic cancer (MCPC; $n=234$ ), whereas 33\% were non-microscopically confirmed pancreatic cancer (NMCPC, $\mathrm{n}=116$ ).

For each analysis, trends were evaluated with the Wald test by assigning participants the median value for each level of the categorical exposure variable among the subcohort members and this variable was entered as a continuous term in the Cox regression model.

In the present study the overall analyses were performed on all pancreatic cancer cases. Additional analyses were restricted to MCPC cases, in order to create a group with a higher degree of diagnostic certainty of pancreatic cancer, which was shown to be of importance in previous analyses. ${ }^{40}$

In additional analyses, individuals who reported a history of diabetes at baseline ( $n=159$ ) were excluded. To evaluate whether early symptoms of disease before diagnosis could have influenced the results, early cases (diagnosed within 2 years after baseline) were excluded in additional analyses. We also investigated whether or not individuals that reported to have consumed equal number of eggs or equal amounts of fresh meat and processed meat 5 years before baseline compared to baseline eating habits, had different risk estimates than the total population. All analyses were performed using the STATA statistical software package (intercooled STATA, version 9; 
Stata Corporation, College Station, TX). All $p$ values were based on two-sided tests and considered statistically significant if $<0.05$.

\section{RESULTS}

In Table 5.1, baseline characteristics (stratified by gender) are presented. Most characteristics did not differ between pancreatic cancer cases and subcohort members; however, there were more subjects with a family history of pancreatic cancer among cases than among subcohort members, especially in women. In men, there were more diabetics and smokers among pancreatic cancer cases than among subcohort members. In Table 5.2, baseline dietary intakes of the exposures of interest are presented. No clear differences between cases and subcohort members were observed. The mean age at diagnosis $( \pm S D)$ and median survival time for MCPC cases was $69.5( \pm 5.0)$ years and 2.9 months, respectively. For NMCPC cases, mean age at diagnosis and median survival time was 72.1 ( \pm 5.5 ) years and 4.5 months, respectively.

After adjustment for age and gender, no association was found when examining the association between the intake of total fresh meat, beef, pork, minced meat, liver, chicken, processed meat, fish, and eggs and the risk of pancreatic cancer in the total population (Table 5.3). These findings remained after inclusion of the confounding variables in the multivariable model. In addition, excluding NMCPC cases did not change the risk estimates appreciably. For fresh red meat, an inverse association was observed among microscopically verified cases, showing a statistically significant decreased risk of pancreatic cancer for the highest versus the lowest quintile of red meat intake in the multivariable model (Table 5.3). Also a statistically significant decreased pancreatic cancer risk per increment of $100 \mathrm{~g}$ of red meat intake per week was observed. Although, it should be mentioned that for red meat the proportional hazards assumption was violated. When stratifying the follow-up period into three categories (data not shown), only after 10 years of follow-up a significant decreased risk was observed for the highest versus lowest tertile (multivariable $\mathrm{RR}=0.37,95 \% \mathrm{Cl}$ : 0.18-0.76, $p$ for trend $=0.01$ ). We observed no significant interaction with time ( $p$ for interaction $=0.18$ ) and no decreased risk of such magnitude was seen in the total pancreatic cancer case group. 


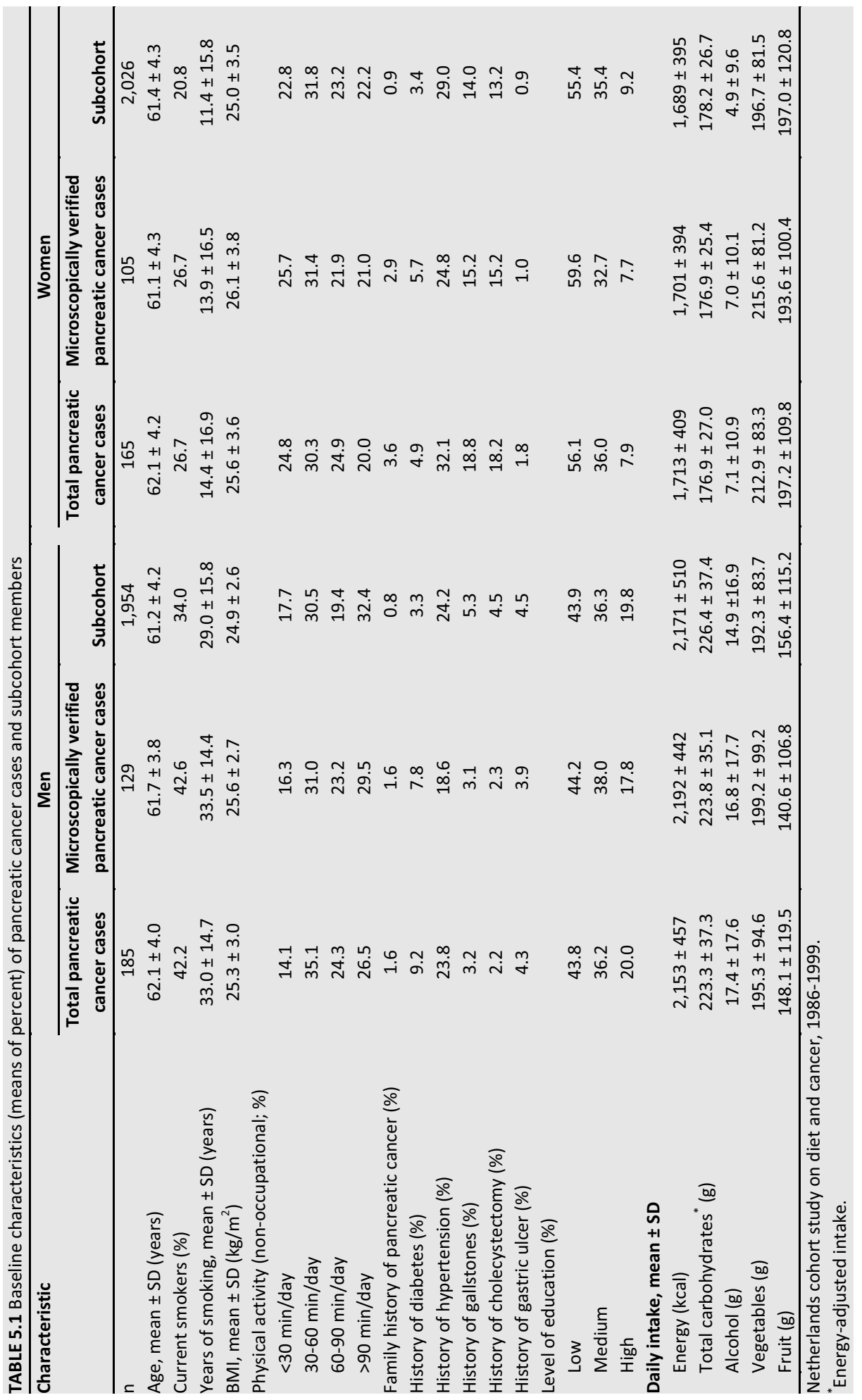




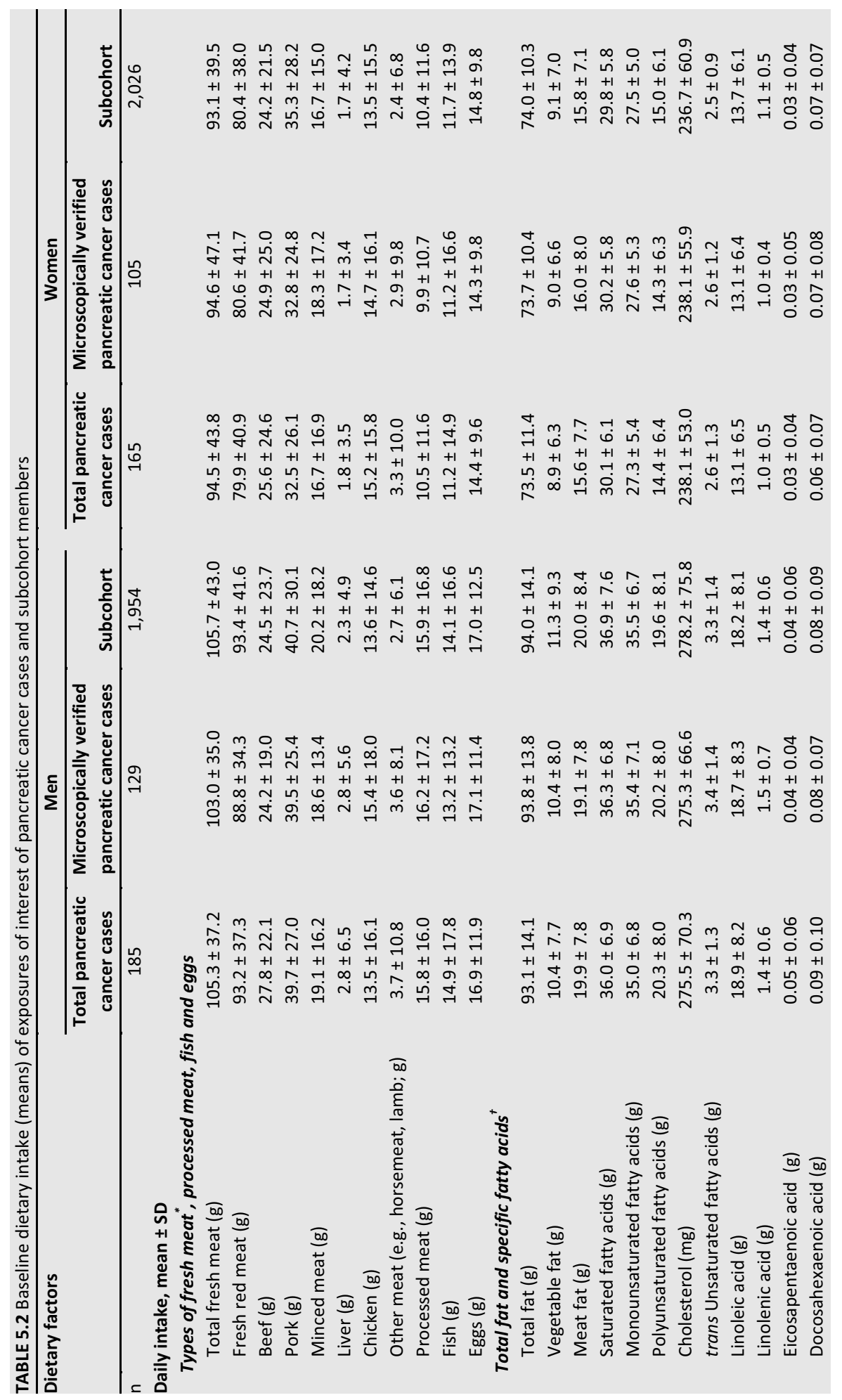




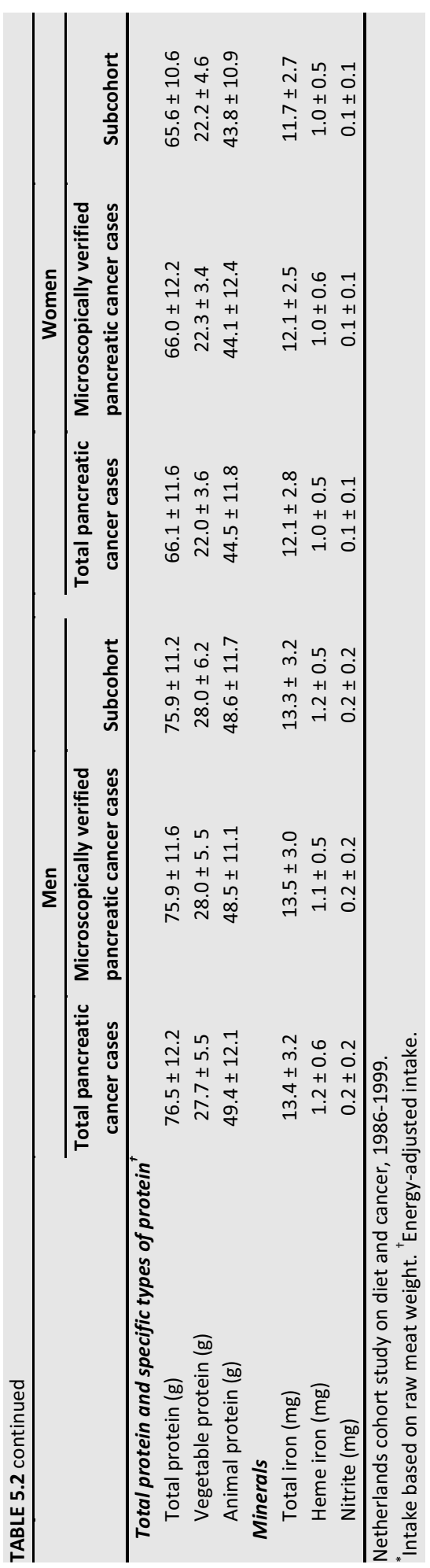


In additional analyses, we investigated whether or not individuals who reported to have consumed equal number of eggs or equal amounts of fresh meat and processed meat 5 years preceding baseline compared to baseline, showed different risk estimates. This was not the case, although among microscopically verified cases ( $n=175)$, multivariable-adjusted red meat intake still showed an inverse association, but this was no longer significant (highest versus lowest quintile $\mathrm{RR}=0.61,95 \% \mathrm{Cl}: 0.34-1.08$ ). Here the proportional hazards assumption was not violated anymore.

No association was found when examining the association between the risk of pancreatic cancer in the total population and the dietary intake of total fat, vegetable fat, SFA, MUFA, PUFA, cholesterol, trans unsaturated fatty acids, LA, linolenic acid, EPA, and DHA in the age- and gender-adjusted or multivariable-adjusted model (Table 5.4). After excluding NMCPC cases, these findings remained. For fat from meat, we observed a significantly decreased risk comparing the highest quintile with the lowest (Table 5.4) after multivariable-adjustment. In addition, a decreased pancreatic cancer risk was observed per isocaloric increment of $10 \mathrm{~g}$ of meat fat per day, but this was not statistically significant.

We did not observe any association between the intake of protein, total iron, heme and nitrite and pancreatic cancer risk (data not shown). Our findings remained the same when looking at men and women separately and after excluding individuals who reported a history of diabetes at baseline from the analyses (data not shown). After excluding the first 2 years of follow-up, the results were not substantially different (data not shown), although per isocaloric increment of $10 \mathrm{~g}$ of meat fat intake per day the decreased risk estimate for pancreatic cancer became significant (multivariable $\mathrm{RR}=0.81,95 \% \mathrm{Cl}: 0.67-0.98)$.

\section{DISCUSSION}

In the present study no association was observed between the intake of total fresh meat, beef, pork, minced meat, chicken, liver, and eggs and pancreatic cancer risk. So far, inconsistent findings have been observed in humans concerning meat intake. ${ }^{3}$

To date, 11 cohort studies have investigated the relation between the intake of total meat, different meat types and eggs and pancreatic cancer risk. ${ }^{3,6,8-12}$ Two studies have observed a positive association with total meat intake, ${ }^{3,11}$ the Multiethnic Cohort Study has observed increased risks with the intake of beef and pork, ${ }^{3}$ and a cohort among $7^{\text {th }}$-day Adventists has observed a positive association with egg intake. ${ }^{3}$ Inverse associations were observed with the intake of pork in a study of Swedish twins ${ }^{8}$ and with the intake of poultry among Swedish women. ${ }^{3}$ Other cohort studies did not observe an association with pancreatic cancer risk. ${ }^{3,6,9,10,12}$ 


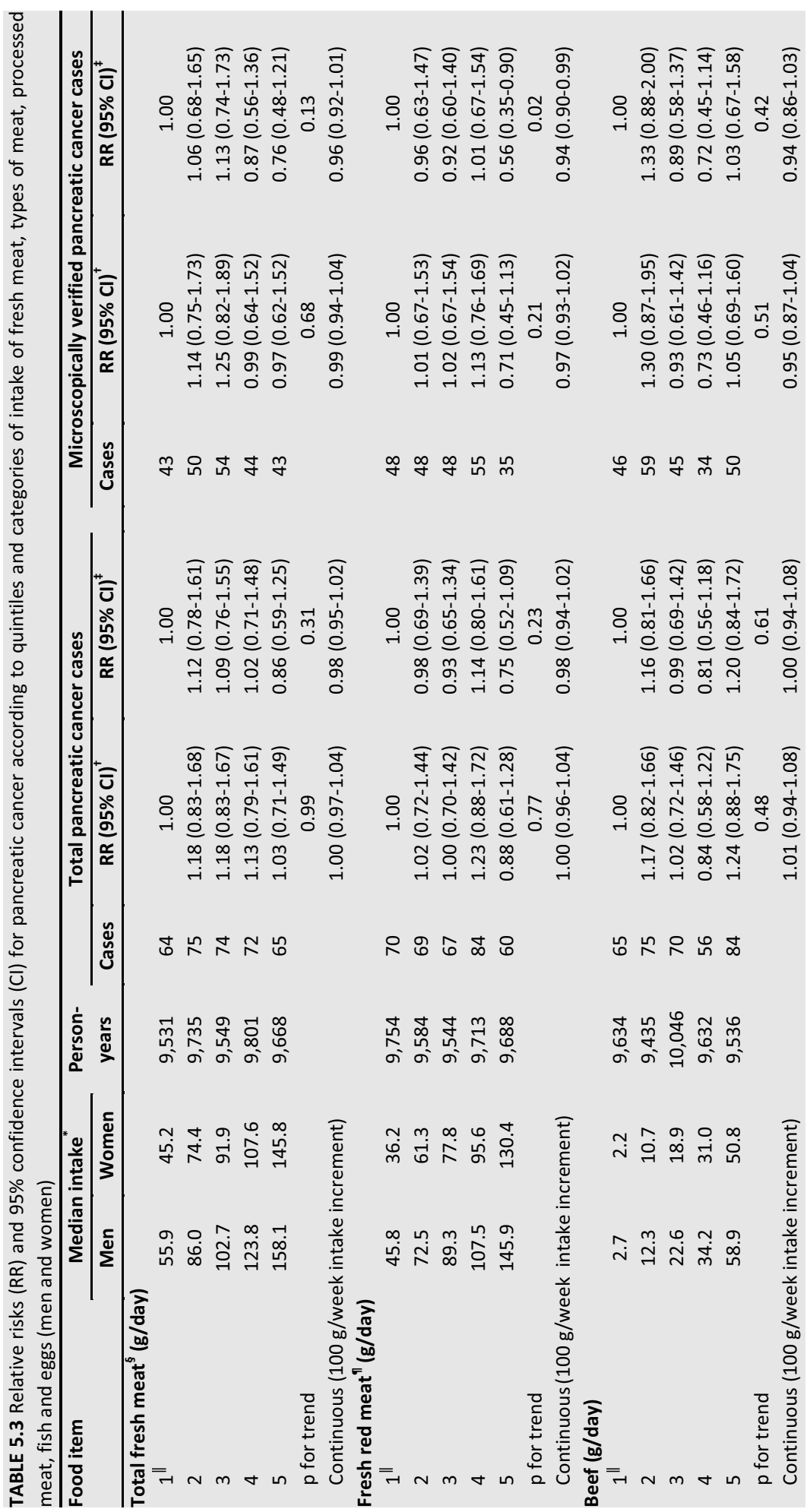




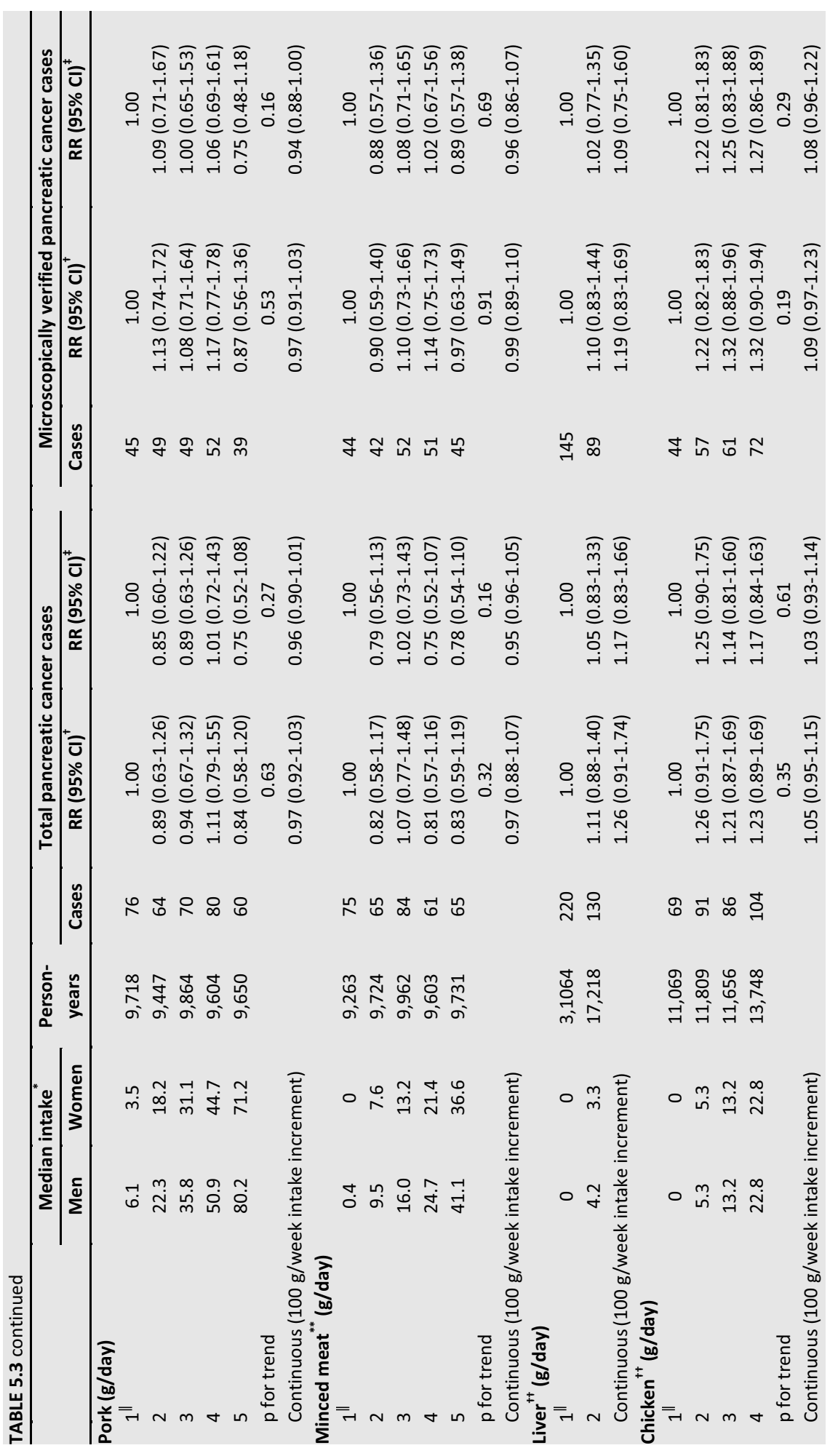




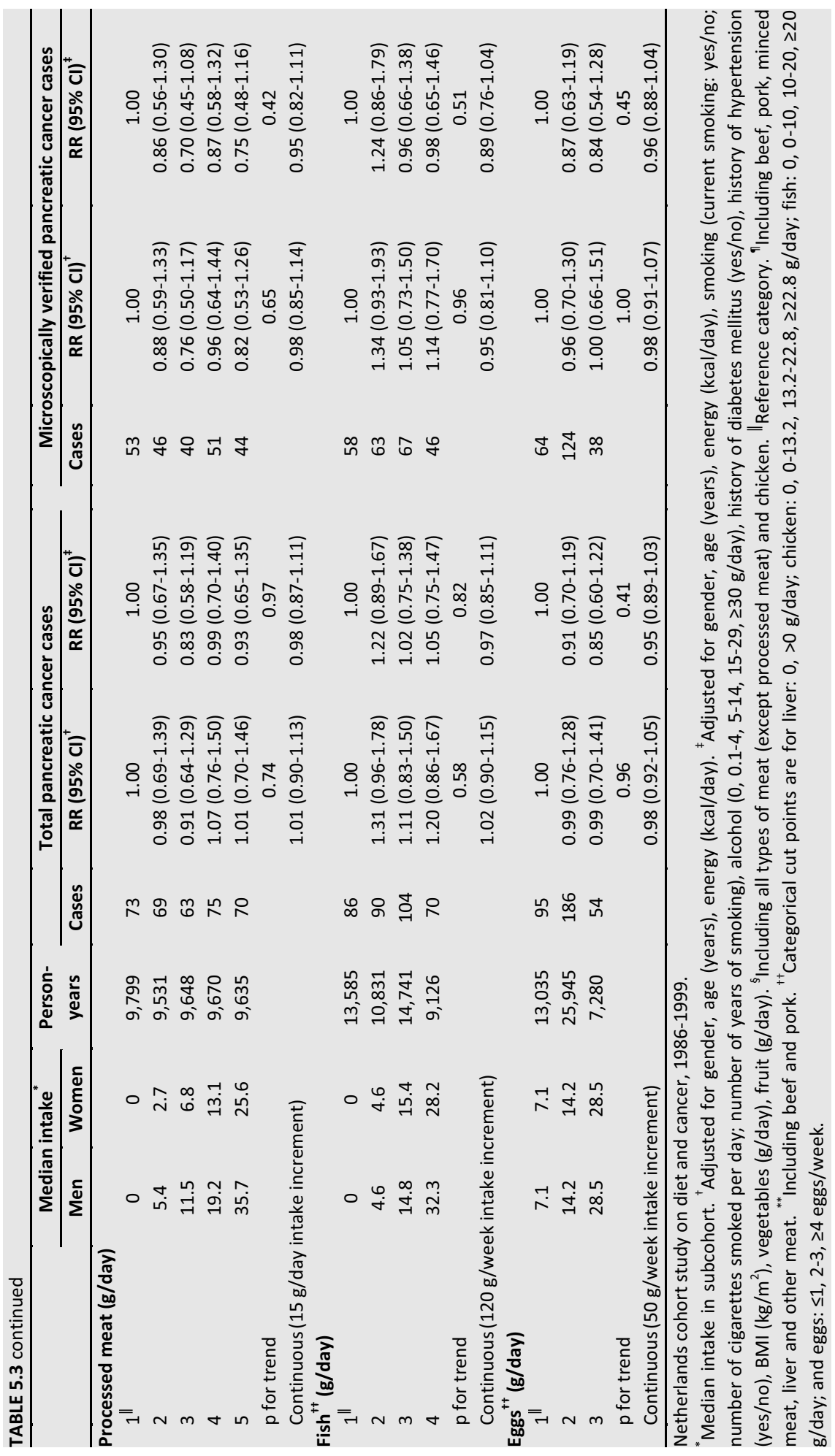


Findings in the 20 case-control studies, examining the relation between the intake of meat and eggs and pancreatic cancer risk, ${ }^{3,6,13-16,19}$ were even more diverse. On one hand, positive associations with meat intake were observed in at least eight casecontrol studies. The meat items reported in these studies were total meat, ${ }^{3,16}$ beef, ${ }^{3,6,15,16}$ pork, $^{3}$ chicken, ${ }^{16}$ and liver. ${ }^{3}$ On the other hand, inverse associations were observed with the intake of different kinds of animal products, including total meat (including fish and processed meat), white meat (chicken and fish), and chicken.,15 Regarding egg intake, both positive $e^{3,14,15}$ and inverse associations ${ }^{3}$ have been observed. However, because pancreatic cancer is rapidly fatal, many case-control studies have relied on next-of-kin interviews to determine exposures, which may have introduced differential misclassification of the exposure in these types of study.

During the process of food preparation, numerous carcinogens are produced. Heterocyclic amines (HCAs) are formed by cooking meat at high temperature. Grilling or barbecuing meat and fish with intense heat over a direct flame, results in fat dripping on the hot fire; this produces polycyclic aromatic hydrocarbons (PAHs) that stick to the surface of the food. ${ }^{20,21}$ In our study, the true association might be masked since we could not investigate the association between meat-cooking methods and pancreatic cancer. In the original FFQ of this cohort, data on meat preparation was not collected. Future studies should carefully distinguish cooking methods to investigate the extent to which different cooking methods are associated with pancreatic carcinogenesis. Some observational studies have already evaluated meat-cooking methods. A Finnish cohort of male smokers (ATBC Study) has observed no association with fried meat intake, ${ }^{12}$ whereas four case-control studies have observed positive associations with higher consumption of grilled and fried foods, such as meat. ${ }^{6,16,19}$ Recently, two epidemiological studies specifically assessed meat-cooking methods with respect to pancreatic cancer risk, finding positive associations with the intake of grilled/barbecued meat, high-temperature cooked meat, and broiled meat, but not with meat prepared differently. ${ }^{11,13}$ In addition, some other studies have observed positive associations with meat-derived HCAs and benzo(a)pyrene, a marker of PAHs, and pancreatic cancer risk. ${ }^{11,41,42}$

Regarding fresh red meat intake, we observed a statistically significant inverse association with pancreatic cancer among microscopically verified cases, although this decrease was only observed for the highest versus the lowest quintile. The risk estimates for red meat intake seemed to change, however, during follow-up, although the interaction with time was not significant. In the subgroup of individuals who reported to have consumed equal amounts of meat 5 years preceding baseline compared to baseline, the inverse association for red meat intake was no longer statistically significant. In addition, because red meat is a rich source of iron and heme, a similar decreased pancreatic cancer risk would be expected with the intake of total iron and heme, but this was not the case. 


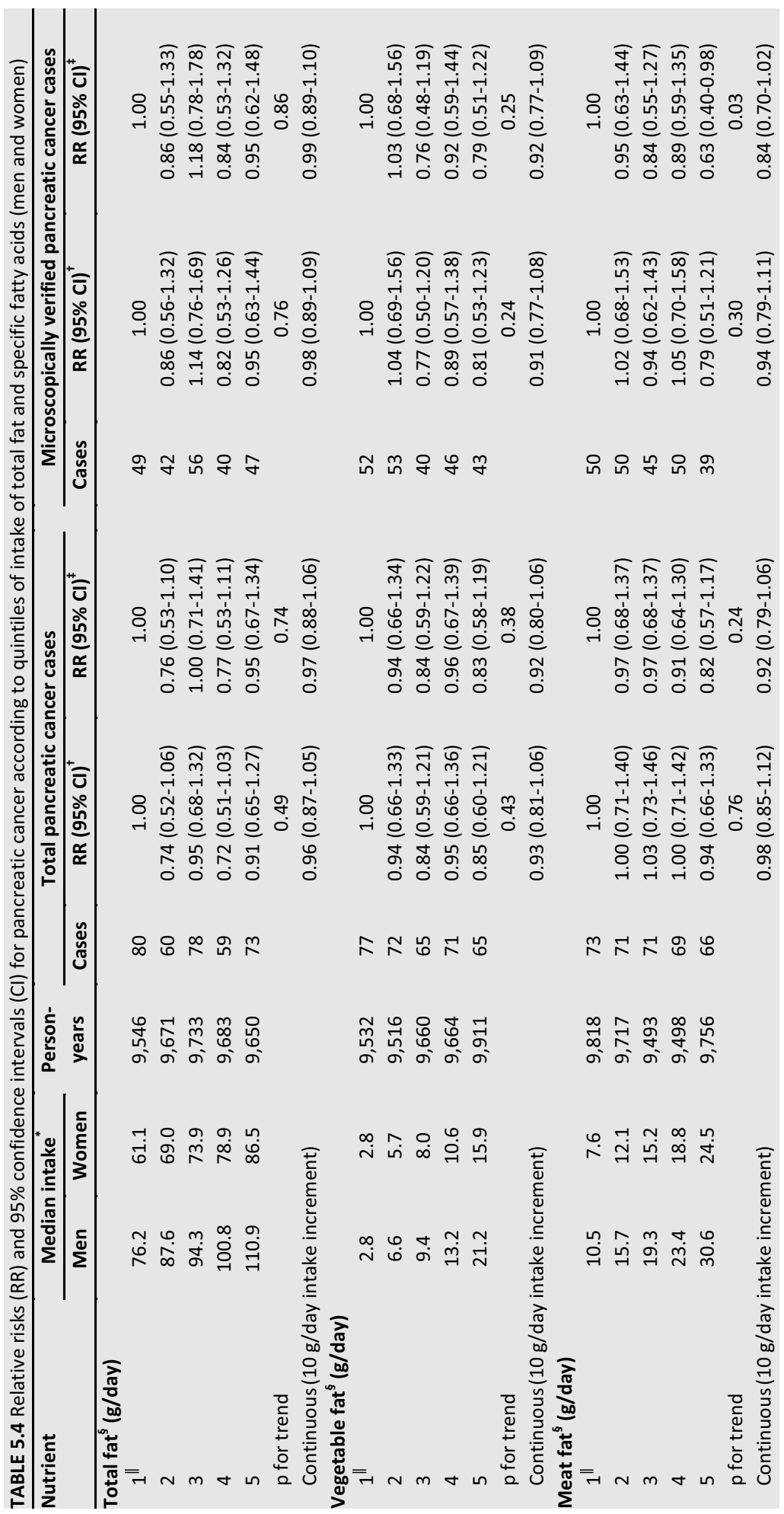




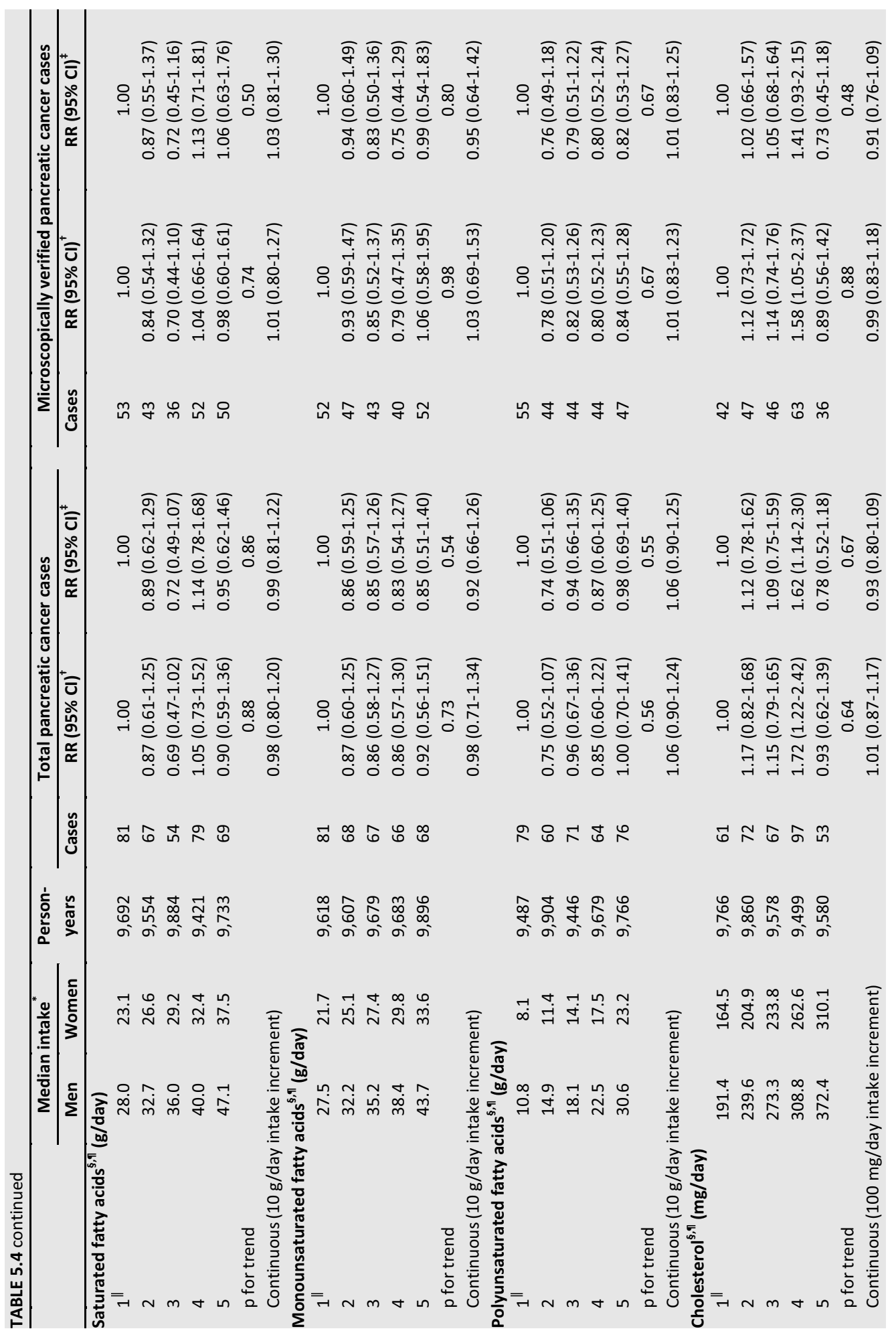




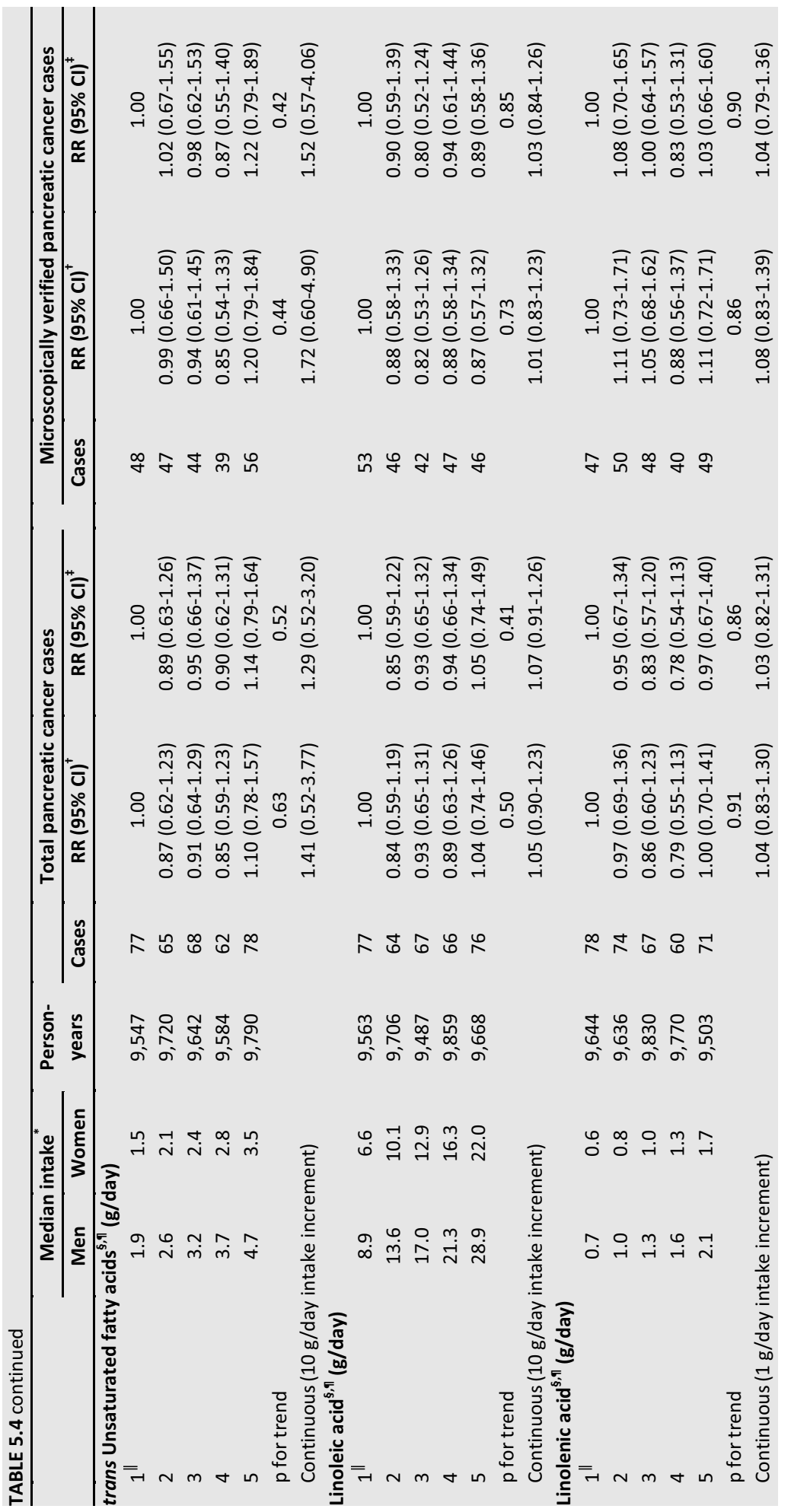




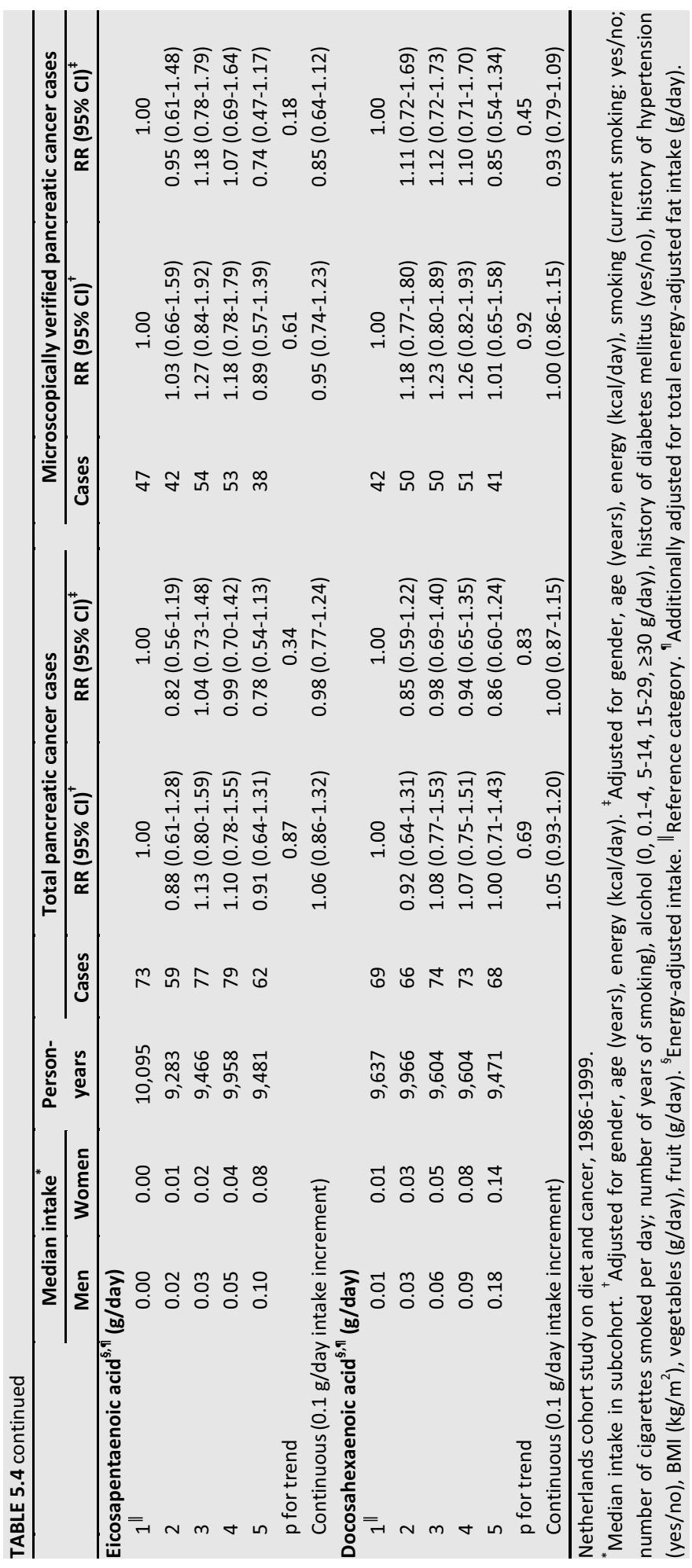


Eight cohort studies ${ }^{3,6,10-12}$ and eight case-control studies ${ }^{3,6,13,15}$ reported specifically on red meat intake in relation to pancreatic cancer risk. Five cohort studies have showed an increased risk for the highest versus lowest intake, ${ }^{3,11}$ which was statistically significant in four. ${ }^{3,11}$ of the case-control studies, six have observed an increased risk for the highest versus the lowest intake, ${ }^{3,6,13,15}$ which was statistically significant in two. ${ }^{3}$ Recently, in a systematic literature review of pancreatic cancer by an Expert Panel Report, a pooled risk estimate of 1.00 (95\% Cl: 0.95-1.05) for cohort studies and of 1.11 (95\% Cl: 1.08-1.15) for case-control studies on red meat intake was reported, ${ }^{3}$ but these estimates were only based on two of the eight cohort studies and three of the eight case-control studies. The inverse association we observed has not been reported in previous studies. This result should be interpreted with caution because this finding might have been due to chance because of the multiple comparisons that were made in the present study.

Dietary $\mathrm{N}$-nitroso compounds can be formed endogenously or are preformed in foods preserved with nitrite, such as processed meat. These compounds may play a role in human pancreatic cancer as well. ${ }^{21}$ In a population-based case-control study, Coss et al. have observed an increased pancreatic cancer risk with the consumption of dietary nitrite from animal sources. ${ }^{43}$ No association was observed in the four studies that investigated the relation between nitrite intake and pancreatic cancer risk, ${ }^{12,14,17,18}$ while of the 20 epidemiological studies investigating processed meat, ${ }^{3,6,8-13,15,19}$ only the Multiethnic Cohort Study and five case-control studies have observed a positive association. ${ }^{3,6,15,19}$ We observed in our study neither an increased pancreatic cancer risk with processed meat intake nor with dietary nitrite intake.

Animal studies have shown that the development of tumors is generally enhanced by long-chain $\omega-6$ polyunsaturated fatty acids (PUFA), especially linoleic acid (LA), but inhibited by $\omega-3$ PUFA. LA promotes pancreatic carcinogenesis via an accelerated prostaglandin synthesis, caused by metabolism of LA-derived arachidonic acid, ${ }^{23,44}$ whereas $\omega-3$ PUFAs can lead to a reduction in the availability of prostaglandins. ${ }^{22}$ Prostaglandins may be involved in the development of pancreatic carcinogenesis in animals. ${ }^{23,44}$ Saturated fatty acids (SFA), on the other hand, seems not to be involved in the enhancement or promotion of pancreatic carcinogenesis in rats. ${ }^{45}$

In our study, we observed no association when examining the relation between dietary intake of total fat, vegetable fat, SFA, monounsaturated fatty acids (MUFA), PUFA, cholesterol, LA, and linolenic acid, and the risk of pancreatic cancer. So far, 18 case-control studies have analyzed dietary fat, and different types of fatty acids. ${ }^{3,6,14,}$ 15,17,18 Positive associations were observed for the following: total fat, ${ }^{3,6,15,17}$ SFA, ${ }^{15,17}$ MUFA, ${ }^{15}$ and cholesterol. ${ }^{3,14,15}$ Inverse associations were observed with intake of total fat, $^{3,6}$ SFA, $^{3}$ MUFA, $^{3}$ PUFA, ${ }^{3,14}$ and LA. ${ }^{3}$ Of the four prospective studies that investigated the relation between dietary fat and risk of pancreatic cancer, ${ }^{3,6,10,12}$ only the ATBC Study has observed a positive association with the intake of SFA. ${ }^{12}$

The association between fatty acids from fish and pancreatic cancer has not been investigated often and so far, no association has been observed. ${ }^{3,16}$ of the 15 case- 
control studies that analyzed the intake of fish and shellfish, ${ }^{3,6,15,16}$ only two have observed an inverse association, ${ }^{3,6}$ whereas three studies have observed a positive association. ${ }^{3}$ The nine cohort studies investigating the relation between fish intake and pancreatic cancer risk, have all observed no association. ${ }^{3,6,8-10,12}$ In the current study, we observed no association for intake of fish and the fish n-3 PUFA, EPA and DHA.

For fat from meat, we observed a significantly decreased risk. Because red meat intake and fat from meat are strongly correlated $(r=0.73)$, we assume that this decreased risk can, in part, be explained by the decreased risk we observed with red meat intake. So far, only animal fat has been examined, observing a positive association in only one ${ }^{15}$ of the three studies. $3,10,15$

A limitation of our study is the use of a single measure of dietary intake that may not have been representative of the dietary habits of the study participants over the course of follow-up. However, the FFQ was tested for reproducibility by Goldbohm et al., who concluded that the single measurement of intake of diet in the NLCS can characterize dietary habits for a period of at least 5 years. ${ }^{33}$ In addition, meat and egg intake appeared to be stable over time as indicated by the analyses restricted to individuals who reported to have consumed equal amounts of meat or equal number of eggs 5 years preceding baseline compared to baseline, which showed similar findings compared to the overall analyses.

Strengths of this study include the possibility to further restrict the analyses to MCPC cases only, ${ }^{40}$ the large sample size, and detailed information on potential risk factors of pancreatic cancer. Differential follow-up is unlikely to have made a material contribution to our findings, as completeness of follow-up was high. ${ }^{28}$ The prospective design avoided recall bias and the need to use next-of-kin respondents, but misclassification of exposure may have occurred. However, from our validation study it was concluded that the questionnaire could satisfactorily rank subjects according to the intake of meat and dietary fat. ${ }^{29}$ If misclassification has occurred, we expect this to be nondifferential and risk estimates will be most likely biased towards the null value.

In conclusion, we observed no association between a high intake of meat, types of meat, fish, eggs, dietary total fat and different types of fat and pancreatic cancer risk in the NLCS. It is possible that the true association between meat intake and pancreatic cancer might be masked because we could not investigate the relation with meatcooking methods. Therefore it is important for future studies to investigate the relation between different meat-cooking methods and pancreatic cancer. 


\section{REFERENCES}

1. Jemal A, Siegel R, Ward E, et al. Cancer statistics, 2008. CA Cancer J Clin 2008;58:71-96.

2. Karim-Kos HE, de Vries E, Soerjomataram I, Lemmens V, Siesling S, Coebergh JW. Recent trends of cancer in Europe: a combined approach of incidence, survival and mortality for 17 cancer sites since the 1990s. Eur J Cancer 2008;44:1345-89.

3. World Cancer Research Fund/American Institute for Cancer research. Food, nutrition, physical activity, and the prevention of cancer: a global perspective. Washington DC: AICR, 2007.

4. Fuchs CS, Colditz GA, Stampfer MJ, et al. A prospective study of cigarette smoking and the risk of pancreatic cancer. Arch Intern Med 1996;156:2255-60.

5. Huxley R, Ansary-Moghaddam A, Berrington de Gonzalez A, Barzi F, Woodward M. Type-II diabetes and pancreatic cancer: a meta-analysis of 36 studies. Br J Cancer 2005;92:2076-83.

6. Anderson KE, Mack TM, Silverman DT. Cancer of the pancreas. In: Schottenfeld D, Fraumeni JF Jr., eds. Cancer epidemiology and prevention, $3^{\text {rd }}$ ed. New York: Oxford University Press, 2006. P. 721-62.

7. Ghadirian P, Thouez JP, PetitClerc C. International comparisons of nutrition and mortality from pancreatic cancer. Cancer Detect Prev 1991;15:357-62.

8. Isaksson B, Jonsson F, Pedersen NL, Larsson J, Feychting M, Permert J. Lifestyle factors and pancreatic cancer risk: a cohort study from the Swedish Twin Registry. Int J Cancer 2002;98:480-2.

9. Lin Y, Kikuchi S, Tamakoshi A, et al. Dietary habits and pancreatic cancer risk in a cohort of middle-aged and elderly Japanese. Nutr Cancer 2006;56:40-9.

10. Michaud DS, Giovannucci E, Willett WC, Colditz GA, Fuchs CS. Dietary meat, dairy products, fat, and cholesterol and pancreatic cancer risk in a prospective study. Am J Epidemiol 2003;157:1115-25.

11. Stolzenberg-Solomon RZ, Cross AJ, Silverman DT, et al. Meat and meat-mutagen intake and pancreatic cancer risk in the NIH-AARP cohort. Cancer Epidemiol Biomarkers Prev 2007;16:2664-75.

12. Stolzenberg-Solomon RZ, Pietinen P, Taylor PR, Virtamo J, Albanes D. Prospective study of diet and pancreatic cancer in male smokers. Am J Epidemiol 2002;155:783-92.

13. Anderson KE, Sinha R, Kulldorff $M$, et al. Meat intake and cooking techniques: associations with pancreatic cancer. Mutat Res 2002;506-507:225-31.

14. Baghurst PA, McMichael AJ, Slavotinek AH, Baghurst KI, Boyle P, Walker AM. A case-control study of diet and cancer of the pancreas. Am J Epidemiol 1991;134:167-79.

15. Chan JM, Wang F, Holly EA. Pancreatic cancer, animal protein and dietary fat in a population-based study, San Francisco Bay Area, California. Cancer Causes Control 2007;18:1153-67.

16. Farrow DC, Davis S. Diet and the risk of pancreatic cancer in men. Am J Epidemiol 1990;132:423-31.

17. Ghadirian $P$, Simard A, Baillargeon J, Maisonneuve P, Boyle P. Nutritional factors and pancreatic cancer in the francophone community in Montreal, Canada. Int J Cancer 1991;47:1-6.

18. Howe GR, Jain M, Miller AB. Dietary factors and risk of pancreatic cancer: results of a Canadian population-based case-control study. Int J Cancer 1990;45:604-8.

19. Norell SE, Ahlbom A, Erwald R, et al. Diet and pancreatic cancer: a case-control study. Am J Epidemiol 1986;124:894-902.

20. Wakabayashi K, Nagao M, Esumi H, Sugimura T. Food-derived mutagens and carcinogens. Cancer Res 1992;52:2092s-8s.

21. Risch HA. Etiology of pancreatic cancer, with a hypothesis concerning the role of N-nitroso compounds and excess gastric acidity. J Natl Cancer Inst 2003;95:948-60.

22. Woutersen RA, Appel MJ, van Garderen-Hoetmer A, Wijnands MV. Dietary fat and carcinogenesis. Mutat Res 1999;443:111-27.

23. Appel MJ, van Garderen-Hoetmer A, Woutersen RA. Effects of dietary linoleic acid on pancreatic carcinogenesis in rats and hamsters. Cancer Res 1994;54:2113-20.

24. van den Brandt PA, Goldbohm RA, van 't Veer P, Volovics A, Hermus RJ, Sturmans F. A large-scale prospective cohort study on diet and cancer in The Netherlands. J Clin Epidemiol 1990;43:285-95.

25. Prentice RL. A case-cohort design for epidemiologic cohort studies and disease prevention trials. Biometrika 1986;73:1-11. 
26. van den Brandt PA, Schouten LJ, Goldbohm RA, Dorant E, Hunen PM. Development of a record linkage protocol for use in the Dutch Cancer Registry for Epidemiological Research. Int J Epidemiol 1990;19: 553-8.

27. van der Sanden GA, Coebergh JW, Schouten LJ, Visser O, van Leeuwen FE. Cancer incidence in The Netherlands in 1989 and 1990: first results of the nationwide Netherlands cancer registry. Coordinating Committee for Regional Cancer Registries. Eur J Cancer 1995;31A:1822-9.

28. Goldbohm RA, van den Brandt PA, Dorant E. Estimation of the coverage of Dutch municipalities by cancer registries and PALGA based on hospital discharge data. Tijdschr Soc Gezondheidsz 1994;72: 80-4.

29. Goldbohm RA, van den Brandt PA, Brants HA, et al. Validation of a dietary questionnaire used in a large-scale prospective cohort study on diet and cancer. Eur J Clin Nutr 1994;48:253-65.

30. Anonymous. NEVO-tabel: Nederlands voedingsstoffenbestand 1986-1987 (Nevo table: Dutch Food Composition Table 1986-1987 [in Dutch]). The Hague, the Netherlands: Voorlichtingsbureau voor de voeding, 1986.

31. Schuurman AG, van den Brandt PA, Dorant E, Brants HA, Goldbohm RA. Association of energy and fat intake with prostate carcinoma risk: results from The Netherlands Cohort Study. Cancer 1999;86:

1019-27.

32. van Poppel G, van Erp-Baart M-A, Leth $T$, et al. Trans fatty acids in foods in Europe: the TRANSFAIR study. J Food Composition Anal 1998;11:112-36.

33. Goldbohm RA, van 't Veer P, van den Brandt PA, et al. Reproducibility of a food frequency questionnaire and stability of dietary habits determined from five annually repeated measurements. Eur J Clin Nutr 1995;49:420-9.

34. Friedman GD, van den Eeden SK. Risk factors for pancreatic cancer: an exploratory study. Int J Epidemiol 1993;22:30-7.

35. Balder HF, Vogel J, Jansen MC, et al. Heme and chlorophyll intake and risk of colorectal cancer in the Netherlands Cohort Study. Cancer Epidemiol Biomarkers Prev 2006;15:717-25.

36. Willett W. Implications of total energy intake for epidemiologic analyses. In: Willett W., ed. Nutritional Epidemiology. New York: Oxford University Press, 1998. P. 273-301.

37. Volovics A, van den Brandt PA. Methods for the analysis of case-cohort studies. Biom J 1997;39: 195-214.

38. Lin DY, Wei $\mathrm{L}$. The robust inference for the Cox proportional hazards model. J Am Stat Assoc 1989;84: 1074-8.

39. Schoenfeld D. Partial residuals for the proportional hazards regression model. Biometrika 1982;69: 239-41.

40. Verhage BA, Schouten LJ, Goldbohm RA, van den Brandt PA. Anthropometry and pancreatic cancer risk: an illustration of the importance of microscopic verification. Cancer Epidemiol Biomarkers Prev 2007;16:1449-54

41. Anderson KE, Kadlubar FF, Kulldorff $M$, et al. Dietary intake of heterocyclic amines and benzo(a)pyrene: associations with pancreatic cancer. Cancer Epidemiol Biomarkers Prev 2005;14:2261-5.

42. Li D, Day RS, Bondy ML, et al. Dietary mutagen exposure and risk of pancreatic cancer. Cancer Epidemiol Biomarkers Prev 2007;16:655-61.

43. Coss A, Cantor KP, Reif JS, Lynch CF, Ward MH. Pancreatic cancer and drinking water and dietary sources of nitrate and nitrite. Am J Epidemiol 2004;159:693-701.

44. Heukamp I, Kilian M, Gregor Jl, et al. Impact of polyunsaturated fatty acids on hepato-pancreatic prostaglandin and leukotriene concentration in ductal pancreatic cancer - is there a correlation to tumour growth and liver metastasis? Prostaglandins Leukot Essent Fatty Acids 2006;74:223-33.

45. Roebuck BD, Yager JD, Jr., Longnecker DS, Wilpone SA. Promotion by unsaturated fat of azaserineinduced pancreatic carcinogenesis in the rat. Cancer Res 1981;41:3961-6. 



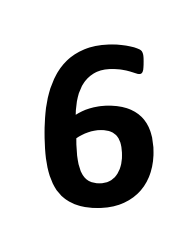

\section{Intake of vegetables, fruits, carotenoids, and vitamins $C$ and $E$ and pancreatic cancer risk in the Netherlands Cohort Study}

Mirjam M Heinen

Bas AJ Verhage

R Alexandra Goldbohm

Piet $A$ van den Brandt 


\section{ABSTRACT}

Epidemiological data investigating the relation between fruit and vegetable consumption and pancreatic cancer risk have shown inconsistent results so far. Most casecontrol studies observed an inverse association with total fruit and vegetable consumption, whereas results from most cohort studies have largely been null. We examined prospectively the relation between pancreatic cancer risk and intake of vegetables, fruits, carotenoids and vitamins $C$ and $E$. The Netherlands Cohort Study consisted of 120,852 men and women who completed a questionnaire at baseline in 1986, including a validated 150-item food frequency questionnaire. After 16.3 years of follow-up, 423 cases were available for analysis. Total vegetable and total fruit consumption were not associated with pancreatic cancer risk (highest versus lowest quintile, multivariable-adjusted hazard rate ratio $=1.23,95 \%$ confidence interval: $0.86-1.75$ and multivariable-adjusted hazard rate ratio $=0.90,95 \%$ confidence interval: 0.66-1.24, respectively). Also, for cooked vegetables, raw vegetables, and vegetables and fruits classified into subgroups, no associations were observed. Dietary carotenoids, vitamin $\mathrm{C}$ and $\mathrm{E}$ intake and supplements containing vitamin $\mathrm{C}$ or $\mathrm{E}$ were not associated with pancreatic cancer risk. The results were not modified by sex, smoking status and body mass index. In conclusion, we observed no association between a high consumption of vegetables and fruits and pancreatic cancer risk in this large cohort study, which is in agreement with previous prospective studies. Furthermore, we observed no association between the intake of carotenoids, vitamins and vitamin supplements and pancreatic cancer risk. 


\section{INTRODUCTION}

Pancreatic cancer is the $5^{\text {th }}$ leading cause of death in Europe and $4^{\text {th }}$ in the United States. ${ }^{1,2}$ Pancreatic cancer is diagnosed most often at advanced stages and patients diagnosed with pancreatic cancer have a 5 -year survival rate of $6 \%$ or less. ${ }^{2,3}$ So far, cigarette smoking, diabetes mellitus, and body fatness are identified as risk factors. ${ }^{4-6}$

Fruits and vegetables contain numerous substances with potential anticarcinogenic activity (including vitamins, carotenoids, and Allium compounds) ${ }^{7}$ and could therefore play a role in prevention of pancreatic cancer. Potential mechanisms of action include antioxidant protection against free-radical damage to DNA, enhancing immune function, and inhibiting insulin-like growth factor (IGF) binding to IGFreceptors. ${ }^{4,7}$ In addition, short-term animal experiments suggest that beta-carotene and the vitamins $C$ and $E$ hinder the development of preneoplastic lesions in both rats and hamster pancreas, ${ }^{8}$ but long-term studies demonstrated this inhibiting effect only for beta-carotene and vitamin C and only in rat pancreas. ${ }^{8,9}$

Epidemiological data have shown inconsistent results so far. Most case-control studies have observed an inverse association with total fruit and vegetable consumption. ${ }^{10-15}$ Among specific subgroups of vegetables, the most consistent association has been found for cruciferous or Brassica vegetables. ${ }^{11,12,15}$ On the other hand, results from most cohort studies have largely been null. ${ }^{16-22}$ The results from the Multiethnic Cohort Study suggests that vegetables may afford some protection against pancreatic cancer in high-risk subgroups, namely current smokers and overweight/obese persons. ${ }^{18}$ Regarding the relation between antioxidant intake and pancreatic cancer risk, intake of vitamin $\mathrm{C}$ and beta-carotene have been investigated most often, showing both inverse associations ${ }^{11,14,23}$ and no association. ${ }^{15,19,20,24,25}$ Data on use of vitamin supplements has been very sparse; $;^{10,15,20,24}$ of these studies only one observed an inverse association with vitamin C supplement use. ${ }^{15} \mathrm{~A}$ recent Expert Panel Report found only suggestive evidence that fruits protect against pancreatic cancer, whereas the evidence was inconclusive for vegetables and vitamin $\mathrm{C}^{4}$

In the current study, we investigated the association between pancreatic cancer risk and the overall consumption of vegetables and fruits and consumption of subgroups of vegetables and fruits in a large prospective cohort study in the Netherlands. In addition, we investigated the relation between pancreatic cancer risk and dietary carotenoids, vitamins $\mathrm{C}$ and $\mathrm{E}$, and supplements containing vitamin $\mathrm{C}$ and $\mathrm{E}$.

\section{MATERIAL AND METHODS}

\section{Study population and cancer follow-up}

The study design of the Netherlands Cohort Study (NLCS) has been reported in detail elsewhere. ${ }^{26}$ Briefly, the NLCS was initiated in September 1986 and included initially 58,279 men and 62,573 women aged 55-69 years from 204 Dutch municipalities with 
computerized population registries. A self-administered food frequency and lifestyle questionnaire was completed at baseline. For efficiency in the processing of the questionnaire and follow-up, the case-cohort approach was used. ${ }^{27}$ Incident cases were derived from the entire cohort, whereas the person-years at risk were estimated from a random sample of 5,000 subjects (2,411 men and 2,589 women). This subcohort was chosen immediately after baseline and followed up for vital status information. The entire cohort is being monitored for cancer occurrence by annual record linkage to the Netherlands Cancer Registry and the Netherlands Pathology Registry. ${ }^{28,29}$ A total of 16.3 years of follow-up (baseline to December 2002) was used for the current analysis. Only one subcohort member was lost to follow-up and completeness of follow-up was estimated to be $>96 \%$. $^{30}$

All prevalent cancer cases at baseline other than skin cancer were excluded, resulting in a subcohort of 4,774 men and women. Of the 567 incident pancreatic cancer cases (ICD-O-3 code C25), cases with endocrine subtypes (ICD-O-3 code C25.4; $n=1)$ were excluded. Sixty two percent of the 566 pancreatic cancer cases were microscopically confirmed pancreatic cancer (MCPC, $n=350$ ), whereas such confirmation was lacking for $38 \%(n=216)$. Diagnosis of the latter group was made by the treating clinician and was based on clinical symptoms, physical examination and imaging results, and data were abstracted and recorded by a trained tumor registrar. ${ }^{31}$ The NLCS has been approved by the institutional review boards of the TNO Nutrition and Food Research Institute (Zeist, the Netherlands) and Maastricht University (Maastricht, the Netherlands).

\section{Questionnaire}

The dietary section of the baseline questionnaire was a 150 -item semiquantitative food frequency questionnaire (FFQ), which concentrated on habitual consumption during the year preceding the start of the study. Questionnaire data were key-entered and processed for all incident cases in the cohort and subcohort members in a standardized manner, blinded with respect to case/subcohort status. This was done to minimize observer bias in the coding and interpretation of the data.

Data were obtained concerning consumption frequency of vegetables (i.e., Brussels sprouts, cauliflower, cabbage [white/green], kale, string beans, broad beans, spinach, endive [raw and cooked], lettuce, carrots [raw and cooked], sweet peppers, sauerkraut, tomatoes, red beets, mushrooms, gherkins, rhubarb, leek, and onions), for summer and winter separately, and fruits (i.e., mandarins, oranges, grapefruits, orange/grapefruit juice, grapes, bananas, apples/pears, and strawberries). Based on data from the Dutch Nutrition Survey, ${ }^{32}$ onions and sweet peppers were considered to be eaten cooked, whereas tomatoes were considered to be eaten raw. The questionnaire covered most vegetables and fruits eaten regularly in 1986, with the exception of chicory, red cabbage, and cucumber. In the Netherlands, broccoli was a rarely available vegetable in 1986 and therefore not included. Furthermore, in an open-ended question, participants could enter which other foods they consumed on a regular basis as 
well as the frequency (number of times per week) and amount of consumption on each occasion.

Consumption frequency was specified by using categories ranging from "never or less than once per month" to "three to seven times per week" for vegetable consumption and to "six or seven times per week" for fruit consumption. In addition, for individual fruit items, the amount consumed on each consumption day was asked. For onions and tomatoes, participants were asked to report the number they usually ate per week; for sweet peppers per month; and for mushrooms, how many 250-g boxes per month. Frequency of consumption and usual serving size of tomato/vegetable juice, processed orange/grapefruit juice and other fruit juices was also asked.

Participants were asked about usual serving sizes for string beans and cooked endive only; the mean of these serving sizes were used as a representative of solid and leafy vegetables, respectively. This average individual serving size was multiplied with a vegetable-specific factor calculated from pilot study data, to derive an individual serving size for each vegetable. This procedure was chosen because in a pilot study it was shown that serving sizes of different types of cooked vegetables were correlated within subjects. Mean daily vegetable consumption (g/day) was calculated by multiplying the frequency of consumption and serving size. Frequency of intake and standard serving sizes were used to calculate consumption of individual fruit items in $\mathrm{g} / \mathrm{day}$.

The mean daily intake of vitamins $C$ and $E$ were calculated by using the computerized Dutch food composition table. ${ }^{33}$ For calculating the intake of specific carotenoids, an additional food composition table was used. Briefly, foods that are the main sources of carotenoids (e.g., vegetables) were sampled and analyzed for alpha-carotene, betacarotene, lutein, zeaxanthin, and lycopene; the database was completed with data from the literature and information from food manufacturers. ${ }^{34}$ In the carotenoids food composition table, lutein and zeaxanthin were combined, because most literature sources had not distinguished these two carotenoids. Most vegetables, however, contain primarily lutein and only minor amounts of zeaxanthin. Information on dietary supplement use was collected with an open-ended question with space for four different supplements. ${ }^{35}$ Participants were asked whether they used vitamin tablets, drops, or other supplements during the 5 years before baseline. Furthermore, they were asked what type of supplement they have used, type of brand, what dosage and for how long they have used the supplement.

Subjects with incomplete or inconsistent dietary data (336 subcohort members, 46 cases) were excluded from analyses. ${ }^{36}$ Throughout the FFQ data cleaning was conducted using standardized algorithms to detect and, in some cases, correct likely errors, while tallying the errors for each person. Questions on vegetable consumption appeared early in the food frequency questionnaire. This led to some subjects' making mistakes on these particular items (e.g., improbably high summed frequencies for vegetable consumption, errors in separate consumption frequencies for summer and winter, and improbably high or low reported portion sizes), while items on other food groups appearing later in the questionnaire were filled out without any problems. 
When more than three errors were encountered on the vegetable items, that subject was excluded from the analyses of vegetable consumption (241 subcohort members, 26 cases). The FFQ had been validated and tested for reproducibility. ${ }^{36,37}$ Crude Pearson correlation coefficients between the 9-day diet record and the questionnaire were 0.74 for energy and 0.58 for vitamin C. The Spearman correlation coefficients for total vegetables and total fruits were 0.38 and 0.60 , respectively. ${ }^{36}$ On average, vegetable consumption appeared to be slightly overestimated and fruit consumption to be under-estimated by the FFQ as compared with the diet records. ${ }^{36}$

\section{Statistical analysis}

Analyses were performed for total vegetable consumption, total fruit consumption, consumption of vegetables and fruits combined, cooked and raw vegetables, vegetables categorized in subgroups (Brassica vegetables, cooked and raw leafy vegetables, Allium vegetables, and legumes), total fruit, citrus fruit and consumption of individual vegetables and fruits as listed in the questionnaire. "Total vegetable consumption" is the summed total for all vegetables mentioned in the questionnaire and in the openended question, excluding dried pulses. Dried pulses were considered only in the analysis of legumes. The composition of each vegetable and fruit group is given in the "Appendix" section. In addition, analyses were performed for tomato/vegetable juice, processed orange/grapefruit juice, and other juices. Other exposure variables were the carotenoids alpha-carotene, beta-carotene, lutein + zeaxanthin, lycopene, and betacryptoxanthin, the vitamins $\mathrm{C}$ and $\mathrm{E}$ and use of any supplement - including multivitamins - containing vitamin $\mathrm{C}$ or $\mathrm{E}$.

Participants were categorized according to quintile of intake of relevant food groups or nutrients (with the lowest quintile of intake regarded as the reference group), depending on the sex-specific distribution in the subcohort. For vitamin $\mathrm{C}$, however, the validation study had pointed out that quintiles 2 and 3 and quintiles 4 and 5 could not be distinguished; therefore, we reduced vitamin $C$ intake to three categories. ${ }^{36}$ Participants were categorized as users or nonusers of supplements containing vitamin $\mathrm{C}$ or $\mathrm{E}$. Continuous variables were constructed as well. For vegetables and fruits an increment of $25 \mathrm{~g} /$ day was used based on data of the pilot study. This increment corresponds to a consumption frequency of approximately once per week for cooked vegetables.

Age- and sex-adjusted and multivariable-adjusted hazard rate ratios (HRs) and corresponding $95 \%$ confidence intervals (95\% Cls) were estimated by using Cox proportional hazards models. The total person-years at risk, estimated from the subcohort, were used in the analyses. ${ }^{38}$ Standard errors were estimated by using a robust covariance matrix estimator to account for increased variance due to sampling from the cohort. ${ }^{39}$ All analyses were conducted for both sexes combined and separately for men and women.

Based on literature, the following variables were considered as potential confounders: age, sex, smoking, body mass index (BMI), intake of energy, coffee and alco- 
hol, total red meat consumption, level of education, non-occupational physical activity, family history of pancreatic cancer, history of diabetes mellitus, hypertension, gallstones, cholecystectomy, and gastric ulcer. These potential confounding variables were added to the multivariable-adjusted model if they (i) were associated with the disease and with total vegetable and total fruit intake and (ii) changed the age- and sex adjusted regression coefficients by at least 10 percent (using a backwards stepwise procedure). This resulted in a multivariable-adjusted model including age at baseline (years), sex, cigarette smoking (current smoking: yes/no; number of cigarettes smoked per day; number of years of smoking), BMI $\left(\mathrm{kg} / \mathrm{m}^{2}\right)$, intake of energy ( $\mathrm{kcal} /$ day), coffee (number of cups/day) and alcohol (g/day), total red meat consumption (g/day), family history of pancreatic cancer (yes/no), and history of diabetes mellitus (yes/no). The independent contribution of each vegetable subgroup was assessed by an analysis in which all vegetable subgroups were included in the model simultaneously. For analysis on antioxidant intake, the independent contribution of each specific vitamin and carotenoid to the risk of pancreatic cancer was assessed by an analysis in which all these were included in the model simultaneously. In additional analyses, the HRs were adjusted for total vegetable and fruit intake. For each analysis, trends were evaluated with the Wald test by assigning participants the median value for each level of the categorical exposure variable among the subcohort members and this variable was entered as a continuous term in the Cox regression model.

To permit comparison, we restricted age-adjusted analyses to subjects included in multivariable-adjusted analyses (e.g., with no missing values on confounding variables), which left 3,937 subcohort members (1,930 men and 2,007 women) and 448 exocrine pancreatic cancer cases (240 men and 208 women) for analysis on fruit consumption and on intake of carotenoids, vitamins and vitamin supplements. For the analysis on vegetable consumption, 3,734 subcohort members and 428 exocrine pancreatic cancer cases were available. The proportional hazards assumption, which was tested using the scaled Schoenfeld residuals, ${ }^{40}$ was violated for many of the exposure variables. Because early symptoms of disease before diagnosis could have influenced the results, the early cases (diagnosed within 2 years after baseline) were excluded; this resolved our problem of assumptions being violated. Therefore, all analyses were done excluding the first 2 years of follow-up: 69 subcohort members and 25 pancreatic cancer cases were excluded for the analysis on fruits, juices, carotenoids, and vitamin intake and use of vitamin supplements. For the analysis on vegetable intake, 64 subcohort members and 22 pancreatic cancer cases were excluded.

In the present study the overall analyses were performed on all pancreatic cancer cases. We restricted additional analyses to MCPC cases to create a group with a higher degree of diagnostic certainty of pancreatic cancer, which was shown to be important in previous studies. ${ }^{41,42}$ We also conducted analyses separately for current, former, and never smokers to determine whether smoking modifies the association of total vegetable and total fruit intake with risk of pancreatic cancer. Also, analyses for total vegetable and fruit intake were conducted stratified by BMI level (cutoff: $25 \mathrm{~kg} / \mathrm{m}^{2}$ ) to 
examine whether fruit and vegetable intake may differentially affect those at higher risk. In addition, interactions on a multiplicative scale of total vegetable and total fruit consumption with smoking status and BMI were tested. All analyses were performed using the STATA statistical software package (intercooled STATA, version 9; Stata Corporation, College Station, TX). All $p$ values were based on two-sided tests and considered statistically significant if $<0.05$.

\section{RESULTS}

In Table 6.1, baseline characteristics are presented. Most characteristics did not differ between pancreatic cancer cases and subcohort members; however, there were more current smokers and more subjects with a family history of pancreatic cancer among pancreatic cancer cases than among subcohort members. In Table 6.2, we present baseline dietary intakes of the specific vegetables and fruits as listed in the questionnaire. Because the specific vegetables and fruits had a right-skewed distribution, we present the median and interquartile range. The specific vegetables and fruits are presented in increasing order of the percentage of nonusers. The most eaten vegetables in our population were string beans, cauliflower and lettuce, whereas gherkins and raw carrots were only consumed by approximately $30 \%$ of our participants. Apples, pears, strawberries, and oranges were the most consumed fruits, whereas grapefruits, raisins and other dried fruit were the least consumed fruits in our population. No real differences were observed between cases and subcohort members regarding the intake of specific vegetables and fruits. 
TABLE 6.1 Baseline characteristics (means or percent) of pancreatic cancer cases and subcohort members; Netherlands Cohort Study on diet and cancer, 1986-2002*

\begin{tabular}{|c|c|c|}
\hline Characteristic & All pancreatic cancer cases & Subcohort \\
\hline $\mathrm{n}$ & 423 & 3,868 \\
\hline Male sex (\%) & 52.7 & 48.7 \\
\hline Age, mean \pm SD (years) & $62.1 \pm 4.1$ & $61.3 \pm 4.2$ \\
\hline Current smokers (\%) & 34.0 & 27.0 \\
\hline Years of smoking ${ }^{\dagger}$, mean \pm SD (years) & $33.3 \pm 12.6$ & $31.5 \pm 12.2$ \\
\hline $\mathrm{BMI}$, mean $\pm \mathrm{SD}\left(\mathrm{kg} / \mathrm{m}^{2}\right)$ & $25.4 \pm 3.2$ & $25.0 \pm 3.1$ \\
\hline \multicolumn{3}{|l|}{ Physical activity (non-occupational) (\%) } \\
\hline$<30 \mathrm{~min} /$ day & 20.3 & 20.1 \\
\hline $30-60 \mathrm{~min} /$ day & 32.1 & 31.3 \\
\hline $60-90 \mathrm{~min} /$ day & 25.8 & 21.4 \\
\hline$>90 \mathrm{~min} / \mathrm{day}$ & 21.8 & 27.2 \\
\hline Family history of pancreatic cancer (\%) & 3.1 & 0.8 \\
\hline History of diabetes mellitus (\%) & 5.4 & 3.4 \\
\hline History of hypertension (\%) & 25.1 & 26.3 \\
\hline History of gallstones (\%) & 10.2 & 9.8 \\
\hline History of cholecystectomy (\%) & 9.2 & 9.0 \\
\hline History of gastric ulcer (\%) & 8.3 & 8.2 \\
\hline \multicolumn{3}{|l|}{ Level of education (\%) } \\
\hline Low & 51.1 & 49.7 \\
\hline Medium & 34.2 & 36.0 \\
\hline High & 14.7 & 14.3 \\
\hline \multicolumn{3}{|l|}{ Daily intake, mean \pm SD } \\
\hline Energy (kcal) & $1,928 \pm 476$ & $1,924 \pm 514$ \\
\hline Total fat ${ }^{\ddagger}(\mathrm{g})$ & $83.7 \pm 15.5$ & $83.8 \pm 15.8$ \\
\hline Total carbohydrates ${ }^{\ddagger}(\mathrm{g})$ & $202.0 \pm 39.9$ & $201.7 \pm 40.1$ \\
\hline Alcohol (g) & $12.6 \pm 16.1$ & $10.3 \pm 14.3$ \\
\hline Coffee (number of cups) & $4.5 \pm 2.3$ & $4.3 \pm 2.2$ \\
\hline Total red meat intake (g) & $86.1 \pm 38.8$ & $86.7 \pm 40.3$ \\
\hline
\end{tabular}

First 2 years of follow-up excluded from the analysis; numbers of cases and subcohort members adjusted accordingly. ${ }^{\dagger}$ Never smokers excluded. ${ }^{\ddagger}$ Energy-adjusted intake.

In Table 6.3, HRs are presented for quintiles of total vegetable and fruit intake, total vegetable intake, intake of vegetable subgroups, total fruit intake and citrus fruit intake. After adjustment for age and sex, trends in risk for cooked vegetables and Brassica vegetables were (statistically significantly) positive; however, none of the HRs in the categorical analyses were significant (Table 6.3). When the confounders were included in the model, these positive trends became non-significant. For all other vegetable and fruit groups, we observed no associations. All HRs for an increment in daily mean intake of $25 \mathrm{~g} /$ day for vegetables and fruits, were approximately one (Table 6.3). When we included simultaneously all vegetable subgroups (continuously) in the model, results were similar (results not shown). Additional adjustment for fruit and vegetable consumption did also not alter the results (results not shown). We have also investigated whether specific vegetables and fruits were associated with pancreatic cancer risk; no associations were observed (results not shown). Also the intake of toma- 
to/vegetable juice, processed orange/grapefruit juice and other fruit juices were not associated with pancreatic cancer risk (results not shown).

TABLE 6.2 Daily (median) intake of specific vegetable and fruit items of subcohort members and pancreatic cancer cases; Netherlands Cohort Study on diet and cancer, 1986-2002*

\begin{tabular}{|c|c|c|c|c|}
\hline \multirow[t]{2}{*}{ Dietary factors } & \multicolumn{2}{|c|}{ Subcohort } & \multicolumn{2}{|c|}{ All pancreatic cancer cases } \\
\hline & $\%$ nonusers & Median (P25-P75) $^{\dagger}$ & $\%$ nonusers & Median (P25-P75) \\
\hline Vegetable consumption & \multicolumn{2}{|c|}{$\mathrm{n}=3,670$} & \multicolumn{2}{|r|}{$n=406$} \\
\hline String beans (g) & 1.6 & $17.2(10.4-25.2)$ & 3.9 & $18.0(11.7-29.9)$ \\
\hline Cauliflower (g) & 7.2 & $13.3(8.3-20.2)$ & 8.9 & $14.0(8.4-21.2)$ \\
\hline Lettuce (g) & 9.2 & $7.1(3.6-10.7)$ & 12.6 & $7.1(3.6-10.7)$ \\
\hline Carrots, prepared (g) & 11.5 & $8.1(4.4-13.5)$ & 12.6 & $7.8(5.0-13.6)$ \\
\hline Endive, prepared (g) & 14.1 & $11.8(6.6-18.7)$ & 15.5 & $12.1(6.8-20.4)$ \\
\hline Brussels sprouts (g) & 15.2 & $8.0(4.7-12.2)$ & 12.3 & $8.2(5.4-12.5)$ \\
\hline Sauerkraut (g) & 16.2 & $5.9(3.2-9.0)$ & 15.0 & $6.0(3.7-9.2)$ \\
\hline Tomatoes (g) & 18.2 & 23.5 (14.1-32.9) & 17.2 & $23.5(14.1-37.6)$ \\
\hline Onions (g) & 19.8 & 21.9 (11.0-32.9) & 19.0 & 21.9 (11.0-32.9) \\
\hline Spinach (g) & 20.0 & $10.1(6.1-16.0)$ & 20.0 & $9.7(5.6-16.0)$ \\
\hline Beetroot (g) & 24.6 & $8.9(5.0-13.6)$ & 26.1 & $9.2(5.2-14.3)$ \\
\hline Kale (g) & 25.1 & $3.6(1.9-5.3)$ & 21.7 & $3.9(1.9-5.5)$ \\
\hline Cabbage (white/green; g) & 28.6 & $7.7(4.2-12.7)$ & 29.6 & $7.4(4.4-13.1)$ \\
\hline Leek $(\mathrm{g})$ & 31.8 & $10.2(5.4-16.7)$ & 28.8 & $11.2(6.8-18.9)$ \\
\hline Dried pulses (g) & 38.5 & $10.7(4.3-17.3)$ & 38.4 & $8.5(4.3-16.0)$ \\
\hline Mushrooms (g) & 39.0 & $4.4(4.4-8.9)$ & 36.2 & $4.4(4.4-8.9)$ \\
\hline Broad beans (g) & 43.3 & $5.6(2.9-10.5)$ & 46.1 & $5.7(2.8-10.3)$ \\
\hline Sweet peppers (g) & 46.2 & $3.5(2.6-6.1)$ & 46.3 & $3.5(2.6-6.1)$ \\
\hline Endive, raw (g) & 55.6 & $4.3(2.0-7.4)$ & 56.9 & $4.3(2.0-7.4)$ \\
\hline Rhubarb (g) & 58.7 & $3.4(1.4-5.9)$ & 60.8 & $3.4(1.4-6.2)$ \\
\hline Carrots, raw (g) & 67.2 & $4.7(2.0-10.0)$ & 70.9 & $5.0(2.8-10.0)$ \\
\hline Gherkins (g) & 69.3 & $3.1(1.4-6.3)$ & 66.3 & $1.8(1.4-5.4)$ \\
\hline Fruit consumption & \multicolumn{2}{|r|}{$n=3,868$} & \multicolumn{2}{|r|}{$n=423$} \\
\hline Apples, pears (g) & 13.4 & $80.1(44.5-115.8)$ & 15.8 & $80.1(44.5-115.8)$ \\
\hline Strawberries (g) & 14.0 & $7.1(3.6-11.2)$ & 13.9 & $7.1(3.6-8.9)$ \\
\hline Oranges and fresh orange juice $(\mathrm{g})$ & 16.2 & $42.7(14.8-83.3)$ & 17.7 & $45.4(12.8-83.3)$ \\
\hline Grapes $(\mathrm{g})$ & 36.9 & $3.3(1.3-8.5)$ & 36.4 & $3.3(1.6-7.1)$ \\
\hline Mandarins (g) & 40.5 & $3.8(1.9-8.2)$ & 40.9 & $3.3(1.9-8.2)$ \\
\hline Bananas (g) & 46.9 & $10.7(4.3-18.5)$ & 50.1 & $10.7(4.3-18.5)$ \\
\hline \multicolumn{5}{|l|}{ Grapefruits and fresh grapefruit } \\
\hline juice $(g)$ & 70.0 & $16.0(7.4-40.1)$ & 71.4 & $16.0(7.4-40.1)$ \\
\hline Raisins/other dried fruit (g) & 74.8 & $1.3(0.7-2.8)$ & 76.4 & $1.3(0.7-2.8)$ \\
\hline
\end{tabular}

First 2 years of follow-up excluded from the analysis; numbers of cases and subcohort members adjusted accordingly. ${ }^{\dagger}$ In users only. 
TABLE 6.3 Age- and sex-adjusted and multivariable-adjusted hazard rate ratios (HRs) and 95\% Cls for pancreatic cancer according to quintiles of vegetable and fruit consumption; Netherlands Cohort Study on diet and cancer, 1986-2002

\begin{tabular}{|c|c|c|c|c|c|c|}
\hline \multirow[t]{2}{*}{ Food item } & \multicolumn{2}{|c|}{ Median intake $^{\dagger}$} & \multirow{2}{*}{$\begin{array}{l}\text { Person- } \\
\text { years }\end{array}$} & \multirow[b]{2}{*}{ Cases } & \multirow[b]{2}{*}{ HR $(95 \% \mathrm{CI})^{\ddagger}$} & \multirow[b]{2}{*}{ HR $(95 \% \mathrm{CI})^{5}$} \\
\hline & Men & Women & & & & \\
\hline \multicolumn{7}{|c|}{ Vegetables and fruit combined" (g/day) } \\
\hline $1^{\pi}$ & 175.1 & 213.7 & 9,002 & 97 & 1.00 & 1.00 \\
\hline 2 & 255.4 & 300.2 & 9,293 & 72 & $0.70(0.51-0.97)$ & $0.74(0.53-1.03)$ \\
\hline 3 & 321.1 & 371.2 & 9,844 & 72 & $0.67(0.48-0.92)$ & $0.71(0.51-0.99)$ \\
\hline 4 & 397.0 & 451.0 & 9,305 & 85 & $0.82(0.60-1.11)$ & $0.89(0.64-1.23)$ \\
\hline 5 & 528.6 & 589.8 & 8,870 & 80 & $0.80(0.58-1.10)$ & $0.89(0.64-1.24)$ \\
\hline$p$ for tren & & & & & 0.49 & 0.94 \\
\hline Continuo & intake & rement) & & & $0.99(0.98-1.01)$ & $1.00(0.98-1.02)$ \\
\hline \multicolumn{7}{|c|}{ Total vegetables" (g/day) } \\
\hline $1^{\pi}$ & 103.6 & 106.2 & 8,977 & 69 & 1.00 & 1.00 \\
\hline 2 & 144.4 & 149.2 & 9,653 & 78 & $1.07(0.76-1.51)$ & $1.09(0.77-1.55)$ \\
\hline 3 & 178.3 & 182.9 & 9,783 & 92 & $1.24(0.89-1.73)$ & $1.26(0.90-1.77)$ \\
\hline 4 & 217.2 & 224.0 & 9,575 & 89 & $1.23(0.88-1.72)$ & $1.27(0.90-1.78)$ \\
\hline 5 & 287.5 & 299.4 & 8,326 & 78 & $1.24(0.88-1.75)$ & $1.23(0.86-1.75)$ \\
\hline $\mathrm{p}$ for tren & & & & & 0.15 & 0.20 \\
\hline Continuo & intake & rement) & & & $1.02(0.99-1.05)$ & $1.02(0.98-1.05)$ \\
\hline \multicolumn{7}{|c|}{ Prepared vegetables (g/day) } \\
\hline $1^{\pi}$ & 79.3 & 80.5 & 9,062 & 75 & 1.00 & 1.00 \\
\hline 2 & 115.0 & 115.9 & 9,406 & 71 & $0.92(0.65-1.29)$ & $0.96(0.68-1.36)$ \\
\hline 3 & 143.6 & 144.0 & 10,002 & 79 & $0.96(0.69-1.36)$ & $0.99(0.71-1.39)$ \\
\hline 4 & 177.0 & 177.7 & 9,518 & 96 & $1.25(0.90-1.72)$ & $1.31(0.95-1.82)$ \\
\hline 5 & 236.5 & 234.1 & 8,326 & 85 & $1.25(0.90-1.74)$ & $1.23(0.88-1.72)$ \\
\hline$p$ for trer & & & & & 0.04 & 0.07 \\
\hline Continuo & intake & rement) & & & $1.03(0.99-1.07)$ & $1.02(0.98-1.07)$ \\
\hline \multicolumn{7}{|c|}{ Raw vegetables (g/day) } \\
\hline $1^{\pi}$ & 6.7 & 9.4 & 9,209 & 75 & 1.00 & 1.00 \\
\hline 2 & 19.2 & 24.7 & 9,024 & 86 & $1.16(0.83-1.61)$ & $1.15(0.83-1.61)$ \\
\hline 3 & 30.6 & 36.5 & 9,451 & 84 & $1.10(0.79-1.53)$ & $1.13(0.80-1.57)$ \\
\hline 4 & 45.5 & 52.0 & 9,586 & 85 & $1.08(0.78-1.50)$ & $1.08(0.77-1.52)$ \\
\hline 5 & 73.3 & 77.7 & 9,044 & 76 & $1.04(0.74-1.46)$ & $1.06(0.75-1.49)$ \\
\hline$p$ for trer & & & & & 0.95 & 0.99 \\
\hline Continuo & intake & rement) & & & $1.00(0.91-1.09)$ & $1.00(0.91-1.10)$ \\
\hline \multicolumn{7}{|c|}{ Brassica vegetables (g/day) } \\
\hline $1^{\pi}$ & 10.6 & 10.6 & 8,968 & 71 & 1.00 & 1.00 \\
\hline 2 & 21.0 & 19.8 & 9,669 & 70 & $0.92(0.65-1.30)$ & $0.94(0.66-1.34)$ \\
\hline 3 & 29.4 & 28.1 & 9,541 & 85 & $1.13(0.81-1.58)$ & $1.13(0.80-1.58)$ \\
\hline 4 & 39.8 & 38.2 & 9,443 & 97 & $1.32(0.96-1.83)$ & $1.37(0.99-1.91)$ \\
\hline 5 & 58.7 & 57.9 & 8,694 & 83 & $1.24(0.88-1.73)$ & $1.24(0.88-1.74)$ \\
\hline$p$ for trer & & & & & 0.05 & 0.06 \\
\hline Continuo & intake & rement) & & & $1.08(0.96-1.22)$ & $1.07(0.95-1.21)$ \\
\hline
\end{tabular}


TABLE 6.3 continued

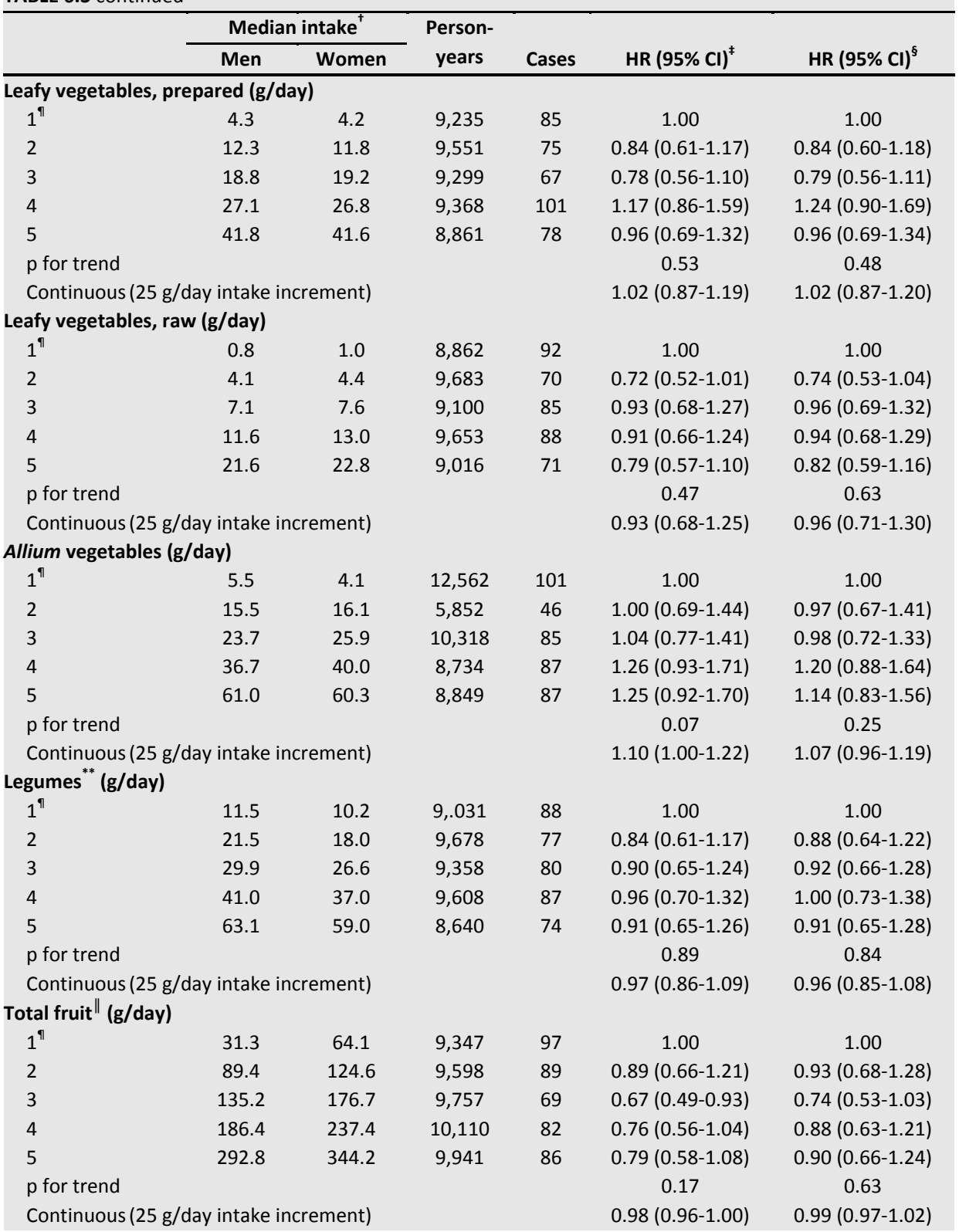


TABLE 6.3 continued

\begin{tabular}{|c|c|c|c|c|c|c|}
\hline & \multicolumn{2}{|c|}{ Median intake $^{\dagger}$} & \multirow{2}{*}{$\begin{array}{c}\text { Person- } \\
\text { years }\end{array}$} & \multirow[b]{2}{*}{ Cases } & \multirow[b]{2}{*}{$\mathrm{HR}(95 \% \mathrm{Cl})^{\ddagger}$} & \multirow[b]{2}{*}{$\mathrm{HR}(95 \% \mathrm{Cl})^{\S}$} \\
\hline & Men & Women & & & & \\
\hline \multicolumn{7}{|c|}{ Citrus fruit (g/day) } \\
\hline $1^{\text {ๆ }}$ & 0 & 3.7 & 9,130 & 91 & 1.00 & 1.00 \\
\hline 2 & 8.5 & 27.7 & 9,915 & 79 & $0.80(0.58-1.10)$ & $0.84(0.60-1.16)$ \\
\hline 3 & 29.5 & 59.9 & 10,047 & 82 & $0.80(0.58-1.10)$ & $0.87(0.63-1.21)$ \\
\hline 4 & 64.1 & 90.8 & 9,659 & 95 & $0.94(0.69-1.28)$ & $1.04(0.76-1.42)$ \\
\hline 5 & 128.7 & 170.4 & 10,004 & 76 & $0.73(0.53-1.01)$ & $0.79(0.57-1.10)$ \\
\hline \multicolumn{3}{|c|}{$p$ for trend } & & & 0.31 & 0.56 \\
\hline \multicolumn{3}{|c|}{ Continuous ( $25 \mathrm{~g} /$ day intake increment) } & & & $0.99(0.95-1.03)$ & $0.99(0.96-1.03)$ \\
\hline
\end{tabular}

First 2 years of follow-up excluded from the analysis. ${ }^{\dagger}$ Median intake in subcohort. ${ }^{\ddagger}$ The model included age (years) and sex. ${ }^{5}$ The model included age (years), sex, smoking (current smoking: yes/no; number of cigarettes smoked per day; number of years of smoking), body mass index $\left(\mathrm{kg} / \mathrm{m}^{2}\right)$, family history of pancreatic cancer (yes/no), history of diabetes mellitus (yes/no), intake of energy (kcal/day), red meat (g/day), coffee (number of cups/day), and alcohol (g/day). "Including vegetables/fruits originating from an open-ended question on frequently consumed items not listed in the questionnaire. "Reference category. ${ }^{* *}$ Also includes dried pulses, which were not included in total vegetables.

In Table 6.4, HRs are presented for carotenoids and vitamin intake. We did not observe any association for the intake of carotenoids, vitamin $C$ and $E$ and intake of supplements containing vitamin C or E. We simultaneously included the carotenoids and vitamins in a model; this did not alter the HRs (data not shown). Also, additional adjustment for fruit and vegetable consumption did not alter the results (results not shown).

Results did not differ between men and women and using the total follow-up period including the first 2 years of follow-up (results not shown). The exclusion of participants without histological confirmed pancreatic cancer did not change the null findings (results not shown). We investigated whether smoking status (never/ex/current) and BMI $\left(<25 \mathrm{~kg} / \mathrm{m}^{2}\right.$ versus $\left.\geq 25 \mathrm{~kg} / \mathrm{m}^{2}\right)$ modified the associations between vegetable and fruit intake and pancreatic cancer risk; risk estimates were not different for never, former and currents smokers and for normal versus overweight persons (results not shown). In addition, the multiplicative interaction terms were not statistically significant ( $p$ for interaction $=0.60$ for vegetables and 0.79 for fruit). 
TABLE 6.4 Age- and sex-adjusted and multivariable-adjusted hazard rate ratios (HRs) and 95\% Cls for pancreatic cancer according to quintiles or categories of carotenoids and vitamins $C$ and $E$ intake; Netherlands Cohort Study on diet and cancer, 1986-2002*

\begin{tabular}{|c|c|c|c|c|c|c|}
\hline \multirow[t]{2}{*}{ Nutrient } & \multicolumn{2}{|c|}{ Median intake $^{+}$} & \multirow{2}{*}{$\begin{array}{c}\text { Person- } \\
\text { years }\end{array}$} & \multirow[b]{2}{*}{ Cases } & \multirow[b]{2}{*}{ HR $(95 \% \mathrm{CI})^{\ddagger}$} & \multirow[b]{2}{*}{$\mathrm{HR}(95 \% \mathrm{CI})^{5}$} \\
\hline & Men & Women & & & & \\
\hline \multicolumn{7}{|c|}{ Alpha-carotene (mg/day) } \\
\hline $1^{\|}$ & 0.2 & 0.2 & 9,260 & 74 & 1.00 & 1.00 \\
\hline 2 & 0.4 & 0.4 & 9,507 & 89 & $1.16(0.84-1.61)$ & $1.23(0.88-1.71)$ \\
\hline 3 & 0.6 & 0.6 & 9,908 & 74 & $0.92(0.66-1.30)$ & $1.00(0.70-1.41)$ \\
\hline 4 & 0.8 & 0.8 & 10,130 & 102 & $1.26(0.92-1.73)$ & $1.39(1.00-1.94)$ \\
\hline 5 & 1.3 & 1.3 & 9,950 & 84 & $1.06(0.77-1.48)$ & $1.21(0.86-1.71)$ \\
\hline$p$ for $t r$ & & & & & 0.67 & 0.24 \\
\hline Contin & day inta & ncrement) & & & $1.00(0.98-1.01)$ & $1.00(0.99-1.02)$ \\
\hline \multicolumn{7}{|c|}{ Beta-carotene (mg/day) } \\
\hline $1^{\|}$ & 1.5 & 1.4 & 9,152 & 77 & 1.00 & 1.00 \\
\hline 2 & 2.1 & 2.0 & 9,841 & 74 & $0.89(0.64-1.25)$ & $0.92(0.65-1.29)$ \\
\hline 3 & 2.7 & 2.6 & 9,693 & 94 & $1.15(0.84-1.59)$ & $1.24(0.89-1.72)$ \\
\hline 4 & 3.4 & 3.3 & 10,100 & 84 & $1.02(0.73-1.41)$ & $1.12(0.80-1.57)$ \\
\hline 5 & 4.7 & 4.7 & 9,968 & 94 & $1.14(0.83-1.57)$ & $1.28(0.91-1.80)$ \\
\hline $\mathrm{p}$ for $\mathrm{tr}$ & & & & & 0.29 & 0.08 \\
\hline Contin & y intak & rement) & & & $1.00(0.94-1.06)$ & $1.02(0.96-1.09)$ \\
\hline \multicolumn{7}{|c|}{ Lutein + Zeaxanthin (mg/day) } \\
\hline $1^{\|}$ & 1.4 & 1.3 & 9,326 & 89 & 1.00 & 1.00 \\
\hline 2 & 1.9 & 1.8 & 9,861 & 72 & $0.77(0.55-1.07)$ & $0.79(0.57-1.10)$ \\
\hline 3 & 2.4 & 2.3 & 9,879 & 83 & $0.89(0.65-1.22)$ & $0.95(0.69-1.31)$ \\
\hline 4 & 2.9 & 2.8 & 9,883 & 85 & $0.92(0.67-1.27)$ & $0.98(0.71-1.36)$ \\
\hline 5 & 3.8 & 3.8 & 9,806 & 94 & $1.03(0.76-1.41)$ & $1.08(0.78-1.50)$ \\
\hline$p$ for $\operatorname{tr}$ & & & & & 0.42 & 0.29 \\
\hline Contin & y intak & rement) & & & $1.02(0.93-1.11)$ & $1.03(0.94-1.12)$ \\
\hline \multicolumn{7}{|c|}{ Beta-cryptoxanthin (mg/day) } \\
\hline $1^{\|}$ & 0.01 & 0.03 & 9,116 & 89 & 1.00 & 1.00 \\
\hline 2 & 0.04 & 0.09 & 10,068 & 85 & $0.86(0.63-1.19)$ & $0.92(0.66-1.28)$ \\
\hline 3 & 0.10 & 0.17 & 9,736 & 75 & $0.78(0.56-1.08)$ & $0.87(0.62-1.22)$ \\
\hline 4 & 0.20 & 0.27 & 9,904 & 96 & $0.96(0.70-1.30)$ & $1.06(0.77-1.46)$ \\
\hline 5 & 0.36 & 0.50 & 9,931 & 78 & $0.77(0.56-1.07)$ & $0.85(0.61-1.18)$ \\
\hline$p$ for $t r$ & & & & & 0.41 & 0.73 \\
\hline Contin & /day in & increment) & & & $0.99(0.96-1.03)$ & $1.00(0.97-1.03)$ \\
\hline \multicolumn{7}{|c|}{ Lycopene (mg/day) } \\
\hline $1^{\|}$ & 0.1 & 0.2 & 9,177 & 81 & 1.00 & 1.00 \\
\hline 2 & 0.4 & 0.6 & 9,846 & 82 & $0.92(0.67-1.28)$ & $0.91(0.65-1.27)$ \\
\hline 3 & 0.7 & 0.9 & 9,858 & 73 & $0.84(0.60-1.17)$ & $0.85(0.61-1.20)$ \\
\hline 4 & 1.1 & 1.3 & 10,043 & 97 & $1.08(0.79-1.47)$ & $1.10(0.80-1.52)$ \\
\hline 5 & 2.0 & 2.3 & 9,830 & 90 & $1.04(0.76-1.43)$ & $1.03(0.74-1.43)$ \\
\hline$p$ for $\operatorname{tr}$ & & & & & 0.46 & 0.46 \\
\hline Contin & day inta & ncrement) & & & $1.01(0.98-1.05)$ & $1.02(0.98-1.05)$ \\
\hline \multicolumn{7}{|c|}{ Vitamin $\mathrm{C}^{\text {I }}$ (mg/day) } \\
\hline $1^{\|}$ & 52.1 & 58.9 & 9,138 & 85 & 1.00 & 1.00 \\
\hline 2 & 82.0 & 93.0 & 19,807 & 163 & $0.85(0.65-1.13)$ & $0.91(0.68-1.21)$ \\
\hline 3 & 130.1 & 140.5 & 19,809 & 175 & $0.92(0.70-1.21)$ & $1.00(0.74-1.33)$ \\
\hline$p$ for $t r$ & & & & & 0.86 & 0.74 \\
\hline Contin & ay inta & crement) & & & $1.00(0.98-1.02)$ & $1.01(0.98-1.03)$ \\
\hline
\end{tabular}


TABLE 6.4 continued

\begin{tabular}{|c|c|c|c|c|c|c|}
\hline & \multicolumn{2}{|c|}{ Median intake $^{\dagger}$} & \multirow{2}{*}{$\begin{array}{c}\text { Person- } \\
\text { years }\end{array}$} & \multirow[b]{2}{*}{ Cases } & \multirow[b]{2}{*}{$\operatorname{HR}(95 \% \mathrm{Cl})^{\ddagger}$} & \multirow[b]{2}{*}{$\operatorname{HR}(95 \% \mathrm{Cl})^{\S}$} \\
\hline & Men & Women & & & & \\
\hline \multicolumn{7}{|c|}{ Vitamin E (mg/day) } \\
\hline $1^{\|}$ & 7.2 & 6.1 & 9,430 & 90 & 1.00 & 1.00 \\
\hline 2 & 10.6 & 8.5 & 9,644 & 80 & $0.90(0.66-1.24)$ & $0.93(0.66-1.29)$ \\
\hline 3 & 13.5 & 11.0 & 9,552 & 94 & $1.08(0.79-1.47)$ & $1.12(0.80-1.56)$ \\
\hline 4 & 17.2 & 14.4 & 9,993 & 80 & $0.86(0.63-1.18)$ & $0.91(0.64-1.30)$ \\
\hline 5 & 23.7 & 19.6 & 10,135 & 79 & $0.84(0.61-1.16)$ & $0.93(0.64-1.36)$ \\
\hline$p$ for trend & & & & & 0.23 & 0.63 \\
\hline Continuous ( & intak & rement) & & & $0.97(0.89-1.05)$ & $1.00(0.90-1.11)$ \\
\hline \multicolumn{7}{|c|}{ Vitamin C-containing supplement } \\
\hline Noll & - & - & 43,350 & 383 & 1.00 & 1.00 \\
\hline Yes & & & 5,404 & 40 & $0.84(0.59-1.18)$ & $0.83(0.58-1.18)$ \\
\hline \multicolumn{7}{|c|}{ Vitamin E-containing supplement } \\
\hline Noll & - & - & 45,481 & 397 & 1.00 & 1.00 \\
\hline Yes & & & 3,273 & 26 & $0.92(0.60-1.40)$ & $0.89(0.58-1.37)$ \\
\hline
\end{tabular}

First 2 years of follow-up excluded from the analysis. ${ }^{\dagger}$ Median intake in subcohort. ${ }^{\ddagger}$ The model included age (years) and sex. ${ }^{5}$ The model included age (years), sex, smoking (current smoking: yes/no; number of cigarettes smoked per day; number of years of smoking), body mass index $\left(\mathrm{kg} / \mathrm{m}^{2}\right)$, family history of pancreatic cancer (yes/no), history of diabetes mellitus (yes/no), intake of energy (kcal/day), red meat (g/day), coffee (number of cups/day), and alcohol (g/day). "Reference category. "Category 2 = quintiles $2+3$ and category 3 $=$ quintiles $4+5$.

\section{DISCUSSION}

In the present study no association was observed between pancreatic cancer risk and consumption of vegetables, fruits and juices. We also observed no association between pancreatic cancer risk and the intake of carotenoids, vitamins and vitamin supplements. These results are in agreement with other cohort studies. Results were not modified by sex, smoking status and BMI.

Inverse associations have been observed with vegetable intake in several casecontrol studies. The vegetable items reported in these studies were diverse, including total vegetable plus fruit, ${ }^{12,13}$ total vegetables, ${ }^{11,12,15}$ Brassica vegetables, ${ }^{11,13,15}$ dark green leafy vegetables, ${ }^{12}$ Allium vegetables, ${ }^{12}$ carrots, $^{12,13}$ and raw vegetables. ${ }^{11,13,15}$ Also for fruit items inverse associations have been reported for several types of fruit, including total fruit, ${ }^{10,11,13}$ citrus fruit, ${ }^{13}$ oranges, ${ }^{14}$ and bananas. ${ }^{14}$ Cohort studies on the other hand, have mainly reported null associations. ${ }^{16-22}$ Only a few prospective studies observed protective effects of vegetables and fruits on pancreatic cancer, showing inverse associations for total fruit in Japanese men (not in women), ${ }^{43}$ cabbage consumption among Swedish women, ${ }^{44}$ vegetarian protein products, beans, lentils and peas and dried fruit intake among Adventists. ${ }^{45}$ However, two of these studies had low case numbers $(<150) .{ }^{44,45}$ The Multiethnic Cohort Study observed an increased pancreatic cancer risk for high intake of fruit; this was, however, most apparent among non-smokers and no association has been found for citrus fruit. ${ }^{46}$ For fruit juices mixed 
results have been observed as well, showing inverse associations ${ }^{12,43}$ and no associations. $^{11,21}$

The Multiethnic Cohort Study found no association between total vegetable intake and pancreatic cancer risk overall; they found, however, some protection against pancreatic cancer in high-risk subgroups (i.e., current smokers and overweight/obese persons). They observed a significantly inverse association with dark green vegetable consumption among current smokers. ${ }^{18}$ They also observed an inverse association with total vegetables in overweight/obese persons $\left(\geq 25 \mathrm{~kg} / \mathrm{m}^{2}\right)$. We, as well as others, ${ }^{21,47}$ did not observe such findings.

For carotenoids and vitamins, case-control studies observed inverse associations for beta-carotene, ${ }^{11,23}$ lycopene (in men), ${ }^{25}$ vitamin $C_{1}^{11,14,23}$ and $E_{;}{ }^{14,23}$ cohort studies reported only null findings on these carotenoids and vitamin intake. ${ }^{19,20}$ Other carotenoids, such as alpha-carotene, lutein plus zeaxanthin and beta-cryptoxanthin, have only been investigated in case-control studies so $\mathrm{far}^{15,25}$ showing no associations with pancreatic cancer risk.

Inconsistencies could have occurred because case-control studies are prone to more biases compared with cohort studies, including recall bias; risk estimates might be either exaggerated or underestimated because dietary intake is assessed in cases after diagnosis. Also selection bias is a problem due to high and rapid fatality rates of pancreatic cancer cases. Differential misclassification of the exposure could also have occurred due to the need to use next-of-kin interviews in case-control studies because pancreatic cancer is rapidly fatal. In addition, for several studies no dietary information was available on individual vegetables or fruits ${ }^{16,17,22}$ and some studies had small sample sizes ( $\mathrm{n}$ cases $<150$ ). ${ }^{19,22,44,45}$

In the current study, an extensive list of vegetables and fruits was assessed. On the other hand, dietary assessment is liable to error and may have resulted in misclassification of exposure. Vegetables are generally considered as food items that are not very easy to assess in FFQs, particularly if portion sizes have to be estimated. We have intended to minimize the amount of uninformative data. Subjects with incomplete or inconsistent dietary data and, specifically, those participants who appeared not to have understood how to answer the questions on vegetable consumption, were excluded. If misclassification has occurred, we expect this to be non-differential and risk estimates will be most likely biased towards the null value. In the NLCS validation study, the correlation coefficient between the 9-day diet record and the FFQ for total vegetable consumption was $0.38 .{ }^{36}$ This correlation is low, but comparable to the figure reported for other prospective studies. ${ }^{43,44,48}$ One of the reasons for the low correlation could be that our study population may have been too homogeneous regarding intake and therefore may have yielded too little contrast between highest and lowest quintile of total vegetable consumption to detect differences in pancreatic cancer risk. Due to individual preferences, however, contrast in consumption frequency of many specific vegetables as well as for fruit is much higher. Although we cannot entirely exclude the possibility that the absence of protective effects of vegetables and fruits 
on pancreatic cancer is due to measurement error or too little contrast in our data, this can not be unique for our study and it does not explain why especially case-control studies observed protective associations. A large European cohort study - which also did not observe an association between pancreatic cancer risk and fruit and vegetable consumption - has a wider range of fruit and vegetable intake compared with other prospective cohort studies, caused by inclusion of participants from Northern to Southern Europeans countries. ${ }^{21}$ However, their range of fruit and vegetable intake was comparable to ours.

Strengths of this study include the possibility to further restrict the analyses to MCPC cases only ${ }^{42}$ and the large sample size. Differential follow-up is unlikely to have made a material contribution to our findings, as completeness of follow-up was high. ${ }^{30}$ The prospective design avoided recall bias and the need to use next-of-kin respondents.

In conclusion, we observed no association between pancreatic cancer risk and a high consumption of vegetables and fruits in the NLCS, which is in agreement with previous prospective studies. Furthermore, we observed no association between the intake of alpha-carotene, beta-carotene, lutein plus zeaxanthin, beta-cryptoxanthin, lycopene, and vitamins $\mathrm{C}$ and $\mathrm{E}$ and pancreatic cancer risk.

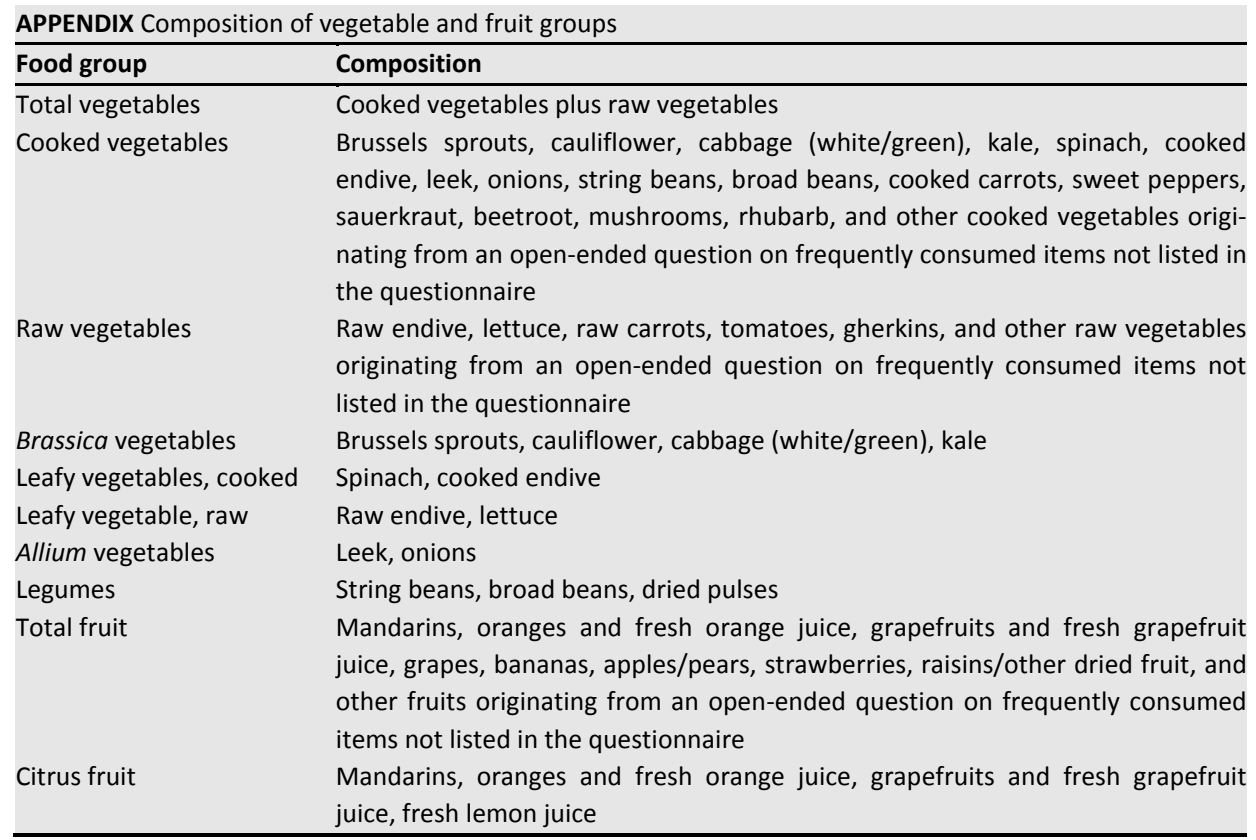




\section{REFERENCES}

1. Ferlay J, Autier $\mathrm{P}$, Boniol $\mathrm{M}$, Heanue $\mathrm{M}$, Colombet $\mathrm{M}$, Boyle $\mathrm{P}$. Estimates of the cancer incidence and mortality in Europe in 2006. Ann Oncol 2007;18:581-92.

2. Jemal A, Siegel R, Ward E, et al. Cancer statistics, 2008. CA Cancer J Clin 2008;58:71-96.

3. Karim-Kos HE, de Vries E, Soerjomataram I, Lemmens V, Siesling S, Coebergh JW. Recent trends of cancer in Europe: a combined approach of incidence, survival and mortality for 17 cancer sites since the 1990s. Eur J Cancer 2008;44:1345-89.

4. World Cancer Research Fund/American Institute for Cancer research. Food, nutrition, physical activity, and the prevention of cancer: a global perspective. Washington DC: AICR, 2007.

5. Fuchs CS, Colditz GA, Stampfer MJ, et al. A prospective study of cigarette smoking and the risk of pancreatic cancer. Arch Intern Med 1996;156:2255-60.

6. Huxley R, Ansary-Moghaddam A, Berrington de Gonzalez A, Barzi F, Woodward M. Type-II diabetes and pancreatic cancer: a meta-analysis of 36 studies. Br J Cancer 2005;92:2076-83.

7. McCullough ML, Giovannucci EL. Diet and cancer prevention. Oncogene 2004;23:6349-64.

8. Appel MJ, van Garderen-Hoetmer A, Woutersen RA. Lack of inhibitory effects of beta-carotene, vita$\min C$, vitamin $E$ and selenium on development of ductular adenocarcinomas in exocrine pancreas of hamsters. Cancer Lett 1996;103:157-62.

9. Woutersen RA, Appel MJ, Van Garderen-Hoetmer A. Modulation of pancreatic carcinogenesis by antioxidants. Food Chem Toxicol 1999;37:981-4.

10. Anderson LN, Cotterchio M, Gallinger S. Lifestyle, dietary, and medical history factors associated with pancreatic cancer risk in Ontario, Canada. Cancer Causes Control 2009;20:825-34.

11. Bueno de Mesquita HB, Maisonneuve P, Runia S, Moerman CJ. Intake of foods and nutrients and cancer of the exocrine pancreas: a population-based case-control study in The Netherlands. Int J Cancer 1991;48:540-9.

12. Chan JM, Wang F, Holly EA. Vegetable and fruit intake and pancreatic cancer in a population-based case-control study in the San Francisco bay area. Cancer Epidemiol Biomarkers Prev 2005;14:2093-7.

13. Howe GR, Burch JD. Nutrition and pancreatic cancer. Cancer Causes Control 1996;7:69-82.

14. Ji BT, Chow WH, Gridley G, et al. Dietary factors and the risk of pancreatic cancer: a case-control study in Shanghai China. Cancer Epidemiol Biomarkers Prev 1995;4:885-93.

15. Silverman DT, Swanson CA, Gridley G, et al. Dietary and nutritional factors and pancreatic cancer: a case-control study based on direct interviews. J Natl Cancer Inst 1998;90:1710-9.

16. Coughlin SS, Calle EE, Patel AV, Thun MJ. Predictors of pancreatic cancer mortality among a large cohort of United States adults. Cancer Causes Control 2000;11:915-23.

17. George SM, Park Y, Leitzmann MF, et al. Fruit and vegetable intake and risk of cancer: a prospective cohort study. Am J Clin Nutr 2009;89:347-53.

18. Nothlings U, Wilkens LR, Murphy SP, Hankin JH, Henderson BE, Kolonel LN. Vegetable intake and pancreatic cancer risk: the multiethnic cohort study. Am J Epidemiol 2007;165:138-47.

19. Shibata A, Mack TM, Paganini-Hill A, Ross RK, Henderson BE. A prospective study of pancreatic cancer in the elderly. Int J Cancer 1994;58:46-9.

20. Stolzenberg-Solomon RZ, Pietinen P, Taylor PR, Virtamo J, Albanes D. Prospective study of diet and pancreatic cancer in male smokers. Am J Epidemiol 2002;155:783-92.

21. Vrieling A, Verhage BA, van Duijnhoven FJ, et al. Fruit and vegetable consumption and pancreatic cancer risk in the European Prospective Investigation into Cancer and Nutrition. Int J Cancer 2009;124: 1926-34.

22. Zheng W, McLaughlin JK, Gridley G, et al. A cohort study of smoking, alcohol consumption, and dietary factors for pancreatic cancer (United States). Cancer Causes Control 1993;4:477-82.

23. Baghurst PA, McMichael AJ, Slavotinek AH, Baghurst KI, Boyle P, Walker AM. A case-control study of diet and cancer of the pancreas. Am J Epidemiol 1991;134:167-79.

24. Howe GR, Jain M, Miller AB. Dietary factors and risk of pancreatic cancer: results of a Canadian population-based case-control study. Int J Cancer 1990;45:604-8. 
25. Nkondjock A, Ghadirian P, Johnson KC, Krewski D. Dietary intake of lycopene is associated with reduced pancreatic cancer risk. J Nutr 2005;135:592-7.

26. van den Brandt PA, Goldbohm RA, van 't Veer P, Volovics A, Hermus RJ, Sturmans F. A large-scale prospective cohort study on diet and cancer in The Netherlands. J Clin Epidemiol 1990;43:285-95.

27. Prentice RL. A case-cohort design for epidemiologic cohort studies and disease prevention trials. Biometrika 1986;73:1-11.

28. Casparie M, Tiebosch AT, Burger G, et al. Pathology databanking and biobanking in The Netherlands, a central role for PALGA, the nationwide histopathology and cytopathology data network and archive. Cell Oncol 2007;29:19-24.

29. van den Brandt PA, Schouten LJ, Goldbohm RA, Dorant E, Hunen PM. Development of a record linkage protocol for use in the Dutch Cancer Registry for Epidemiological Research. Int J Epidemiol 1990;19: 553-8.

30. Goldbohm RA, van den Brandt PA, Dorant E. Estimation of the coverage of Dutch municipalities by cancer registries and PALGA based on hospital discharge data. Tijdschr Soc Gezondheidsz 1994;72: 80-4.

31. van der Sanden GA, Coebergh JW, Schouten LJ, Visser O, van Leeuwen FE. Cancer incidence in The Netherlands in 1989 and 1990: first results of the nationwide Netherlands cancer registry. Coordinating Committee for Regional Cancer Registries. Eur J Cancer 1995;31A:1822-9.

32. What does the Netherlands consume; results of the national food consumption survey of 1987-1988 [in Dutch]. Rijswijk, the Netherlands: Distributiecentrum DOP, 1988.

33. Anonymous. NEVO-tabel: Nederlands voedingsstoffenbestand 1986-1987 (Nevo table: Dutch Food Composition Table 1986-1987 [in Dutch]). The Hague, the Netherlands: Voorlichtingsbureau voor de voeding, 1986.

34. Goldbohm RA, Brants HA, Hulshof KF, van den Brandt PA. The contribution of various foods to intake of vitamin A and carotenoids in The Netherlands. Int J Vitam Nutr Res 1998;68:378-83.

35. Dorant E, van den Brandt PA, Goldbohm RA, Hermus RJ, Sturmans F. Agreement between interview data and a self-administered questionnaire on dietary supplement use. Eur J Clin Nutr 1994;48:180-8.

36. Goldbohm RA, van den Brandt PA, Brants HA, et al. Validation of a dietary questionnaire used in a large-scale prospective cohort study on diet and cancer. Eur J Clin Nutr 1994;48:253-65.

37. Goldbohm RA, van 't Veer P, van den Brandt PA, et al. Reproducibility of a food frequency questionnaire and stability of dietary habits determined from five annually repeated measurements. Eur J Clin Nutr 1995;49:420-9.

38. Volovics A, van den Brandt PA. Methods for the analysis of case-cohort studies. Biom J 1997;39: 195-214.

39. Barlow WE, Ichikawa L, Rosner D, Izumi S. Analysis of case-cohort designs. J Clin Epidemiol 1999;52: 1165-72.

40. Schoenfeld D. Partial residuals for the proportional hazards regression model. Biometrika 1982;69: 239-41.

41. Malats N, Real FX, Porta M. DDT and pancreatic cancer. J Natl Cancer Inst 1993;85:328-9.

42. Verhage BA, Schouten $\amalg$, Goldbohm RA, van den Brandt PA. Anthropometry and pancreatic cancer risk: an illustration of the importance of microscopic verification. Cancer Epidemiol Biomarkers Prev 2007;16:1449-54.

43. Lin Y, Kikuchi S, Tamakoshi A, et al. Dietary habits and pancreatic cancer risk in a cohort of middle-aged and elderly Japanese. Nutr Cancer 2006;56:40-9.

44. Larsson SC, Hakansson N, Naslund I, Bergkvist L, Wolk A. Fruit and vegetable consumption in relation to pancreatic cancer risk: a prospective study. Cancer Epidemiol Biomarkers Prev 2006;15:301-5.

45. Mills PK, Beeson WL, Abbey DE, Fraser GE, Phillips RL. Dietary habits and past medical history as related to fatal pancreas cancer risk among Adventists. Cancer 1988;61:2578-85.

46. Nothlings U, Murphy SP, Wilkens LR, Henderson BE, Kolonel LN. Dietary glycemic load, added sugars, and carbohydrates as risk factors for pancreatic cancer: the Multiethnic Cohort Study. Am J Clin Nutr 2007;86:1495-501. 
47. Mueller NT, Odegaard A, Anderson K, et al. Soft drink and juice consumption and risk of pancreatic cancer: the Singapore Chinese Health Study. Cancer Epidemiol Biomarkers Prev 2010;19:447-55.

48. Smith-Warner SA, Elmer PJ, Fosdick L, Tharp TM, Randall B. Reliability and comparability of three dietary assessment methods for estimating fruit and vegetable intakes. Epidemiology 1997;8:196-201. 


\title{
Active and passive smoking and the risk of pancreatic cancer in the Netherlands Cohort Study
}

\author{
Mirjam M. Heinen \\ Bas A.J. Verhage \\ R. Alexandra Goldbohm \\ Piet A. van den Brandt
}




\section{ABSTRACT}

\section{Background}

To date, cigarette smoking is the most consistent risk factor for pancreatic cancer. We prospectively examined the role of active cigarette smoking, smoking cessation, and passive smoking as determinants for pancreatic cancer.

\section{Methods}

The Netherlands Cohort Study consisted of 120,852 men and women who completed a baseline questionnaire in 1986 . After 16.3 years of follow-up, 520 incident pancreatic cancer cases were available for analysis. A case-cohort approach was employed using the person-years of follow-up of a random subcohort $(n=5,000)$, which was chosen immediately after baseline.

\section{Results}

Compared with never cigarette smokers, both former and current cigarette smokers had an increased pancreatic cancer risk (multivariable-adjusted hazard rate ratio $[H R]=$ 1.34, 95\% confidence interval $[\mathrm{Cl}]: 1.02-1.75$ and $\mathrm{HR}=1.82,95 \% \mathrm{Cl}: 1.40-2.38$, respectively). We observed an increased pancreatic cancer risk per increment of 10 years of smoking ( $\mathrm{HR}=1.15,95 \% \mathrm{Cl}: 1.08-1.22)$ and an HR of 1.08 per increment of 10 cigarettes/day (95\% Cl: 0.98-1.19). Quitting smoking gradually reduced pancreatic cancer risk and approached unity after $\geq 20$ years of quitting. No association was observed for passive smoking exposure and pancreatic cancer risk in women; in men, this association was not investigated because $>90 \%$ of the men were ever smokers.

\section{Conclusions}

Overall, our findings confirmed that cigarette smoking is an important risk factor for pancreatic cancer, whereas quitting smoking reduced risk. No association was observed between passive smoking exposure and pancreatic cancer risk in women.

\section{Impact}

Quitting smoking would benefit the burden on pancreatic cancer incidence. 


\section{INTRODUCTION}

To date, cigarette smoking is the most consistent risk factor for pancreatic cancer. ${ }^{1}$ Most studies, including several cohort studies, a meta-analysis, and a pooled analysis of eight cohorts, indicated that current smokers had about a 2-fold increased pancreatic cancer risk compared with never smokers. ${ }^{2-6}$ Former smokers experience lower increased risks of pancreatic cancer as compared with current smokers, with risks ranging from 1.1 to $1.6^{2,7-11}$ Pancreatic cancer risk increases with both number of cigarettes smoked daily ${ }^{3,5-8,12}$ and duration of smoking. ${ }^{3,5,8,10,11}$ After quitting cigarette smoking, the risk decreases gradually within 10 to 15 years towards unity. ${ }^{5,8,12,13}$

Data on the effect of passive smoking on pancreatic cancer risk is scarce because studies have been hindered by the relatively few non-smokers of any type of tobacco. Exclusion of tobacco smokers from such studies is important to estimate the independent effect of passive smoking. Thus far, four case-control ${ }^{14-17}$ and four cohort studies $^{7,9,18,19}$ have examined the relationship between passive smoking exposure and the risk of pancreatic cancer. Three of these studies observed a positive association with passive smoking in never smokers. ${ }^{7,15,18}$

In the current study, we examined active cigarette smoking, smoking cessation, and passive smoking as determinants for pancreatic cancer in a large prospective cohort study in the Netherlands.

\section{MATERIALS AND METHODS}

\section{Study population and cancer follow-up}

The study design of the Netherlands Cohort Study has been reported in detail elsewhere. $^{20}$ Briefly, the Netherlands Cohort Study was begun in September 1986 and included initially 58,279 men and 62,573 women ages 55 to 69 years from 204 Dutch municipalities with computerized population registries. A self-administered food frequency and lifestyle questionnaire was completed at baseline. For increased efficiency in the processing of the questionnaire and follow-up, the case-cohort approach was used. ${ }^{21}$ Incident cases were derived from the entire cohort, whereas the person-years at risk were estimated from a random sample of 5,000 subjects (2,411 men and 2,589 women). This subcohort was chosen immediately after baseline and followed up for vital status information. The entire cohort is being monitored for cancer occurrence by annual record linkage to the Netherlands Cancer Registry and the Netherlands Pathology Registry. ${ }^{22,23}$ A total of 16.3 years of follow-up (baseline to December 2002) was used for the current analysis. Only one subcohort member was lost to follow-up and completeness of follow-up was estimated to be $>96 \%{ }^{24}$

All prevalent cancer cases at baseline other than skin cancer were excluded, resulting in a subcohort of 4,774 men and women. Of the 567 incident pancreatic cancer cases (International Classification of Diseases for Oncology-3 code C25), cases with 
endocrine subtypes (International Classification of Diseases for Oncology-3 code C25.4; $n=1$ ) were excluded. Sixty-two percent of the 566 pancreatic cancer cases were microscopically confirmed pancreatic cancer $(n=350)$, whereas confirmation was lacking for $38 \%$ (non-microscopically confirmed pancreatic cancer; $n=216$ ). Diagnosis of the latter group was made by the treating clinician and was based on clinical symptoms, physical examination, and imaging results. Data were abstracted and recorded by a trained tumor registrar. ${ }^{25}$ The Netherlands Cohort Study has been approved by the institutional review boards of the TNO Nutrition and Food Research Institute (Zeist, the Netherlands) and Maastricht University (Maastricht, the Netherlands).

\section{Exposure assessment}

In the questionnaire, tobacco smoking was addressed through questions on smoking status (never, former, or current smoker) and inhalation for cigarette, cigar, and pipe smokers. ${ }^{26,27}$ In addition, open-ended questions were asked on the ages at first and last exposure to smoking, smoking frequency, and smoking duration for cigarette, cigar, and pipe smokers. Furthermore, questions were asked about the cigarette brand most commonly smoked with or without filter-tip and the proportion of a cigarette actually smoked (using a visual analog scale). ${ }^{27}$ Using cigarette brand-specific information obtained from the Dutch Inspectorate for Health Protection, the Dutch Foundation on Smoking and Health, and the Dutch Foundation of the Tobacco Industry in combination with daily cigarette smoking frequency and the proportion of a cigarette actually smoked, we calculated the daily exposure to tar and nicotine for ever cigarette smokers. ${ }^{27}$ Passive smoking exposure was investigated using questions on smoking habits of parents and spouses, exposure to passive smoking at work (past or present), and duration of current daily exposure to passive smoking (open-ended question; private and occupational settings combined). ${ }^{27}$ The dietary section of the questionnaire was a 150 item semiquantitative food frequency questionnaire. Questionnaire data were keyentered and processed for all incident cases in the cohort and subcohort members in a standardized manner, blinded with respect to case/subcohort status. This was done to minimize observer bias in the coding and interpretation of the data. Subcohort members and cases with incomplete or inconsistent dietary data were excluded from analyses. These subjects had either (i) left $>60$ (of the 150 items) questionnaire items blank and ate $<35$ items at least once a month or (ii) left one or more item blocks (groups of items, e.g., beverages) blank. Additional details are given elsewhere. ${ }^{28}$ This resulted in a final subcohort of 4,438 subjects (2,191 men and 2,247 women) and 520 exocrine pancreatic cancer cases ( 280 men and 240 women) available for analysis.

\section{Statistical analysis}

Age-adjusted and multivariable-adjusted hazard rate ratios (HR) and corresponding 95\% confidence intervals $(95 \% \mathrm{Cl}$ ) were estimated using Cox proportional hazards models. The total person-years at risk estimated from the subcohort were used in the analyses. ${ }^{29}$ Standard errors were estimated using a robust covariance matrix estimator 
to account for increased variance due to sampling from the cohort. ${ }^{30}$ We tested the proportional hazards assumption using the scaled Schoenfeld residuals. ${ }^{31}$ Interactions on a multiplicative scale between sex and any of the smoking variables used in the current study were tested for pancreatic cancer and never found to be statistically significant ( $p$ for interaction $>0.05$ ). Therefore, results for analyses on cigarette smoking are presented for both sexes combined. No analyses were done on cigar and pipe smoking because among never cigarette smokers, only three cases ever smoked cigars or pipes. For passive smoking exposure, analyses were restricted to women (124 cases, 1,312 subcohort members) who never smoked cigarettes, cigars, or pipes. We excluded men in these analyses because $>90 \%$ of the men were ever smokers.

Based on questionnaire data, the following categorical variables were constructed for active cigarette smoking: status (former smoker/current smoker), frequency (0.1$<10,10-<20, \geq 20$ cigarettes/day), inhalation (no/yes), filter usage (filter-tipped/nonfilter-tipped), duration (0.1-<20, 20-<40, $\geq 40$ years), time since cessation (quit $\geq 20,15$ $<20,10-<15,0.1-<10$ years, or current smoker), and $\operatorname{tar}(0.1-<200,200-<400, \geq 400$ $\mathrm{mg} /$ day) and nicotine exposure $(0.1-<10,10-<20,20-<30, \geq 30 \mathrm{mg} /$ day). HRs for pa $\mathrm{n}-$ creatic cancer were estimated accordingly, with subjects who never smoked cigarettes regarded as the reference group. HRs were also estimated for continuous exposures using an increment of 10 cigarettes per day for frequency. For duration and years since cessation, an increment of 10 years was used. For tar and nicotine exposure, we used an increment of $100 \mathrm{mg}$ and $10 \mathrm{mg} /$ day, respectively. Passive smoking exposure was operationalized in four separate variables: spouse smoking status (never smoked/ former smokers/current smokers), parental smoking (no/yes), exposure to passive smoking at work (never exposed/occasionally exposed/regularly or always exposed), and duration of passive smoking exposure (categorical variable: never, $0.1-<3, \geq 3$ hours/day; continuous variable: increments of 1 hour/day).

Based on the literature, the following variables were considered as potential confounders: age, sex, body mass index (BMI), energy intake, alcohol intake, intake of vegetables and fruit, level of education, moderate non-occupational physical activity, family history of pancreatic cancer, history of diabetes mellitus, and hypertension. These potential confounding variables were added to the multivariable-adjusted model if they $(i)$ were associated with the disease and with the exposure of interest and (ii) changed the risk estimate by at least $10 \%$ (using a backwards stepwise procedure). For analyses on cigarette smoking, the following confounders were included in the first multivariable-adjusted model: age at baseline (years), sex, BMI $\left(\mathrm{kg} / \mathrm{m}^{2}\right)$, alcohol intake (g/day), and intake of fruit (g/day). For analyses on passive smoking, the following confounders were included in the multivariable-adjusted model: age at baseline (years), BMI $\left(\mathrm{kg} / \mathrm{m}^{2}\right)$, and level of education (primary school or lower vocational school/intermediate vocational school or high school/higher vocational school or college). In additional analyses on cigarette smoking, we included smoking status, duration, and frequency simultaneously into the model to identify which factor of smoking in this model is most important to pancreatic cancer risk. In additional analyses on the 
categorical variable of time since cessation, frequency and duration were included in the model. For the continuous variable of time since cessation, frequency, duration, and current smoking status (yes/no) were additionally included in the model. Furthermore, we investigated whether inhalation and filter usage had any effect on top of duration, frequency, and current smoking status. We also investigated this for tar and nicotine exposure; however, we did not include frequency in these models because the variables of tar and nicotine exposure were calculated by multiplying the number of cigarettes per day by the amount of tar and nicotine per cigarette. In additional analyses, we excluded cigar or pipe smokers. To enable comparison, age- and sex-adjusted analyses were restricted to subjects included in multivariable-adjusted analyses. For each analysis, trends were evaluated with the Wald test by assigning participants the median value for each level of the categorical exposure variable among the subcohort members and this variable was entered as a continuous term in the Cox regression model. For the trend analysis on cigarette smoking variables, never cigarette smokers were excluded to evaluate whether a large amount of exposure was measurably worse than a small amount of exposure.

In the present study, the overall analyses included all pancreatic cancer cases. We restricted additional analyses to microscopically confirmed pancreatic cancer cases to create a group with a higher degree of diagnostic certainty of pancreatic cancer, which was shown to be important in previous studies. ${ }^{32,33}$ In additional analyses, individuals who reported a history of diabetes at baseline $(n=185)$ were excluded. To evaluate whether early symptoms of disease before diagnosis could have influenced the results, early cases (diagnosed within 2 years after baseline) were excluded in additional analyses.

In addition, we calculated the population-attributable fraction (PAF) of pancreatic cancer cases to estimate how many cases theoretically could be prevented if no individuals would smoke. The PAF was calculated according to the following equation: PAF $=P_{d} \times([R R-1] / R R) \cdot{ }^{34,35} P_{d}$ is the proportion of smokers among all pancreatic cancer cases, and RR is the adjusted risk estimate of pancreatic cancer risk comparing ever versus never smokers. The confidence limits were estimated using: In(1-PAF). ${ }^{34}$ All analyses were done using the STATA statistical software package (Intercooled STATA, version 9). All $p$ values were based on two-sided tests and considered statistically significant if $p<0.05$. 


\section{RESULTS}

In Table 7.1, baseline characteristics (stratified by sex) are presented. Most characteristics did not differ between pancreatic cancer cases and subcohort members; however, there were more current smokers among cases than among subcohort members, especially in men.

TABLE 7.1 Baseline characteristics (means or percent) of pancreatic cancer cases and subcohort members; Netherlands Cohort Study on diet and cancer (1986-2002)

\begin{tabular}{|c|c|c|c|c|}
\hline \multirow[t]{2}{*}{ Characteristics } & \multicolumn{2}{|c|}{ Men } & \multicolumn{2}{|c|}{ Women } \\
\hline & $\begin{array}{c}\text { Total pancreatic } \\
\text { cancer cases }\end{array}$ & Subcohort & $\begin{array}{c}\text { Total pancreatic } \\
\text { cancer cases }\end{array}$ & Subcohort \\
\hline $\mathrm{n}$ & 280 & 2,191 & 240 & 2,247 \\
\hline Age, mean \pm SD (years) & $62.0 \pm 3.9$ & $61.3 \pm 4.2$ & $62.5 \pm 4.3$ & $61.4 \pm 4.3$ \\
\hline \multicolumn{5}{|l|}{ Use of tobacco products, $n(\%)$} \\
\hline Never tobacco smoker & $14(5.0)$ & $201(9.2)$ & $124(51.7)$ & $1,312(58.4)$ \\
\hline Ever cigarette smoker & $181(64.6)$ & $1,322(60.3)$ & 115 (47.9) & $930(41.4)$ \\
\hline Ever cigar smoker & $1(0.4)$ & $46(2.1)$ & - & - \\
\hline Ever pipe smoker & $2(0.7)$ & $8(0.4)$ & - & - \\
\hline Ever cigar and pipe smoker & $3(1.1)$ & $23(1.0)$ & - & - \\
\hline \multicolumn{5}{|l|}{ Ever cigarette and other type of tobacco } \\
\hline \multicolumn{5}{|l|}{ Cigarette smoking features } \\
\hline \multicolumn{5}{|l|}{ Smoking status, n (\%) } \\
\hline Never & $20(7.1)$ & $278(12.7)$ & $124(51.7)$ & $1,312(58.4)$ \\
\hline Former smoker & $128(45.7)$ & $1,130(51.6)$ & $50(20.8)$ & $463(20.6)$ \\
\hline Current smoker & $132(47.2)$ & $783(35.7)$ & $66(27.5)$ & $472(21.0)$ \\
\hline Duration $^{*}$, mean \pm SD (years) & $36.1 \pm 11.9$ & $33.7 \pm 11.8$ & $29.0 \pm 12.2$ & $27.8 \pm 12.5$ \\
\hline Frequency ${ }^{*}$, mean \pm SD (cigarettes/day) & $17.3 \pm 11.5$ & $17.0 \pm 10.6$ & $11.4 \pm 8.0$ & $11.4 \pm 8.3$ \\
\hline Age at first exposure ${ }^{*}$, mean $\pm S D$ (years) & $17.3 \pm 4.4$ & $17.1 \pm 3.8$ & $23.3 \pm 7.7$ & $23.7 \pm 8.9$ \\
\hline Age at cessation ${ }^{*}$, mean \pm SD (years) & $48.2 \pm 11.0$ & $46.6 \pm 10.2$ & $49.2 \pm 10.3$ & $46.8 \pm 11.1$ \\
\hline \multicolumn{4}{|l|}{ Inhalation ${ }^{*}, \mathrm{n}(\%)$} & $7.0 \pm 10.3$ \\
\hline No & $57(23.0)$ & $385(20.7)$ & 57 (49.6) & $424(46.5)$ \\
\hline Yes & $191(77.0)$ & $1,478(79.3)$ & $58(50.4)$ & $487(53.5)$ \\
\hline \multicolumn{5}{|l|}{ Filter usage ${ }^{*}, \mathrm{n}(\%)$} \\
\hline Filter-tipped & $40(20.9)$ & $244(17.4)$ & $68(70.8)$ & $530(72.0)$ \\
\hline Non-filter-tipped & $151(79.1)$ & $1,158(82.6)$ & $28(29.2)$ & $206(28.0)$ \\
\hline $\mathrm{Tar}^{*}$, mean $\pm \mathrm{SD}$ (mg/day) & $357.3 \pm 237.3$ & $348.0 \pm 227.2$ & $165.4 \pm 149.1$ & $156.8 \pm 148.5$ \\
\hline Nicotine ${ }^{*}$, mean \pm SD (mg/day) & $31.3 \pm 25.7$ & $30.2 \pm 24.3$ & $12.5 \pm 11.1$ & $12.3 \pm 11.4$ \\
\hline \multicolumn{5}{|l|}{ Passive smoking $^{\dagger}$} \\
\hline \multicolumn{5}{|l|}{ Spouse smoking status, $\mathrm{n}(\%)$} \\
\hline Never & $12(92.3)$ & $128(69.2)$ & $21(18.9)$ & $182(15.8)$ \\
\hline Ever & $1(7.7)$ & $57(30.8)$ & $90(81.1)$ & $972(84.2)$ \\
\hline \multicolumn{5}{|l|}{ Parental smoking, $\mathrm{n}(\%)$} \\
\hline No parent smoked & $1(7.1)$ & $47(24.0)$ & $20(16.5)$ & $193(15.2)$ \\
\hline One or both parents smoked & $13(92.9)$ & $149(76.0)$ & $101(83.5)$ & $1,079(84.8)$ \\
\hline \multicolumn{5}{|c|}{ Passive smoking exposure at work (past or present), $\mathrm{n}(\%)$} \\
\hline Low exposure & $5(41.7)$ & $97(53.3)$ & 64 (71.1) & $578(60.0)$ \\
\hline High exposure & $7(58.3)$ & 85 (46.7) & 26 (28.9) & $386(40.0)$ \\
\hline
\end{tabular}




\begin{tabular}{|c|c|c|c|c|}
\hline & \multicolumn{2}{|c|}{ Men } & \multicolumn{2}{|c|}{ Women } \\
\hline & $\begin{array}{c}\text { Total pancreatic } \\
\text { cancer cases }\end{array}$ & Subcohort & $\begin{array}{c}\text { Total pancreatic } \\
\text { cancer cases }\end{array}$ & Subcohort \\
\hline $\begin{array}{l}\text { Duration current passive smoking expo- } \\
\text { sure, mean } \pm S D \text { (hours/day) }\end{array}$ & $8.2 \pm 4.7$ & $3.7 \pm 4.1$ & $4.7 \pm 5.5$ & $4.4 \pm 4.7$ \\
\hline $\mathrm{BMI}$, mean $\pm \mathrm{SD}\left(\mathrm{kg} / \mathrm{m}^{2}\right)$ & $25.2 \pm 3.0$ & $25.0 \pm 2.6$ & $25.5 \pm 3.6$ & $25.1 \pm 3.6$ \\
\hline \multicolumn{5}{|l|}{ Physical activity (non-occupational), n (\%) } \\
\hline$<30 \mathrm{~min} /$ day & 50 (17.9) & $396(18.3)$ & $57(23.9)$ & $553(24.9)$ \\
\hline $30-60 \mathrm{~min} / \mathrm{day}$ & $94(33.6)$ & $675(31.2)$ & $77(32.2)$ & $691(31.2)$ \\
\hline $60-90 \mathrm{~min} / \mathrm{day}$ & $66(23.6)$ & $405(18.7)$ & $62(25.9)$ & $498(22.5)$ \\
\hline$>90 \mathrm{~min} /$ day & $70(25.0)$ & $689(31.8)$ & $43(18.0)$ & $476(21.5)$ \\
\hline Family history of pancreatic cancer, $\mathrm{n}(\%)$ & $5(1.8)$ & $22(1.0)$ & $9(3.8)$ & $20(0.9)$ \\
\hline History of diabetes, $\mathrm{n}(\%)$ & $21(7.5)$ & $75(3.4)$ & $10(4.2)$ & $80(3.6)$ \\
\hline History of hypertension, n (\%) & $58(20.7)$ & $512(23.4)$ & $73(30.4)$ & $662(29.5)$ \\
\hline \multicolumn{5}{|l|}{ Level of education, n (\%) } \\
\hline Low & $132(47.5)$ & $997(45.7)$ & $137(57.3)$ & $1,266(56.7)$ \\
\hline Medium & $89(32.0)$ & $775(35.6)$ & $83(34.7)$ & 771 (34.5) \\
\hline High & $57(20.5)$ & $408(18.7)$ & $19(8.0)$ & $197(8.8)$ \\
\hline \multicolumn{5}{|l|}{ Daily intake, mean \pm SD } \\
\hline Energy (kcal) & $2,164 \pm 466$ & $2,166 \pm 511$ & $1,688 \pm 397$ & $1,686 \pm 398$ \\
\hline Total carbohydrates ${ }^{\ddagger}(\mathrm{g})$ & $224.0 \pm 38.5$ & $226.7 \pm 37.5$ & $177.3 \pm 26.8$ & $178.8 \pm 26.7$ \\
\hline Total fat ${ }^{\ddagger}(\mathrm{g})$ & $92.7 \pm 13.4$ & $93.9 \pm 14.3$ & $74.1 \pm 10.9$ & $74.0 \pm 10.3$ \\
\hline Alcohol (g) & $18.0 \pm 19.2$ & $15.0 \pm 16.8$ & $6.6 \pm 10.3$ & $5.9 \pm 9.5$ \\
\hline Vegetables (g) & $192.8 \pm 86.1$ & $191.6 \pm 84.9$ & $205.1 \pm 85.4$ & $195.5 \pm 81.3$ \\
\hline Fruit (g) & $148.6 \pm 120.6$ & $154.0 \pm 114.1$ & $192.6 \pm 107.8$ & $196.4 \pm 121.1$ \\
\hline
\end{tabular}

${ }^{*}$ Never smokers excluded. ${ }^{\dagger}$ Ever smokers excluded. ${ }^{\ddagger}$ Energy-adjusted intake.

Compared with never cigarette smokers, both former and current cigarette smokers had an increased pancreatic cancer risk (age-adjusted $\mathrm{HR}=1.37,95 \% \mathrm{Cl}$ : 1.05 1.78 and $\mathrm{HR}=1.88,95 \% \mathrm{Cl}: 1.44-2.44$, respectively; Table 7.2 ). We observed an increased pancreatic cancer risk of $51 \%(95 \% \mathrm{Cl}: 1.12-2.04)$ with smoking $\geq 20$ cigarettes/day compared with never cigarette smoking (Table 7.2), but no clear doseresponse relation was present ( $p$ for trend $=0.96$ ). Smokers smoking one package per day (i.e., 20 cigarettes/day) had a similar risk, showing an increased risk of $49 \%$ (95\% $\mathrm{Cl}$ : 1.05-2.12; data not shown). Most pancreatic cancer cases smoked <40 cigarettes/day; only 15 cases smoked $\geq 40$ cigarettes. For duration of smoking, we observed a significantly increased pancreatic cancer risk per increment of 10 years (age-adjusted $\mathrm{HR}=1.15,95 \% \mathrm{Cl}: 1.08-1.22$; Table 7.2), with a clear dose-response effect observing a 2 -fold increased cancer risk comparing $\geq 40$ years of smoking to never cigarette smoking. Quitting smoking gradually reduced the risk of pancreatic cancer and approached unity after $\geq 20$ years of quitting smoking (Table 7.2). 
TABLE 7.2 Age- and sex-adjusted and multivariable-adjusted HRs for pancreatic cancer according to cigarette smoking status, frequency, duration and time since cessation (categorical and continuous analyses); Netherlands Cohort Study on Diet and Cancer (1986-2002)

\begin{tabular}{|c|c|c|c|c|}
\hline \multicolumn{5}{|c|}{ All pancreatic cancer cases } \\
\hline Cigarette smoking variable & \multirow{2}{*}{$\begin{array}{l}\text { Person- } \\
\text { years }^{*}\end{array}$} & \multirow{2}{*}{$\begin{array}{l}\text { No. of } \\
\text { cases }\end{array}$} & \multirow{2}{*}{$\begin{array}{c}\begin{array}{c}\text { Age- and sex- } \\
\text { adjusted }\end{array} \\
\text { HR }(95 \% \mathrm{Cl})\end{array}$} & \multirow{2}{*}{$\begin{array}{c}\begin{array}{c}\text { Multivariable- } \\
\text { adjusted }^{\dagger}\end{array} \\
\text { HR }(95 \% \mathrm{Cl})\end{array}$} \\
\hline & & & & \\
\hline \multicolumn{5}{|l|}{ Smoking status } \\
\hline Never $^{\ddagger}$ & 22,003 & 130 & 1.00 & 1.00 \\
\hline Former smoker & 20,383 & 165 & $1.37(1.05-1.78)$ & $1.34(1.02-1.75)$ \\
\hline Current smoker & 14,782 & 155 & $1.88(1.44-2.44)$ & $1.82(1.40-2.38)$ \\
\hline \multicolumn{5}{|l|}{ Frequency (cigarettes/day) } \\
\hline Never $^{\ddagger}$ & 22,003 & 130 & 1.00 & 1.00 \\
\hline $0.1-<10$ & 10,103 & 83 & $1.42(1.05-1.91)$ & $1.43(1.06-1.93)$ \\
\hline $10-<20$ & 12,068 & 129 & $1.89(1.42-2.52)$ & $1.83(1.37-2.45)$ \\
\hline$\geq 20$ & 12,993 & 108 & $1.51(1.12-2.04)$ & $1.38(1.01-1.87)$ \\
\hline$p$ for trend $d^{\S}$ & & & 0.96 & 0.55 \\
\hline Continuous (increment of & rettes/day) & & $1.12(1.03-1.23)$ & $1.08(0.98-1.19)$ \\
\hline \multicolumn{5}{|l|}{ Duration (years) } \\
\hline Never $^{\ddagger}$ & 22,003 & 130 & 1.00 & 1.00 \\
\hline $0.1-<20$ & 6,693 & 47 & $1.29(0.90-1.86)$ & $1.30(0.90-1.86)$ \\
\hline $20-<40$ & 16,965 & 130 & $1.41(1.07-1.86)$ & $1.38(1.04-1.83)$ \\
\hline$\geq 40$ & 11,507 & 143 & $2.13(1.61-2.82)$ & $2.03(1.53-2.70)$ \\
\hline$p$ for trend ${ }^{\S}$ & & & 0.01 & 0.02 \\
\hline Continuous (increment of & & & $1.16(1.09-1.23)$ & $1.15(1.08-1.22)$ \\
\hline \multicolumn{5}{|c|}{ Time since cessation } \\
\hline Never ${ }^{\ddagger}$ & 22,003 & 130 & 1.00 & 1.00 \\
\hline Quit $\geq 20$ years & 6,311 & 45 & $1.17(0.81-1.71)$ & $1.19(0.81-1.73)$ \\
\hline Quit $15-<20$ years & 3,073 & 27 & $1.43(0.89-2.27)$ & $1.42(0.89-2.27)$ \\
\hline Quit $10-<15$ years & 3,890 & 32 & $1.45(0.95-2.22)$ & $1.42(0.92-2.18)$ \\
\hline Quit $0.1-<10$ years & 7,055 & 61 & $1.49(1.06-2.08)$ & $1.41(1.00-1.98)$ \\
\hline Current smoker & 14,782 & 155 & $1.88(1.45-2.44)$ & $1.83(1.40-2.39)$ \\
\hline \multicolumn{3}{|c|}{ Continuous (increment of 10 years) ${ }^{\S}$} & $0.85(0.75-0.97)$ & $0.87(0.76-0.99)$ \\
\hline
\end{tabular}

Number of cases and person-years do not add up to the total number because of missing values for covariables. ${ }^{\dagger}$ Adjusted for age, sex, fruit intake (g/day), BMI $\left(\mathrm{kg} / \mathrm{m}^{2}\right)$, and alcohol intake (g/day). ${ }^{\ddagger}$ Reference group: never cigarette smokers. ${ }^{\S}$ Never cigarette smokers excluded.

Our findings remained after the inclusion of the confounding variables in the multivariable model (Table 7.2). However, results were modified when smoking variables were included simultaneously into the model. The increased risk estimates observed for current smoking status, frequency, and years of cessation diminished and became non-significant after including other aspects of smoking in the model (data not shown). However, additional adjustment for other smoking aspects had little influence on the risk estimates of years of smoking cigarettes, showing just slightly attenuated HRs compared with the age- and sex-adjusted and the multivariable-adjusted HRs (data not shown).

It made little difference whether subjects did or did not inhale cigarette smoke; we observed in both situations a significantly increased pancreatic cancer risk after 
adjustment for age and sex (Table 7.3). In addition, both filter-tipped and non-filtertipped cigarettes significantly increased pancreatic cancer risk. Exposure to tar and nicotine significantly increased pancreatic cancer risk, but did not show dosedependent relations ( $p$ for trend $>0.05$ ). After inclusion of the confounding variables and the smoking variables duration, current smoking status, and frequency (frequency was only included in the models on inhalation and filter usage), the increased pancreatic cancer risks disappeared (Table 7.3).

TABLE 7.3 Age- and sex-adjusted and multivariable-adjusted HRs for pancreatic cancer according to inhalation, filter usage, and tar and nicotine exposure to cigarettes (categorical and continuous analyses); Netherlands Cohort Study on Diet and Cancer (1986-2002)

\begin{tabular}{|c|c|c|c|c|}
\hline \multicolumn{5}{|c|}{ All pancreatic cancer cases } \\
\hline Exposure variable & \multirow{2}{*}{$\begin{array}{l}\text { Person- } \\
\text { years }^{*}\end{array}$} & \multirow{2}{*}{$\begin{array}{l}\text { No. of } \\
\text { cases }\end{array}$} & \multirow{2}{*}{$\begin{array}{c}\begin{array}{c}\text { Age- and sex- } \\
\text { adjusted }\end{array} \\
\text { HR }(95 \% \mathrm{Cl})\end{array}$} & \multirow{2}{*}{$\begin{array}{c}\begin{array}{c}\text { Multivariable- } \\
\text { adjusted }^{+}\end{array} \\
\text {HR }(95 \% \mathrm{Cl})\end{array}$} \\
\hline & & & & \\
\hline \multicolumn{5}{|l|}{ Inhalation } \\
\hline Never $^{\dagger}$ & 22,003 & 130 & 1.00 & $1.00^{\ddagger}$ \\
\hline No & 10,010 & 96 & $1.63(1.23-2.17)$ & $1.16(0.75-1.81)$ \\
\hline Yes & 24,870 & 219 & $1.58(1.22-2.06)$ & $1.06(0.64-1.78)$ \\
\hline \multicolumn{5}{|l|}{ Filter usage } \\
\hline Never $^{\dagger}$ & 22,003 & 130 & 1.00 & $1.00^{\ddagger}$ \\
\hline Filter-tipped & 9,756 & 93 & $1.74(1.31-2.32)$ & $1.06(0.64-1.76)$ \\
\hline Non-filter-tipped & 16,701 & 155 & $1.61(1.19-2.18)$ & $1.02(0.58-1.79)$ \\
\hline \multicolumn{5}{|l|}{$\operatorname{Tar}$ (mg/day) } \\
\hline Never $^{\dagger}$ & 22,003 & 130 & 1.00 & $1.00^{\S}$ \\
\hline $0.1-<200$ & 9,406 & 91 & $1.72(1.28-2.30)$ & $0.88(0.49-1.56)$ \\
\hline $200-<400$ & 6,616 & 65 & $1.75(1.24-2.47)$ & $0.77(0.37-1.62)$ \\
\hline$\geq 400$ & 5,089 & 53 & $1.85(1.25-2.73)$ & $0.79(0.34-1.86)$ \\
\hline$p$ for trend" & & & 0.95 & 0.60 \\
\hline Continuous (increr & (day) & & $1.08(1.03-1.14)$ & $1.05(0.92-1.20)$ \\
\hline \multicolumn{5}{|c|}{ Nicotine (mg/day) } \\
\hline Never $^{\dagger}$ & 22,003 & 130 & 1.00 & $1.00^{5}$ \\
\hline $0.1-<10$ & 6,078 & 53 & $1.55(1.10-2.19)$ & $0.87(0.48-1.56)$ \\
\hline $10-<20$ & 4,973 & 49 & $1.78(1.22-2.58)$ & $0.94(0.47-1.88)$ \\
\hline $20-<30$ & 3,752 & 41 & $1.97(1.32-2.92)$ & $0.99(0.45-2.20)$ \\
\hline$\geq 30$ & 6,407 & 67 & $1.88(1.30-2.70)$ & $0.96(0.42-2.19)$ \\
\hline$p$ for trend" & & & 0.59 & 0.96 \\
\hline Continuous (incren & lay) & & $0.85(0.75-0.97)$ & $1.07(1.02-1.12)$ \\
\hline
\end{tabular}

Number of cases and person-years do not add up to the total number because of missing values for covariables. ${ }^{\dagger}$ Reference group: never cigarette smokers. ${ }^{\ddagger}$ Adjusted for age, sex, fruit intake (g/day), BMI $\left(\mathrm{kg} / \mathrm{m}^{2}\right)$, alcohol intake (g/day), frequency (cigarettes/day), duration (years), and current smoking status (yes/no). ${ }^{5}$ Adjusted for age, sex, fruit intake (g/day), BMI $\left(\mathrm{kg} / \mathrm{m}^{2}\right)$, alcohol intake $(\mathrm{g} /$ day), duration (years), and current smoking status (yes/no). "Never cigarette smokers excluded.

When the association between the abovementioned cigarette smoking variables and pancreatic cancer risk were examined for men and women separately (data not shown), the risk estimates seemed to be stronger in men than in women. However, only $7 \%(n=19)$ of the male cases never smoked cigarettes. Excluding non- 
microscopically confirmed pancreatic cancer cases did not change the risk estimates appreciably (data not shown). Also, risk estimates were not affected when excluding current cigar or pipe smokers (43 cases, 342 subcohort members) except for former smokers who still showed an increased but non-significant pancreatic cancer risk (multivariable-adjusted $\mathrm{HR}=1.25,95 \% \mathrm{Cl}$ : 0.94-1.66). The PAF of pancreatic cancer due to ever smoking for men and women combined was estimated as $27 \%$ ( $95 \% \mathrm{Cl}: 15-37$ ), using a HR which was adjusted for age, sex, fruit intake, BMI, and alcohol intake (HR = $1.58,95 \% \mathrm{Cl}: 1.25-2.01)$. Stratified by sex, the PAF of pancreatic cancer due to ever smoking was estimated as $46 \%(95 \% \mathrm{Cl}: 17-65)$ for men and as $16 \%(95 \% \mathrm{Cl}: 5-27)$ for women.

Regarding passive smoking in women, after adjusting for age, we observed no association between pancreatic cancer risk and smoking status from the spouse, parental smoking, being exposed at work to passive smoking (past or present), or duration of current passive smoking exposure (both in occupational and private setting; Table 7.4). Results were similar when including confounders into the model (Table 7.4) or when restricting the analyses to microscopically verified cases (data not shown). Our findings remained the same after excluding individuals who reported a history of diabetes at baseline from the analyses or after excluding the first 2 years of follow-up (data not shown).

TABLE 7.4 Age-adjusted and multivariable-adjusted HRs for pancreatic cancer according to passive smoking exposure in never-smoking women; Netherlands Cohort Study on Diet and Cancer (1986-2002)

\begin{tabular}{|c|c|c|c|c|}
\hline \multicolumn{5}{|c|}{ All pancreatic cancer cases } \\
\hline Passive smoking & \multirow{2}{*}{$\begin{array}{l}\text { Person- } \\
\text { years }^{*}\end{array}$} & \multirow{2}{*}{$\begin{array}{l}\text { No. of } \\
\text { cases }^{*}\end{array}$} & \multirow{2}{*}{$\begin{array}{c}\begin{array}{c}\text { Age- and sex- } \\
\text { adjusted }\end{array} \\
\text { HR }(95 \% \mathrm{Cl})\end{array}$} & \multirow{2}{*}{$\begin{array}{c}\begin{array}{c}\text { Multivariable- } \\
\text { adjusted }^{+}\end{array} \\
\text {HR }(95 \% \mathrm{Cl})\end{array}$} \\
\hline & & & & \\
\hline \multicolumn{5}{|l|}{ Spouse smoking status } \\
\hline Never ${ }^{\ddagger}$ & 2,625 & 20 & 1.00 & 1.00 \\
\hline Former smoker & 8,055 & 46 & $0.72(0.41-1.26)$ & $0.67(0.38-1.17)$ \\
\hline Current smoker & 6,198 & 42 & $0.87(0.49-1.53)$ & $0.78(0.44-1.39)$ \\
\hline \multicolumn{5}{|l|}{ Parental smoking } \\
\hline No parents smoked ${ }^{\ddagger}$ & 2,815 & 20 & 1.00 & 1.00 \\
\hline One or both parents smoked & 15,645 & 97 & $0.91(0.55-1.50)$ & $0.90(0.54-1.50)$ \\
\hline \multicolumn{5}{|c|}{ Passive smoking exposure at work (past or present) } \\
\hline Never $^{\ddagger}$ & 3,943 & 28 & 1.00 & 1.00 \\
\hline Occasionally exposed & 4,611 & 34 & $1.10(0.64-1.86)$ & $1.08(0.64-1.84)$ \\
\hline Regularly or always exposed & 5,600 & 25 & $0.64(0.36-1.12)$ & $0.61(0.34-1.07)$ \\
\hline \multicolumn{5}{|c|}{ Duration current passive smoking exposure (hours/day; occupational and private) } \\
\hline No exposure ${ }^{\ddagger}$ & 5,463 & 34 & 1.00 & 1.00 \\
\hline$>0-<3$ & 4,969 & 35 & $1.14(0.70-1.87)$ & $1.14(0.70-1.88)$ \\
\hline$\geq 3$ & 4,698 & 32 & $1.17(0.70-1.95)$ & $1.07(0.64-1.80)$ \\
\hline $\mathrm{p}$ for trend & & & 0.64 & 0.93 \\
\hline Continuous (increment of $1 \mathrm{~h}$ & day) & & $0.85(0.75-0.97)$ & $1.02(0.98-1.07)$ \\
\hline \multicolumn{5}{|c|}{$\begin{array}{l}\text { Missing values for passive smoking characteristics gave rise to diminished numbers of person-years and } \\
\text { pancreatic cancer cases for the different passive smoking variables. }{ }^{\dagger} \text { Adjusted for age, } \mathrm{BMI}\left(\mathrm{kg} / \mathrm{m}^{2}\right) \text {, and level } \\
\text { of education (primary school or lower vocational school/intermediate, vocational school or high school/ } \\
\text { higher vocational school or college). }{ }^{+} \text {Reference group. }\end{array}$} \\
\hline
\end{tabular}




\section{DISCUSSION}

In the current analysis, we observed an $80 \%$ increased risk of pancreatic cancer for current smokers compared with never cigarette smokers, which is in agreement with other studies. . $^{3,7-11,36}$ In addition, we observed an increased pancreatic cancer risk for former smokers compared with never smokers and for incremental increases in num-

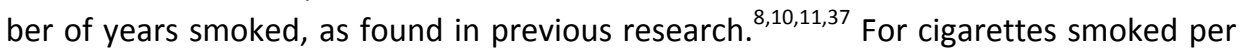
day, we observed an increased risk as well; however, the magnitude was less strong than in other cohort studies observing 2- to 3-fold increased risks for $\geq 20$ cigarettes/day. ${ }^{5,7-9,12}$ Based on the current study, $27 \%$ of pancreatic cancer cases could hypothetically be prevented if people would not smoke. Similar estimates were found in previous studies $\left(24 \%,{ }^{37} 25 \%,{ }^{12}\right.$ and $\left.27 \%{ }^{10}\right)$. A few studies, however, found lower PAF values $\left(15 \%{ }^{5}\right.$ and $\left.7 \%{ }^{38}\right)$. This might be due to the fact that the PAF is very dependent on the prevalence of smoking in a population. This was also shown when we estimated the PAF separately for men and women, observing a PAF of $46 \%$ for men (93\% ever smokers among male cases) and of $16 \%$ for women ( $50 \%$ ever smokers among female cases).

After $\geq 20$ years of quitting smoking, pancreatic cancer risk approached the risk of never smokers. This was observed by one previous cohort as well, ${ }^{8}$ whereas other studies observed risk estimates similar to never smokers after 5 to 10 years. ${ }^{7,12,13,36} \mathrm{~A}$ pooled cohort analysis observed a risk similar to that of never smokers after 15 years of cessation. $^{5}$

It is not yet clear how the risk of pancreatic cancer is affected by different aspects of smoking behavior. When we investigated which smoking aspect was most important in pancreatic cancer etiology by including smoking variables simultaneously in the model, only duration had a significant effect on pancreatic cancer risk. Accordingly, we concluded that duration seemed to affect pancreatic cancer risk the most in our cohort.

Not many studies included other aspects of smoking factors into a model, when examining smoking in relation to pancreatic cancer. Of the few studies that included smoking factors simultaneously in the model, however, all used a different model. Lynch et al. ${ }^{5}$ adjusted for years of cessation in the analysis on number of cigarettes and duration, observing for both smoking factors an increased pancreatic cancer risk. Fuchs et al. ${ }^{12}$ and Vrieling et al. ${ }^{7}$ corrected for pack-years investigating the relation with time since quitting, observing risks comparable to that of never smokers after $\geq 10$ and $\geq 5$ years of quitting smoking, respectively. Vrieling et al. ${ }^{7}$ also corrected for pack-years in the analyses on number of cigarettes and duration, observing similar risk estimates as for the model not including pack-years: a significant increased pancreatic cancer risk for number of cigarettes in current smokers, but no association for duration in current and former smokers. Jee et al. ${ }^{37}$ corrected in a similar way we did, by including duration and frequency simultaneously in a model of current smokers. However, their 
results were different from ours: they observed a clear dose-response relation for frequency, but no association with duration in their Korean population.

However, when highly intercorrelated smoking factors are included simultaneously into a model, the problem of multi-collinearity may arise. ${ }^{39}$ In our analyses, some of the confidence intervals widened because some of the smoking variables were highly correlated (e.g., correlation of quitting smoking and duration $=-0.71$ ), which indicates that multi-collinearity might have played a role to a certain degree.

After adjustment for duration, frequency, and smoking status, no association was observed for filter usage, inhalation, and exposure to tar and nicotine. Silverman et al. ${ }^{10}$ observed an approximately $50 \%$ increased risk both for filter- and non-filtertipped cigarettes compared with non-smokers. Although they did not adjust for frequency or duration. As far as we know, no previous studies investigating pancreatic cancer risk in relation to nicotine and tar exposure have been conducted. For lung cancer, most epidemiologic studies showed an increased lung cancer risk after exposure to tar, including studies that adjusted for number of cigarettes smoked per day and duration of smoking. ${ }^{40}$

The amounts of nicotine and tar were established using a smoking machine and were, besides the amount of nicotine in tobacco, dependent on cigarette design features such as type of filter, combustion rate, and paper porosity. ${ }^{41}$ The amount of nicotine to which a smoker is exposed is mainly dependent on the smoking behavior of the individual smoker, which is always focused on reaching a nicotine level in the blood that is satisfying for a smoker. Therefore, filter cigarettes or less nicotine per cigarette will probably lead to deeper inhalation, more cigarettes per day, or blocking the vents in the filter of a filter cigarette with the fingers or lips to establish the desired nicotine levels in the blood. ${ }^{41}$ This means that the exposure to tar and nicotine used in the present study, which were established by a smoking machine, might not reflect the real dose that the subjects in our cohort were exposed to. This may have influenced (most probably underestimated) our results. However, subjects smoking filter-tipped cigarettes were far less heavy smokers ( $\geq 20$ cigarettes/day) than non-filter-tipped smokers ( $26.8 \%$ versus $43.8 \%$, respectively).

It is not clear yet when smoking exerts its effects on the pancreatic carcinogenic process. ${ }^{1}$ Our smoking cessation results, together with results from other studies, ${ }^{5,8,10,12,38}$ might support more a late-stage mechanistic effect. However, we do not know the minimal time required for the carcinogenic process to occur for pancreatic cancer; it could take place in a relatively short amount of time. ${ }^{1}$

Despite the fact that smoking is an established risk factor for pancreatic cancer, the mechanism behind this causal relation remains unclear. Nicotine itself is not carcinogenic; however, it is very addictive, resulting in a continuous exposure to a mixture of known (and unknown) carcinogens. ${ }^{42}$ The only pancreatic carcinogens known to be present in tobacco products are 4-(methylnitrosamino)-1-(3-pyridyl)-1-butanone (NNK) and its metabolite 4-(methylnitrosamino)-1-(3-pyridyl)-1-butanol. ${ }^{42}$ NNK induced tumors of the pancreas when administered in drinking water to rats, ${ }^{43}$ and autopsy 
studies have shown substantial pancreatic tissue damage among smokers compared with non-smokers. ${ }^{44}$ In addition, NNK levels in the pancreatic cancer juice of smokers were significantly higher than those in the juice of non-smokers. ${ }^{45}$ Regarding tar, experimental evidence showed that tobacco tar could induce skin cancer in mice and rabbits. $^{46}$

It has been hypothesized that the solvent properties of alcohol may enhance the effects of exposure to carcinogens in tobacco. ${ }^{47}$ In a previous report, we reported that current smokers who consumed $\geq 30 \mathrm{~g}$ of ethanol/day experienced a $\mathrm{HR}$ of $2.4(95 \% \mathrm{Cl}$ : 1.06-5.41) compared with abstainers who never smoked, when we investigated the interaction between ethanol intake and cigarette smoking. ${ }^{48}$ However, the interaction term was not found to be significant ( $p$ for interaction $=0.97$ ).

Similar to other previous studies, ${ }^{9,14,16,17,19}$ we did not find any association between passive smoking exposure and pancreatic cancer risk. However, three previous studies did observe a positive association for passive smoking. A prospective study in women, investigating both adult passive exposure and exposure during childhood, observed an increased risk only for maternal smoking $(\mathrm{RR}=1.52,95 \% \mathrm{Cl}: 0.97-2.39) .{ }^{18}$ A small Egyptian case-control study observed a positive association between adult passive exposure and pancreatic cancer risk. ${ }^{15}$ And a prospective study among Europeans observed an increased pancreatic cancer risk among never smokers who were exposed during childhood to passive smoking on a daily basis $(\mathrm{HR}=2.61,95 \% \mathrm{Cl}$ : 0.96 7.10) and a borderline statistically significant $54 \%$ increased risk for never smokers exposed to passive smoking at home and/or at work. ${ }^{7}$

Environmental tobacco smoke is composed of sidestream smoke released by the burning tip of a cigarette or other smoking device and of mainstream smoke exhaled by the smoker. ${ }^{49}$ Sidestream smoke is the main component of this mixture and contains many of the same toxic constituents as mainstream smoke inhaled by smokers. However, sidestream smoke dilutes quickly; consequently, exposures to non-smokers are much lower than to smokers. ${ }^{49}$ Studies have shown that non-smokers exposed to passive smoke take up and metabolize NNK, which provides experimental support for the hypothesis that passive smoking can cause smoking-related cancer. ${ }^{50}$ In addition, pooled analyses showed that spousal and workplace exposure to passive smoking was associated with a 20 to $25 \%$ excess risk of lung cancer. ${ }^{51}$

In the current analysis, we were unable to adequately investigate pipe and cigar smoking because among never cigarettes smokers, only three cases ever smoked cigars or pipes and just $1.7 \%$ of all subcohort members smoked cigars or pipes only. Of the studies that have investigated pipe and cigar smoking in relation to pancreatic cancer, $3,14,52$ only three studies have been able to investigate pipe and cigar smoking separately, excluded lifelong cigarette smokers, or have been able to stratify by frequency or duration of pipe or cigar smoking. ${ }^{14,52-54}$ Pooled estimates for pipe smoking showed a non-significantly increased pancreatic cancer risk of 39\% whereas for cigar smoking, a significantly increased risk of $53 \%$ was observed. ${ }^{3}$ 
The case-cohort approach was used because this is a more efficient design compared with a full-cohort analysis in which all questionnaires have to be entered before the analyses could be performed, whereas in the case-cohort approach, only the data for cases and subcohort members need to be entered. In our situation, this was most profitable because our questionnaire is very detailed and only the first page could be optically scanned. Also, another advantage is that exposure data can be processed during rather than after case ascertainment in comparison with a nested case-control design. One of the limitations of the case-cohort design is that the variance estimates will not be as small as compared with a full cohort analysis, leading to slightly larger confidence intervals. Another disadvantage might be the difficulty of analyzing data in a case-cohort study; however, more and more statistical software packages, such as the statistical package we used (Intercooled STATA, version 9), which contains software for analysis of case-cohort data, are becoming available.

One of the limitations regarding the analysis on passive smoking is that we were unable to perform the analysis using individuals never exposed in any way to smoking as reference group, as only one female case was never exposed to smoke. In addition, misclassification could have occurred because we did not have any information on the number of smokers and of cigarettes smoked, room volume, ventilation, and duration of the different exposures. ${ }^{49}$ Future studies should incorporate a more comprehensive and more accurate measure of passive smoking exposure. Another limitation of our study is that no information was collected about changes in cigarette smoking status during the follow-up period. After years of declining, especially among men, smoking rates leveled off in the late 1980s and have not changed until $2000 .^{55}$ Few people ages $\geq 50$ years will start smoking, but more people will quit while ageing. ${ }^{55}$ A substantial proportion of the cohort members might have stopped smoking during the 16 years of follow-up, although they would still be classified as current smokers in the current analysis. This may have resulted in an underestimation of the smoking effect.

The possibility to further restrict the analyses to microscopically verified cases only, in which misclassification by disease status would be less likely than among nonmicroscopically confirmed pancreatic cancer cases, ${ }^{32}$ was one of the strengths of this study. Other strengths include the large sample size and detailed information on potential risk factors of pancreatic cancer. Differential follow-up is unlikely to have made a material contribution to our findings because the completeness of follow-up was high. ${ }^{24}$ The prospective design avoided recall bias and the need to use next-of-kin respondents.

In summary, our findings confirmed that cigarette smoking is an important risk factor for pancreatic cancer, whereas quitting smoking reduced risk. Therefore from a public health perspective, quitting smoking could decrease the incidence of pancreatic cancer. On the other hand, we did not observe any association between passive smoking exposure and pancreatic cancer risk in women. 


\section{REFERENCES}

1. Anderson KE, Mack TM, Silverman DT. Cancer of the pancreas. In: Schottenfeld D, Fraumeni JF Jr., eds. Cancer epidemiology and prevention, $3^{\text {rd }}$ ed. New York: Oxford University Press, 2006. P. 721-62.

2. Batty GD, Kivimaki M, Gray L, Smith GD, Marmot MG, Shipley MJ. Cigarette smoking and site-specific cancer mortality: testing uncertain associations using extended follow-up of the original Whitehall study. Ann Oncol 2008;19:996-1002.

3. lodice $S$, Gandini S, Maisonneuve P, Lowenfels AB. Tobacco and the risk of pancreatic cancer: a review and meta-analysis. Langenbecks Arch Surg 2008;393:535-45.

4. Luo J, Iwasaki M, Inoue M, et al. Body mass index, physical activity and the risk of pancreatic cancer in relation to smoking status and history of diabetes: a large-scale population-based cohort study in Japan - the JPHC study. Cancer Causes Control 2007;18:603-12.

5. Lynch SM, Vrieling A, Lubin JH, et al. Cigarette smoking and pancreatic cancer: a pooled analysis from the pancreatic cancer cohort consortium. Am J Epidemiol 2009;170:403-13.

6. Stevens RJ, Roddam AW, Spencer EA, et al. Factors associated with incident and fatal pancreatic cancer in a cohort of middle-aged women. Int J Cancer 2009;124:2400-5.

7. Vrieling A, Bueno-de-Mesquita HB, Boshuizen HC, et al. Cigarette smoking, environmental tobacco smoke exposure and pancreatic cancer risk in the European prospective investigation into cancer and nutrition. Int J Cancer 2010;126:2394-403.

8. Coughlin SS, Calle EE, Patel AV, Thun MJ. Predictors of pancreatic cancer mortality among a large cohort of United States adults. Cancer Causes Control 2000;11:915-23.

9. Gallicchio L, Kouzis A, Genkinger JM, et al. Active cigarette smoking, household passive smoke exposure, and the risk of developing pancreatic cancer. Prev Med 2006;42:200-5.

10. Silverman DT, Dunn JA, Hoover RN, et al. Cigarette smoking and pancreas cancer: a case-control study based on direct interviews. J Natl Cancer Inst 1994;86:1510-6.

11. Yun JE, Jo I, Park J, et al. Cigarette smoking, elevated fasting serum glucose, and risk of pancreatic cancer in Korean men. Int J Cancer 2006;119:208-12.

12. Fuchs CS, Colditz GA, Stampfer MJ, et al. A prospective study of cigarette smoking and the risk of pancreatic cancer. Arch Intern Med 1996;156:2255-60.

13. Larsson SC, Permert J, Hakansson N, Naslund I, Bergkvist L, Wolk A. Overall obesity, abdominal adiposity, diabetes and cigarette smoking in relation to the risk of pancreatic cancer in two Swedish population-based cohorts. Br J Cancer 2005;93:1310-5.

14. Hassan MM, Abbruzzese JL, Bondy ML, et al. Passive smoking and the use of noncigarette tobacco products in association with risk for pancreatic cancer: a case-control study. Cancer 2007;109:2547-56.

15. Lo AC, Soliman AS, El-Ghawalby N, et al. Lifestyle, occupational, and reproductive factors in relation to pancreatic cancer risk. Pancreas 2007;35:120-9.

16. Mizuno S, Watanabe S, Nakamura K, et al. A multi-institute case-control study on the risk factors of developing pancreatic cancer. Jpn J Clin Oncol 1992;22:286-91.

17. Villeneuve PJ, Johnson KC, Mao Y, Hanley AJ. Environmental tobacco smoke and the risk of pancreatic cancer: findings from a Canadian population-based case-control study. Can J Public Health 2004;95:

32-7.

18. Bao Y, Giovannucci E, Fuchs CS, Michaud DS. Passive smoking and pancreatic cancer in women: a prospective cohort study. Cancer Epidemiol Biomarkers Prev 2009;18:2292-6.

19. Nishino $\mathrm{Y}$, Tsubono $\mathrm{Y}, \mathrm{T}$ suji I, et al. Passive smoking at home and cancer risk: a population-based prospective study in Japanese nonsmoking women. Cancer Causes Control 2001;12:797-802.

20. van den Brandt PA, Goldbohm RA, van 't Veer P, Volovics A, Hermus RJ, Sturmans F. A large-scale prospective cohort study on diet and cancer in The Netherlands. J Clin Epidemiol 1990;43:285-95.

21. Prentice RL. A case-cohort design for epidemiologic cohort studies and disease prevention trials. Biometrika 1986;73:1-11.

22. van den Brandt PA, Schouten LJ, Goldbohm RA, Dorant E, Hunen PM. Development of a record linkage protocol for use in the Dutch Cancer Registry for Epidemiological Research. Int J Epidemiol 1990;19: 553-8. 
23. Casparie M, Tiebosch AT, Burger G, et al. Pathology databanking and biobanking in The Netherlands, a central role for PALGA, the nationwide histopathology and cytopathology data network and archive. Cell Oncol 2007;29:19-24.

24. Goldbohm RA, van den Brandt PA, Dorant E. Estimation of the coverage of Dutch municipalities by cancer registries and PALGA based on hospital discharge data. Tijdschr Soc Gezondheidsz 1994;72:

80-4.

25. van der Sanden GA, Coebergh JW, Schouten LJ, Visser O, van Leeuwen FE. Cancer incidence in The Netherlands in 1989 and 1990: first results of the nationwide Netherlands cancer registry. Coordinating Committee for Regional Cancer Registries. Eur J Cancer 1995;31A:1822-9.

26. Luchtenborg M, Weijenberg MP, Kampman E, et al. Cigarette smoking and colorectal cancer: APC mutations, hMLH1 expression, and GSTM1 and GSTT1 polymorphisms. Am J Epidemiol 2005;161: 806-15.

27. Zeegers MP, Goldbohm RA, van den Brandt PA. A prospective study on active and environmental tobacco smoking and bladder cancer risk (The Netherlands). Cancer Causes Control 2002;13:83-90.

28. Goldbohm RA, van den Brandt PA, Brants HA, et al. Validation of a dietary questionnaire used in a large-scale prospective cohort study on diet and cancer. Eur J Clin Nutr 1994;48:253-65.

29. Volovics A, van den Brandt PA. Methods for the analysis of case-cohort studies. Biom J 1997;39: 195-214.

30. Barlow WE, Ichikawa L, Rosner D, Izumi S. Analysis of case-cohort designs. J Clin Epidemiol 1999;52: 1165-72.

31. Schoenfeld D. Partial residuals for the proportional hazards regression model. Biometrika 1982;69: 239-41.

32. Silverman DT, Schiffman M, Devesa S. Diagnostic certainty in pancreatic cancer. J Clin Epidemiol 1996; 49:601-3.

33. Verhage BA, Schouten LJ, Goldbohm RA, van den Brandt PA. Anthropometry and pancreatic cancer risk: an illustration of the importance of microscopic verification. Cancer Epidemiol Biomarkers Prev 2007;16:1449-54.

34. Greenland S. Applications of stratified analysis methods. In: Rothman K, Greenland S, eds. Modern Epidemiology, $2^{\text {nd }}$ ed. Philadelphia: Lipincott-Raven, 1998.

35. Rockhill B, Newman B, Weinberg C. Use and misuse of population attributable fractions. Am J Public Health 1998;88:15-9.

36. Nilsen TI, Vatten LJ. A prospective study of lifestyle factors and the risk of pancreatic cancer in NordTrondelag, Norway. Cancer Causes Control 2000;11:645-52.

37. Jee SH, Samet JM, Ohrr H, Kim JH, Kim IS. Smoking and cancer risk in Korean men and women. Cancer Causes Control 2004;15:341-8.

38. Lin $\mathrm{Y}$, Tamakoshi A, Kawamura $\mathrm{T}$, et al. A prospective cohort study of cigarette smoking and pancreatic cancer in Japan. Cancer Causes Control 2002;13:249-54.

39. Leffondre K, Abrahamowicz M, Siemiatycki J, Rachet B. Modeling smoking history: a comparison of different approaches. Am J Epidemiol 2002;156:813-23.

40. Kabat GC. Fifty years' experience of reduced-tar cigarettes: what do we know about their health effects? Inhal Toxicol 2003;15:1059-102.

41. Stephens WE. Dependence of tar, nicotine and carbon monoxide yields on physical parameters: implications for exposure, emissions control and monitoring. Tob Control 2007;16:170-6.

42. Hecht SS. Cigarette smoking: cancer risks, carcinogens, and mechanisms. Langenbecks Arch Surg 2006;391:603-13.

43. Rivenson A, Hoffmann D, Prokopczyk B, Amin S, Hecht SS. Induction of lung and exocrine pancreas tumors in F344 rats by tobacco-specific and Areca-derived N-nitrosamines. Cancer Res 1988;48: 6912-7.

44. Auerbach O, Garfinkel L. Histologic changes in pancreas in relation to smoking and coffee-drinking habits. Dig Dis Sci 1986;31:1014-20.

45. Prokopczyk B, Hoffmann D, Bologna M, et al. Identification of tobacco-derived compounds in human pancreatic juice. Chem Res Toxicol 2002;15:677-85. 
46. Wynder EL. Tobacco as a cause of lung cancer: some reflections. Am J Epidemiol 1997;146:687-94.

47. Marshall JR, Freudenheim J. Alcohol. In: Schottenfeld D, Fraumeni JF Jr., eds. Cancer Epidemiology and Prevention, $3^{\text {rd }}$ ed. New York: Oxford University Press, 2006. P. 243-58.

48. Heinen MM, Verhage BA, Ambergen TA, Goldbohm RA, van den Brandt PA. Alcohol consumption and risk of pancreatic cancer in the Netherlands cohort study. Am J Epidemiol 2009;169:1233-42.

49. IARC. Composition, exposure and regulations Tobacco smoke and involuntary smoking, IARC monographs on the evaluation of carcinogenic risks to humans, vol. 83. Lyon: International agency for Research on Cancer, 2004. P. 1191-230.

50. Anderson KE, Carmella SG, Ye M, et al. Metabolites of a tobacco-specific lung carcinogen in nonsmoking women exposed to environmental tobacco smoke. J Natl Cancer Inst 2001;93:378-81.

51. Sun S, Schiller JH, Gazdar AF. Lung cancer in never smokers - a different disease. Nat Rev Cancer 2007; 7:778-90.

52. Shanks TG, Burns DM. Disease consequences of cigar smoking. In: Burns DM, Cummings KM, Hoffmann D, eds. Cigars: Health effects and trends, Monograph No. 9, vol. DHHS Publ No. 98-4302. Bethesda (MD): US Department of Health and Human Services, National Institutes of Health, 1998. P. 105-60.

53. Henley SJ, Thun MJ, Chao A, Calle EE. Association between exclusive pipe smoking and mortality from cancer and other diseases. J Natl Cancer Inst 2004;96:853-61.

54. Shapiro JA, Jacobs EJ, Thun MJ. Cigar smoking in men and risk of death from tobacco-related cancers. J Natl Cancer Inst 2000;92:333-7.

55. Blokstra A, Schuit AJ, Factsheet roken. Prevalentie en trend. (Factsheet smoking. Prevalence and trend [in Dutch]). National Institute for Public Health and the Environment, 2003. 


\section{8}

Discussion 
In this chapter, we will discuss the main findings on the associations between pancreatic cancer risk and the lifestyle factors investigated in the current thesis in light of the existing literature. Additionally, we will discuss the literature regarding mechanistic evidence and we will make a final conclusion on the strength of the evidence - both epidemiological and mechanistic - so far. Furthermore, we will discuss some important strengths and weaknesses of the study design of the Netherlands Cohort Study (NLCS) and the analyses performed in this thesis. Finally, recommendations for future epidemiological research are given.

\section{MAIN FINDINGS}

In this thesis, we investigated several hypotheses regarding lifestyle factors, including dietary factors in the NLCS. A modest decreased pancreatic cancer risk has been observed in participants who have participated in sports during the past but not for other types of physical activity (Chapter 2). Findings with respect to proxies for energy restriction did not support our hypothesis that energy restriction may reduce pancreatic cancer risk (Chapter 2). Regarding alcohol intake, a low-to-moderate intake was not associated with pancreatic cancer risk, but a high alcohol intake ( $\geq 30 \mathrm{~g}$ of ethanol/day) increased pancreatic cancer risk with $57 \%$ (Chapter 3 ). No association was observed between the intake of specific beverage types and pancreatic cancer risk apart from alcohol. Also, no association was observed with other dietary factors investigated in this thesis, including glycemic index (GI), glycemic load (GL), intake of carbohydrates, meat, fat, vegetables, fruits, carotenoids, and vitamins $C$ and $E$ (Chapter 4-6). For active cigarette smoking we observed a 2-fold increased risk, whereas quitting smoking reduced pancreatic cancer risk and approached the risk of never smokers after $\geq 20$ years of quitting smoking (Chapter 7 ). No association was observed with passive smoking. All the above mentioned findings were based on all pancreatic cancer cases. When we restricted the analyses to microscopically verified pancreatic cancer cases, to create a group with a higher degree of diagnostic certainty of pancreatic cancer, results were similar to the findings described above.

\section{Evaluation evidence on risk factors for pancreatic cancer}

In the sections below, we will summarize the strength of the evidence, both epidemiological and mechanistic, for the lifestyle factors that were investigated in this thesis. Additionally, we will make a final conclusion on the strength of the evidence so far, by using 5 levels of judgment: "convincing", "probable", "limited - suggestive", "limited no conclusion", or "unlikely" cause of pancreatic cancer (see Table 8.1). The criteria we used to grade the evidence are presented in the footnote of Table 8.1. ${ }^{1}$ 
TABLE 8.1 Judgment of evidence for causality for lifestyle factors, including dietary factors

\begin{tabular}{lcc}
\hline Risk factors & \multicolumn{1}{c}{ Levels of evidence } \\
\cline { 2 - 3 } Environmental and lifestyle factors & Increased risk & Decreased risk \\
Cigarette smoking & Convincing & \\
Passive smoking & Limited - no conclusion & Limited - suggestive \\
Physical activity & & \\
& & \\
Diet & & \\
Energy restriction & Unlikely & \\
Glycemic index and glycemic load & Probable & \\
Alcohol & Unlikely conclusion \\
Carbohydrates & Unlikely & \\
Meat & Unlikely & Unlikely \\
Fat & & \\
Vegetables & & Unlikely \\
Fruits & & Limited - no conclusion \\
Vitamins $C$ and $E$ and carotenoids &
\end{tabular}

Convincing: evidence for a relation is "convincing" if there is evidence from more than one study type, if the majority of independent cohort studies showed a relation with a consistent direction of effect, if evidence comes from good quality studies to exclude the possibility that the observed association results from random or systematic errors, or if there is strong evidence for biological plausibility.

Probable: evidence for a relation is "probable" if there is evidence from at least two independent cohort studies or at least five case-control studies that showed a relation with a consistent direction of effect, if evidence comes from good quality studies to exclude the possibility that the observed association results from random or systematic errors, or if there is evidence for biological plausibility.

Limited - suggestive: evidence for a relation is "limited - suggestive" if there is evidence from at least two independent cohort studies or at least five case-control studies that showed a relation with a generally consistent direction of effect or if there is evidence for biological plausibility.

Limited - no conclusion: evidence for a relation is "limited - no conclusion" if epidemiological studies showed inconsistent effects, if evidence comes from studies of poor quality, or if number of studies available are too low to reach a conclusion at this time point.

Unlikely: evidence for a relation is "unlikely" if there is evidence from more than one study type, if the majority of independent cohort studies showed an effect close to 1.0, if evidence comes from good quality studies to exclude the possibility that the observed association results from random or systematic errors, or if there is absence of biological plausibility. ${ }^{1}$

In our final judgments, more emphasize will be put on evidence from epidemiological data than on mechanistic evidence because it is difficult to extrapolate data from animal and in vitro studies to humans. ${ }^{2}$ These difficulties include the fact that the International Agency for Research on Cancer was unable to classify many substances as carcinogenic to humans due to insufficient evidence whereas many of these substances were shown to be carcinogenic in rodents. ${ }^{2}$ Also, in most used animal models of pancreatic carcinogenesis the induced tumors do not closely resemble the human tumors. ${ }^{3}$ 


\section{Active cigarette smoking and passive smoking \\ Mechanistic evidence}

The mechanism behind the relation between active smoking and pancreatic cancer remains unclear. Nicotine itself is not carcinogenic; however, it is very addictive, which results in a regular use of tobacco and hence in a continuous exposure of human tissues to a mixture of known (and unknown) carcinogens. ${ }^{4}$ Two pancreatic carcinogens are known to be present in tobacco products: 4-(methylnitrosamino)-1-(3-pyridyl)-1butanone (NNK) and its metabolite 4-(methylnitrosamino)-1-(3-pyridyl)-1-butanol (NNAL). ${ }^{4,5}$ NNK and NNAL induced tumors of the pancreas when administered in drinking water to rats, ${ }^{5}$ and autopsy studies have shown substantial pancreatic tissue damage among smokers compared with non-smokers. ${ }^{6}$ In addition, NNK levels in pancreatic cancer juice of smokers were shown to be significantly higher than those in juice of non-smokers. ${ }^{7}$

It is not clear yet when smoking exerts its effects on pancreatic carcinogenic process. $^{8}$ Our smoking cessation results together with results from other studies, ${ }^{9-12}$ might support more a late-stage mechanistic effect. However, we do not know the minimal time required for the carcinogenic process to occur for pancreatic cancer; it could take place in a relatively short period of time. ${ }^{8}$

Environmental tobacco smoke is mainly composed of sidestream smoke and contains many of the same toxic constituents as mainstream smoke inhaled by smokers. ${ }^{13}$ However, sidestream smoke dilutes quickly; consequently exposure to non-smokers is much lower than to smokers. ${ }^{13}$ Studies have shown that non-smokers exposed to passive smoke take up and metabolize NNK, which provides experimental support for the hypothesis that passive smoking can cause smoking-related cancer. ${ }^{14}$

\section{Epidemiological evidence}

A meta-analysis indicated that current cigarette smokers have about a 2-fold increased pancreatic cancer risk compared with never smokers. ${ }^{15}$ For cohort studies, a pooled estimate of 1.70 (95\% confidence interval [Cl]: 1.53-1.90; $n=26)$ and for case-control studies a pooled estimate of 1.77 ( $95 \% \mathrm{Cl}: 1.59-1.97 ; n=33$ ) was observed. We could confirm this finding in the NLCS, were an $80 \%$ increased risk of pancreatic cancer for current cigarette smokers compared with never cigarette smokers was observed. In addition, we observed an increased pancreatic cancer risk for former cigarette smokers compared with never smokers and per increment of 10 years of smoking, as found in previous research. ${ }^{12,15}$ For cigarettes smoked per day we observed an increased risk as well, however, the magnitude was less strong than in other cohort studies observing 2to 3 -fold increased risks for $\geq 20$ cigarettes/day. ${ }^{9-11,16,17}$ Studies, including our study, showed that quitting smoking reduced pancreatic cancer risk, although the time period in which levels were approaching the risk of never smokers differed across these studies ranging from 5 to 20 years. ${ }^{9,10,17}$

Similar to previous epidemiological studies, ${ }^{16,18,19}$ we did not observe an association between passive smoking exposure and the risk of pancreatic cancer. On the other 
hand, three studies did observe a positive association with passive smoking in never smokers. ${ }^{17,20,21}$ Misclassification in our and other studies could have occurred, however, because no information on number of smokers and of cigarettes smoked, room volume, ventilation, and duration of the different exposures were available. ${ }^{13}$

\section{Conclusion}

Judging the evidence, we conclude that there is convincing evidence from both epidemiological and mechanistic studies that active cigarette smoking is a risk factor for pancreatic cancer (Table 8.1). In addition, quitting smoking reduces pancreatic cancer risk. Mechanistic evidence seem to support the hypothesis that passive smoking increases pancreatic cancer risk; however, results from epidemiological studies are too inconsistent to allow conclusions to be reached.

\section{Physical activity \\ Mechanistic evidence}

Even though the mechanism underlying the possible relation between pancreatic cancer risk and physical activity is not clear, it has been suggested that insulin and the insulin-like growth factor (IGF) axis might play a role. Human intervention studies showed that a short bout of exercise increases IGF-1 levels, whereas regular exercise ("training"), leading to a negative energy balance, seems to lower IGF-1 levels. ${ }^{22}$ Also, studies have shown that higher physical activity levels reduce insulin resistance. ${ }^{1,22}$ Experimental studies showed that insulin acts as a growth promoter and mitogen in the pancreas. ${ }^{23,24}$ Furthermore, excess insulin can increase growth hormone receptor levels in the liver which is a key stimulator of IGF-1 production. ${ }^{22}$ Also, insulin can downregulate IGF binding proteins (IGBPs), which would result in more bioavailable IGF-1. IGF-1 can then bind to IGF-1 receptor (IGF-1R), activating intracellular signaling pathways which could lead to increased proliferation in pancreatic cancer cell lines. ${ }^{22,25}$ Observational studies on pancreatic cancer suggest that high insulin concentrations, glucose intolerance and insulin resistance may play a role in pancreatic carcinogenesis. ${ }^{22,26}$ A few nested case-control studies have investigated whether IGF-1 and IGFBP-3 levels were associated with pancreatic cancer risk in humans. These studies showed inconsistent results, observing $\mathrm{no}^{27,28}$ and positive ${ }^{29}$ associations with pancreatic cancer risk. Moreover, two of these studies were rather small, with case numbers $<150 .^{27,29}$ Further studies are needed to elucidate the role of insulin and the IGF axis in the pathogenesis of pancreatic cancer.

\section{Epidemiological evidence}

Some epidemiological studies suggest that higher physical activity levels might decrease risk, especially in overweight or obese persons. ${ }^{30,31}$ Other epidemiological studies, however, did not observe an association with pancreatic cancer risk. ${ }^{32,33}$ Two meta-analyses observed only for occupational physical activity a modest significantly decreased pancreatic cancer risk - which was only based on a few cohort studies (i.e., 
three and four, respectively) - and no association with leisure-time physical activity. ${ }^{34,35}$ Within the NLCS, we were unable to confirm this finding. We observed no association with occupational physical activity and non-occupational physical activity at baseline. We observed, however, a modestly decreased pancreatic cancer risk for participants who reported to have participated in sports in the past compared with participants reporting never to have participated in sports during the past. So far, the findings on physical activity are too inconsistent because different methods have been used in epidemiological studies. ${ }^{34}$ In addition, measuring physical activity in epidemiological studies is difficult because physical activity is a complex behavior that accumulates many short unstructured activities that occur in varying contexts. ${ }^{34}$ The challenge of future studies is to accurately measure all components of physical activity (i.e., both exercise and non-exercise physical activity, with the latter including occupational, household and lifestyle physical activity).

\section{Conclusion}

Although there seems to be support mechanistically, we conclude that there is only suggestive evidence that physical activity is associated with pancreatic cancer risk (Table 8.1). In the future, studies are needed that accurately measure all components of physical activity.

\section{Energy restriction}

\section{Mechanistic evidence}

It has been shown that energy restriction suppresses tumor development in experimental animals. ${ }^{36}$ Also in rat models for pancreatic cancer, it was shown that moderate energy restriction decreased cancer risk. ${ }^{37,38}$ Insulin and IGF might be mechanistically involved in this relation. ${ }^{22,36}$ Experimental studies have shown that energy restriction might reduce levels of circulating IGF-1 and insulin. ${ }^{1,22}$ As discussed in the previous paragraph, insulin and the IGF axis might play a role in pancreatic carcinogenesis. Furthermore, energy restriction may also exert some if its anti-tumor effects by decreasing free-radical oxygen species (ROS) production and enhancing antioxidant defenses. ${ }^{36}$

\section{Epidemiological evidence}

As far as we know, we are the first epidemiological study that investigated the relation between energy restriction and pancreatic cancer risk. The NLCS is comprised of individuals who grew up during a period of severe short-term energy restriction, i.e., the Hunger winter (winter of 1944-1945). We also had information on two preceding periods of more moderate energy restriction: World War II (WW II; 1940-1944) and the Economic Depression (1932-1940). Although individual food intake data is not available for these three time periods, a number of proxy measures have been collected from cohort members that reflect their exposure to energy restriction; that is, place of residence during the Hunger winter and WW II, and employment status of the father 
during the Economic Depression. We observed a modestly decreased pancreatic cancer risk for individuals who resided in a city during the war years compared with those who did not. Regarding the exposure to a short period of severe energy restriction during the Hunger winter, results were not clear. Individuals living in western rural area had an increased pancreatic cancer risk compared with individuals living in nonwestern area, whereas living in a western city was not associated. No association was observed for exposure to energy restriction during the Economic Depression. Previous work on the NLCS cohort has found an inverse association between severe energy restriction during the Hunger winter and colorectal cancer risk in men. ${ }^{39}$

\section{Conclusion}

No conclusions regarding the association between energy restriction and pancreatic cancer risk could be reached because too few studies, especially epidemiologically, have been conducted so far (Table 8.1).

\section{Glycemic index, glycemic load, and carbohydrates Mechanistic evidence}

As already described above, insulin might play a role in pancreatic carcinogenesis. Furthermore, type 2 diabetes seems to develop generally after prolonged periods of high insulin secretion rates with a gradual increase in insulin resistance of the liver and peripheral tissues. ${ }^{22}$ Because insulin is secreted into the blood in response to elevated blood glucose levels, dietary factors increasing these levels may be associated with pancreatic cancer risk. Glycemic index (GI) and glycemic load (GL) are such measures.

\section{Epidemiological evidence}

In this thesis, we did not observe an association between high GL, GI, and total carbohydrate intake and pancreatic cancer risk. These null findings are consistent with four ${ }^{40-43}$ of five cohort studies ${ }^{40-44}$ conducted so far that examined either GL, GI and/or carbohydrate intake in relation to pancreatic cancer risk. Meinhold et al. ${ }^{44}$ observed a significantly increased risk with high GL and carbohydrates intake, but these associations were limited to the first 4 years of follow-up and no association was observed during later follow-up. Also, null findings have been reported in most case-control studies for carbohydrate intake; just few observed an increased risk (summarized in Ref. 1).

\section{Conclusion}

Most epidemiological studies did not observe an association between GL, GI, and carbohydrate intake and pancreatic cancer risk. Mechanistic evidence seems to support a role for insulin in pancreatic cancer etiology and therefore, investigating dietary factors that influence plasma insulin levels seems rational. The major rationale for using $\mathrm{GI}$ values is based on the assumption that postprandial blood glucose responses and insulin responses are highly correlated; however, studies showed that this might not be the 
case. ${ }^{45}$ In addition, the composition of a meal, the amount of rapidly available glucose and resistant starch, the degree of osmolality, the viscosity of the gut's contents, are other important factors influencing the degree of postprandial insulin secretion. ${ }^{45}$ Judging the evidence, we conclude that it is unlikely that $\mathrm{GL}, \mathrm{GI}$, and carbohydrates increase pancreatic cancer risk (Table 8.1).

\section{Alcohol intake \\ Mechanistic evidence}

There is evidence that chronic alcohol consumption may alter pancreatic function, ${ }^{46}$ which may predispose people to pancreatic cancer. Several mechanisms have been suggested. First, heavy alcohol consumption is a known risk factor for chronic pancreatitis, ${ }^{1}$ which has been linked to pancreatic cancer. ${ }^{8}$ In addition, studies have suggested that the metabolites generated during metabolism of alcohol (e.g., acetaldehyde) may be carcinogenic. ${ }^{1,47}$ Furthermore, the effects of alcohol may be mediated through the generation of ROS which can lead to the formation of DNA adducts and initiation of pancreatic carcinogenesis. ${ }^{47,48}$ In some animal studies, ethanol slightly enhanced pancreatic carcinogenesis, but in other studies did not demonstrate any effect on pancreatic carcinogenicity. ${ }^{8,49,50}$ It is still not clear, though, at what stage of pancreatic carcinogenesis ethanol plays a role because this has received limited attention among researchers in the field. ${ }^{48}$ However, given the findings described above, ethanol might play a role at both the initiation and promotion phase.

\section{Epidemiological evidence}

Both findings from cohort studies as from case-controls studies have been inconsistent, observing no association between alcohol consumption and pancreatic cancer risk $^{1,9,51-53}$ or observing an increased risk. ${ }^{1,54-57}$ In the NLCS, no association was observed between low-to-moderate alcohol intake and risk of pancreatic cancer. We did, however, find a significantly increased risk for consumers of a high level of ethanol ( $\geq 30 \mathrm{~g} /$ day) compared with abstention (hazard rate ratio $[\mathrm{HR}]=1.57,95 \% \mathrm{Cl}: 1.03-$ 2.39). A few other studies observed increased pancreatic cancer risks with heavy alcohol use as well, including a pooled analysis of 14 cohorts, $^{54}$ a large US cohort, ${ }^{55}$ and two case-control studies. ${ }^{56,57}$ A recently published meta-analysis observed a $22 \%$ increase in pancreatic cancer risk (95\% Cl: 1.12-1.34; based on eight case-control studies and five cohort studies) for heavy alcohol drinking ( $\geq 3$ drinks/day) compared with non- or occasional drinkers, this result was further strengthened by a dose-risk analysis which showed a significantly increase in cancer risk for an alcohol intake of $\geq 40 \mathrm{~g} / \mathrm{day} .{ }^{58}$ The observed increase in risk with heavy drinking appeared to be stronger in cohort studies versus case-control studies and stronger in studies that adjusted for smoking compared with studies which did not adjust for smoking. Moderate alcohol consumption (<3 drinks/day) did not increase pancreatic cancer risk (risk ratio $[\mathrm{RR}]=0.92,95 \% \mathrm{Cl}$ : 0.86-0.97; based on 17 case-control studies and seven cohort studies). 
Many factors may contribute to the inconsistent results observed in the literature. Half of the observational studies investigating the role of alcohol on the etiology of pancreatic cancer had low case numbers. In addition, heavy alcohol drinkers may have lower participation rates than non-drinkers in both population-based case-control studies and cohort studies. ${ }^{59}$ Furthermore, alcohol intake is assessed by means of selfreport in most studies. ${ }^{58}$ If alcohol drinking is underreported, the RRs would be biased towards unity in case of non-differential underreporting of cases and non-cases.

We did not observe any relation between specific alcoholic beverages and pancreatic cancer risk apart from alcohol. This is in agreement with most epidemiological data, which suggest that it is ethanol itself and not the type of alcoholic beverage which plays a role in carcinogenesis. ${ }^{47}$

\section{Conclusion}

Based on the epidemiological and mechanistic evidence so far, we conclude that heavy alcohol consumption is a probable risk factor for pancreatic cancer (Table 8.1). Low-tomoderate alcohol drinking is most probably not related to pancreatic cancer risk.

\section{Meat and fat intake \\ Mechanistic evidence}

Meat contains numerous carcinogens, such as heterocyclic amines (HCAs), polycyclic aromatic hydrocarbons (PAHs), and $\mathrm{N}$-nitroso compounds, which can be derived either from natural food or during the process of food preparation. ${ }^{60}$ These compounds are metabolically activated after which DNA adducts are formed. ${ }^{61,62}$ Anderson et al. ${ }^{63}$ showed that the pancreas had the metabolic capacity to activate aromatic and heterocyclic amines and found the presence of DNA adducts in human pancreatic tissue. In addition, some other studies have observed positive associations with meat-derived HCAs and benzo(a)pyrene, which is a marker of PAHs, and pancreatic cancer risk. ${ }^{64,65}$

Regarding dietary fat, studies in animals showed that diets high in fat increased the risk of pancreatic cancer compared with low-fat diets. ${ }^{66}$ In addition, they have shown that the development of tumors is generally enhanced by long-chain $\omega-6$ polyunsaturated fatty acids (PUFA), especially linoleic acid (LA), but inhibited by $\omega-3$ PUFA. LA can promote pancreatic carcinogenesis via an accelerated prostaglandin synthesis, caused by metabolism of LA-derived arachidonic acid, ${ }^{67}$ whereas $\omega-3$ PUFAs can lead to a reduction in the availability of prostaglandins. ${ }^{66}$ Prostaglandins may be involved in the development of pancreatic carcinogenesis in animals. ${ }^{67}$ Saturated fat, on the other hand, seems not to be involved in the enhancement or promotion of pancreatic carcinogenesis in rats. ${ }^{38}$

\section{Epidemiological evidence}

Numerous epidemiological studies have investigated the relation between meat, eggs, and different types of fat and pancreatic cancer risk (summarized in Ref. 1). Findings 
from these studies have been very diverse, observing both positive and negative associations, as well as no association. ${ }^{1,8}$

A Finnish cohort of male smokers (ATBC Study) has observed no association with fried meat intake, ${ }^{68}$ whereas some case-control studies have observed positive associations with higher consumption of grilled and fried foods, such as meat. ${ }^{8}$ One large cohort study and one case-control study specifically assessed meat-cooking methods with respect to pancreatic cancer risk, finding positive associations with the intake of grilled/barbecued meat, high-temperature cooked meat, and broiled meat, but not with meat prepared differently. ${ }^{65,69}$ Most other observational studies including ours, were unable to investigate the association between meat-cooking methods and pancreatic cancer risk.

\section{Conclusion}

Epidemiological studies have failed to show an association between meat, processed meat, eggs, fat and different types of fat and pancreatic cancer, even though there seems to be support mechanistically. We conclude that it is unlikely that meat, processed meat, eggs, and different types of fat are associated with pancreatic cancer risk (Table 8.1). However, too few epidemiological studies have assessed whether meat-cooking methods are associated with pancreatic cancer risk. Therefore, future studies should carefully distinguish cooking methods to investigate the extent to which different cooking methods are associated with pancreatic carcinogenesis.

\section{Vegetables, fruits, carotenoids, vitamins C and E (both from diet and supplements) Mechanistic evidence}

Fruits and vegetables contain numerous substances with potential anti-carcinogenic activity (including vitamins, carotenoids, and Allium compounds) ${ }^{70}$ and could therefore play a role in the prevention of pancreatic cancer. Potential mechanisms of action include antioxidant protection against free-radical damage to DNA, enhancing immune function, and inhibiting IGF binding to IGF-receptors. ${ }^{1,70}$ In addition, short-term animal experiments suggest that beta-carotene and the vitamins $C$ and $E$ hinder the development of preneoplastic lesions in both rat and hamster pancreas, ${ }^{71}$ but long-term studies demonstrated this inhibiting effect only for beta-carotene and vitamin $\mathrm{C}$ and only in rat pancreas. ${ }^{71,72}$

\section{Epidemiological evidence}

Epidemiological data have shown inconsistent results so far. Most case-control studies have observed an inverse association with total fruit and vegetable consumption (summarized in Ref. 1). On the other hand, results from most cohort studies including ours, have largely been null. ${ }^{1,9,68,73}$ Regarding the relation between antioxidant intake and pancreatic cancer risk, case-control studies observed inverse associations for betacarotene, ${ }^{74,75}$ lycopene (in men), ${ }^{76}$ vitamin $\mathrm{C}_{1}^{74,75}$ and $\mathrm{E}_{;}^{74}$ cohort studies reported only null findings on these carotenoids and vitamin intake. ${ }^{68,77}$ Other carotenoids, such as 
alpha-carotene, lutein plus zeaxanthin and beta-cryptoxanthin, have only been investigated in case-control studies so far, showing no associations with pancreatic cancer risk. ${ }^{76,78}$ Data on use of vitamin supplements has been very sparse; ${ }^{68,78}$ of these studies only one observed an inverse association with vitamin $C$ supplement use. ${ }^{78}$ Also in the NLCS, no association was observed for the intake of carotenoids, vitamin C and E and pancreatic cancer risk. For fruit intake, the second World Cancer Research Fund/American Institute for Cancer Research expert report observed a pooled risk estimate of 0.92 (95\% Cl: $0.81-1.04)$ for cohort studies and of 0.89 (95\% Cl: $0.82-0.98)$ for casecontrol studies per $100 \mathrm{~g} /$ day of fruit intake. ${ }^{1}$ These estimates were, however, based on only three cohort studies and eight case-control studies.

Inconsistencies could have occurred because case-control studies used proxy interviews or are more prone to systematic biases compared with cohort studies. In addition, for several conducted studies no dietary information was available on individual vegetables or fruits ${ }^{9,51}$ and some studies had small sample sizes ( $\mathrm{n}$ for cases $<150){ }^{74,77}$

\section{Conclusion}

We conclude that it is unlikely that fruit and vegetable intake may reduce pancreatic cancer risk (Table 8.1). For the intake of vitamins $C$ and $E$ and carotenoids - especially for carotenoids other than beta-carotene - the evidence is limited because just few studies have investigated this association or the quality of studies was too low to allow conclusions to be reached.

\section{METHODOLOGICAL ISSUES}

In this section we will discuss some important strengths and weaknesses of the study design of the NLCS and the analyses conducted in the current thesis.

\section{Selection bias}

Selection bias due to selection of the study population is not a major problem in cohort studies because at the start of cohort studies the population is disease-free. Selection bias due to a substantial numbers of subjects lost to follow-up could be a problem in cohort studies when losses to follow-up are correlated with both exposure and disease. ${ }^{79}$ This, however, is not a problem in the NLCS, as completeness of follow-up was estimated to be $>96 \% .{ }^{80}$ Additionally, in 13.3 years of follow-up only two male subcohort members were lost to follow-up and during later follow-up only one. So, it is unlikely that selection bias due to follow-up loss has distorted our analyses. 


\section{Information bias}

Information bias can be introduced into a study by errors in obtaining the information regarding the exposure and outcome of the study. ${ }^{79}$ In the sections below, we will first discuss misclassification of exposure and subsequently misclassification of disease.

\section{Misclassification of exposure}

In our study, non-random misclassification of exposure is unlikely because the selfadministered questionnaire was filled out before cancer was ascertained. But random misclassification of the exposures investigated in this thesis may have occurred because we had to rely on a self-administered questionnaire on dietary habits, lifestyle characteristics, and other potential risk factors for cancer, which might have led to under- or overreporting.

In the NLCS, the dietary section of the questionnaire was a 150 -item semiquantitative food frequency questionnaire (FFQ), which concentrated on the habitual consumption of food and beverages during the year preceding the start of the study. The FFQ is often considered the method of choice for dietary assessment in large-scale epidemiologic studies. ${ }^{81}$ But it is also liable to error and this may have resulted in misclassification of dietary exposure. A validation study and reproducibility study have been performed within the cohort. 82,83

So far, no gold standard for dietary intake to use in validation studies is available. Because the errors of diet records are assumed to be unrelated to the errors of the $F F Q$, this makes it the comparison intake method of choice in validation studies of FFQs. ${ }^{81}$ However, some studies showed that food records can have errors that are correlated with FFQ errors. ${ }^{84}$ Dietary biomarkers would seem better measures as gold standard (because of its uncorrelated measurement errors) or even as a useful measure of dietary intake and nutrient status itself. For several important nutrients, however, no feasible dietary biomarker is available at this moment. ${ }^{85}$ Also, several factors may affect the measurement and utility of a dietary biomarker which influences the validity, application and interpretation of these measures. These factors included the following: genetic variability (e.g., biological variation in nutrient absorption, metabolism); lifestyle (e.g., smoking, alcohol consumption, exercise) or physiologic factors (e.g., stress, underlying disease); dietary factors (e.g., range/frequency of intake, nutrient bioavailability); biological sample (e.g., type, conditions of sample collection); and analytical methodology (e.g., precision, accuracy, detection limits). ${ }^{85}$

The validity of our semiquantitative FFQ was assessed by comparing the FFQ with a 9-day diet record. ${ }^{82}$ This study showed that for most nutrients and food groups mean intake according to the FFQ was lower than according to the record; on average, the questionnaire covered $91 \%$ of the record intake. Pearson correlation coefficients between nutrient intakes assessed by the record and the FFQ ranged from 0.40 for vitamin B1 to 0.86 for alcohol intake, with correlations for most nutrients between 0.60 and 0.80 . The Spearman correlation coefficients ranged from 0.38 for vegetables to 0.83 for alcoholic beverages. For some food groups, such as vegetables, the relative- 
ly low correlation was due to a lack of variation in consumption frequency. It was concluded that the questionnaire could satisfactorily rank subjects according to the intake of nutrient intake and food(group) consumption. ${ }^{82}$ Also, because all these factors were measured before the diagnosis of pancreatic cancer, misclassification is likely to be non-differential with respect to the outcome, which will most likely bias risk estimates towards the null value. ${ }^{79}$

Information bias in our study could have occurred due to preclinical manifestations of disease. Due to these symptoms, subjects may have altered their dietary habits or other habits, such as smoking. Therefore, we have excluded the first 2 years of follow-up in additional analyses for all exposures investigated in the current thesis. These results were not different from the results using the total follow-up time.

Another possible source of misclassification of exposure in cohort studies is changing of habits during follow-up. The information on dietary intake and other lifestyle factors was ascertained only once in the NLCS, and changes in diet and/or lifestyle during follow-up may have weakened true relations between the exposures of interest that were investigated in the current thesis and pancreatic cancer risk. In the reproducibility study of our FFQ, it was shown that correlation coefficients with the baseline questionnaire declined just slightly with time; the average reduction for the nutrients examined was 0.07 over the 5 -year period. ${ }^{83}$ This indicates that the single FFQ measurement can characterize dietary habits for a period of at least 5 years. It is, however, not known whether this applies to the total follow-up period used in this thesis. Data in the Netherlands indicated that people decreased their alcohol intake or even quitted drinking when they become older ( $\geq 60$ years). ${ }^{86}$ Regarding smoking, it is known that few people aged $\geq 50$ years will start smoking, but more people will quit while ageing. ${ }^{87}$ Therefore, a substantial proportion of the cohort members may have quitted smoking or decreased/quitted drinking alcohol during follow-up, although they still would be classified as current users in our analysis. This may have resulted in an underestimation of the effects observed for smoking and alcohol.

\section{Misclassification of disease}

Misclassification of disease could also have occurred in our study. This type of misclassification is more likely to occur in studies on pancreatic cancer than for many other cancers because of the location of the pancreas, and the tendency for adenocarcinomas in sites such as the stomach, colon, prostate, and ovary to metastasize to the upper abdomen. ${ }^{88}$ However, we had the possibility to further restrict the analyses to microscopically verified cases, in which misclassification by disease status would be less likely than among non-microscopically confirmed pancreatic cancer cases. ${ }^{89}$ Results based on these analyses were not materially different from the analyses in which all pancreatic cancer cases were included. Therefore, we believe that misclassification of disease has not distorted our analyses. 


\section{Confounding}

It is very important to adequately control for confounders in epidemiological studies. It is, therefore, important that confounders are determined accurately. If not, this can cause bias in either direction, depending on the direction of the confounding. ${ }^{79}$ In the NLCS, detailed information on potential risk factors for pancreatic cancer was available. We considered variables as possible confounders based on the literature. These potential confounding variables were added to the multivariable-adjusted model if they (i) were associated with the disease and with the exposure of interest and (ii) changed the age- and sex-adjusted regression coefficients by at least $10 \%$ (using a backwards stepwise procedure).

Many of the confounders we included in our multivariable models did not substantially alter the results in our analyses. Smoking, however, was an influential confounder in the analyses of alcohol. Effect estimates were reduced when adding confounders to the model which was mainly attributable to smoking ( $\geq 30 \mathrm{~g}$ of ethanol intake/day versus abstention: age-adjusted $\mathrm{HR}=1.83,95 \% \mathrm{Cl}: 1.24-2.71$ and multivariable-adjusted $\mathrm{HR}=1.57,95 \% \mathrm{Cl}$ : 1.03-2.39; Chapter 3). We were unable to investigate in more depth whether residual confounding due to smoking had affected our results because only four cases who never smoked consumed $\geq 30 \mathrm{~g}$ of ethanol daily. However, other studies have confirmed our increased pancreatic cancer risk in heavy alcohol users, ${ }^{54-56}$ and a meta-analysis showed even a stronger effect estimate for studies that adjusted for smoking. ${ }^{58}$ Furthermore, self-reported smoking status (smoker or nonsmoker) is regarded as quite accurate. ${ }^{90}$ Self-report of number of cigarettes per day, however, may be biased towards round numbers, ${ }^{91}$ which could have resulted in some misclassification. Although we have checked many risk factors for their confounding effects, we cannot entirely exclude the possibility of residual confounding by unmeasured variables or misclassification of a confounder (especially smoking), which might have obscured our results.

\section{RECOMMENDATIONS FOR FUTURE RESEARCH}

\section{Etiology of pancreatic cancer \\ Gene-environment interactions}

So far, we still lack knowledge of the pancreatic cancer etiology with just few established risk factors. ${ }^{92}$ These risk factors alone are most probably not sufficient to explain completely the incidence of pancreatic cancer and therefore novel approaches and strategies are needed to have a major impact on prevention of this rapidly fatal disease. Because both genetic and environmental factors may play a role in the etiology of pancreatic cancer, a possible approach could be to study the combined effect of environmental risk factors and genetic factors. Unfortunately, data on such interactions in pancreatic cancer are scarce at the moment, possibly because of the difficulties in recruiting sufficient numbers of patients and the inaccessibility of pancreatic 
tissue. ${ }^{92}$ The studies conducted so far, have provided some clues to the etiology. KRAS mutations in pancreatic cancer have been associated with smoking, alcohol consumption, organochlorines, and diet. ${ }^{92}$ Additionally, cytochrome P450 (CYP) $1 \mathrm{~A} 2$ and $\mathrm{N}$-acetyltransferase (NAT) 1 genotypes showed significant interactions with smoking in heavy smoking women, whereas a significant interaction of the NAT1 genotype with intake of dietary mutagens (e.g., dietary heterocyclic amines and polycyclic aromatic hydrocarbons) in modification of the risk of pancreatic cancer was observed among men. ${ }^{93}$ Also, a case-control study carried out among Japanese evaluated the effect of alcohol on pancreatic cancer in conjunction with polymorphisms in one-carbon metabolism enzymes, including methylenetetrahydrofolate reductase (MTHFR), methionine synthase (MTR), and methionine synthase reductase (MTRR). ${ }^{56}$ Their results suggested that the effect of alcohol drinking on pancreatic cancer risk may be modified by the following polymorphisms: MTHFR 677 CC genotype, MTR 2756 AA genotype, and MTRR $66 \mathrm{G}$ allele. Finally, a recently published case-control study showed that genetic variations in antioxidant defenses modify the risk of pancreatic cancer in diabetics or persons with a low dietary vitamin E intake. ${ }^{94}$ However, these findings need confirmation in other populations, preferably with large case numbers, before effective strategies for the prevention of this disease may be developed.

\section{Dietary biomarkers}

Because of the complexities and limitations of various dietary assessment methods, dietary biomarkers measured in biological specimens are being increasingly used. ${ }^{85}$ Biomarkers can be defined as a biochemical indicator of dietary intake/nutritional status, or it may be an index of nutrient metabolism, or a marker of the biological consequences of dietary intake. They can be used as (i) a means of validation of dietary instruments; (ii) surrogate indicators of dietary intake; or (iii) integrated measures of nutritional status for a nutrient. ${ }^{95}$ Examples of biomarkers that have a strong relation with dietary intake are doubly labeled water for dietary energy intake, and urinary nitrogen for protein intake. No such biomarkers have, however, been identified for total fat or carbohydrate intake. ${ }^{85}$ In some cases, a biomarker may even be a better indicator of dietary intake if direct measurement of dietary intake by using traditional methods is difficult or impossible. These include selenium, vitamin $\mathrm{E}$ and mutagenic compounds. $^{95}$

As already indicated in the previous section on information bias, the validity, application and interpretation of dietary biomarkers are affected by many factors. More research is needed in this respect; especially the role of interactions between diet and genes needs to be elucidated because data on this is limited. ${ }^{85}$ Furthermore, there is need to identify and validate more and better dietary biomarkers, which should be possible using modern methods like the emerging fields of nutritional metabonomics. ${ }^{85}$ Metabonomics can be an excellent tool to determine specific metabolic profiles, which may be utilized as dietary biomarkers that are specific to various dietary/nutrient intake patterns or dietary changes. In conclusion, dietary biomarkers re- 
quire much further research which can lead to better application and interpretation of these measures to gain further insights in the association of dietary exposures and pancreatic cancer risk.

\section{Diagnostic misclassification}

Some studies showed that diagnostic misclassification could seriously bias pancreatic cancer risk estimates. ${ }^{96,97}$ In a population based case-control study, this was investigated in more depth. In this study, cases were classified as "likely" if at least one of the following criteria was satisfied: (i) a pancreatic mass was known by radiographic visualization or surgery, with a compatible histological diagnosis; (ii) a pancreatic mass was known by surgery and, although a biopsy specimen was not obtained, it appeared to be malignant due to either visible hepatic metastasis or local extension; or (iii) a pancreatic mass was known by radiographic visualization, although a biopsy specimen was not obtained, and there were supporting clinical signs, symptoms, and course (e.g., rapid death). ${ }^{97}$ Cases were considered "unlikely" to have pancreatic cancer if they did not satisfy one of the above mentioned criteria. After adjustment for potential confounders, the observed odds ratio for ever smoker was 1.8 (95\% Cl: 1.4-2.4) for microscopically confirmed cases considered "likely" to have had pancreatic cancer, 1.3 (95\% $\mathrm{Cl}$ : 0.6-2.8) for non-microscopically confirmed cases considered "likely" to have had pancreatic cancer, and 1.0 ( $95 \% \mathrm{Cl}: 0.4-2.4)$ for cases considered "unlikely" to have had pancreatic cancer. These findings suggest that restriction of the case series to "likely" cases with microscopic confirmation will generate the most precise estimates of risk. ${ }^{97}$ Since then, just few studies have reported results restricted to microscopically confirmed cases. ${ }^{17,30,98,99}$ In a previous study within the NLCS on the association of anthropometric factors and risk of pancreatic cancer, BMI was associated with pancreatic cancer only among microscopically verified cases, whereas this association was obscured when non-microscopically verified cases were included. ${ }^{100}$ Differences in characteristics of cases by degree of diagnostic certainty might explain the differences in results described above. American data from SEER registries indicated that the proportion of microscopically verified cases decreases with age. ${ }^{97}$ Porta et al. ${ }^{101}$ observed differences in some case characteristics between a group of cases having a high probability of having pancreatic cancer and less certain cases. These differences included a higher proportion of cases with an interval $\leq 1$ month from the first symptom to diagnosis and a slightly higher proportion of adenocarcinomas in the group with a high probability of having pancreatic cancer. Also, the proportion of smokers and drinkers seem to differ among cases with different diagnostic certainty. In the current thesis, no differences in results were observed between microscopically verified cases and all pancreatic cancer cases. Even though we did not observe obscured results in this thesis when we included non-microscopically verified cases in the analyses, future studies should assess whether heterogeneity exists in risk estimates by degree of diagnostic certainty. ${ }^{97,101}$ 


\section{CONCLUSIONS AND IMPLICATIONS}

In summary, we observed significantly increased pancreatic cancer risks for heavy alcohol consumption and for active cigarette smoking, whereas quitting smoking reduced risk. No association was observed with exposure to passive smoking. Participating in sports in the past moderately decreased pancreatic cancer risk, whereas findings with respect to proxies for energy restriction did not support our hypothesis that energy restriction may reduce pancreatic cancer risk. We observed no association with the other dietary factors that were investigated, including GI, GL, intake of carbohydrates, meat, fat, fruit, vegetables, carotenoids, and vitamins $\mathrm{C}$ and $\mathrm{E}$.

From a public health perspective, a healthy lifestyle, including not smoking, maintaining a healthy weight, being physically active and limiting alcohol use, might reduce the incidence and mortality of pancreatic cancer, which is important for this type of cancer with its extremely poor prognosis. 


\section{REFERENCES}

1. World Cancer Research Fund/American Institute for Cancer research. Food, nutrition, physical activity, and the prevention of cancer: a global perspective. Washington DC: AICR, 2007.

2. Anisimov VN, Ukraintseva SV, Yashin Al. Cancer in rodents: does it tell us about cancer in humans? Nat Rev Cancer 2005;5:807-19.

3. Standop J, Schneider MB, Ulrich A, Pour PM. Experimental animal models in pancreatic carcinogenesis: lessons for human pancreatic cancer. Dig Dis 2001;19:24-31.

4. Hecht SS. Cigarette smoking: cancer risks, carcinogens, and mechanisms. Langenbecks Arch Surg 2006; 391:603-13.

5. Rivenson A, Hoffmann D, Prokopczyk B, Amin S, Hecht SS. Induction of lung and exocrine pancreas tumors in F344 rats by tobacco-specific and Areca-derived N-nitrosamines. Cancer Res 1988;48:

6912-7.

6. Auerbach O, Garfinkel L. Histologic changes in pancreas in relation to smoking and coffee-drinking habits. Dig Dis Sci 1986;31:1014-20.

7. Prokopczyk B, Hoffmann D, Bologna $M$, et al. Identification of tobacco-derived compounds in human pancreatic juice. Chem Res Toxicol 2002;15:677-85.

8. Anderson KE, Mack TM, Silverman DT. Cancer of the pancreas. In: Schottenfeld D, Fraumeni JF Jr., eds. Cancer epidemiology and prevention, $3^{\text {rd }}$ ed. New York: Oxford University Press, 2006. P. 721-62.

9. Coughlin SS, Calle EE, Patel AV, Thun MJ. Predictors of pancreatic cancer mortality among a large cohort of United States adults. Cancer Causes Control 2000;11:915-23.

10. Fuchs CS, Colditz GA, Stampfer MJ, et al. A prospective study of cigarette smoking and the risk of pancreatic cancer. Arch Intern Med 1996;156:2255-60.

11. Lynch SM, Vrieling A, Lubin JH, et al. Cigarette smoking and pancreatic cancer: a pooled analysis from the pancreatic cancer cohort consortium. Am J Epidemiol 2009;170:403-13.

12. Silverman DT, Dunn JA, Hoover RN, et al. Cigarette smoking and pancreas cancer: a case-control study based on direct interviews. J Natl Cancer Inst 1994;86:1510-6.

13. International Agency for Research on Cancer. Composition, exposure and regulations Tobacco smoke and involuntary smoking, vol. 83. Lyon, France: International Agency for Research on Cancer, 2004.

P. 1191-230.

14. Anderson KE, Carmella SG, Ye M, et al. Metabolites of a tobacco-specific lung carcinogen in nonsmoking women exposed to environmental tobacco smoke. J Natl Cancer Inst 2001;93:378-81.

15. lodice S, Gandini S, Maisonneuve P, Lowenfels AB. Tobacco and the risk of pancreatic cancer: a review and meta-analysis. Langenbecks Arch Surg 2008;393:535-45.

16. Gallicchio L, Kouzis A, Genkinger JM, et al. Active cigarette smoking, household passive smoke exposure, and the risk of developing pancreatic cancer. Prev Med 2006;42:200-5.

17. Vrieling A, Bueno-de-Mesquita HB, Boshuizen HC, et al. Cigarette smoking, environmental tobacco smoke exposure and pancreatic cancer risk in the European Prospective Investigation into Cancer and Nutrition. Int J Cancer 2010;126:2394-403.

18. Hassan MM, Abbruzzese JL, Bondy ML, et al. Passive smoking and the use of noncigarette tobacco products in association with risk for pancreatic cancer: a case-control study. Cancer 2007;109:2547-56.

19. Nishino Y, Tsubono Y, Tsuji I, et al. Passive smoking at home and cancer risk: a population-based prospective study in Japanese nonsmoking women. Cancer Causes Control 2001;12:797-802.

20. Bao Y, Giovannucci E, Fuchs CS, Michaud DS. Passive smoking and pancreatic cancer in women: a prospective cohort study. Cancer Epidemiol Biomarkers Prev 2009;18:2292-6.

21. Lo AC, Soliman AS, El-Ghawalby N, et al. Lifestyle, occupational, and reproductive factors in relation to pancreatic cancer risk. Pancreas 2007;35:120-9.

22. Kaaks R, Lukanova A. Energy balance and cancer: the role of insulin and insulin-like growth factor-I. Proc Nutr Soc 2001;60:91-106.

23. Ding XZ, Fehsenfeld DM, Murphy LO, Permert J, Adrian TE. Physiological concentrations of insulin augment pancreatic cancer cell proliferation and glucose utilization by activating MAP kinase, PI3 kinase and enhancing GLUT-1 expression. Pancreas 2000;21:310-20. 
24. Fisher WE, Boros LG, Schirmer WJ. Insulin promotes pancreatic cancer: evidence for endocrine influence on exocrine pancreatic tumors. J Surg Res 1996;63:310-3.

25. Bergmann U, Funatomi H, Yokoyama M, Beger HG, Korc M. Insulin-like growth factor I overexpression in human pancreatic cancer: evidence for autocrine and paracrine roles. Cancer Res 1995;55:2007-11.

26. Stolzenberg-Solomon RZ, Graubard BI, Chari S, et al. Insulin, glucose, insulin resistance, and pancreatic cancer in male smokers. Jama 2005;294:2872-8.

27. Stolzenberg-Solomon RZ, Limburg P, Pollak M, Taylor PR, Virtamo J, Albanes D. Insulin-like growth factor (IGF)-1, IGF-binding protein-3, and pancreatic cancer in male smokers. Cancer Epidemiol Biomarkers Prev 2004;13:438-44.

28. Wolpin BM, Michaud DS, Giovannucci EL, et al. Circulating insulin-like growth factor axis and the risk of pancreatic cancer in four prospective cohorts. Br J Cancer 2007;97:98-104.

29. Lin Y, Tamakoshi A, Kikuchi S, et al. Serum insulin-like growth factor-I, insulin-like growth factor binding protein-3, and the risk of pancreatic cancer death. Int J Cancer 2004;110:584-8.

30. Michaud DS, Giovannucci E, Willett WC, Colditz GA, Stampfer MJ, Fuchs CS. Physical activity, obesity, height, and the risk of pancreatic cancer. Jama 2001;286:921-9.

31. Zhang J, Dhakal IB, Gross MD, et al. Physical activity, diet, and pancreatic cancer: a population-based, case-control study in Minnesota. Nutr Cancer 2009;61:457-65.

32. Berrington de Gonzalez A, Spencer EA, Bueno-de-Mesquita HB, et al. Anthropometry, physical activity, and the risk of pancreatic cancer in the European prospective investigation into cancer and nutrition. Cancer Epidemiol Biomarkers Prev 2006;15:879-85.

33. Nothlings U, Wilkens LR, Murphy SP, Hankin JH, Henderson BE, Kolonel LN. Body mass index and physical activity as risk factors for pancreatic cancer: the Multiethnic Cohort Study. Cancer Causes Control 2007;18:165-75.

34. Bao Y, Michaud DS. Physical activity and pancreatic cancer risk: a systematic review. Cancer Epidemiol Biomarkers Prev 2008;17:2671-82.

35. O'Rorke MA, Cantwell MM, Cardwell CR, Mulholland HG, Murray LJ. Can physical activity modulate pancreatic cancer risk? a systematic review and meta-analysis. Int J Cancer 2010;126:2957-68.

36. Hursting SD, Lavigne JA, Berrigan D, Perkins SN, Barrett JC. Calorie restriction, aging, and cancer prevention: mechanisms of action and applicability to humans. Annu Rev Med 2003;54:131-52.

37. Roebuck BD, Baumgartner KJ, MacMillan DL. Caloric restriction and intervention in pancreatic carcinogenesis in the rat. Cancer Res 1993;53:46-52.

38. Roebuck BD, Yager JD, Jr., Longnecker DS. Dietary modulation of azaserine-induced pancreatic carcinogenesis in the rat. Cancer Res 1981;41:888-93.

39. Hughes LA, van den Brandt PA, Goldbohm RA, et al. Childhood and adolescent energy restriction and subsequent colorectal cancer risk: results from the Netherlands Cohort Study. Int J Epidemiol 2010;39: 1333-44.

40. Johnson KJ, Anderson KE, Harnack L, Hong CP, Folsom AR. No association between dietary glycemic index or load and pancreatic cancer incidence in postmenopausal women. Cancer Epidemiol Biomarkers Prev 2005;14:1574-5.

41. Michaud DS, Liu S, Giovannucci E, Willett WC, Colditz GA, Fuchs CS. Dietary sugar, glycemic load, and pancreatic cancer risk in a prospective study. J Natl Cancer Inst 2002;94:1293-300.

42. Patel AV, McCullough ML, Pavluck AL, Jacobs EJ, Thun MJ, Calle EE. Glycemic load, glycemic index, and carbohydrate intake in relation to pancreatic cancer risk in a large US cohort. Cancer Causes Control 2007;18:287-94.

43. Silvera SA, Rohan TE, Jain M, Terry PD, Howe GR, Miller AB. Glycemic index, glycemic load, and pancreatic cancer risk (Canada). Cancer Causes Control 2005;16:431-6.

44. Meinhold CL, Dodd KW, Jiao L, et al. Available carbohydrates, glycemic load, and pancreatic cancer: is there a link? Am J Epidemiol 2010;171:1174-82.

45. Pi-Sunyer FX. Glycemic index and disease. Am J Clin Nutr 2002;76:290S-8S.

46. Marshall JR, Freudenheim J. Alcohol. In: Schottenfeld D, Fraumeni JF, Jr., eds. Cancer Epidemiology and Prevention, $3^{\text {rd }}$ ed. New York: Oxford University Press, 2006. P. 243-58. 
47. Seitz HK, Stickel F. Molecular mechanisms of alcohol-mediated carcinogenesis. Nat Rev Cancer 2007;7: 599-612.

48. Go VL, Gukovskaya A, Pandol SJ. Alcohol and pancreatic cancer. Alcohol 2005;35:205-11.

49. Pour PM, Reber HA, Stepan K. Modification of pancreatic carcinogenesis in the hamster model. XII. Dose-related effect of ethanol. J Natl Cancer Inst 1983;71:1085-7.

50. Woutersen RA, van Garderen-Hoetmer A, Bax J, Scherer E. Modulation of dietary fat-promoted pancreatic carcinogenesis in rats and hamsters by chronic ethanol ingestion. Carcinogenesis 1989;10: 453-9.

51. Isaksson B, Jonsson F, Pedersen NL, Larsson J, Feychting M, Permert J. Lifestyle factors and pancreatic cancer risk: a cohort study from the Swedish Twin Registry. Int J Cancer 2002;98:480-2.

52. Michaud DS, Giovannucci E, Willett WC, Colditz GA, Fuchs CS. Coffee and alcohol consumption and the risk of pancreatic cancer in two prospective United States cohorts. Cancer Epidemiol Biomarkers Prev 2001;10:429-37.

53. Rohrmann S, Linseisen J, Vrieling A, et al. Ethanol intake and the risk of pancreatic cancer in the European prospective investigation into cancer and nutrition (EPIC). Cancer Causes Control 2009.

54. Genkinger JM, Spiegelman D, Anderson KE, et al. Alcohol intake and pancreatic cancer risk: a pooled analysis of fourteen cohort studies. Cancer Epidemiol Biomarkers Prev 2009;18:765-76.

55. Jiao L, Silverman DT, Schairer C, et al. Alcohol use and risk of pancreatic cancer: the NIH-AARP Diet and Health Study. Am J Epidemiol 2009;169:1043-51.

56. Suzuki T, Matsuo K, Sawaki A, et al. Alcohol drinking and one-carbon metabolism-related gene polymorphisms on pancreatic cancer risk. Cancer Epidemiol Biomarkers Prev 2008;17:2742-7.

57. Gupta S, Wang F, Holly EA, Bracci PM. Risk of pancreatic cancer by alcohol dose, duration, and pattern of consumption, including binge drinking: a population-based study. Cancer Causes Control 2010;21: 1047-59.

58. Tramacere I, Scotti L, Jenab M, et al. Alcohol drinking and pancreatic cancer risk: a meta-analysis of the dose-risk relation. Int J Cancer 2009;126:1474-86.

59. Bagnardi V, Blangiardo M, La Vecchia C, Corrao G. Alcohol consumption and the risk of cancer: a metaanalysis. Alcohol Res Health 2001;25:263-70.

60. Risch HA. Etiology of pancreatic cancer, with a hypothesis concerning the role of N-nitroso compounds and excess gastric acidity. J Natl Cancer Inst 2003;95:948-60.

61. Jiao L, Doll MA, Hein DW, et al. Haplotype of $\mathrm{N}$-acetyltransferase 1 and 2 and risk of pancreatic cancer. Cancer Epidemiol Biomarkers Prev 2007;16:2379-86.

62. Wakabayashi K, Nagao M, Esumi H, Sugimura T. Food-derived mutagens and carcinogens. Cancer Res 1992;52:2092s-8s.

63. Anderson KE, Hammons GJ, Kadlubar FF, et al. Metabolic activation of aromatic amines by human pancreas. Carcinogenesis 1997;18:1085-92.

64. Anderson KE, Kadlubar FF, Kulldorff $M$, et al. Dietary intake of heterocyclic amines and benzo(a)pyrene: associations with pancreatic cancer. Cancer Epidemiol Biomarkers Prev 2005;14:2261-5.

65. Stolzenberg-Solomon RZ, Cross AJ, Silverman DT, et al. Meat and meat-mutagen intake and pancreatic cancer risk in the NIH-AARP cohort. Cancer Epidemiol Biomarkers Prev 2007;16:2664-75.

66. Woutersen RA, Appel MJ, van Garderen-Hoetmer A, Wijnands MV. Dietary fat and carcinogenesis. Mutat Res 1999;443:111-27.

67. Heukamp I, Kilian M, Gregor JI, et al. Impact of polyunsaturated fatty acids on hepato-pancreatic prostaglandin and leukotriene concentration in ductal pancreatic cancer - is there a correlation to tumour growth and liver metastasis? Prostaglandins Leukot Essent Fatty Acids 2006;74:223-33.

68. Stolzenberg-Solomon RZ, Pietinen P, Taylor PR, Virtamo J, Albanes D. Prospective study of diet and pancreatic cancer in male smokers. Am J Epidemiol 2002;155:783-92.

69. Anderson KE, Sinha R, Kulldorff $M$, et al. Meat intake and cooking techniques: associations with pancreatic cancer. Mutat Res 2002;506-507:225-31.

70. McCullough ML, Giovannucci EL. Diet and cancer prevention. Oncogene 2004;23:6349-64. 
71. Appel MJ, van Garderen-Hoetmer A, Woutersen RA. Lack of inhibitory effects of beta-carotene, vitamin C, vitamin E and selenium on development of ductular adenocarcinomas in exocrine pancreas of hamsters. Cancer Lett 1996;103:157-62.

72. Woutersen RA, Appel MJ, Van Garderen-Hoetmer A. Modulation of pancreatic carcinogenesis by antioxidants. Food Chem Toxicol 1999;37:981-4.

73. Vrieling A, Verhage BA, van Duijnhoven FJ, et al. Fruit and vegetable consumption and pancreatic cancer risk in the European Prospective Investigation into Cancer and Nutrition. Int J Cancer 2009;124: 1926-34.

74. Baghurst PA, McMichael AJ, Slavotinek AH, Baghurst KI, Boyle P, Walker AM. A case-control study of diet and cancer of the pancreas. Am J Epidemiol 1991;134:167-79.

75. Bueno de Mesquita HB, Maisonneuve P, Runia S, Moerman CJ. Intake of foods and nutrients and cancer of the exocrine pancreas: a population-based case-control study in The Netherlands. Int J Cancer 1991;48:540-9.

76. Nkondjock A, Ghadirian P, Johnson KC, Krewski D. Dietary intake of lycopene is associated with reduced pancreatic cancer risk. J Nutr 2005;135:592-7.

77. Shibata A, Mack TM, Paganini-Hill A, Ross RK, Henderson BE. A prospective study of pancreatic cancer in the elderly. Int J Cancer 1994;58:46-9.

78. Silverman DT, Swanson CA, Gridley G, et al. Dietary and nutritional factors and pancreatic cancer: a case-control study based on direct interviews. J Natl Cancer Inst 1998;90:1710-9.

79. Rothman KJ, Greenland S. Modern epidemiology, $2^{\text {nd }}$ ed. Philadelphia: Lippincott-Raven Publishers, 1998.

80. Goldbohm RA, van den Brandt PA, Dorant E. Estimation of the coverage of Dutch municipalities by cancer registries and PALGA based on hospital discharge data. Tijdschr Soc Gezondheidsz 1994;72:

80-4.

81. Willett W. Nutritional epidemiology, $2^{\text {nd }}$ ed. New York: Oxford University Press, 1998.

82. Goldbohm RA, van den Brandt PA, Brants HA, et al. Validation of a dietary questionnaire used in a large-scale prospective cohort study on diet and cancer. Eur J Clin Nutr 1994;48:253-65.

83. Goldbohm RA, van 't Veer P, van den Brandt PA, et al. Reproducibility of a food frequency questionnaire and stability of dietary habits determined from five annually repeated measurements. Eur J Clin Nutr 1995;49:420-9.

84. Kipnis V, Freedman LS. Impact of exposure measurement error in nutritional epidemiology. J Natl Cancer Inst 2008;100:1658-9.

85. Jenab M, Slimani N, Bictash M, Ferrari P, Bingham SA. Biomarkers in nutritional epidemiology: applications, needs and new horizons. Hum Genet 2009;125:507-25.

86. Statistics Netherlands. Statistisch jaarboek (Statistical abstract [in Dutch]). The Hague, the Netherlands: Statistics Netherlands, 1996-2001.

87. Blokstra A, Schuit AJ, Factsheet roken. Prevalentie en trend. (Factsheet smoking. Prevalence and trend [in Dutch]). National Institute for Public Health and the Environment, 2003.

88. Hess KR, Varadhachary GR, Taylor SH, et al. Metastatic patterns in adenocarcinoma. Cancer 2006;106: 1624-33.

89. Lyon JL, Robison LM, Moser R, Jr. Uncertainty in the diagnosis of histologically confirmed pancreatic cancer cases. Int J Epidemiol 1989;18:305-8.

90. Patrick DL, Cheadle A, Thompson DC, Diehr P, Koepsell T, Kinne S. The validity of self-reported smoking: a review and meta-analysis. Am J Public Health 1994;84:1086-93.

91. Klesges RC, Debon M, Ray JW. Are self-reports of smoking rate biased? Evidence from the Second National Health and Nutrition Examination Survey. J Clin Epidemiol 1995;48:1225-33.

92. Li D. Molecular epidemiology of pancreatic cancer. Cancer J 2001;7:259-65.

93. Suzuki H, Morris JS, Li Y, et al. Interaction of the cytochrome P4501A2, SULT1A1 and NAT gene polymorphisms with smoking and dietary mutagen intake in modification of the risk of pancreatic cancer. Carcinogenesis 2008;29:1184-91.

94. Tang H, Dong X, Day RS, Hassan MM, Li D. Antioxidant genes, diabetes and dietary antioxidants in association with risk of pancreatic cancer. Carcinogenesis 2010;31:607-13. 
95. Potischman N, Freudenheim JL. Biomarkers of nutritional exposure and nutritional status: an overview. J Nutr 2003;133 Suppl 3:873S-4S.

96. Malats N, Real FX, Porta M. DDT and pancreatic cancer. J Natl Cancer Inst 1993;85:328-9.

97. Silverman DT, Schiffman M, Devesa S. Diagnostic certainty in pancreatic cancer. J Clin Epidemiol 1996; 49:601-3.

98. Bonelli L, Aste H, Bovo P, et al. Exocrine pancreatic cancer, cigarette smoking, and diabetes mellitus: a case-control study in northern Italy. Pancreas 2003;27:143-9.

99. Rulyak SJ, Lowenfels AB, Maisonneuve P, Brentnall TA. Risk factors for the development of pancreatic cancer in familial pancreatic cancer kindreds.Gastroenterology 2003;124:1292-9.

100. Verhage BA, Schouten L, Goldbohm RA, van den Brandt PA. Anthropometry and pancreatic cancer risk: an illustration of the importance of microscopic verification. Cancer Epidemiol Biomarkers Prev 2007;16:1449-54.

101. Porta M, Malats N, Pinol JL, Rifa J, Andreu M, Real FX. Diagnostic certainty and potential for misclassification in exocrine pancreatic cancer. PANKRAS I Project Investigations. J Clin Epidemiol 1994;47: 1069-79. 
Summary 


\section{SUMMARY}

Pancreatic cancer is the $5^{\text {th }}$ leading cause of cancer death in Europe and $4^{\text {th }}$ in the United States. Survival rates for pancreatic cancer are amongst the worst of all cancers with a median survival of about 3 months and a 5 -year survival rate of $\leq 6 \%$.

Because the pancreas is intimately related to digestion and absorption, it is reasonable to place diet high among the possible risk factors for pancreatic cancer. However, the specific dietary components and mechanisms that might be involved in the etiology of pancreatic cancer remain unclear, primarily because of limited and inconsistent study findings. One of the reasons that study findings have been inconsistent between case-control studies and cohort studies might be because case-control studies are prone to more biases, including recall bias, compared with cohort studies. Recall bias could lead to risk estimates that are either exaggerated or underestimated because dietary intake is assessed in cases after diagnosis. Furthermore, patients in case-control studies tend to report current rather than past diet which can introduce bias because current diet might be influenced by prediagnostic symptoms of disease. Differential misclassification of the exposure could also have occurred due to the need to use next-of-kin interviews in case-control studies because pancreatic cancer is rapidly fatal. In addition, case-control studies of pancreatic cancer are highly susceptible to selection bias due to the high fatality rates among pancreatic cancer cases. Pancreatic cancer shows relatively low incidence rates, which has resulted in relatively low case numbers in most prospective studies. A large-scale cohort study with a substantial number of cases would be informative to overcome these biases and to make a substantial contribution to the epidemiological knowledge regarding the association between risk factors and pancreatic cancer risk. The prospective design avoids differential misclassification and the need to use next-of-kin respondents.

The overall aim of this thesis was to investigate the associations between dietary and lifestyle factors and pancreatic cancer risk. These factors were investigated within the context of the Netherlands Cohort Study (NLCS) on diet and cancer. This prospective study was initiated in September 1986. At baseline, a total of 120,852 men and women aged 55 to 69 years returned a self-administered questionnaire on habitual dietary, lifestyle, and other risk factors for pancreatic cancer. For increased efficiency in the processing of the questionnaire and follow-up, the case-cohort approach was used. A randomly drawn subcohort consisting of 5,000 men and women was actively followed up for vital status to estimate the accumulating person time at risk, whereas the entire cohort was followed up annually for cancer occurrence by record linkage to the Netherlands Cancer Registry and the Netherlands Pathology Registry. Follow-up is still ongoing for the NLCS, which is why two different follow-up periods were used in this thesis. For the first part of the thesis, a total of 13.3 years of follow-up (baseline to December 1999) was used for the analysis, for which 408 incident exocrine pancreatic cancer cases were available. Sixty-six percent of these cases were microscopically confirmed pancreatic cancer $(n=269)$. When data became available in 2008 for a period 
of 16.3 years, the follow-up period was extended. This extended follow-up period was used for the analyses described in the last chapters of this thesis, for which 520 incident exocrine pancreatic cancer cases (62\% microscopically confirmed) were available.

Some studies have shown that diagnostic misclassification could seriously bias pancreatic cancer risk estimates. In a previous analysis of anthropometric measures and pancreatic cancer risk within the NLCS, a significantly positive association between body mass index and pancreatic cancer risk was observed only among microscopically verified cases, whereas this association was obscured when non-microscopically verified cases were included. Therefore, next to the overall analyses including all pancreatic cancer cases, we restricted additional analyses in this thesis to microscopically verified cases to create a group with a higher degree of diagnostic certainty of pancreatic cancer.

Previous studies showed that higher physical activity levels and energy restriction might decrease pancreatic cancer risk. In Chapter 2, we present the results for both non-occupational and occupational physical activity as well as energy restriction in relation to pancreatic cancer risk. The NLCS is comprised of individuals who grew up during the war years (1940-1944), the Hunger winter (winter of 1944-1945), and the Economic Depression (1932-1940). This gave us the opportunity to study the effect of energy restriction during adolescence on the risk of pancreatic cancer in later life. A number of proxy measures have been collected from cohort members that reflect the exposure to energy restriction during these three time periods. A modestly decreased pancreatic cancer risk was observed for individuals who resided in a city during the war years compared with those who did not. This was meant to indicate a period of more moderate energy restriction. Regarding the exposure to a short period of severe energy restriction during the Hunger winter, results were not clear. Individuals living in western rural area had an increased pancreatic cancer risk compared with individuals living in non-western area, whereas living in a western city was not associated. No association was observed for exposure to energy restriction during the Economic Depression. Regarding physical activity, a modestly decreased pancreatic cancer risk was observed for respondents who reported to have ever participated in sports in the past. Non-occupational physical activity at baseline and occupational physical activity were not associated with pancreatic cancer risk.

So far, most cohort studies and case-control studies have provided little or no support for a positive association between low-to-moderate alcohol use and pancreatic cancer risk, but some studies suggested that heavy alcohol intake might increase risk. In Chapter 3, the association between alcohol consumption and pancreatic cancer risk was examined. Compared with abstention, consuming less than 3 glasses of alcohol was not associated with pancreatic cancer risk, whereas consuming 3 or more glasses of alcohol increased pancreatic cancer risk with $57 \%$. In a subgroup of stable alcohol users (no change during the 5 years before baseline), a similarly increased pancreatic 
cancer risk was found. No associations were observed between consumption of specific alcoholic beverages and risk of pancreatic cancer, which suggests that it is ethanol itself and not the type of alcoholic beverage which plays a role in pancreatic carcinogenesis.

Studies have shown that insulin might play a role in pancreatic carcinogenesis. Insulin is secreted into the blood in response to elevated blood glucose levels; therefore, dietary factors increasing blood glucose levels may be associated with pancreatic cancer risk. Glycemic index and glycemic load are such measures. In Chapter 4, it was examined whether these dietary measures were positively associated with pancreatic cancer risk, but no association was observed between dietary glycemic load and glycemic index and pancreatic cancer risk in the NLCS. Also, no association was observed between the intake of carbohydrates and mono- and disaccharides and pancreatic cancer risk.

Numerous carcinogens can be produced during the process of meat preparation, which may increase pancreatic cancer risk. Furthermore, animal studies showed that polyunsaturated fatty acids increase pancreatic cancer risk. So far, findings from the numerous epidemiological studies that investigated the association between the intake of meat and different types of fat and pancreatic cancer risk have been inconsistent. In Chapter 5, the results are described on the associations between the consumption of fresh meat, other types of meat, and the intake of different types of fat and risk of pancreatic cancer: no association was observed. Also, no association was observed between the consumption of fish and eggs and pancreatic cancer risk.

Fruits and vegetables contain numerous substances with potential anticarcinogenic activity and could therefore play a role in prevention of pancreatic cancer. Most casecontrol studies observed an inverse association with total fruit and vegetable consumption, whereas results from most cohort studies have largely been null. In Chapter 6, we described the results of the association between fruit and vegetable consumption and pancreatic cancer risk in the NLCS. Total vegetable and total fruit consumption were not associated with pancreatic cancer risk. Also, no association was observed for cooked vegetables, raw vegetables, and other specific subgroups of vegetables and fruits. Dietary carotenoids, vitamin C and E intake and use of supplements containing vitamin $\mathrm{C}$ or $\mathrm{E}$ were neither associated with pancreatic cancer risk.

To date, cigarette smoking is the most consistent risk factor for pancreatic cancer. In Chapter 7, the results of the analyses on active and passive cigarette smoking in relation to pancreatic cancer risk were presented. Compared to the risk of never cigarette smokers, former and current cigarette smokers had a $37 \%$ and $88 \%$ increased pancreatic cancer risk, respectively. We observed an increased pancreatic cancer risk of 51\% for those smoking $\geq 20$ cigarettes/day compared with never cigarette smoking, but no 
dose-response relation was present. A dose-response effect was observed with duration of smoking. The hazard rate ratio for pancreatic cancer risk was 2.03 comparing smokers who smoked $\geq 40$ years with never cigarette smokers. Pancreatic cancer risk was gradually reduced with increasing years of quitting among former smokers and approached the risk of never cigarette smokers after $\geq 20$ years of quitting. No association was observed for passive smoking exposure and pancreatic cancer risk in women. Exclusion of ever tobacco smokers when examining the association between passive smoking and cancer risk is important to estimate the independent effect of passive smoking. Therefore, this association was not investigated in men because $>90 \%$ of the men in the NLCS were ever smokers.

When for Chapter $\mathbf{2}$ till $\mathbf{7}$ additional analyses were restricted to microscopically verified pancreatic cancer cases, results were similar to the results including all pancreatic cancer cases.

In Chapter 8, the main findings on the associations between pancreatic cancer risk and the lifestyle factors investigated in the current thesis were discussed in light of the existing literature - both epidemiological and mechanistic - and a final conclusion was made on the strength of the evidence so far. Additionally, some important strengths and weaknesses of the study design of the NLCS and the analyses performed in this thesis were discussed, including confounding and misclassification of exposure and disease. Some studies showed that diagnostic misclassification could seriously bias pancreatic cancer risk estimates. Differences in characteristics of cases, including age, proportion of smokers and drinkers, and tumor characteristics, by degree of diagnostic certainty might explain these biased results. However, as mentioned above, in the current thesis results restricted to microscopically verified cases were similar to the results including all pancreatic cancer cases. Furthermore, we have described that studying the combined effect of environmental risk factors and genetic factors and identifying more and better dietary biomarkers might gain further insights in the possible association of dietary exposures and pancreatic cancer risk.

In summary, we observed significantly increased pancreatic cancer risks for heavy alcohol consumption and for active cigarette smoking, whereas quitting smoking reduced risk. No association was observed with exposure to passive smoking. Participating in sports in the past moderately decreased pancreatic cancer risk, whereas findings with respect to proxies for energy restriction did not support our hypothesis that energy restriction may reduce pancreatic cancer risk. We observed no association with the other dietary factors that were investigated, including glycemic index, glycemic load, intake of carbohydrates, meat, fat, fruit, vegetables, carotenoids, and vitamins $\mathrm{C}$ and $\mathrm{E}$. 

Samenvatting 


\section{SAMENVATTING}

Alvleesklierkanker staat op de $5^{\text {de }}$ plaats van de ranglijst van doodsoorzaken aan kanker in Europa en op de $4^{\text {de }}$ plaats in the Verenigde Staten. Overlevingskansen voor alvleesklierkanker behoren tot de slechtste van alle vormen van kanker met een mediane overleving van ongeveer 3 maanden en een 5 -jaars overlevingskans van $6 \%$ of minder.

Omdat de alvleesklier een belangrijke rol speelt in de spijsvertering en absorptie, zou voeding een mogelijk risicofactor voor alvleesklierkanker kunnen zijn. De specifieke voedingscomponenten en -mechanismen die mogelijk betrokken zijn in de etiologie van alvleesklierkanker zijn echter tot op heden nog onduidelijk. Dit komt voornamelijk door het beperkt aantal onderzoeken, voornamelijk cohortonderzoeken, die dit hebben onderzocht die tevens inconsistente bevindingen lieten zien. Een van de redenen dat er inconsistente bevindingen zijn gevonden tussen patiëntcontroleonderzoeken en cohortonderzoeken kan zijn dat patiëntcontroleonderzoeken gevoeliger zijn voor vertekeningen van onderzoeksresultaten dan cohortonderzoeken. De voedingsinname van patiënten is nagevraagd na vaststelling van de diagnose en dit kan leiden tot systematische verschillen in de hoeveelheid informatie en de nauwkeurigheid van de informatie tussen patiënten en controlepersonen (recall bias). Dit kan leiden tot het over- of onderschatten van het risico. Verder hebben patiënten in patiëntcontroleonderzoeken de neiging hun huidige voedingsinname te rapporteren in plaats van hun vroegere voedingsinname. Vanwege klachten veroorzaakt door hun ziekte, kunnen patiënten echter hun huidige voedingsinname hebben aangepast voordat hun ziekte is gediagnosticeerd. In patiëntcontroleonderzoeken moet vaak de informatie over de risicofactoren van patiënten worden nagevraagd aan naaste familieleden. Dit komt omdat de meeste patiënten na het vaststellen van de diagnose alvleesklierkanker zeer snel overlijden, waardoor navraag bij de patiënt zelf vaak niet mogelijk is. Dit kan leiden tot differentiële missclassificatie van risicofactoren. Het zeer snel overlijden van patiënten na vaststelling van de diagnose zorgt er ook voor dat patiëntcontroleonderzoeken naar alvleesklierkanker zeer gevoelig zijn voor selectie bias. Het aantal nieuwe gevallen van alvleesklierkanker in de bevolking is relatief laag waardoor het aantal gevallen in de meeste prospectieve onderzoeken ook relatief laag is. Een grootschalig cohortonderzoek met een aanzienlijk aantal patiënten zou deze vertekeningen van onderzoeksresultaten kunnen overwinnen en zou een belangrijke bijdrage kunnen leveren aan de epidemiologische kennis over het verband tussen risicofactoren en alvleesklierkanker. De prospectieve opzet van de het cohortonderzoek vermijdt differentiële misclassificatie en de noodzaak om gegevens van patiënten na te vragen aan naaste familie.

De doelstelling van dit proefschrift was het onderzoeken van de verbanden tussen voedings- en leefstijlfactoren en het risico op alvleesklierkanker. Hierbij werd gebruik gemaakt van de onderzoeksgegevens uit de Nederlandse Cohort Studie (NLCS) naar voeding en kanker. Dit prospectief onderzoek is gestart in september 1986. In totaal 
hebben 120.852 mannen en vrouwen in de leeftijd van 55 tot 69 jaar in 1986 een vragenlijst retour gezonden over hun gebruikelijke eetgewoonten, leefstijl en andere risicofactoren voor alvleesklierkanker. Vanwege de efficiëntie in het verwerken van de vragenlijsten en het opvolgen van de deelnemers, is the case-cohortbenadering gebruikt. Een aselect getrokken steekproef uit het cohort, het subcohort bestaande uit 5.000 mannen en vrouwen, werd opgevolgd voor informatie over overlijden. Zo kon voor elk subcohortlid het totaal aantal persoonsjaren die hij of zij had bijgedragen aan het onderzoek worden vastgesteld wat weer werd gebruikt voor een schatting van de opgebouwde persoonsjaren in het hele cohort. Voor het hele cohort werd jaarlijks het optreden van kanker vastgesteld door een koppeling tussen de gegevens van de NLCS en de Nederlandse Kanker Registratie en Pathologisch-Anatomisch Landelijk Geautomatiseerd Archief (PALGA). De deelnemers binnen de NLCS worden nog steeds opgevolgd, waardoor in dit proefschrift twee verschillende follow-up periodes zijn gebruikt. Voor het eerste gedeelte van het proefschrift hebben we een follow-up tijd van 13.3 jaar gebruikt (start van het onderzoek tot en met december 1999), waarbinnen 408 alvleesklierkankerpatiënten zijn gediagnosticeerd. Hiervan hadden $66 \%$ patiënten ( $\mathrm{n}=$ 269) microscopische bevestiging. In 2008 werd de follow-up periode verlengd toen informatie beschikbaar kwam voor een periode van 16.3 jaar. Voor de laatste hoofdstukken van dit proefschrift is van deze verlengde follow-up periode gebruik gemaakt, waarbinnen 520 alvleesklierkankerpatiënten (62\% microscopisch bevestigd) zijn gediagnosticeerd.

Sommige onderzoeken hebben laten zien dat het verkeerd classificeren van patiënten (diagnostische misclassificatie) de risicoschattingen voor alvleesklierkanker ernstig kunnen vertekenen. In een vorig onderzoek binnen de NLCS naar het verband tussen antropometrie en alvleesklierkanker, werd al gezien dat er een significant positief verband bestaat tussen de body mass index en alvleesklierkanker binnen de groep patiënten met microscopisch bevestigde alvleesklierkanker. Dit verband werd niet meer aangetoond zodra ook de patiënten zonder microscopische bevestiging werden geïncludeerd in deze analyse. Daarom hebben we in dit proefschrift eerst alle analyses uitgevoerd met alle alvleesklierkankerpatiënten, waarna we vervolgens extra analyses uitgevoerd hebben waarin alleen patiënten met microscopisch bevestigde alvleesklierkanker zijn geïncludeerd. Dit om een groep met patiënten te krijgen waarvan met meer zekerheid gezegd kan worden dat ze alvleesklierkanker hebben.

Voorgaande onderzoeken lieten zien dat hogere lichamelijke activiteitenniveaus en energierestrictie het risico op het krijgen van alvleesklierkanker zou kunnen verlagen. In Hoofdstuk 2 presenteren we de resultaten voor lichamelijke activiteit, zowel tijdens als buiten het werk, en energierestrictie in relatie tot het risico op alvleesklierkanker. De NLCS bestaat uit individuen die zijn opgegroeid gedurende de oorlogsjaren (19401944), de Hongerwinter (winter van 1944-1945) en de crisisjaren (1932-1940). Dit gaf ons de gelegenheid het effect te bestuderen van energierestrictie gedurende de adolescentie op het krijgen van alvleesklierkanker op latere leeftijd. Informatie over een 
aantal proxy-maten van de deelnemers zijn met dit doel verzameld om zo hun blootstelling aan energierestrictie gedurende de drie bovenstaande periodes te meten. $\mathrm{Er}$ werd een verlaagd risico op alvleesklierkanker aangetoond voor individuen die gedurende de oorlogsjaren in een stad woonden vergeleken met diegenen die niet in een stad woonden. Deze proxy-maat was een maat voor een meer gematigde energierestrictie. Wat betreft de blootstelling aan een korte periode van extreme energierestrictie gedurende de Hongerwinter waren resultaten niet eenduidig. Individuen die in het westen op het platteland woonden hadden een verhoogd risico op alvleesklierkanker vergeleken met individuen die niet in het westen woonden, terwijl het wonen in een stad in het westen niet was geassocieerd. Geen associatie werd waargenomen voor de blootstelling aan energierestrictie gedurende de Economische Depressie. Voor lichamelijke activiteit werd er een verlaagde kans op het krijgen van alvleesklierkanker gezien voor de deelnemers die in 1986 rapporteerden ooit aan sport gedaan te hebben. Voor lichamelijke activiteit in 1986 buiten het werk en lichamelijke activiteit tijdens het werk bleek er geen verband te bestaan met het risico op alvleesklierkanker.

Tot dusverre hebben de meeste cohort- en patiëntcontroleonderzoeken geen tot weinig bewijs geleverd dat er een positief verband bestaat tussen laag-tot-matig alcoholgebruik en het risico op het krijgen van alvleesklierkanker. Maar er zijn onderzoeken die erop duiden dat overmatig alcoholgebruik het risico zou kunnen verhogen. In Hoofdstuk 3 is de relatie tussen alcoholconsumptie en alvleesklierkanker onderzocht. Het drinken van minder dan 3 glazen alcohol was niet geassocieerd met het risico op alvleesklierkanker ten opzichte van geheelonthouding. Echter verhoogde het drinken van 3 of meer alcoholische consumpties de kans op het krijgen van alvleesklierkanker met $57 \%$ ten opzichte van geheelonthouding. In een subgroep van stabiele alcohol gebruikers (geen verandering in gebruik gedurende de 5 jaar voor de start van het onderzoek) werd een vergelijkbaar verhoogde kans op het krijgen van alvleesklierkanker aangetoond. Er bleek geen verband te bestaan tussen de inname van specifieke alcoholische dranken en het risico op alvleesklierkanker, wat suggereert dat het alcohol zelf is dat een rol speelt in het ontstaan en de groei (carcinogenese) van alvleesklierkanker en niet de soort alcoholische drank.

Onderzoeken hebben laten zien dat insuline een rol speelt in de carcinogenese van alvleesklierkanker. Insuline wordt afgegeven in het bloed als reactie op verhoogde bloedglucose waarden. Daarom zouden voedingsfactoren die bloedglucosewaarden verhogen, geassocieerd kunnen zijn met het risico op alvleesklierkanker. Glykemische index en glykemische load zijn voorbeelden van dergelijke factoren. In Hoofdstuk 4 is onderzocht of deze voedingsfactoren positief geassocieerd waren met het risico op alvleesklierkanker, maar er bleek geen verband te bestaan tussen de glykemische index en glykemische load en het risico op alvleesklierkanker binnen de NLCS. Ook bleek er geen verband te bestaan tussen de inname van koolhydraten en mono- en disacchariden en het risico op alvleesklierkanker. 
Bij de bereiding van vlees kunnen vele kankerverwekkende stoffen ontstaan welke het risico op alvleesklierkanker zouden kunnen verhogen. Verder liet dieronderzoek zien dat meervoudig onverzadigde vetzuren het risico op alvleesklierkanker verhogen. Bevindingen van de talrijke epidemiologische onderzoeken die tot dusverre gedaan zijn naar de relatie tussen de inname van vlees en verschillende soorten vet en het risico op alvleesklierkanker, zijn inconsistent. In Hoofdstuk 5 zijn de resultaten beschreven van het verband tussen verschillende soorten vlees en inname van verschillende vetsoorten en het risico op alvleesklierkanker: er bleek geen verband te bestaan. Tevens bleek er geen verband te bestaan tussen de consumptie van vis en eieren en het risico op alvleesklierkanker.

Fruit en groenten bevatten vele stoffen met potentiële antikankerverwekkende werking en zou daarom een rol kunnen spelen in de preventie van alvleesklierkanker. De meeste patiëntcontroleonderzoeken hebben een beschermend effect aangetoond van totaal fruit en groente consumptie, terwijl voor de meest cohortonderzoeken geen verband bleek te bestaan. In Hoofdstuk 6 hebben we de resultaten beschreven over de relatie tussen fruit en groenteconsumptie en het risico op alvleesklierkanker binnen de NLCS. Voor totale groente en totale fruitconsumptie bleek geen verband te bestaan met het risico op alvleesklierkanker. Ook bleek er geen verband te bestaan voor gekookte groenten, rauwe groenten en andere subgroepen van groente en fruit. Ook voor carotenoïden, vitamine $C$ en $E$ inname en het gebruik van supplementen die vitamine $\mathrm{C}$ of $\mathrm{E}$ bevatten bleek geen verband te bestaan met het risico op alvleesklierkanker.

Tot op heden is het roken van sigaretten een van de meest consistente risicofactoren van alvleesklierkanker. In Hoofdstuk 7 zijn de resultaten van de analyses naar het actief en passief roken van sigaretten in relatie tot het risico op alvleesklierkanker gepresenteerd. Zowel ex- als huidige sigarettenrokers hadden een verhoogde kans van respectievelijk $37 \%$ en $88 \%$ op het krijgen van alvleesklierkanker ten opzichte van nooit sigarettenrokers. We zagen een verhoogd alvleesklierkanker risico van $51 \%$ voor diegenen $\geq 20$ sigaretten/dag rookten vergeleken met diegenen die nooit sigaretten rookten, maar er werd geen dosisrespons relatie aangetoond. Er werd een dosisrespons relatie gezien met het aantal jaren roken. De hazard ratio voor het risico op alvleesklierkanker was 2.03 wanneer rokers die $\geq 40$ jaar hadden gerookt vergeleken werden met mensen die nooit hadden gerookt. Het risico op alvleesklierkanker werd geleidelijk verlaagd met het toenemend aantal jaren dat ex-rokers gestopt waren met roken en naderde na $\geq 20$ jaar het risico van nooit sigarettenrokers. Er bleek geen verband te bestaan tussen de blootstelling aan passief roken en alvleesklierkanker bij vrouwen. Het is belangrijk om mensen die ooit gerookt hebben uit te sluiten bij onderzoek naar de relatie tussen passief roken en het risico op kanker om het onafhankelijke effect van passief roken te kunnen schatten. Daarom hebben we deze relatie niet onderzocht 
bij mannen aangezien meer dan $90 \%$ van de mannen binnen de NLCS ooit hadden gerookt.

Toen voor de Hoofdstukken $\mathbf{2}$ tot en met $\mathbf{7}$ aanvullende analyses uitgevoerd werden waarin we ons beperkten tot de patiënten met microscopisch bevestigde alvleesklierkanker, waren de resultaten van deze analyses vergelijkbaar met de resultaten van de analyses waarin alle alvleesklierkanker patiënten waren geïncludeerd.

In Hoofdstuk 8 zijn de belangrijkste bevindingen van de in dit proefschrift onderzochte verbanden tussen alvleesklierkanker en de leefstijlfactoren, bediscussieerd in het licht van de bestaande literatuur, zowel epidemiologisch en mechanistisch, en is er een eindconclusie getrokken over de sterkte van het bewijs tot dusverre. Vervolgens zijn er een aantal belangrijke sterke en zwakke punten van de opzet van de NLCS en de analyses uitgevoerd in dit proefschrift bediscussieerd, waaronder confounding en misclassificatie van de risicofactoren en ziekte. Sommige onderzoeken lieten zien dat diagnostische misclassificatie de risicoschattingen voor alvleesklierkanker ernstig kunnen vertekenen. Verschillen in de karakteristieken van patiënten, waaronder leeftijd, proportie van rokers en drinkers, en tumor karakteristieken, binnen de mate van diagnostische misclassificatie zou deze vertekende resultaten kunnen verklaren. Zoals hierboven al beschreven is, lieten de onderzoeken beschreven in dit proefschrift echter geen verschil zien tussen de resultaten van de analyses beperkt tot patiënten met microscopisch bevestigde alvleesklierkanker en de resultaten van de analyses met alle alvleesklierkankerpatiënten. Verder hebben we beschreven dat het onderzoeken van het gecombineerde effect van omgevingsrisicofactoren en genetische factoren en het identificeren van meer en betere biomarkers meer inzicht zou kunnen geven in het mogelijke verband tussen voedingsrisicofactoren en het risico op alvleesklierkanker.

Samenvattend zagen we significant verhoogde risico's op het krijgen van alvleesklierkanker voor overmatig alcoholgebruik en voor het roken van sigaretten, terwijl het stoppen met roken het risico verlaagde. Er bleek geen verband te bestaan met blootstelling aan passief roken. Het ooit aan gesport gedaan te hebben verlaagde het risico op het krijgen van alvleesklierkanker. Bevingendingen met betrekking tot de proxymaten voor energierestrictie ondersteunde onze hypothese niet dat energierestrictie het risico op het krijgen van alvleesklierkanker zou verlagen. Er bleek geen verband te bestaan met de andere onderzochte voedingsfactoren, waaronder glykemische index, glykemische load, de inname van koolhydraten, vlees, vet, fruit, groente, carotenoïden en vitamine $\mathrm{C}$ en $\mathrm{E}$. 


\section{Dankwoord}




\section{DANKWOORD}

Een proefschrift schrijf je nooit alleen, dus bij deze wil ik alle mensen die direct danwel indirect hebben bijgedragen aan de totstandkoming van dit proefschrift.

Als eerste wil ik mijn compromotor en mijn promotor bedanken. Bas, ik heb heel veel van je geleerd in de afgelopen 4 jaar en ik wil je dan bedanken voor de geweldige manier waarop je me hebt begeleidt. Ik vond onze discussies altijd erg leerzaam en ook heel leuk. Vooral jouw vermogen om alles in een breder perspectief te plaatsen wanneer ik weer eens dreigde te verzuipen in al die kleine details... Je kon alles ook zo goed uitleggen en het werd je ook nooit teveel om dit te doen. Maar ja, je bent ook niet voor niks docent van het jaar geworden! Ik zat in ieder geval altijd weer barstenvol energie na onze besprekingen om er weer vol tegenaan te kunnen gaan. Ook onze discussies en gesprekken over niet onderzoeksgerelateerde zaken waren heel interessant en leuk. De tijd vloog altijd voorbij tijdens een overleg. Natuurlijk wil ik je ook heel erg bedanken voor de mooie kaft die je voor mij hebt gemaakt; niet alleen jij bent daar heel erg trots op, maar ik ook!! Ik had me geen beter en mooier ontwerp kunnen voorstellen. Ik ben heel blij dat ik nog een 2-jarige postdoctraject onder jouw begeleiding mag doen en dat we dus ook nog geen afscheid hoeven te nemen!

Piet, jou wil ik graag bedanken voor het goed in de gaten houden van de tijdsplanning en de hoofdlijnen van het project. Tevens heb je me geleerd efficiënter te werken. Ook wil ik je bedanken voor je kritische commentaar op de artikelen (die je ook altijd stipt op tijd klaar had!). Ook waardeer ik je humor die je soms op hele onverwachte momenten (en hoeken) liet zien.

Graag wil ik tevens mijn coauteurs bedanken die altijd de moeite hebben genomen om mijn manuscripten te becommentariëren. Sandra, ik heb je kritische blik op de artikelen altijd heel erg gewaardeerd. Je kennis met betrekking tot de voedingskant (zowel praktisch als methodologisch) is echt enorm en ik heb dan onze discussies (via de mail danwel via de telefoon) altijd erg gewaardeerd en ook heel veel van geleerd. Dit alles zorgde er altijd weer voor dat het artikel een stuk beter werd! Dr. Lumey, ik heb het altijd erg gewaardeerd dat u mijn artikelen heeft willen becommentariëren. Dr. Ambergen, uw hulp bij de spline analyses die ik plotseling moest uitvoeren omdat reviewers hierom gevraagd hadden, heb ik zeer gewaardeerd. Zeker omdat dit ook in zeer korte tijd moest gebeuren en ik op dat moment nog amper wist wat deze analyse techniek inhield. Henny, je bent maar op een artikel in dit boekje coauteur maar ik wil je niet alleen bedanken voor je bijdrage aan dat artikel. Je vond namelijk ook altijd (snel) tijd om mijn andere vraagjes over de voedselfrequentievragenlijst en andere voedingsgerelateerde vragen die ik maar had, te beantwoorden. 
Mireille, als mijn kamergenote gedurende de afgelopen 4 jaren wil ik jou graag bedanken voor de fijne tijd. De leuke gesprekken, vaak over alles behalve werk ;-), waren een welkome afwisseling van het werk. Ik vind het dan ook heel leuk dat ik nog steeds bij je op de kamer zit nu ik als postdoc ben begonnen!

Ook wil ik alle NLCS leden bedanken uit Maastricht en van TNO. Jullie bijdrage aan de opzet dan wel uitvoer van de NLCS hebben ervoor gezorgd dat ik dit proefschrift heb kunnen schrijven. Bedankt!

Mijn (oud-)collega's wil ik graag bedanken voor de fijne tijd die ik mede dankzij jullie heb gehad (en nog steeds heb!) op de afdeling Epidemiologie. Altijd was er tijd voor een gezellig praatje bij de koffiehoek of op de gang. Bedankt voor jullie collegialiteit en gezelligheid!

Pieter E., ook al heb je geen directe bijdrage geleverd aan dit boekje, toch wil ik je graag bedanken voor je werk aan de analyses over medische aandoeningen en alvleesklierkanker. Onze samenwerking is altijd heel prettig verlopen en ik ben blij dat jij de eerste stagiair was die ik mocht begeleiden. Nou nog het artikel in een mooi blad gepubliceerd krijgen!

Dan nog mijn mede-promovendi van Epidemiologie: Janneke, Jessie, Laura, Colinda, Brenda, Stefan, Esther, Caroline, José, Monique L., Karolina, Sander, Anne, Nadine, Milan en Ivette. Jullie wil ik graag bedanken voor de gezellige lunches/lunchwandelingen en de plezierige AIO-uitjes. Ik kon altijd bij jullie terecht als ik het even had gehad met mijn promotietraject, maar ook hebben we de leuke momenten kunnen delen. Of we hadden het gewoon even over zaken die helemaal niets met het werk van doen hadden. Voor diegenen die nog niet gepromoveerd zijn: succes met jullie promotieonderzoek!

Graag wil ik ook nog Yvonne en Nathalie bedanken: ik kon altijd bij jullie terecht als er weer eens een afspraak met Piet moest worden ingepland of als ik weer eens een vraagje had over wat dan ook...

Harry en Jos, bedankt voor al die keren dat jullie voor me klaarstonden als ik weer eens technische vragen had of als ik weer eens ruzie met mijn pc had (ik heb nu eenmaal twee linkerhanden wat betreft een computer...).

Dan mijn paranimfen, Audrey en Mirjam. Ik ben heel blij en trots dat jullie op deze belangrijke dag naast me willen staan. Mirjam, als mijn allerbeste vriendin heb ik jouw vriendschap altijd heel erg gewaardeerd en ook je geduld als ik weer eens niet kon afspreken omdat mijn werk voorging... Ik zal vanaf nu mijn leven proberen te beteren. Audrey, aangezien je nu net zelf gepromoveerd bent, ben ik erg blij dat jij me met raad en daad terzijde staat in het laatste gedeelte van mijn promotietraject. Maar ook omdat je gewoon een hele leuke en vooral ook fijne collega bent! 
Dankzij mijn vrienden kon ik af en toe het werk het werk laten en lekker genieten van het leven buiten werk!

Erik, Nuria, Rita, Luis, Ester, Ruben, Hilde, Bea, Stephanie, Siu Hing, Alissa, and Baerbel: when I started with my PhD project in 2006 I hardly knew anyone but that soon changed thanks to you guys. You made my life in Maastricht really enjoyable with all the coffee-breaks, dinners, going outs etc. Some of you already left (or will leave soon) Maastricht, but I hope we'll all keep contact! Also the last holiday in Portugal with Nuria, Esther, Mike, Lars and Alejandro for the wedding of Rita and Luis: that was the best break before handing in my thesis to the reading committee. I really needed that, thanks guys!

Ook wil ik mijn oud-ProVUM maatjes niet vergeten: Floris, Cynthia, Jennifer, Janine, en Conrad. Jullie zijn echte vrienden geworden gedurende de tijd dat we ons hard maakten voor de Maastrichtse promovendi! En ik hoop jullie nu ook weer wat vaker te kunnen zien nu ik bijna klaar ben met mijn promotietraject.

De JCM, de Journal Club Maastricht, wil ik hier ook graag noemen. Janaica, Martine, Joris, Sil, Petra, Mandy, Viola, Luc, Merijn, Francien, Eline, Sander en Baerbel, bedankt voor alle leuke en zeer interessante discussies over de artikelen die door een van ons werden ingebracht. Maar ook bedankt voor het leuke en gezellige samenzijn, het samen eten en de leuke uitjes die werden georganiseerd. En ik ben heel blij dat ik bij de JCM mag blijven ook nu dat ik bijna ga promoveren!!

Lisette, Tamara, Sandra, Janneke en Céline, oud-studiegenootjes van Voeding en Diëtetiek. Helaas zie ik jullie minder vaak als ik zou willen en hopelijk komt daar vanaf nu verandering in, maar ik wil jullie graag bedanken voor de gezellige tijd die ik elke keer met jullie had op het moment dat we elkaar weer eens zagen! Ook wil ik jullie bedanken voor de interesse in mijn onderzoek. Janneke, je bent nu zelf ook aan een promotietraject begonnen: heel veel succes daarmee en je kunt altijd bij mij terecht met vragen en andere zaken over je promotietraject!

Mijn lieve familieleden, jullie wil ik graag bedanken voor al jullie blijvende interesse in mijn onderzoek. Ook al heb ik vaak moeten uitleggen dat promoveren en afstuderen twee heel verschillende dingen zijn, ik vond het altijd heel fijn dat jullie elke keer vroegen hoe het stond met mijn onderzoek en mijn 'scriptie'. Jullie dachten waarschijnlijk lang dat ik een soort 'eeuwige student' zou blijven, maar het is nu toch echt bijna klaar: mijn proefschrift is een feit!

En dan, last but not least, pap, mam en Arnoud, bedankt voor al die tijd dat jullie er voor me zijn geweest, voor jullie onvoorwaardelijke steun en jullie begrip als ik weer eens geen tijd had om naar jullie toe te komen. Zonder jullie steun zou het een stuk moeilijker zijn geweest. Bedankt voor alles!! 
Curriculum vitae

187 



\section{ABOUT THE AUTHOR}

Mirjam Heinen was born on February 141979 in 's-Hertogenbosch, the Netherlands. She completed secondary school (pre-university education) at the Bisschop Bekkers College in Eindhoven in 1997. After that, she started her studies in Nutrition and Dietetics at the Arnhem-Nijmegen University of Professional Education in Nijmegen. In 2001, she graduated and obtained a Bachelor's degree. After that, she started working as a dietician at Maastricht University, at the Department of Human Biology, where she provided assistance in dietary intervention studies. In 2003, she started her studies in Nutrition and Health at the Wageningen University. Her internship was carried out at the Division of Experimental Therapy and the Department of Epidemiology, Netherlands Cancer Institute/Antonie van Leeuwenhoek hospital, where she assisted in a dietary intervention study and wrote, together with a fellow student, a thesis entitled "Covariate changes during a cross-over dietary intervention study". Her practical period was conducted at Department of Cancer and Population Studies, Queensland Institute of Medical Research in Brisbane, Australia. During this practical period she investigated the association between antioxidant status and risk of keratinocytic skin cancer in a longitudinal community based study, which resulted in two peer reviewed publications. In 2006, she graduated and obtained her Master's degree. After that, she started her PhD project at the Department of Epidemiology, Maastricht University. The studies performed within this project resulted in the current thesis. Since July 2010, Mirjam has been working as a postdoc at the Department of Epidemiology, investigating the role of alcohol intake in the etiology of lymphatic malignancies. 


\section{LIST OF PUBLICATIONS}

\section{Submitted manuscripts}

Heinen MM, Verhage BA, Goldbohm RA, van den Brandt PA. Intake of vegetables, fruits, carotenoids, and vitamins $C$ and $E$ and pancreatic cancer risk in the Netherlands Cohort Study.

Heinen MM, Verhage BA, Goldbohm RA, Lumey L, van den Brandt PA. Physical activity, energy restriction, and the risk of pancreatic cancer: a prospective study in the Netherlands.

\section{Peer reviewed publications}

Heinen MM, Verhage BA, Goldbohm RA, van den Brandt PA. Active and passive smoking and the risk of pancreatic cancer in the Netherlands cohort study. Cancer Epidemiol Biomarkers Prev 2010;19(6):1612-22.

Keszei AP, Verhage BA, einen MM, Goldbohm RA, van den Brandt PA. Dietary folate and folate vitamers and the risk of pancreatic cancer in the Netherlands cohort study. Cancer Epidemiol Biomarkers Prev 2009;18(6):1785-91.

Heinen MM, Verhage BA, Goldbohm RA, van den Brandt PA. Meat and fat intake and pancreatic cancer risk in the Netherlands Cohort Study. Int J Cancer 2009;125(5):111826.

Van der Pols JC, Heinen MM, Hughes MC, Ibiebele TI, Marks GC, Green AC. Serum antioxidants and skin cancer risk: an 8-year community-based follow-up study. Cancer Epidemiol Biomarkers Prev 2009; 18(4):1167-73.

Heinen MM, Verhage BA, Ambergen TA, Goldbohm RA, van den Brandt PA. Alcohol consumption and risk of pancreatic cancer in the Netherlands cohort study. Am J Epidemiol 2009;169(10):1233-42.

Heinen MM, Verhage BA, Lumey L, Brants HA, Goldbohm RA, van den Brandt PA. Glycemic load, glycemic index, and pancreatic cancer risk in the Netherlands Cohort Study. Am J Clin Nutr 2008;87(4):970-7.

Weijenberg MP, Mullie PF, Brants HA, Heinen MM, Goldbohm RA, van den Brandt PA. Dietary glycemic load, glycemic index and colorectal cancer risk: results from the Netherlands Cohort Study. Int J Cancer 2008;122(3):620-9. 
Heinen MM, Hughes MC, Ibiebele TI, Marks GC, Green AC, van der Pols JC. Intake of antioxidant nutrients and the risk of skin cancer. Eur J Cancer 2007;43(18):2707-16.

De Weerd S, Steegers EA, Heinen MM, van den Eertwegh S, Vehof RM, SteegersTheunissen RP. Preconception nutritional intake and lifestyle factors: first results of an explorative study. Eur J Obstet Gynecol Reprod Biol 2003;111(2):167-72.

\section{Abstracts/presentations}

Tobacco exposure and the risk of pancreatic cancer: Results of the Netherlands Cohort Study. Poster presentation during de AACR Frontiers in Cancer Prevention Research 2009 te Houston, TX, U.S.

Smoking and risk of pancreatic cancer: Results of the Netherlands Cohort Study. Oral presentation during WEON (annually Dutch national epidemiological conference) 2009, Amsterdam, the Netherlands.

Alcohol and pancreatic cancer risk in the Netherlands Cohort Study. Poster presentation during the Wageningen Nutritional Sciences Forum 2009 "Too Much - Too Little".

Alcohol and pancreatic cancer risk in the Netherlands Cohort Study. Poster presentation during the WEON 2008, Groningen, the Netherlands.

Glycemic load, glycemic index and pancreatic cancer risk: Results from the Netherlands Cohort Study. Oral presentation during the Master class "Diet and Cancer" organized by Wageningen University, 2007, the

Netherlands.

Glycemic load, glycemic index and risk of pancreatic cancer: Results of the Netherlands Cohort Study. Oral presentation during the WEON 2007, Maastricht, the Netherlands.

Glycemic load, glycemic index and pancreatic cancer risk in the Netherlands Cohort Study. Oral presentation during the NUTRIM Masterclass with prof. G. Colditz, 2007, Maastricht University, Maastricht, the Netherlands. 